CENTRO UNIVERSITÁRIO FEI

JOSÉ CARLOS DE ANDRADE NETO

AVALIAÇÃO DA ADSORÇÃO DE CROMO EM CARBOXIMETILCELULOSE OBTIDA A PARTIR DE PALHA DE MILHO MODIFICADA E ATIVADA COM DIFERENTES LÍQUIDOS IÔNICOS

São Bernardo do Campo 
CENTRO UNIVERSITÁRIO FEI

JOSÉ CARLOS DE ANDRADE NETO

\section{AVALIAÇÃO DA ADSORÇÃO DE CROMO EM CARBOXIMETILCELULOSE OBTIDA A PARTIR DE PALHA DE MILHO MODIFICADA E ATIVADA COM DIFERENTES LÍQUIDOS IÔNICOS}

Dissertação de Mestrado apresentado ao Centro Universitário FEI, como parte dos requisitos necessários para obtenção do título de Mestre em Engenharia Química. Orientado pela Prof. ${ }^{a}$ Dra. Andreia de Araújo Morandim Giannetti.

São Bernardo do Campo 
Andrade Neto, José Carlos de.

Avaliação da adsorção de cromo em carboximetilcelulose obtida a partir de palha de milho modificada e ativada com diferentes líquidos iônicos / José Carlos de Andrade Neto. São Bernardo do Campo, 2019. 203 f. : il.

Dissertação - Centro Universitário FEI.

Orientadora: Prof. ${ }^{a}$ Dra. Andreia de Araújo Morandim Giannetti.

1. CMC. 2. Ativação com LI. 3. Adsorção de cromo hexavalente. 4. Tratamento de efluentes. I. Araújo Morandim Giannetti, Andreia de, orient. II. Título.

Elaborada pelo sistema de geração automática de ficha catalográfica da FEI com os dados fornecidos pelo(a) autor(a). 


\section{APRESENTAÇÃO DE DISSERTAÇÃO \\ ATA DA BANCA EXAMINADORA}

PGQ-10

Aluno: José Carlos de Andrade Neto

Matrícula: 417111-2

Título do Trabalho: Avaliação da adsorção de cromo em carboximetilcelulose obtida a partir de palha de milho modificada e ativada com diferentes líquidos iônicos.

Área de Concentração: Engenharia Química

Orientador: Profa Dra Andreia de Araújo Morandim Giannetti

Data da realização da defesa: 20/02/2019

\section{ORIGINAL ASSINADA}

Avaliação da Banca Examinadora:

São Bernardo do Campo,

\section{MEMBROS DA BANCA EXAMINADORA}

Profa Dra Andreia de Araújo Morandim Giannetti Ass.:

Prof. Dr. Ricardo Belchior Torres

Ass.:

Profa Dra Sílvia Helena Prado Bettini

Ass.:

A Banca Julgadora acima-assinada atribuiu ao aluno o seguinte resultado:

APROVADO $\bigotimes$

REPROVADO

\section{VERSÃO FINAL DA DISSERTAC̄ÃO}

APROVO A VERSÃO FINAL DA DISSERTAÇÃO EM QUE FORAM INCLUÍDAS AS RECOMENDAÇÕES DA BANCA EXAMINADORA
Aprovação do Coordenador do Programa de Pós-graduação

Prof. Dr. Ricardo Belchior Torres 
Dedico este trabalho a todos aqueles que estiveram ao meu lado durante o período de elaboração e desenvolvimento do mesmo. Especialmente, aos meus pais, amigos e orientadora. 


\section{AGRADECIMENTOS}

A minha orientadora, Prof. a Dra. Andreia de Araújo Morandim Giannetti, por todo o apoio, dedicação empenho e tempo sem os quais não seria possível a finalização deste trabalho, agradeço também pelos conselhos, por acreditar na minha capacidade e por empegar e compartilhar seu conhecimento e experiências que auxiliaram na concretização de mais um passo na minha carreira acadêmica.

Aos meus pais que sempre apoiaram minhas decisões sem nem ao menos questionar, me dando força e aconselhamentos nos momentos de desânimo e dificuldades.

A Fundação de Amparo à Pesquisa do Estado de São Paulo (FAPESP) pela bolsa concedida e pelo financiamento do presente trabalho (Processo ${ }^{\circ}$ 2017/05485-3).

A Coordenação de Aperfeiçoamento de Pessoal de Nível Superior - Brasil (CAPES), pelo de financiamento do presente trabalho, mesmo que por um curto período.

Aos amigos que estiveram ao meu lado compartilhando conhecimento, apoio e momentos de descontração, em especial aos amigos, Aline Generich Zacarelli, Andressa Carolina de Almeida, Kevy Pontes Eliodório, Luccas Lossano Name e Vanessa Tiemi Murakami.

A Comissão de Bolsa de Estudo em Engenharia Química composta por Prof. Dr. Ricardo Belchior Torres, Prof. ${ }^{a}$ Dra. Maristhela Passoni de Araújo Marin e Marina Saviolli Reis da Silva pela concessão da bolsa CAPES.

Ao Centro Universitário FEI, pela disponibilização da estrutura e recursos essenciais para realização deste trabalho.

Ao Prof. ${ }^{\circ}$ Dr. Gilberto José Pereira pela orientação, auxílio e disponibilidade do Laboratório de Cerâmicos do Departamento de Engenharia de Materiais para caracterizações realizadas neste trabalho.

Ao LMA-IQ e ao Laboratório de RMN da UNESP-Araraquara pela disponibilidade de utilização do microscópio eletrônico de varredura de alta resolução bem como realização dos ensaios de RMN utilizado no presente trabalho. 


\section{RESUMO}

Atualmente, muitos estudos relacionados a tratamento de efluentes contendo metais pesados estão sendo desenvolvidos, principalmente os que possibilitam a utilização de resíduos lignocelulósicos e polímeros naturais para a obtenção de novos adsorventes. Dessa forma, durante o desenvolvimento do presente trabalho, inicialmente, foi realizada a síntese da carboximetilcelulose (CMC) a partir da palha de milho sendo a mesma caracterizada via FTIR e RMN no estado líquido, onde observou-se as principais bandas características referentes a $\mathrm{C}=\mathrm{O}$, C-O, e $\mathrm{C}-\mathrm{C}$ bem como, a presença sinais referentes aos grupamentos carboxil $(\mathrm{C}=\mathrm{O})$ e carboximetil $\left(-\mathrm{CH}_{2}\right)$, que confirmam a formação da CMC. Em seguida, foram realizadas as modificações CMC com quitosana (Q), empregando-se o ácido ferúlico (F) e a $N, N^{\prime}$ diisopropilcarbodiimida (DIC) como reagentes de reticulação, obtendo-se dois novos adsorventes CMCQF e CMCQDIC, respectivamente nomeados a partir do reagentes utilizados na síntese, que foram caracterizados via FTIR e ${ }^{13} \mathrm{C}-\mathrm{RMN}$ no estado sólido, sendo verificada a presença das bandas das ligações $\mathrm{C}=\mathrm{O}$ e $\mathrm{C}-\mathrm{N}$, referentes a $\mathrm{CMC}$ e quitosana, respectivamente, para ambos os adsorventes. Para o adsorvente CMCQF, observou-se bandas referentes a ligação $\mathrm{C}=\mathrm{C}$ do anel aromático do ácido ferúlico e, para o CMCQDIC, bandas referentes a $-\mathrm{CH}_{3}$ dos grupamentos isopropil. Também foram observados sinais referentes ao carbono do grupamento carboxil, para o adsorvente CMCQF o sinal referente carbonos do anel aromático do ácido ferúlico e, para o CMCQDIC, sinal referente ao carbono ligado ao nitrogênio do DIC, que confirmam a formação dos adsorventes. As condições ideais de aplicação em processo de adsorção de cromo hexavalente foram determinadas e, para ambos os adsorventes, foi estabelecido a temperatura ideal de $20^{\circ} \mathrm{C}$ segundo o modelo de Langmuir. Quanto ao tempo e pH ideais, foram de 60 min e 3,0 para CMCQF e, de 180 min e 2,5, para CMCQDIC, sendo observado um aumento na capacidade de adsorção de 45,9 \% para CMCQF e 81,5 \% para CMCQDIC, em relação a quitosana pura, que é um polímero natural alvo de muitos estudos presentes na literatura. Além disso, foram realizados processo de ativação com diferentes líquidos iônicos (LIs), sendo que os melhores resultados foram encontrados com a utilização do acetato de terc-butilamônio e lactato de terc-butilamônio, com aumento da capacidade de adsorção de 7,32 e 5,19 \% para CMCQF e CMCQDIC, respectivamente.

Palavras-chave: CMC, Ativação com LI, Adsorção de cromo hexavalente, Tratamento de efluentes. 


\begin{abstract}
Several studies related to the treatment of effluents containing heavy metals have currently been developed, especially those which allow the use of lignocellulosic residues and natural polymers to obtain new adsorbents. During the development of this study, CMC from corn stover was initially obtained, which is characterized by FTIR and NMR in solid state. In these analyses, it was possible to observe the presence of the main characteristic bands regarding $\mathrm{C}=\mathrm{O}, \mathrm{C}-\mathrm{O}$, and $\mathrm{C}-\mathrm{C}$, as well as chemical displacements due to the presence of carboxyl $(\mathrm{C}=\mathrm{O})$ and carboxymethyl $\left(\mathrm{CH}_{2}-\right)$ groups, respectively, which confirms the formation of carboxymethylcellulose (CMC). In this context, having obtained CMC, modifications in this structure with chitosan $(\mathrm{Q})$ were carried out and two new adsorbents (CMCQF and CMCQDIC) were produced, applying ferulic acid (F) and $N, N$ '-diisopropylcarbodiimide (DIC) as reticulation reagents. These new materials were characterized by FTIR and ${ }^{13} \mathrm{C}-\mathrm{NMR}$ and the presence of the main bands was verified, which are characteristic of $\mathrm{CMC}(\mathrm{C}=\mathrm{O})$ and chitosan (C-N), for both adsorbents. This study also analyzed the presence of bands for the adsorbent $\mathrm{CMCQF}$ regarding the $\mathrm{C}=\mathrm{C}$ bond present in the aromatic ring of the ferulic acid. For the CMCQDIC adsorbent, bands were observed regarding $-\mathrm{CH}_{3}$ from isopropyl groups. According to ${ }^{13} \mathrm{C}$-NMR spectrum analyses, it was possible to confirm signals regarding the carbon of the carboxyl group and the aromatic ring of the ferulic acid, as well as a signal regarding the carbonnitrogen bond of DIC, which confirms the formation of the adsorbents. The ideal application conditions in the adsorption of the hexavalent chromium process were determined, and for both adsorbents, the ideal temperature was $20^{\circ} \mathrm{C}$ according to the Langmuir model. Concerning the appropriate time and $\mathrm{pH}$, it was possible to verify $60 \mathrm{~min}$ and 3.0 for CMCQF, and $180 \mathrm{~min}$ and 2.5 for CMCQDIC, respectively. Besides, an increase in the adsorption capacity to $45.9 \%$ for CMCQF and $81.5 \%$ for CMCQDIC was observed regarding the pure chitosan, which is a natural polymer under study in the literature. Activation processes were also carried out with different ionic liquids (ILs), causing an increase in the adsorption capacity for all adsorbents, mainly when using terc-butylammonium acetate for CMCQF and terc-butylammonium lactate for CMCQDIC with 7.32 e $5.19 \%$ of increasing, respectively.
\end{abstract}

Keywords: CMC. IL activation. Adsorption of hexavalent chromium. Treatment of effluents. 


\section{LISTA DE ILUSTRAÇOES}

Figura 1 - Processo adsorção e dessorção ...................................................................... 30

Figura $\quad 2$ - Principais adsorventes e aplicações ............................................................... 33

Figura 3 - Representação dos tipos de isotermas de adsorção ........................................... 36

Figura 4 - Representação geral do equilíbrio em processo de adsorção ...............................36

Figura $\quad 5$ - Mecanismo de transferência de massa em adsorventes .................................... 42

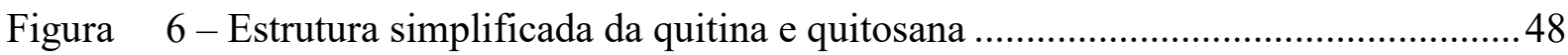

Figura 7 -Adsorção de íons cromo hexavalente pela quitosana......................................... 48

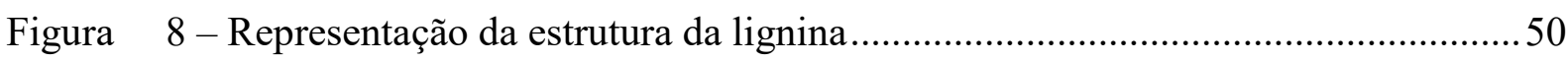

Figura 9 - Representação da estrutura da hemicelulose ................................................. 50

Figura 10 - Anel glicosídico presente na estrutura da celulose ........................................51

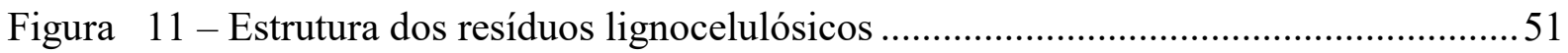

Figura 12 - Representação simplificada da estrutura celulose e derivados ...........................52

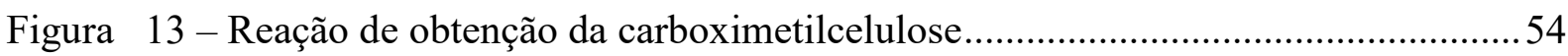

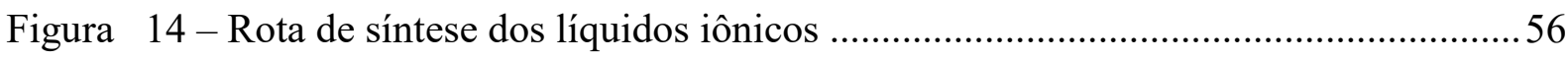

Figura 15 - Representação do processo de adsorção ..........................................................57

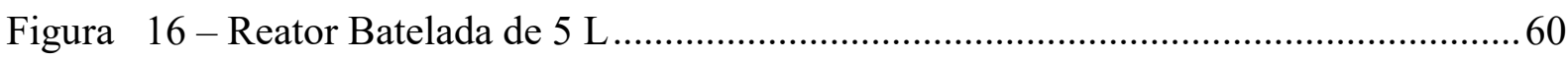

Figura 17 - Sistema reativo utilizado no branqueamento ................................................ 61

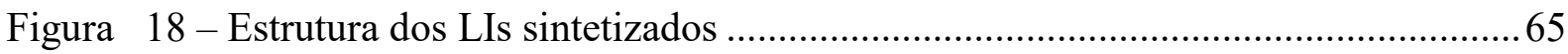

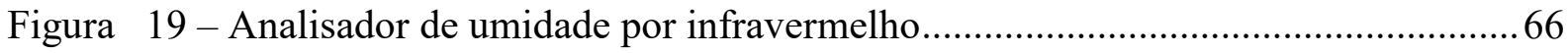

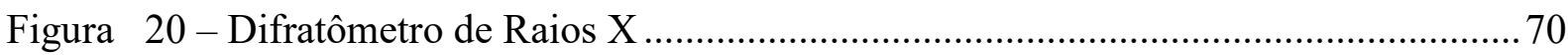

Figura 21 - Microscópio eletrônico de varredura de alta resolução....................................... 71

Figura 22 - Espectrofotômetro na região do infravermelho................................................ 72

Figura 23 - Espectrômetro de RMN Bruker Avance III 600 HD ....................................... 74

Figura 24 - Espectrômetro de RMN Bruker Avance III 400 WB........................................ 74

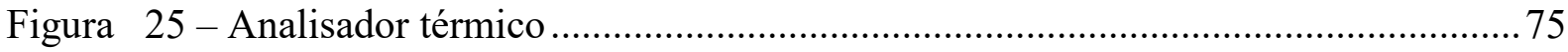

Figura 26 - Analisador de tamanho de partícula ............................................................. 76

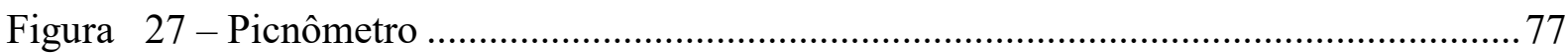

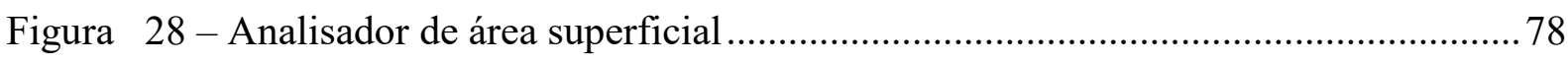

Figura 29 - Reação de caracterização do cromo hexavalente ............................................... 79

Figura 30 - Características da palha de milho no decorrer do tratamento ........................... 80

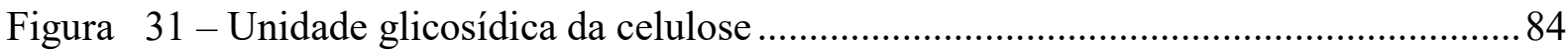

Figura 32 - Comparação entre os espectros de FTIR da palha de milho bruta e tratada .......84 
Figura 33 - Espectro de ${ }^{13} \mathrm{C}-\mathrm{RMN}$ no estado sólido da palha de milho após o tratamento a $9,4 \mathrm{~T}$

Figura 34 - Comparação entre os difratogramas obtidos para as palhas bruta e tratadas ...... 86

Figura 35 - Micrografias referentes a cada etapa de tratamento da ampliação de $10.000 x$...87

Figura 36 - Representação do mecanismo de síntese da carboximetilcelulose ..................... 88

Figura 37 - FTIR comparativo entre CMC sintetizada, comercial e da palha de milho........89

Figura 38 - Comparação entre os espectros de ${ }^{13} \mathrm{C}-\mathrm{RMN}$ para a $\mathrm{CMC}$ e celulose no estado sólido a $9,4 \mathrm{~T}$

Figura 39 - Ampliação do espectro de ${ }^{1} \mathrm{H}-\mathrm{RMN}$ para a CMC utilizando como solvente $\mathrm{D}_{2} \mathrm{O}$ a $14,1 \mathrm{~T}$

Figura 40 - Representação da unidade de repetição da celulose e CMC ..............................91

Figura 41 - Proposta de mecanismo para a obtenção do adsorvente CMCQPVA.................93

Figura 42 - Proposta de mecanismo para a obtenção do adsorvente CMCQF ...................... 94

Figura 43 - Proposta de mecanismo para a obtenção do adsorvente CMCQDIC .................. 94

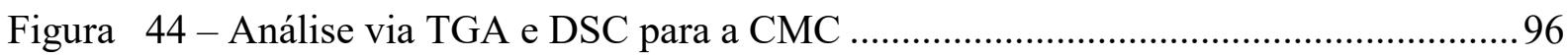

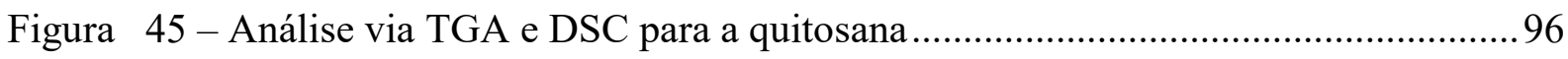

Figura 46 - Análise termogravimétrica referente ao CMCQF .............................................97

Figura 47 - Análise termogravimétrica referente ao CMCQDIC ....................................... 98

Figura 48 - Comparativos entre os espectros de FTIR para o CMCQDIC ............................99

Figura 49 - Espectro de FTIR referente ao CMCQDIC ........................................................99

Figura 50 - Comparativos entre os espectros de FTIR para o CMCQF.............................. 100

Figura 51 - Espectro de FTIR referente ao CMCQF ......................................................... 100

Figura 52 -Comparação entre os espectros de ${ }^{13} \mathrm{C}-\mathrm{RMN}$ no estado sólido para a quitosana,

CMC e o adsorvente CMCQF a 9,4 T

Figura 53 - Espectros de ${ }^{13} \mathrm{C}-\mathrm{RMN}$ no estado sólido para o adsorvente CMCQF a 9,4 T ..102

Figura 54 -Comparação entre os espectros de ${ }^{13} \mathrm{C}-\mathrm{RMN}$ no estado sólido para a quitosana, CMC e o adsorvente CMCQDIC a 9,4 T.

Figura 55 - Espectros de ${ }^{13} \mathrm{C}-\mathrm{RMN}$ no estado sólido para o adsorvente CMCQDIC a 9,4 $\mathrm{T}$

Figura 56 - Capacidade de adsorção em função do tempo ................................................ 107

Figura 57 - Modelo de pseudo-primeira ordem para CMCQF ......................................... 108

Figura 58 - Modelo de pseudo-primeira ordem para CMCQDIC …................................. 108

Figura 59 - Modelo de pseudo-segunda ordem para CMCQF........................................... 109

Figura 60 - Modelo de pseudo-segunda ordem para CMCQDIC ...................................... 109 
Figura 61 - Modelo de Weber-Morris para CMCQF ....................................................... 110

Figura 62 - Modelo de Weber-Morris para CMCQDIC .................................................... 110

Figura 63 - Micrografias dos adsorventes com ampliação de 3.000x ................................ 112

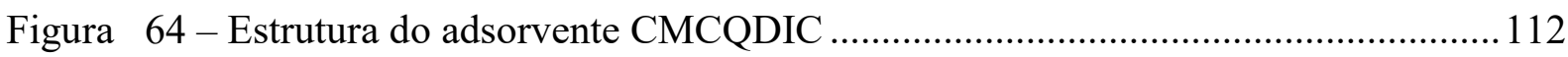

Figura 65 - Capacidade de adsorção em função do pH (CMCQF) ..................................... 115

Figura 66 - Capacidade de adsorção em função do pH (CMCQDIC) ................................. 116

Figura 67 - Mecanismos de adsorção do cromo hexavalente para o CMCQF ....................116

Figura 68 - Mecanismos de adsorção do cromo hexavalente para o CMCQDIC ................117

Figura 69 - Isotermas de Langmuir para CMCQF .......................................................... 121

Figura 70 - Isotermas de Langmuir para CMCQDIC .................................................... 121

Figura 71 - Isoterma de Freundlich para CMCQF ........................................................ 123

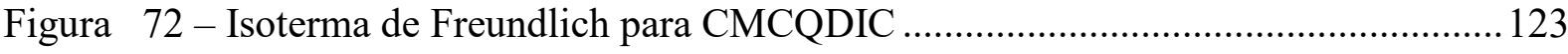

Figura 73 - Isoterma de Temkin para CMCQF............................................................ 124

Figura 74 - Isoterma de Temkin para CMCQDIC ........................................................... 124

Figura 75 - Processo de adsorção até elevados tempos de contato..................................... 126

Figura 76 - Capacidade em função da concentração para o CMCQF ……….......................127

Figura 77 - Capacidade em função da concentração para o CMCQDIC .............................. 127

Figura 78 - Linearização da equação de Van’t Hoff para o CMCQF ..................................128

Figura 79 - Linearização da equação de Van’t Hoff para o CMCQDIC ..............................129

Figura 80 - Capacidades obtidas nas condições ideais ..................................................... 131

Figura 81 - Estruturas dos ácidos, aminas e LIs sintetizados .......................................... 133

Figura 82 - Dados de capacidade de adsorção para o CMCQF ativado .............................. 136

Figura 83 - Dados de capacidade de adsorção para o CMCQDIC ativado........................... 137

Figura 84 - Curva de Calibração para CMCQF ................................................................... 155

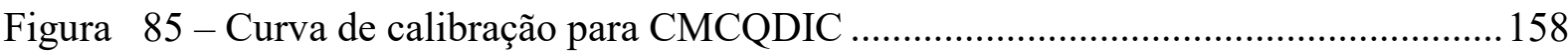

Figura 86 - Curva de calibração para CMCQDIC .............................................................. 160

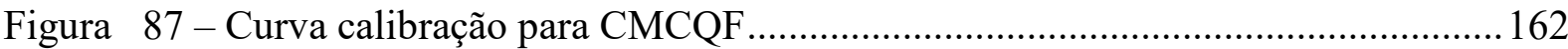

Figura 88 - Curva de calibração para CMCQDIC ............................................................... 166

Figura 89 - Distribuição de tamanho de partícula para a CMC, quitosana e adsorventes ... 171

Figura 90 - Espectro de ${ }^{1} \mathrm{H}-\mathrm{RMN}$ obtido para a sec-butilamina $\left(\mathrm{CDCl}_{3}, 14,1 \mathrm{~T}\right) \ldots \ldots \ldots \ldots \ldots . . . .173$

Figura 91 - Espectro de ${ }^{13} \mathrm{C}-\mathrm{RMN}$ obtido para a sec-butilamina $\left(\mathrm{CDCl}_{3}, 14,1 \mathrm{~T}\right) \ldots \ldots \ldots \ldots . . .173$

Figura 92 - Espectro de ${ }^{1} \mathrm{H}-\mathrm{RMN}$ obtido para a terc-butilamina $\left(\mathrm{CDCl}_{3}, 14,1 \mathrm{~T}\right) \ldots \ldots \ldots \ldots . . .174$

Figura 93 - Espectro de ${ }^{13} \mathrm{C}$ - $\mathrm{RMN}$ obtido para a terc-butilamina $\left(\mathrm{CDCl}_{3}, 14,1 \mathrm{~T}\right) \ldots \ldots \ldots \ldots . . .174$

Figura 94 - Espectro de ${ }^{1} \mathrm{H}-\mathrm{RMN}$ obtido para o ácido acético $\left(\mathrm{CDCl}_{3}, 14,1 \mathrm{~T}\right) \ldots \ldots \ldots \ldots \ldots . . . . .175$ 
Figura 95 - Espectro de ${ }^{13} \mathrm{C}-\mathrm{RMN}$ obtido para o ácido acético $\left(\mathrm{CDCl}_{3}, 14,1 \mathrm{~T}\right) \ldots \ldots \ldots \ldots \ldots . . . .175$

Figura 96 - Espectro de ${ }^{1} \mathrm{H}-\mathrm{RMN}$ obtido para o ácido láctico $\left(\mathrm{CDCl}_{3}, 14,1 \mathrm{~T}\right) \ldots \ldots \ldots \ldots \ldots . . . . .176$

Figura 97 - Espectro de ${ }^{13} \mathrm{C}-\mathrm{RMN}$ obtido para o ácido láctico $\left(\mathrm{CDCl}_{3}, 14,1 \mathrm{~T}\right) \ldots \ldots \ldots \ldots \ldots . . . .176$

Figura 98 - Espectro de ${ }^{1} \mathrm{H}-\mathrm{RMN}$ obtido para o $\mathrm{AS}\left(\mathrm{CDCl}_{3}, 14,1 \mathrm{~T}\right)$.............................. 177

Figura 99 - Espectro de ${ }^{13} \mathrm{C}-\mathrm{RMN}$ obtido para o $\mathrm{AS}\left(\mathrm{CDCl}_{3}, 14,1 \mathrm{~T}\right)$.............................. 177

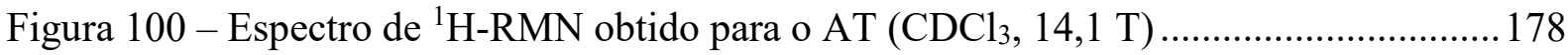

Figura 101 - Espectro de ${ }^{13} \mathrm{C}-\mathrm{RMN}$ obtido para o AT $\left.\mathrm{CDCl}_{3}, 14,1 \mathrm{~T}\right)$................................ 178

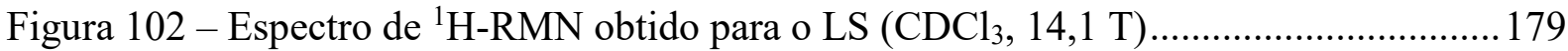

Figura 103 - Espectro de ${ }^{13} \mathrm{C}$-RMN obtido para o LS $\left(\mathrm{CDCl}_{3}, 14,1 \mathrm{~T}\right)$...............................179

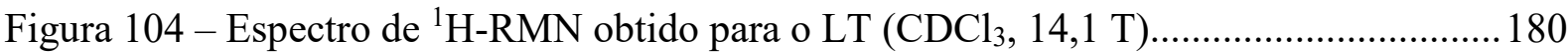

Figura 105 - Espectro de ${ }^{13} \mathrm{C}-\mathrm{RMN}$ obtido para o LT $\left(\mathrm{CDCl}_{3}, 14,1 \mathrm{~T}\right)$............................. 180

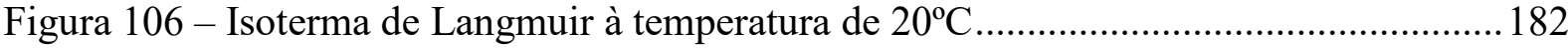

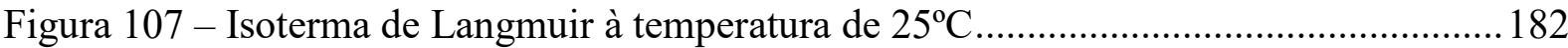

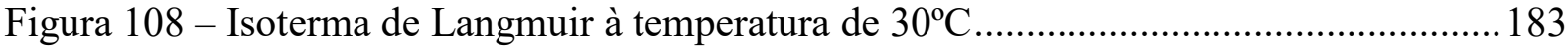

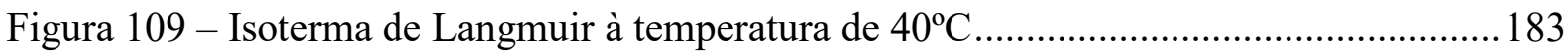

Figura 110 - Isoterma de Langmuir à temperatura de $50^{\circ} \mathrm{C}$............................................... 184

Figura 111 - Isoterma de Freundlich à temperatura de $20^{\circ} \mathrm{C}$............................................. 184

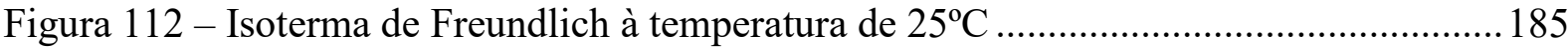

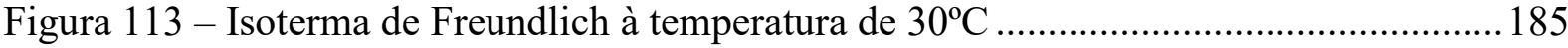

Figura 114 - Isoterma de Freundlich à temperatura de $40^{\circ} \mathrm{C}$............................................. 186

Figura 115 - Isoterma de Freundlich à temperatura de $50^{\circ} \mathrm{C}$.............................................. 186

Figura 116 - Isoterma de Temkin à temperatura de $20^{\circ} \mathrm{C}$.................................................. 187

Figura 117 - Isoterma de Temkin à temperatura de $25^{\circ} \mathrm{C}$................................................... 187

Figura 118 - Isoterma de Temkin à temperatura de $30^{\circ} \mathrm{C}$................................................... 188

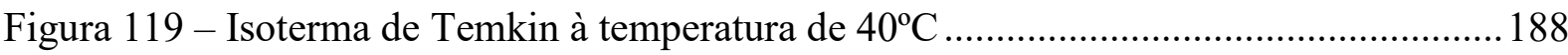

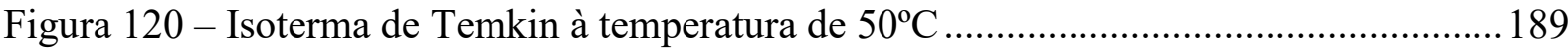

Figura 121 - Isoterma de Langmuir à temperatura de $20^{\circ} \mathrm{C}$................................................ 191

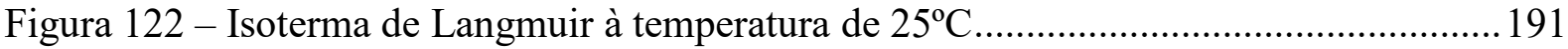

Figura 123 - Isoterma de Langmuir à temperatura de $30^{\circ} \mathrm{C}$................................................. 192

Figura 124 - Isoterma de Langmuir à temperatura de $40^{\circ} \mathrm{C}$................................................ 192

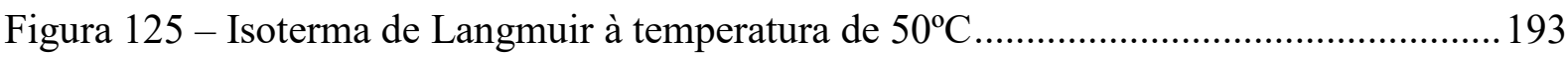

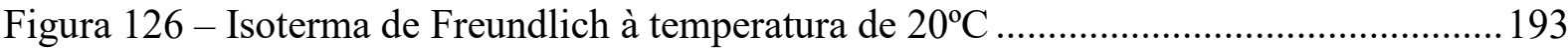

Figura 127 - Isoterma de Freundlich à temperatura de $25^{\circ} \mathrm{C}$.............................................. 194

Figura 128 - Isoterma de Freundlich à temperatura de $30^{\circ} \mathrm{C}$............................................. 194 


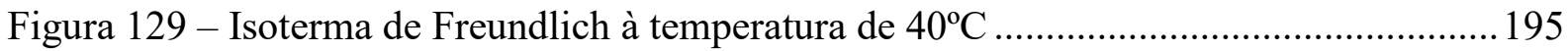

Figura 130 - Isoterma de Freundlich à temperatura de $50^{\circ} \mathrm{C}$............................................ 195

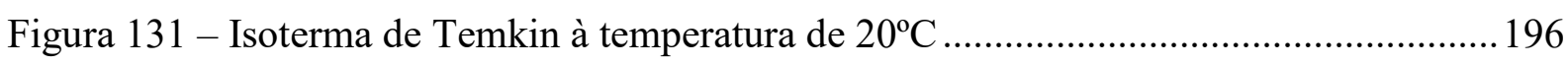

Figura 132 - Isoterma de Temkin à temperatura de $25^{\circ} \mathrm{C}$............................................... 196

Figura 133 - Isoterma de Temkin à temperatura de $30^{\circ} \mathrm{C}$............................................... 197

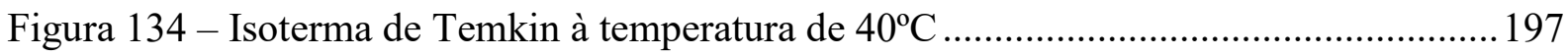

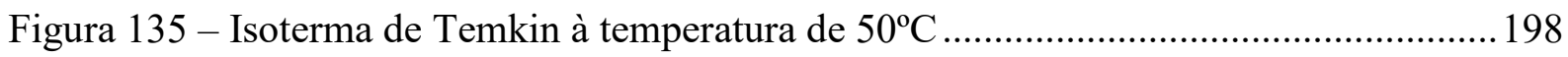

Figura 136 - Micrografias dos resíduos lignocelulósicos com ampliação de 50x .................200

Figura 137 - Micrografias dos resíduos lignocelulósicos com ampliação de 200x ...............200

Figura 138 - Micrografias dos resíduos lignocelulósicos com ampliação de 1.000x ...........200

Figura 139 - Micrografias dos resíduos lignocelulósicos com ampliação de 3.000x ...........201

Figura 140 - Micrografias dos resíduos lignocelulósicos com ampliação de 10.000x ..........201

Figura 141 - Micrografias dos resíduos lignocelulósicos com ampliação de 25.000x ..........201

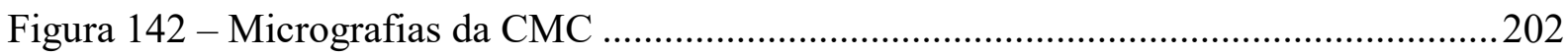

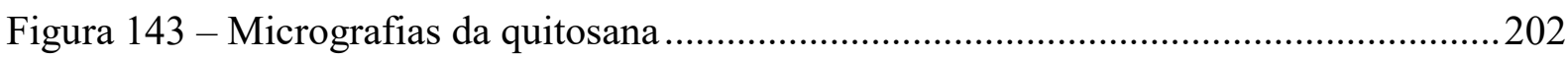

Figura 144 - Micrografias do adsorvente CMCQF ..........................................................203

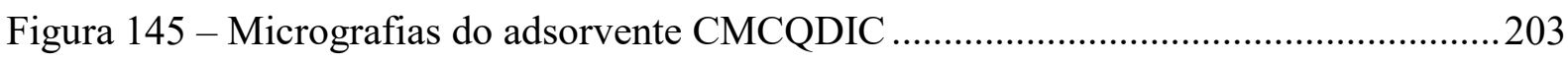




\section{LISTA DE TABELAS}

Tabela 1 - Íons metálicos e efeitos adversos a saúde........................................................2 23

Tabela 2 - Precipitação química de alguns íons de metais pesados ......................................28

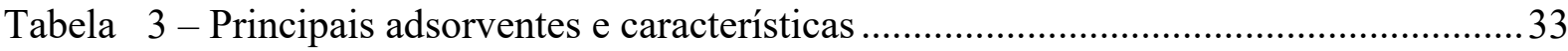

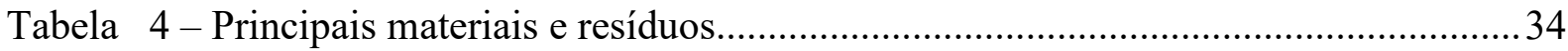

Tabela 5 - Exemplos de processos de tratamento de materiais lignocelulósicos...................53

Tabela 6 - Relação entre o fator de separação e o tipo de isoterma.......................................39

Tabela 7 - Relação entre o fator de separação e o tipo de isoterma....................................... 40

Tabela 8 - Teores de umidades referentes a cada etapa do processo .................................. 81

Tabela 9 - Teores percentuais de cinzas referentes a cada etapa de tratamento .................... 81

Tabela 10 - Teores de lignina referentes a cada etapa de tratamento ................................... 82

Tabela 11 - Teores de holocelulose referentes a cada etapa do processo de tratamento .........82

Tabela 12 - Teores de celulose referentes a cada etapa do processo de tratamento ................83

Tabela 13 - Teores de hemicelulose referentes a cada etapa de tratamento ............................83

Tabela 14 - Índice de cristalinidade para as palhas bruta e tratadas ........................................ 86

Tabela 15 - Dados de empregados no cálculo do GS por titulometria .................................. 91

Tabela 16 - Deslocamentos químicos e integrais referentes ao espectro de ${ }^{1} \mathrm{H}-\mathrm{RMN}$ para a

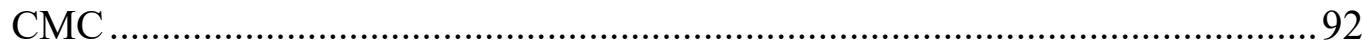

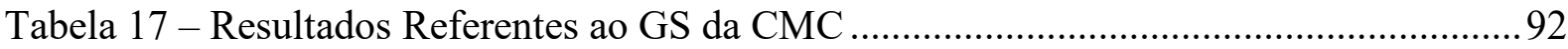

Tabela 18 - Resultados preliminares de capacidade de adsorção .......................................... 95

Tabela 19 - Análise DSC para a CMC, quitosana e, adsorventes CMCQF e CMCQDIC ......98

Tabela 20 - Densidade real obtida para a CMC, quitosana e, adsorventes ............................ 104

Tabela 21 - Tamanho de partícula médio observado para a CMC, quitosana e adsorventes 105

Tabela 22 - Resultados referentes ao ensaio de cinética de adsorção.................................... 106

Tabela 23 - Comparação dos parâmetros obtidos pelos três modelos cinéticos .................... 113

Tabela 24 - Dados da influência no pH no processo de adsorção referente ao CMCQF ...... 115

Tabela 25 - Dados para o estudo de isotermas à temperatura de $20^{\circ} \mathrm{C}$................................. 118

Tabela 26 - Dados para o estudo de isotermas à temperatura de $25{ }^{\circ} \mathrm{C}$.................................. 118

Tabela 27 - Dados para o estudo de isotermas à temperatura de $30^{\circ} \mathrm{C}$.................................. 119

Tabela 28 - Dados para o estudo de isotermas à temperatura de $40^{\circ} \mathrm{C}$................................. 119

Tabela 29 - Dados para o estudo de isotermas à temperatura de $50{ }^{\circ} \mathrm{C}$................................ 120

Tabela 30 - Parâmetros para a isoterma de Langmuir ......................................................... 122

Tabela 31 - Parâmetros para a isoterma de Freundlich......................................................... 123 
Tabela 32 - Parâmetros para a isoterma de Temkin obtidos para o CMCQF

Tabela 33 - Parâmetros termodinâmicos obtidos.

Tabela 34 - Comparação entre condições de cada adsorvente.

Tabela 35 - Dados de capacidade obtidos na condição ideal.

Tabela 36 - Deslocamentos químicos $\left({ }^{1} \mathrm{H},{ }^{13} \mathrm{C}\right)$, multiplicidade $\left({ }^{1} \mathrm{H}\right)$, número de hidrogênios, constantes de acoplamento $(J)$ referentes aos espectros ${ }^{1} \mathrm{H}-\mathrm{RMN}$ e ${ }^{13} \mathrm{C}-\mathrm{RMN}$ para o AS e precursores

Tabela 37 - Deslocamentos químicos $\left({ }^{1} \mathrm{H},{ }^{13} \mathrm{C}\right)$, multiplicidade $\left({ }^{1} \mathrm{H}\right)$, número de hidrogênios, constantes de acoplamento $(J)$ referentes aos espectros ${ }^{1} \mathrm{H}-\mathrm{RMN}$ e ${ }^{13} \mathrm{C}-\mathrm{RMN}$ para o AT e precursores

Tabela 38 - Deslocamentos químicos $\left({ }^{1} \mathrm{H},{ }^{13} \mathrm{C}\right)$, multiplicidade $\left({ }^{1} \mathrm{H}\right)$, número de hidrogênios, constantes de acoplamento $(J)$ referentes aos espectros ${ }^{1} \mathrm{H}-\mathrm{RMN}$ e ${ }^{13} \mathrm{C}-\mathrm{RMN}$ para o LS e precursores

Tabela 39 - Deslocamentos químicos $\left({ }^{1} \mathrm{H},{ }^{13} \mathrm{C}\right)$, multiplicidade $\left({ }^{1} \mathrm{H}\right)$, número de hidrogênios, constantes de acoplamento $(J)$ referentes aos espectros ${ }^{1} \mathrm{H}-\mathrm{RMN}$ e ${ }^{13} \mathrm{C}-\mathrm{RMN}$ para o LT e precursores

Tabela 40 - Resultados de adsorção para os adsorventes ativados ...................................... 136

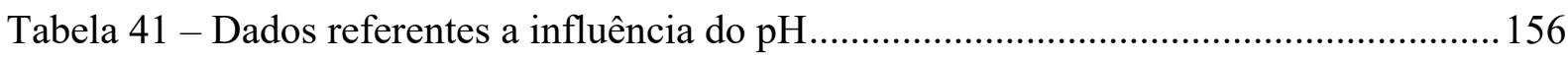

Tabela 42 - Dados de cinética de adsorção para CMCQF ..................................................... 157

Tabela 43 - Dados de cinética de adsorção para CMCQDIC .............................................. 159

Tabela 44 - Dados referentes a influência do pH para CMCQDIC …..................................... 161

Tabela 45 - Dados dos efluentes utilizados nos ensaios de isotermas para CMCQF ............ 162

Tabela 46 - Dados experimenteis referentes à temperatura de $20^{\circ} \mathrm{C}$ para o CMCQF .......... 163

Tabela 47 - Dados experimenteis referentes à temperatura de $25^{\circ} \mathrm{C}$ para o CMCQF .......... 163

Tabela 48 - Dados experimenteis referentes à temperatura de $30^{\circ} \mathrm{C}$ para o CMCQF .......... 164

Tabela 49 - Dados experimenteis referentes à temperatura de $40{ }^{\circ} \mathrm{C}$ para o CMCQF .......... 164

Tabela 50 - Dados experimenteis referentes à temperatura de $50{ }^{\circ} \mathrm{C}$ para o CMCQF .......... 165

Tabela 51 - Dados dos efluentes utilizados nos ensaios de isotermas para CMCQDIC........ 166

Tabela 52 - Dados experimenteis referentes à temperatura de $20^{\circ} \mathrm{C}$ para o CMCQDIC ..... 167

Tabela 53 - Dados experimenteis referentes à temperatura de $25{ }^{\circ} \mathrm{C}$ para o CMCQDIC ..... 167

Tabela 54 - Dados experimenteis referentes à temperatura de $30^{\circ} \mathrm{C}$ para o CMCQDIC ..... 168

Tabela 55 - Dados experimenteis referentes à temperatura de $40{ }^{\circ} \mathrm{C}$ para o CMCQDIC ..... 168

Tabela 56 - Dados experimenteis referentes à temperatura de $50{ }^{\circ} \mathrm{C}$ para o CMCQDIC ..... 169 


\section{LISTA DE ABREVIAÇÕES}

IARC International Agency for Research on Cancer

CMC Carboximetilcelulose

Q Quitosana

DIC N,N'-diisopropilcarbodiimida

F Ácido ferúlico

PVA Poli (álcool vinílico)

CMCQF Nomenclatura adotado referente ao adsorvente sintetizado por meio da junção das abreviaturas dos reagentes utilizados na obtenção do mesmo (CMC, Q e F)

CMCQDIC Nomenclatura adotado referente ao adsorvente sintetizado por meio da junção das abreviaturas dos reagentes utilizados na obtenção do mesmo (CMC, Q e DIC)

CMCQPVA Nomenclatura adotado referente ao adsorvente sintetizado por meio da junção das abreviaturas dos reagentes utilizados na obtenção do mesmo (CMC, Q e PVA)

LI Líquido iônico

FTIR Fourier-transform infrared spectroscopy

ART $\quad$ Attenuated total reflectance

DRX Difração de raios X

MEV-FEG Microscopia eletrônica de varredura de alta eficiência

RMN Ressonância magnética nuclear

${ }^{1} \mathrm{H}-\mathrm{RMN}$ Ressonância magnética nuclear de hidrogênio

${ }^{13} \mathrm{C}-\mathrm{RMN}$ Ressonância magnética nuclear de carbono

$\mathrm{D}_{2} \mathrm{O} \quad$ Óxido de deutério

$\mathrm{CDCl}_{3} \quad$ Clorofórmio deuterado

$\delta \mathrm{H} \quad$ Deslocamento químico de hidrogênio

$\delta \mathrm{C} \quad$ Deslocamento químico de Carbono

m Multiplicidade do sinal de hidrogênio

$\mathrm{n}^{\circ} \mathrm{H} \quad$ Número de hidrogênios

J Constante de acoplamento

$I_{\mathrm{CH}_{2}} \quad$ Integral do sinal de hidrogênio do grupo carboximetílico

$I_{H A} \quad$ Integral do sinal de hidrogênio glicosídicos 


\begin{tabular}{|c|c|}
\hline rpm & Rotações por minuto \\
\hline TGA & Thermogravimetric analysis \\
\hline $\mathrm{DSC}$ & Differential scanning calorimetry \\
\hline $\mathrm{T}_{\text {melting }}$ & Temperatura de fusão \\
\hline$\Delta \mathrm{H}_{\text {meilting }}$ & Entalpia de fusão \\
\hline GS & Grau de substituição \\
\hline B.E.T. & Brunauer, Emmett, Teller \\
\hline IC & Índice de cristalinidade \\
\hline IR & Infrared spectrum \\
\hline$\% \mathrm{TC}$ & Teor percentual de cinzas \\
\hline $\mathrm{MC}$ & Massa de cinzas após a calcinação \\
\hline MA & Massa de amostra utilizada \\
\hline$\%$ Lig & Toer de lignina \\
\hline $\mathrm{m}_{\text {lig }}$ & Massa de lignina \\
\hline $\mathrm{m}_{\mathrm{t}}$ & Massa de inicial de amostra \\
\hline$\%$ Holo & Teor de holocelulose \\
\hline $\mathrm{m}_{\text {holo }}$ & Massa de holocelulose \\
\hline $\mathrm{m}_{\mathrm{m}}$ & Massa de material analisado \\
\hline$\% \mathrm{Cel}_{\text {Holo }}$ & Teor de celulose em relação a massa de holocelulose \\
\hline $\mathrm{m}_{\mathrm{cel}}$ & Massa de celulose \\
\hline$\% \mathrm{Cel}$ & Teor de celulose \\
\hline$\%$ Hemi & Teor de hemicelulose \\
\hline AS & Acetato de sec-butilamônio \\
\hline AT & Acetato de terc-butilamônio \\
\hline LS & Lactato de sec-butilamônio \\
\hline $\mathrm{LT}$ & Lactato de terc-butilamônio \\
\hline
\end{tabular}




\section{SUMÁRIO}

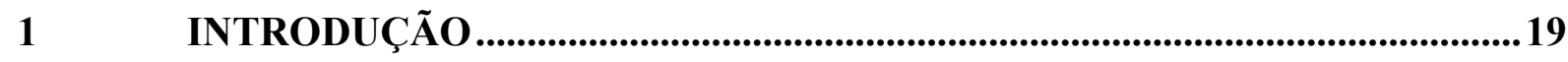

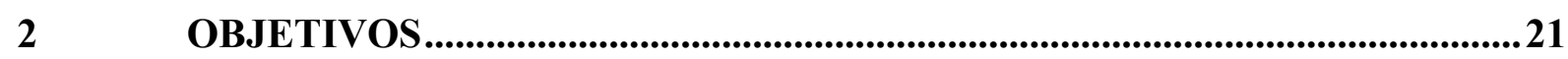

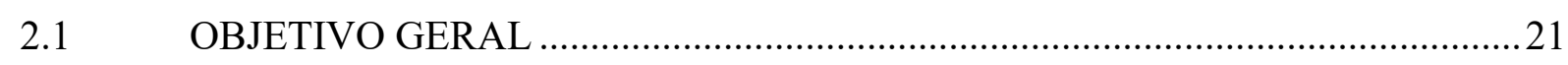

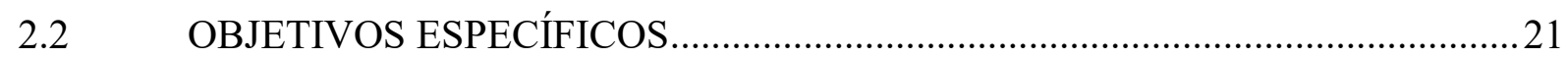

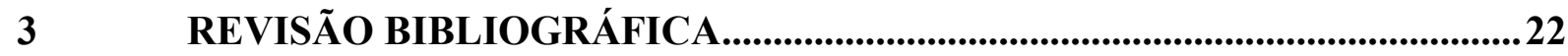

3.1 CONTAMINAÇÃO DE EFLUENTES COM METAIS PESADOS ......................22

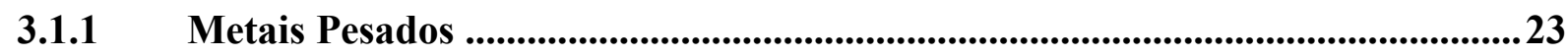

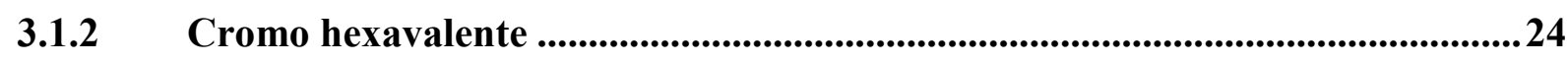

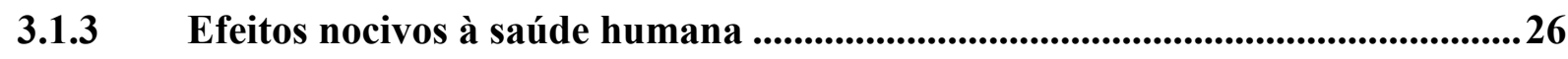

3.2 PRINCIPAIS PROCESSOS DE TRATAMENTO DE EFLUENTES ....................27

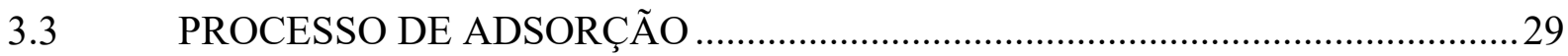

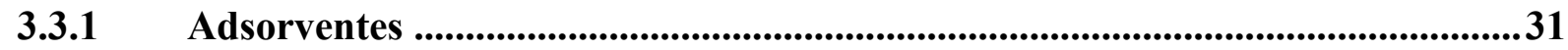

3.4 ESTUDO DE VARIÁVEIS DO PROCESSO DE ADSORÇÃO.............................34

3.4.1 Isotermas de adsorção ...................................................................................................34

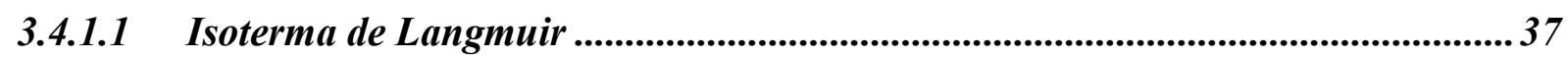

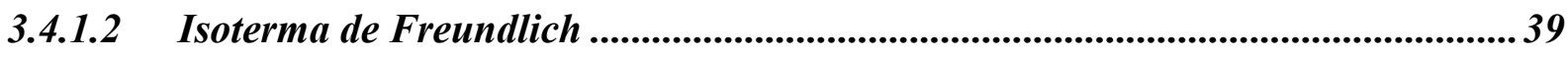

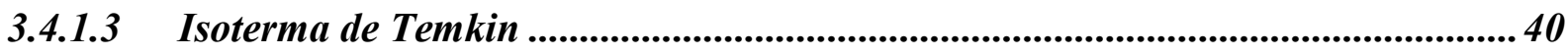

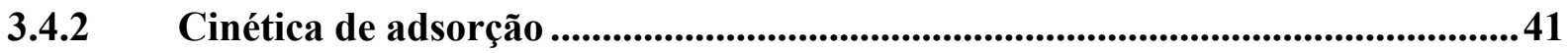

3.4.2.1 Modelos cinéticos ................................................................................................................ 43

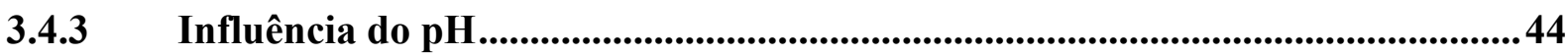

3.4.4 Formalismo de termodinâmica de adsorção......................................................... 45

3.5 POLÍMEROS NATURAIS EM PROCESSOS DE ADSORÇÃO ..........................47

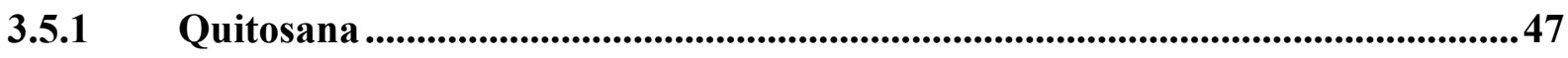

3.5.2 Resíduos Lignocelulósicos ...............................................................................................49

3.5.3 Carboximetilcelulose.......................................................................................................53

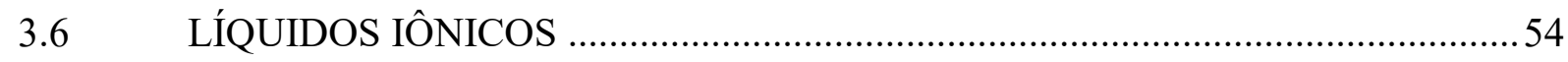

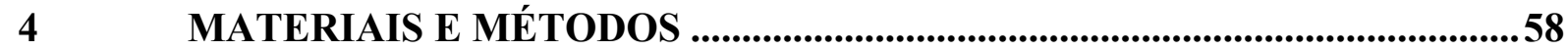

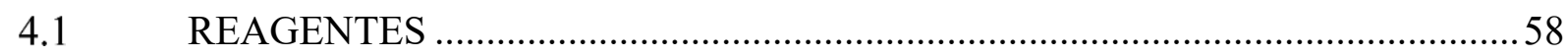

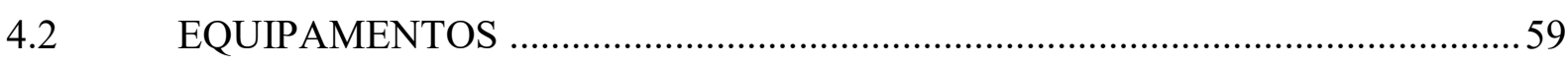

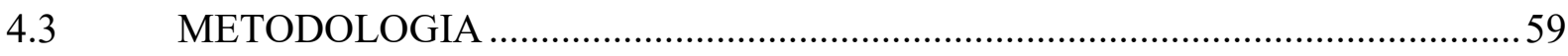

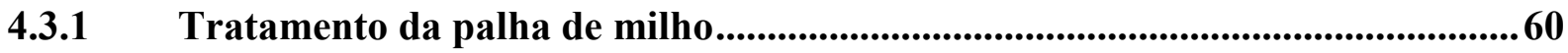

4.3.2 Obtenção da carboximetilcelulose (CMC) a partir da palha de milho ..............61 
4.3.3 Modificação da carboximetilcelulose (CMC) com quitosana ........................... 62

4.3.3.1 Modificação da CMC utilizando-se o ácido ferúlico ............................................... 62

4.3.3.2 Modificação da CMC utilizando-se a N,N'-diisopropilcarbodiimida .................... 62

4.3.3.3 Modificação da CMC utilizando-se álcool polivinílico........................................ 62

4.3.3.4 Teste inicial de adsorção de cromo hexavalente...................................................... 63

4.3.4 Estudo de adsorção de cromo hexavalente com os adsorventes selecionados .. 63

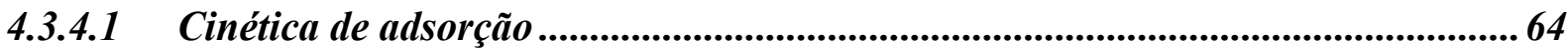

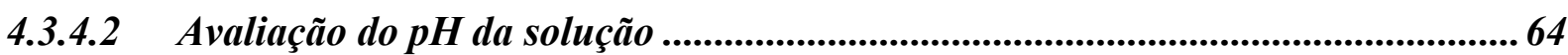

4.3.4.3 Construção das Isotermas de Langmuir, Freundlich e Temkin .......................... 64

4.3.5 Síntese dos líquidos iônicos................................................................................65

4.3.6 Tratamento da CMC modificada com os líquidos iônicos .................................65

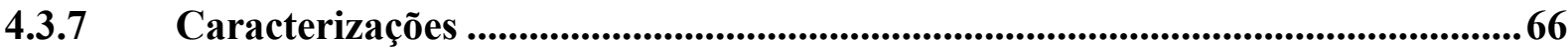

4.3.7.1 Determinação da composição da palha de milho ..................................................66

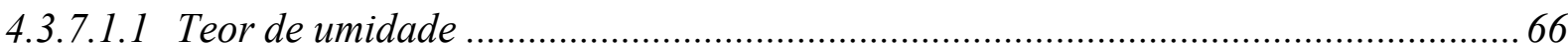

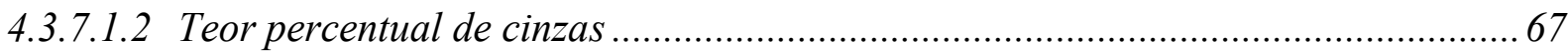

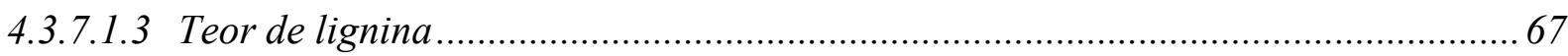

4.3.7.1.4 Teor de holocelulose, celulose e hemicelulose ....................................................... 67

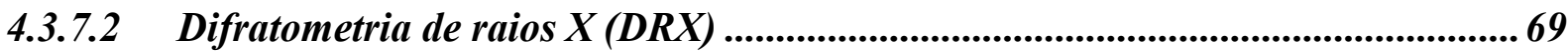

4.3.7.3 Microscopia eletrônica de varredura de alta resolução (MEV-FEG) .................. 70

4.3.7.4 Espectoscopia na região do infravermelho (FTIR) ............................................ 71

4.3.7.5 Determinação do grau de substituição (GS) ............................................................. 72

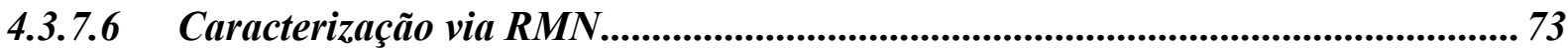

4.3.7.7 Análise Térmica ................................................................................................. 75

4.3.7.8 Distribuição do tamanho de partícula ..................................................................76

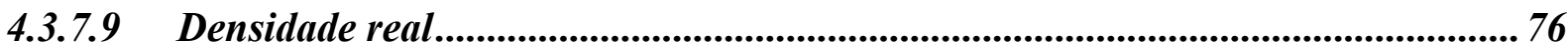

4.3.7.10 Área superficial ..................................................................................................77

4.3.7.11 Método colorimétrico da difenilcarbazida .........................................................78

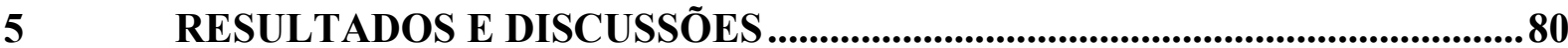

5.1 OBTENÇÃO DA CARBOXIMETILCELULOSE (CMC) ..................................... 80

5.1.1 Tratamento e caracterização da palha de milho .................................................80

5.1.2 Síntese e caracterização da carboximetilcelulose .............................................. 87

5.2 OBTENÇÃO DOS ADSORVENTES E TESTE INICIAL DE ADSORÇÃO ........92

5.3 CARACTERIZAÇÃO DOS ADSORVENTES ESCOLHIDOS ............................95

5.4 ESTUDO DE ADOSRÇÃO DE CROMO HEXAVALENTE ................................ 105 


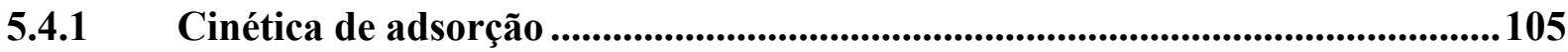

5.4.2 Influência do pH....................................................................................................114

5.4.3 Isotermas de adsorção …………………………..................................................117

5.4.4 Termodinâmica de adsorção ......................................................................................128

5.4.5 Comparação entre os adsorventes ..........................................................................130

5.5 INFLUENCIA DOS LÍQUIDOS IÔNICOS NO PROCESSO DE ADSORÇÃO 132

5.5.1 Obtenção e caracterização dos líquidos iônicos .....................................................132

5.5.2 Processo de adsorção com adsorventes ativados com os líquidos iônicos........135

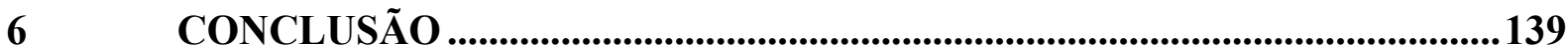

REFERÊNCIAS ......................................................................................................... 140

Apêndice A - Dados experimentais de adsorção...................................................154

Apêndice B - Distribuição de tamanho de partícula ............................................170

Apêndice $\mathrm{C}$ - Espectros de ${ }^{1} \mathrm{H}-\mathrm{RMN}$ e ${ }^{13} \mathrm{C}-\mathrm{RMN}$ dos precursores de síntese e dos líquidos iônicos sintetizados .................................................172

Apêndice D - Isotermas de Adsorção para CMCQF...........................................181

Apêndice E - Isotermas de Adsorção para CMCQDIC .......................................190

Apêndice F - Micrografias ..................................................................................199 


\section{INTRODUÇÃO}

Com o avanço da atividade industrial muitas transformações socioeconômicas e ambientais ocorreram uma vez que, com crescimento populacional, surgiu uma maior demanda de produtos industrializados que acarretou uma maior produção de efluentes industriais sendo, esses, os maiores responsáveis por poluir e contaminar água e solo. Dessa forma, surge a necessidade de tratamento e recuperação desses efluentes com o intuito de prevenir os efeitos nocivos que possam causar (JOBBY et al, 2018; IHSANULLAH et al., 2017).

O tratamento desses rejeitos industriais se torna ainda mais necessário quando íons de metais pesados estão presentes pois, os mesmos, apresentam alta toxicidade, elevada solubilidade em água e são biocumulativos sendo que, pequenos traços, podem resultar em altos danos ao meio ambiente e seres humanos. Porém, dentre os metais pesados, o cromo apresenta uma maior preocupação, pois no estado hexavalente é altamente tóxico e cancerígeno (BURAKOV et al., 2018; GORE et al., 2016).

Devido aos elevados riscos, se faz necessária a remoção desses metais pesados, ao menos, até o limite estabelecido por órgãos regulamentadores quando presentes nos efluentes (SIYAL et al, 2018; ZHANG; ZENG; CHENG, 2016).

Dessa forma, surgem estudos e desenvolvimento de diversos métodos mecânicos, físicoquímicos e biológico para tratamento desses efluentes sendo, os métodos de adsorção, um dos mais estudados atualmente devido à sua alta eficiência, flexibilidade, baixo custo, facilidade de operação, e possibilidade de aplicação de inúmeros materiais como adsorventes (CAROLIN et al., 2017; GOMES; PICCIN; GUTTERRES, 2016; GORE et al., 2016; LI et al., 2016).

Para isso, vários materiais adsorventes podem ser utilizados para eliminação ou redução da concentração de íons de metais pesados, destacando-se o carbono ativado, sílica gel, argilas minerais, resinas, zeólitas e substâncias poliméricas. Porém, muitos dos adsorventes utilizados atualmente apresentam elevados custos ou baixa seletividade, sendo importantes o desenvolvimento de novos materiais que apresentem uma maior eficiência na adsorção e com um menor custo de obtenção (SIYAL et al, 2018; BURAKOV et al., 2018; GORE et al., 2016; LI et al., 2016; MA et al., 2018; POLOWCZYK et al., 2016; MALEKIA et al., 2015; XIAO et al., 2015; YUE et al., 2015;).

Nesse contexto, os materiais polissacarídeos como a carboximetilcelulose, quitosana, amido, materiais lignocelulósicos, celulose e derivados, devido a inúmeras vantagens como a biodegradabilidade, não-toxicidade, fontes de obtenção abundantes e baixo custo, e também por apresentarem grupamentos funcionais, como aminos, hidroxilas e carboxilas, responsáveis 
por aumentar a interação entre o metal contaminante proporcionando uma elevada capacidade de adsorção tonam-se uma excelente escolha como adsorvente (VAKILI et al., 2018; BORSAGLI et al., 2015; SALIM, 2015).

Essa capacidade de adsorção se deve à presença de ligações de hidrogênio, interações dipolo-dipolo e interações íon-dipolo, que podem ser potencializadas por meio da realização de tratamentos que envolvem a modificação das estruturas desses materiais polissacarídeos e, também, processos de ativação envolvendo as mais diversas metodologias (VAKILI et al., 2018; BORSAGLI et al., 2015; SALIM, 2015; XIE et al., 2015; KUMAR et al., 2012).

Visando contribuir de maneira significativa com os trabalhos que estão sendo realizados, principalmente os referentes a processos de adsorção, o presente estudo buscou a obtenção de novos adsorventes utilizando a palha de milho, devido ao fato de ser um resíduo lignocelulósico de alta disponibilidade e apresenta uma baixa quantidade de lignina que facilita a extração da celulose presente em sua estrutura, para a obtenção da carboximetilcelulose e modificação a estrutura da mesma com quitosana.

Além disso, foi realizada a submissão desses novos adsorventes a ativação com diferentes líquidos iônicos e, por fim, a análise da eficiência desses materiais poliméricos, em relação a adsorção de íons cromo hexavalente. 


\section{OBJETIVOS}

Com a crescente preocupação com questões ambientais, bem como a necessidade de desenvolvimento de novos adsorventes que apresentem uma melhora nos processos de adsorção, em especial aqueles envolvendo íons de metais pesados, os objetivos geral e específicos do presente estudo encontram-se descritos nos itens 2.1 e 2.2.

\subsection{OBJETIVO GERAL}

O presente estudo teve como objetivo avaliar a adsorção de cromo em carboximetilcelulose obtida a partir de palha de milho modificada com quitosana e ativada com diferentes líquidos iônicos.

\subsection{OBJETIVOS ESPECÍFICOS}

A partir do objetivo geral, os seguintes objetivos específicos foram traçados:

a) tratamento da palha de milho;

b) obtenção da carboximetilcelulose;

c) modificação da carboximetilcelulose com a quitosana;

d) caracterização dos novos adsorventes;

e) determinação das condições ideias do processo de adsorção de cromo hexavalente (tempo, temperatura e $\mathrm{pH}$ );

f) síntese e caracterização dos líquidos iônicos (lactato de sec-butilamônio, lactato de terc-butilamônio, acetato de sec-butilamônio e, acetato de terc-butilamônio);

g) modificação dos novos adsorventes com os líquidos iônicos;

h) comparação da capacidade de adsorção dos novos adsorventes após a modificação e, também, após ativação com os líquidos iônicos. 


\section{REVISÃO BIBLIOGRÁFICA}

Atualmente, com a rápida industrialização e crescimento populacional, efluentes industriais têm sido liberados exaustivamente e, nesse contexto, os mesmos se tornaram um grave problema ambiental. Assim, torna-se necessária a realização de pesquisas referentes ao tratamento e principais contaminantes desses efluentes como, por exemplo, os íons de metais pesados, bem como referentes às novas metodologias de tratamento sendo, um exemplo, as relacionadas a processos de adsorção (CAMPOS et al. 2019; SHARMA et al., 2019).

Portanto, os principais tópicos destacados e importantes para contextualizar essa problemática são: contaminação de efluentes com metais pesados, com destaque para o cromo hexavalente e os problemas gerados pelo seu acúmulo no meio ambiente, métodos de tratamento de metais pesados com destaque no processo de adsorção e obtenção de novos materiais adsorventes, bem como estudo das principais variáreis envolvidas em processos de adsorção e no desenvolvimento de novos materiais adsorventes, descritos nos itens de 3.1 a 3.6.

\subsection{CONTAMINAÇÃO DE EFLUENTES COM METAIS PESADOS}

Dentre os aspectos negativos causados pelo desenvolvimento industrial, a poluição gerada torna-se uma questão muito alarmante, uma vez que os avanços tecnológicos propiciaram uma melhor qualidade de vida e, os problemas ambientais causados pela geração de rejeitos, podem ser responsáveis por reduzir essa melhora, pois muitos dos efluentes industriais produzidos podem apresentar contaminantes orgânicos e inorgânicos que são nocivos ao meio ambientes e ao ser humano (ABDELRAHMANA; HEGAZEY, 2019; SIYAL et al., 2018; CAROLIN et al., 2017).

Nesse contexto, o uso racional dos recursos hídricos torna-se uma das grandes preocupações em escala mundial, uma vez que a água se mostra um dos recursos mais comprometidos pelas atividades industriais, que geram grandes quantidades de efluentes contaminados e, aliado a isso, o fato de muitas regiões do mundo não terem acesso a esse recurso, mostrando ser uma questão socioeconômica e não apenas ambiental (BURAKOV et al., 2018; IHSANULLAH et al., 2016; CAROLIN et al., 2017).

Dessa forma, efluentes que contêm resíduos com elevada toxicidade, como nitratos, fosfatos, sedimentos, compostos radioativos, corantes, pigmentos e metais pesados provenientes de diversas indústrias devem ser controlados e tratados adequadamente, por meio do tratamento imediato, de preferência, na própria indústria onde o resíduo é gerado, para 
diminuir os impactos ambientais que possam vir a causar caso entre em contato com o meio ambiente pois, muitas vezes, esses contaminantes não são biodegradáveis e tendem a ser biocumulativos (JOBBY et al., 2018; SIYAL et al., 2018 UDDIN, 2017; ZHANG; ZENG; CHENG, 2016).

\subsubsection{Metais Pesados}

De forma geral, os metais pesados são elementos que possuem peso atômico entre 63,5 e 220,6 g.mol ${ }^{-1}$ e, densidade maior que $5 \mathrm{~g} . \mathrm{cm}^{-3}$, porém, também podem ser definidos como elementos metálicos com alta densidade e que são tóxicos mesmo em baixas concentrações, além de apresentarem como características não serem degradáveis, tendência de se bioacumularem e persistirem na natureza (JOBBY et al., 2018; CAROLIN et al., 2017).

Os metais pesados mais comuns são o cobre, níquel, cromo, mercúrio, chumbo, cádmio, arsênio e zinco que podem ser encontrados em diferentes estados oxidativos e apresentam toxicidade específicas e, efeitos adversos a saúde humana, conforme listado na tabela 1.

Tabela 1 - Íons metálicos e efeitos adversos a saúde

\begin{tabular}{|c|c|}
\hline Íons metálico & Efeito adverso \\
\hline Chumbo & $\begin{array}{l}\text { Problemas cardiovasculares, hiperatividade e de desenvolvimento do QI em } \\
\text { crianças, anemia e problemas de pressão. }\end{array}$ \\
\hline Arsênio & Câncer, problemas dermatológicos, gastrointestinais e cardiorrenais. \\
\hline Níquel & Eczema, câncer, afetam o DNA. \\
\hline Cromo & $\begin{array}{l}\text { Problemas de circulação, dermatite, problemas nos rins, câncer de pulmão, } \\
\text { mutagênese e até mesmo morte. }\end{array}$ \\
\hline Cobre & Dor abdominal, diarreia, fraqueza, cólicas. \\
\hline Zinco & Dor abdominal, anemia, problemas neurológicos. \\
\hline Cádmio & Prejudicam os rins, pulmões, fígado, coração, ossos e carcinogênico. \\
\hline Mercúrio & $\begin{array}{l}\text { Afetam o sistema nervoso, digestivo e imunológico, pulmões e rins. Causam } \\
\text { problemas na pele, olhos e gastrointestinais podendo ser tóxico para os rins se } \\
\text { ingerido. }\end{array}$ \\
\hline
\end{tabular}

Fonte: Autor “adaptado de" Burakov et al., 2018; Sherlala et al., 2018; Gore et al., 2016; Zhou et al., 2016

Quando presentes em efluentes são oriundos, principalmente, das indústrias de fertilizantes, pesticidas, revestimento de metais, metalurgia, mineração, têxtil, corantes, tintas e vernizes sendo que, segundo estudos, alguns desses metais pesados apresentam potencial carcinogênico como é caso do cromo, arsênio, cádmio, chumbo, níquel e mercúrio, que 
acarretam uma preocupação ainda maior quanto em contato com meio ambiente (NITHYA et al., 2018; JOBBY et al., 2018; CAROLIN et al., 2017; AHMED; AHMARUZZAMAN, 2016).

Destes, os efluentes contaminados com cromo em seu estado hexavalente tem sido alvo de maior preocupação devido à alta toxicidade, elevada solubilidade em água, mesmo em baixas concentrações, potencial carcinogênico e mutagênico e, ao elevado número de indústrias que geram efluentes com elevadas concentrações do mesmo (KONG et al., 2019; SHARMA et al., 2019; ZHANG et al., 2019; NELLAIAPPAN; KUMAR, 2018; RANGABHASHIYAM; BALASUBRAMANIAN, 2018; GORE et al., 2016).

Dessas indústrias, destacam-se as de produção de plástico, pigmento, preservativo de madeira, galvanoplastia, curtimento de couro, cimento, mineração, tingimento, tratamento de seda, tintas e vernizes, vidro, materiais refratários, fertilizantes, catalisadores nas reações halogenações, alquilação e craqueamento catalítico de hidrocarbonetos, na indústria cerâmica e de aditivo propelente, que liberam grandes quantidades de efluentes contendo elevadas concentrações de cromo hexavalente (KONG et al., 2019; SARODE et al., 2019; SHARMA et al., 2019; NELLAIAPPAN; KUMAR, 2018; RANGABHASHIYAM; BALASUBRAMANIAN, 2018; XIANG et al., 2016; ZHOU et al., 2016; KAHU et al., 2016).

No Brasil, que é o terceiro maior produtor mundial de couro, a indústria do curtume é uma das grandes responsáveis pela geração de efluentes com presença de cromo hexavalente, uma vez que é utilizado cromo na forma de sais para o processamento da pele e consequente produção de couro (PACHECO, 2014).

\subsubsection{Cromo hexavalente}

O cromo (Cr) é um metal de transição duro, acinzentado e, ranqueado como o vigésimoprimeiro elemento mais abundante na crosta terrestre, sendo encontrado, naturalmente, no solo na forma de bentorita $\left[\mathrm{Ca}_{6}(\mathrm{CrAl})_{2}\left(\mathrm{SO}_{4}\right)_{3}\right]$, cromita $\left(\mathrm{FeCr}_{2} \mathrm{O}_{4}\right)$, tarapacaíta $\left(\mathrm{K}_{2} \mathrm{CrO}_{4}\right)$, vauquelinita $\left(\mathrm{CuPb}_{2} \mathrm{CrO}_{4}-\mathrm{PO}_{4} \mathrm{OH}\right)$ e, crocoita $\left(\mathrm{PbCrO}_{4}\right)$. $\mathrm{O}$ mesmo, pode ser encontrado em concentrações entre 0,1 e $6,0 \mu \mathrm{g} . \mathrm{L}^{-1}$ para água doce e, entre 0,2 e $50 \mu \mathrm{g} . \mathrm{L}^{-1}$ para a água do mar, ou no ar atmosférico devida a poeira soprada pelo vento de incêndios florestais, partículas salinas do mar e cinzas de erupções vulcânicas, geralmente, em concentrações entre 0,015 e $0,03 \mu \mathrm{g} . \mathrm{m}^{-3}$ (CAROLIN et al., 2017; SHAHID et al., 2017; CHOPPALA; BOLAN; PARK, 2013).

No mundo, a extração anual de cromo proveniente de minas terrestres é estimada entre $4,35 \times 10^{5}$ e $1,18 \times 10^{6}$ toneladas métricas, onde cerca de $80 \%$ desse minério é destinado para 
utilização na indústria metalúrgica, sendo que quase 170.000 toneladas de resíduos de $\mathrm{Cr}$ é descarregado no meio ambiente anualmente em todo o mundo (CHOPPALA; BOLAN; PARK, 2013).

$\mathrm{Na}$ indústria o cromo é empregado na forma de ácido crômico $\left(\mathrm{H}_{2} \mathrm{CrO}_{4}\right)$ na galvanoplastia e conservantes de madeira para aumenta a resistência à corrosão, de dicromato de potássio $\left(\mathrm{K}_{2} \mathrm{Cr}_{2} \mathrm{O}_{7}\right)$ como catalisador, de dicromato de sódio $\left(\mathrm{Na}_{2} \mathrm{Cr}_{2} \mathrm{O}_{7}\right)$ em pigmentos, corantes, vidro e plástico com a finalidade de conferir revestimento anticorrosivo e, na forma de sulfato de cromo (III) [ $\left.\mathrm{Cr}_{2}\left(\mathrm{SO}_{4}\right)_{3}\right]$, no curtimento de do couro (CAMPOS et al., 2019; PACHECO, 2014; CHOPPALA; BOLAN; PARK, 2013).

Na tabela periódica, é primeiro elemento do grupo VI, com número atômico igual a 24, massa molar de 52 g.mol ${ }^{-1}$, densidade de 7,19 g.cm ${ }^{-3}$ e ponto de fusão de $1857^{\circ} \mathrm{C}$. Existe em quatro diferentes isótopos estáveis $\left({ }^{50} \mathrm{Cr},{ }^{52} \mathrm{Cr},{ }^{53} \mathrm{Cr}\right.$ e $\left.{ }^{54} \mathrm{Cr}\right)$ e pode variar entre os estados oxidativos dentro do intervalo de -2 a +6 , sendo os estados trivalente $\left[\mathrm{Cr}^{3+}\right.$ ou $\left.\mathrm{Cr}(\mathrm{III})\right]$ e, hexavalente $\left[\mathrm{Cr}^{6+}\right.$ ou $\left.\mathrm{Cr}(\mathrm{VI})\right]$ os mais comuns e predominantes por serem mais estáveis. Destes, o Cr(III) é encontrado em condições redutoras e o $\mathrm{Cr}(\mathrm{VI})$ se manifesta em condições oxidativas, além de apresentar toxicidade maior em relação ao $\mathrm{Cr}$ (III). Dificilmente é encontrado na forma elementar $\left(\mathrm{Cr}^{0}\right)$, pois em contato com o ar atmosférico oxida a óxido de cromo $\left(\mathrm{Cr}_{2} \mathrm{O}_{3}\right)$ na forma de uma camada densa e não porosa (JOBBY et al., 2018; BISWAS et al., 2017; CAROLIN et al., 2017; SHAHID et al., 2017; CHOPPALA; BOLAN; PARK, 2013).

O cromo é um elemento biologicamente importante, pois é necessário no metabolismo de açúcares, lipídeos e proteínas nos mamíferos, tonando-se um micronutriente essencial na dieta humana e animal, porém em doses muito elevados, o cromo torna-se tóxico, sendo que, o nível de toxicidade, varia de acordo com estados oxidativo.

O cromo hexavalente é o estado oxidativo que apresenta maior toxicidade, sendo classificado como um dos dezesseis elementos com maior efeito nocivo ao ser humano, onde o contágio pode ocorrer por inalação, ingestão e contato com a pele. O mesmo pode causar disfunção renal e hepática, diarreia, úlcera, hemorragia, irritação na pele e nos olhos, além de ser conhecido por ser altamente cancerígeno e mutagênico, podendo levar a morte se em concentrações superiores a 0,1 mg de cromo por g de massa corporal (SU et al., 2019; VAKILI et al., 2018; JOBBY et al., 2018).

$\mathrm{O}$ cromo hexavalente $\left(\mathrm{Cr}^{6+}\right)$ é considerado extremamente prejudicial à saúde humana quando em concentrações acima das permitidas pela legislação $\left(0.5-2 \mu \mathrm{g} . \mathrm{L}^{-1}\right)$, podendo ser encontrado nas formas de cromato $\left(\mathrm{HCrO}_{4}^{-} / \mathrm{CrO}_{4}{ }^{2-}\right)$ ou dicromato $\left(\mathrm{Cr}_{2} \mathrm{O}^{-2} / \mathrm{HCr}_{2} \mathrm{O}_{7}^{-}\right)$, dependendo do $\mathrm{pH}$ e da concentração, sendo que, em $\mathrm{pH}$ maiores que 7 , os íons $\mathrm{Cr}^{6+}$ se 
manifestam na forma de $\mathrm{CrO}_{4}{ }^{2-}$ e, na faixa de $\mathrm{pH}$ de 1 a $6,{\mathrm{o} \mathrm{HCrO}_{4}}^{-}$é a espécie predominante, sendo todos esses compostos altamente solúveis em água (JOBBY et a., 2018; LYTRAS et al., 2017; SHAHID et al., 2017).

\subsubsection{Efeitos nocivos à saúde humana}

As formas de contaminação por cromo hexavalente podem ocorrer por inalação, contato com a pele e ingestão, e os efeitos causados pelo contágio são divididos em cancerígenos e não cancerígenos. Sendo que, os não cancerígenos incluem efeitos sistêmicos, imunológicos, neurológicos, reprodutivos, de desenvolvimento, genético e, até mesma a morte (JOBBY et al., 2018; CAROLIN et al., 2017, SHAHID et al., 2017, BISWAS et al., 2017; CHOPPALA; BOLAN; PARK, 2013;GUERTIN; JACOBS; ACAKIAN, 2005).

A contaminação por contato com a pele ocorre por meio de águas e solos contaminados sendo, os principais sintomas observados vermelhidão, edemas e necrose. A contaminação por ingestão ocorre por meio de água com metais dissolvidos e alimentos contaminados. Dentre os efeitos noviços observados por esse tipo de contágio, destacam-se: disfunção pulmonar, problemas circulatórios, queimaduras gastrointestinais, hemorragia, danos aos rins e fígados, diminuição da fertilidade, má formação em fetos, anomalias em cromossomos das células, entre outras (JOBBY et al., 2018; NELLAIAPPAN; KUMAR, 2018; RANGABHASHIYAM; BALASUBRAMANIAN, 2018; CHOPPALA; BOLAN; PARK, 2013; GUERTIN; JACOBS; ACAKIAN, 2005).

A contaminação por inalação ocorre, geralmente, em indústrias que utilizam esse tipo de metal e os trabalhadores podem ficar expostos às partículas suspensas no ar, que afetam o trato respiratório causando asma, úlceras, perfurações no septo nasal ou, se inalado pela boca, pode causar úlcera estomacal e efeitos mutagênicos nos cromossomos (JOBBY et al., 2018; NELLAIAPPAN; KUMAR, 2018; RANGABHASHIYAM; BALASUBRAMANIAN, 2018; GUERTIN; JACOBS; ACAKIAN, 2005).

No geral, os efeitos citados anteriormente, apesar de alarmantes e preocupantes, não são conclusivos em seres humanos, pois foram observados em teste realizados com animais. Contudo, um dos efeitos comprovados é o desenvolvimento de câncer de pulmão em trabalhadores expostos ao cromo por inalação em indústrias de revestimento de metais fazendo com que a Agência Internacional de Pesquisas em Câncer (IARC) classificasse o cromo hexavalente como carcinogênico (SAMUEL et al., 2019; SARODE et al., 2019; CHEN et al., 2018; SHARID et al., 2017; GUERTIN; JACOBS; ACAKIAN, 2005). 
Dessa forma, a partir dos conhecimentos dos efeitos adversos que a exposição ao cromo hexavalente possa causar a saúde humana, o desenvolvimento e aplicação de metodologia capazes de retirar o mesmo dos efluentes torna-se de suma importância, evitando e diminuindo a contaminação de águas e solos por meio do seu descarte sem tratamento prévio.

\subsection{PRINCIPAIS PROCESSOS DE TRATAMENTO DE EFLUENTES}

Diversos métodos para tratamento de efluentes contendo metais pesados estão sendo utilizados ou estudados atualmente, podendo ser citados os métodos mecânicos, físico-químicos e biológico, como a precipitação, floculação, oxidorredução, eletrodiálise, osmose reversa, biorremediação, utilização de resinas de troca iônica e métodos de adsorção. Entretanto, muitos desses métodos apresentam desvantagens quanto à aplicação em larga escala, a geração de resíduos que necessitam de tratamento e custo elevado, apesar de apresentarem alta eficiência de remoção (SARODE et al., 2019; WANG et al., 2019; BALLADARES et al, 2018; HARGREAVES et al., 2018; BORSAGLI et al., 2015; KAHU et al., 2016; LUO et al., 2015; MATOUQ et al., 2015; SALIM, 2015; TAN et al., 2015).

Dentre os processos citados, o mais amplamente utilizado é a precipitação química, por meio da adição de um agente químico como, por exemplo, hidróxido de cálcio, hidróxido de potássio e, hidróxido de sódio, que proporciona o aumento do $\mathrm{pH}$, favorecendo a precipitação dos íons de metais pesados na forma de hidróxidos (Tabela 2). Porém, apesar de ser uma forma de tratamento eficiente e barata, apresenta como desvantagem a formação de quantidade significativas lama química que necessitam de tratamento (SARODE et al., 2019; BALLADARES et al, 2018; CAROLIN et al., 2017).

A oxidorredução e a floculação são outros métodos químicos utilizados no tratamento de efluentes sendo que, ao primeiro, se adiciona o agente químico no intuito de alterar o estado oxidativo do componente para outro estado menos tóxico e, em seguida, realiza-se a remoção do contaminante por meio do princípio da precipitação química. No segundo, utiliza-se agentes floculantes inorgânico que reagem com as moléculas desestabilizadas, como íons metálicos, dispersas no efluente formando macromoléculas que são removidas por filtração ou sedimentação (CAROLIN et al., 2017). 
Tabela 2 - Precipitação química de alguns íons de metais pesados

\begin{tabular}{c|c|c|c|c}
\hline Íon removido & Concentração inicial & Precipitante & pH ideal & \%Remoção \\
\hline $\mathrm{Zn}^{2+}$ & $32 \mathrm{mg} \cdot \mathrm{L}^{-1}$ & $\mathrm{CaO}$ & $9-10$ & $99-99,3$ \\
$\mathrm{Cu}^{2+}, \mathrm{Zn}^{2+}, \mathrm{Cr}^{3+}, \mathrm{Pb}^{2+}$ & $100 \mathrm{mg} . \mathrm{L}^{-1}$ & $\mathrm{CaO}$ & $7-11$ & $99,37-99,6$ \\
$\mathrm{Cu}^{2+}, \mathrm{Zn}^{2+}, \mathrm{Pb}^{2+}$ & $0.018,1.34,2.3 \mathrm{~mol} \cdot \mathrm{L}^{-1}$ & $\mathrm{H}_{2} \mathrm{~S}$ & 3 & $100>94>92$ \\
$\mathrm{Cr}^{3+}$ & $5363 \mathrm{mg} \cdot \mathrm{L}^{-1}$ & $\mathrm{CaO}$ ou $\mathrm{MgO}$ & 3 & $>99$ \\
$\mathrm{Hg}^{2+}$ & $65.6,188 \mu \mathrm{g} \cdot \mathrm{L}^{-1}$ & 1,3-Benzenodiamidoetanotiolato & 4,7 e 6,4 & $>99,9$ \\
\hline
\end{tabular}

Fonte: Autor "adaptado de" SARODE et al., 2019

Contudo, apesar de larga aplicação dessas técnicas ainda apresentam a desvantagens de gerar grandes quantidades de lama química, gerando outro resíduo a ser tratado, e não garantirem a remoção total dos metais e, ainda, formar subprodutos que também podem ser poluentes, necessitando a utilização de técnica complementar de tratamento. Salienta-se também que os agentes floculantes mais utilizados como sulfato de alumínio $\left[\mathrm{Al}_{2}\left(\mathrm{SO}_{4}\right)_{3}\right]$, sulfato de ferro $\left[\mathrm{Fe}_{2}\left(\mathrm{SO}_{4}\right)_{3}\right]$ e cloreto de ferro $\left[\mathrm{FeCl}_{3}\right]$ apresentam custo elevado e são utilizados em quantidades significativas (HARGREAVES et al., 2018; AJAO et al., 2018; CAROLIN et al., 2017).

Outras técnicas possíveis de serem aplicadas são a osmose reversa e a eletrodiálise, que são métodos que utilizam membranas semipermeáveis de baixa porosidade que permitem passagem de água, porém, retém os íons de metais pesados. Destas, a osmose reversa consiste na aplicação de uma pressão no sistema maior que a pressão osmótica exercida pelos íons dissolvidos no efluente que se deseja tratar, fazendo com que a água passe para o lado da membrana em que não há íons metálicos, retendo os mesmos. Na eletrodiálise, aplica-se uma corrente elétrica entre os eletrodos que são separados pela membrana. Dessa forma, quando ocorrem a migração dos cátions e ânions para o cátodo e ânodo, respectivamente, os mesmos ficam retidos (SARODE et al., 2019; CAROLIN et al., 2017; LI et al, 2017; NEMATI; HOSSEINI; SHABNIAN; 2017).

Todavia, esses processos apresentam as vantagens de diminuir a quantidade de lama formada, não necessitam de agentes químicos e altos índices de recuperação de água porém, necessitam de uma elevada demanda de energia, dificultando a recuperação da membrana que necessita de manutenção com maior periodicidade, tonando o processo caro e de difícil aplicação em larga escala (CAROLIN et al., 2017; LI et al, 2017; NEMATI; HOSSEINI; SHABNIAN; 2017).

Já o processo de biorremediação consiste na utilização de microrganismos, como bactérias, fungos, leveduras e algas, que promovem a redução, degradação ou imobilização de 
metais pesados disponíveis no efluente por meio da bioacumulação, biossorção, biotransformação e biomineralização, apresentando resultados eficazes no tratamento de efluentes contendo íons de metais pesados. Entretanto, muitas vezes as condições que esses efluentes são dispostos, como elevada concentração e elevado $\mathrm{pH}$, podem interferir no crescimento desses microrganismos, resultando em baixas taxas de remoção, o que acaba por restringir o uso da técnica (JACOB et al., 2018; JOBBY et al., 2018; CAROLIN et al., 2017).

A aplicação de resinas de troca iônica é um dos processos amplamente utilizados no tratamento de efluente e de alta eficiência na remoção de metais pesados. A técnica consiste na substituição de um íon na superfície da resina por outro presente no efluente por meio de ligações covalentes sendo que, essas resinas, podem ser naturais ou sintéticas e apresentam como vantagem a facilidade de recuperação por meio de lavagem com agentes químicos, porém, gera resíduos secundários passivos de tratamento e são materiais de custo elevado e de difícil utilização em larga escala (MA et al., 2018; CAROLIN et al., 2017).

Devido à alta eficiência, flexibilidade, baixo custo e simplicidade de operação, bem como possibilidade de aplicação de inúmeros adsorventes naturais e sintéticos e, também, por ser uma operação unitárias largamente aplicada em escala industrial, o processo de adsorção ainda é um dos principais métodos estudados atualmente (BURAKOV et al., 2018; SIYAL et al., 2018; VAKILI et al., 2018; CAROLIN et al., 2017).

Porém, para se aplicar o processo de adsorção no tratamento de efluentes contendo íons de metais pesados como os íons de cromo hexavalente, existe a necessidade de se utilizar adsorventes com características ideais de porosidade, tamanho de partícula e, principalmente, a presença de grupamentos que favoreçam o processo de adsorção. Sendo, interessante a aplicação de materiais que apresentem grupamentos amínicos, hidroxílicos e carboxílicos. Também existe a necessidade de se estudar as características ideais de realização do processo (TAHAR et al., 2018; CHEN et al., 2018; CAROLIN et al., 2017; NGAH; TEONG; HANAFIAH, 2011).

\subsection{PROCESSO DE ADSORÇÃO}

O processo de adsorção apresenta inúmeras vantagens econômicas e elevada capacidade de remoção de contaminantes de efluentes e, devido a esse fato, tem despertado o interesse na indústria química e de pesquisadores, já que se mostra capaz de reduzir a concentração de poluentes que geram riscos à saúde e ao meio ambiente até níveis permitidos por órgão regulamentadores (GHNIMIA; FRINI-SRASRA, 2018). 
A adsorção é um processo de transferência de fase amplamente usado na prática para remover substâncias de fases fluidas (gases ou líquidos), com o enriquecimento de espécies químicas por meio do aumento de concentração de partículas na superfície e interface entre duas fases. Esse aumento da concentração ocorre devido a atração entre os átomos da superfície de um sólido, chamado de adsorvente, e as partículas ou moléculas da fase fluida, chamada de adsorvato. Esse fenômeno ocorre devido a interações intramoleculares, principalmente às ligações de hidrogênio, interações dipolo-dipolo e interações íon-dipolo. Onde o processo inverso a adsorção é chamado de dessorção (Figura 1) (BURAKOV et al., 2018; GOMES et al., 2016; SALIM, 2015; WORCH, 2012; ROUQUEROL; ROUQUEROL; SING, 1999; FAUST; ALY, 1987).

Figura 1 - Processo adsorção e dessorção

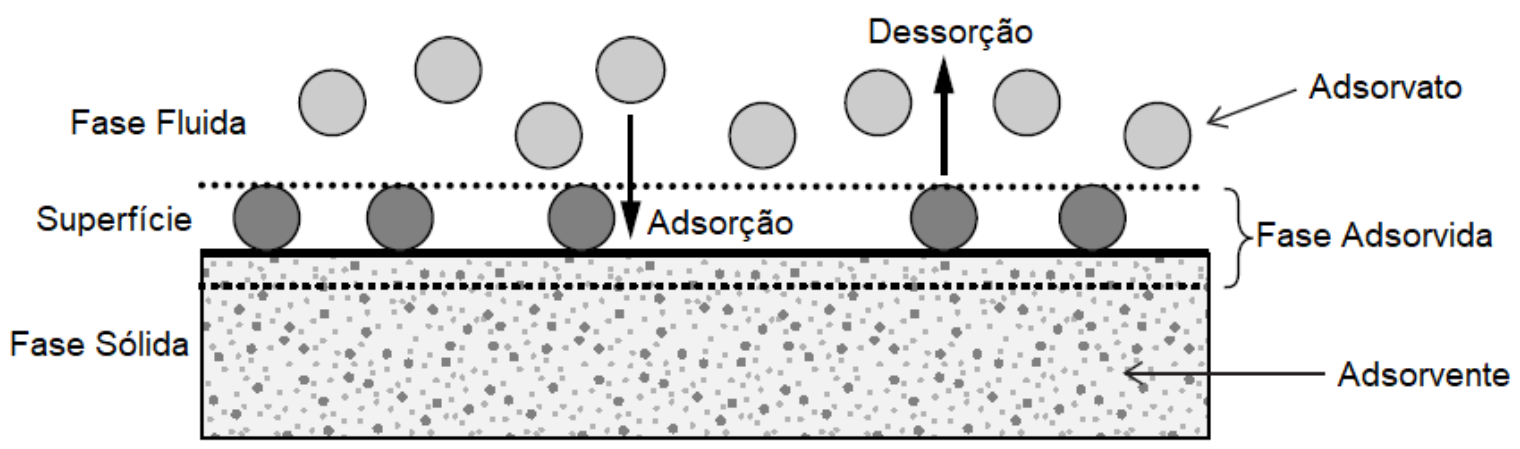

Fonte: Autor "adaptado de" Worch, 2012

A técnica é amplamente utilizada em tratamento de água, principalmente na remoção de substâncias orgânicas e íons inorgânicos de água potável, águas residuais, águas subterrâneas, água de piscina e água de aquários. Geralmente, utiliza-se como adsorvente o carbono ativado, mas também são utilizados óxidos e hidróxidos metálicos, zeólitas e argilas minerais (BURAKOV et al., 2018; CAROLIN et al., 2017; WORCH, 2012).

Esse fenômeno físico-químico e espontâneo pode ocorrer seguindo dois tipos de interações: adsorção física também conhecida como fisiossorção e, adsorção química ou quimiossorção. A adsorção física é um processo de adsorção que ocorre devido as interações eletrostáticas e forças de van der Waals entre a superfície do adsorvente e o adsorvato. A mesma não envolve reação química e é totalmente reversível, não existindo um sítio específico, ou seja, o adsorvato pode estar presente em toda superfície do adsorvente, além de apresentar baixa entalpia de adsorção podendo alcançar no máximo $50 \mathrm{~kJ} \cdot \mathrm{mol}^{-1}$ (BURAKOV et al., 2018; WORCH, 2012; ROUQUEROL; ROUQUEROL; SING, 1999; FAUST; ALY, 1987). 
Por outro lado, a quimiossorção é um processo de adsorção que envolve a formação de ligações químicas, geralmente covalente, entre adsorvato e adsorvente e não reversível, e altamente sítio específica, ou seja, esse processo ocorre em pontos definidos e favoráveis do adsorvente. A mesma apresenta elevada entalpia de adsorção, geralmente maior que $50 \mathrm{~kJ} . \mathrm{mol}^{-}$ ${ }^{1}$, devido a formação de uma nova ligação para retenção do adsorvato (BURAKOV et al., 2018; ROUQUEROL; ROUQUEROL; SING, 1999; FAUST; ALY, 1987).

Contudo, o mecanismo de adsorção segue uma série de etapas sucessivas, que são independentes do tipo de interação. Estas envolvem o transporte do adsorvato da fase fluida para a camada limite localizada em torno do adsorvente. Em seguida ocorrer o transporte por meio da camada limite para a superfície externa do adsorvente, chamado de difusão externa. Depois há o transporte para o interior da partícula adsorvente (denominada difusão intrapartícula ou difusão interna) por difusão nos poros e/ou por difusão no longo da superfície interna (difusão superficial). Por fim, ocorre a interação química entre as moléculas de adsorvato e o adsorvente (WORCH, 2012; FAUST; ALY, 1987).

O conhecimento sobre a estrutura química e as características dos adsorventes são de grande importância, uma vez que são responsáveis por interagir com o adsorvato e explicam como ocorrerá a retenção do mesmo, seja por meio de interações físicas ou químicas, uma vez que os materiais utilizados como adsorventes devem apresentar alta interação com o contaminante que se deseja remover do efluente (BURAKOV et al., 2018).

Deve-se conhecer também as características do adsorvato, como a carga, tamanho e estrutura química, a fim de escolher de forma adequada o adsorvente que favoreça o desempenho e maximize a remoção desse contaminante, tendo em vista que o custo do adsorvente impacta de forma significativa no custo do processo de adsorção (BURAKOV et al., 2018).

\subsubsection{Adsorventes}

O estudo envolvendo o processo de adsorção está diretamente ligado a escolha do adsorvente, bem como as propriedades desse material, uma vez que interage diretamente com as substâncias a serem adsorvidas. Neste contexto, muitos materiais estão sendo estudados e utilizados, no intuito de obter melhores resultados de adsorção, como: polímeros, resíduos lignocelulósicos e resíduos indústrias, além de os mais convencionais como carbono ativado, óxidos metálicos, sílica, argilas minerais e zeólitas (BURAKOV et al., 2018; CEGłOWSKI et al., 2018; CAROLIN et al., 2017). 
De modo geral, a busca por adsorventes ideais deve levar em consideração todas as etapas envolvidas no processo de adsorção e características como elevada área específica e porosidade para promover maior contato com a fase fluida e gerando a ocupação dos sítios ativos pelo adsorvato (WORCH, 2012; XU et al, 2018; SEADER; HENLEY, 1998).

Contudo, características como elevada capacidade de adsorção, alta seletividade, boa estabilidade química e mecânica, compatibilidade, facilidade de recuperação e operação, disponibilidade, biodegradabilidade e baixa toxidade, são fatores muito importantes na escolha de adsorventes, uma vez que tornam o material ambientalmente favorável de forma que contribui para redução de poluentes e não apresentam riscos ao meio ambiente (CEGŁOWSKI et al., 2018; CAROLIN et al., 2017).

As características do meio fluido também impactam na escolha do adsorvente pois, o adsorvato deve se difundir no adsorvente até alcançar o sitio ativo e ficar retido. Para isso, o adsorvente e a fase fluida devem ser quimicamente compatíveis, porém, de forma inerte, para que não ocorram mudanças na estrutura do sólido e, também, para que o mesmo não seja solúvel no meio fluido (ROUQUEROL; ROUQUEROL; SING, 1999).

Os principais adsorventes utilizados no tratamento de efluentes e nos processos de adsorção e separação de componentes são o carvão ativado, sílica gel, argilas minerais, zeólitas e resinas (Tabela 3), empregados com a finalidade de secagem de sistemas, remoção de íons metálicos e remoção e separação de compostos orgânicos, como ilustrado na figura 2 (BURAKOV et al., 2018; WORCH, 2012; CAROLIN et al., 2017).

Entretanto, apesar de amplamente utilizados, esses adsorventes convencionais apresentam limitações. No caso das resinas, zeólitas e carvão ativado, os mesmos apresentam elevado custo de síntese sendo que, esse último, apresenta também dificuldade de regeneração e reutilização, podendo apresentar baixa seletividade para metais pesados, enquanto a sílica gel e as argilas minerais apresentam baixa capacidade de adsorção (SIYAL et al., 2018; CEGLOWSKI et al., 2018). 
Tabela 3 - Principais adsorventes e características

\begin{tabular}{|c|c|}
\hline Adsorventes & Característica \\
\hline Carbono ativado & $\begin{array}{l}\text { Apresenta uma estrutura porosa bem desenvolvida que confere uma alta } \\
\text { área especifica e ainda a possibilidade de utilização de diversos grupos } \\
\text { funcionais na sua superfície. }\end{array}$ \\
\hline Sílica gel & $\begin{array}{l}\text { Apresenta uma estrutura porosa e granular de alta área superficial sendo } \\
\text { obtida a partir do silicato de sódio perante tratamento ácido. }\end{array}$ \\
\hline Argilas minerais & $\begin{array}{l}\text { Apresenta alta área de superfície, plasticidade, força de ligação, elevado } \\
\text { potencial zeta, propriedade de troca de cátion, basicidade, resistência ao } \\
\text { desgaste por impacto e por ataque químico. }\end{array}$ \\
\hline Zeólitas & $\begin{array}{l}\text { São estruturas cristalinas e minerais de aluminossilicatos formados por } \\
\text { meio de interligações tetraédricas de alumina }\left(\mathrm{AlO}_{4}\right) \text { e sílica }\left(\mathrm{SiO}_{4}\right) \text {, } \\
\text { possuem alta capacidade de trocas de íons, alta área superficial, caráter } \\
\text { hidrofílico e podem ocorrer de forma natural ou por meio de produção } \\
\text { indústrial. }\end{array}$ \\
\hline Resinas & $\begin{array}{l}\text { São copolímeros a base de monômeros aromáticos e esteres acrílicos } \\
\text { capazes de formar ligações coordenadas com a maioria dos íons de metais } \\
\text { tóxicos. }\end{array}$ \\
\hline
\end{tabular}

Fonte: Autor "adaptado de" Burakov et al., 2018; Ma et al, 2018; Siyal et al., 2018; Wen; Dong; Zeng, 2018; Carolin et al., 2017; Sharata, 2016

Figura 2 - Principais adsorventes e aplicações

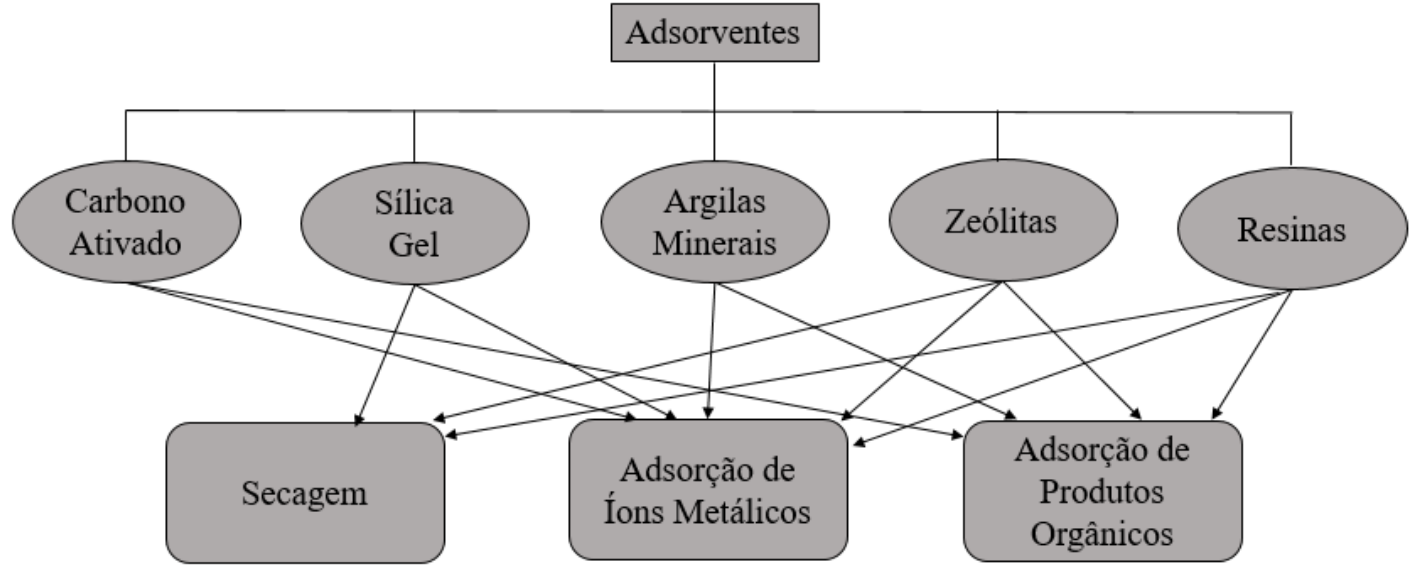

Fonte: Autor “adaptado de” Burakov et al., 2018; Carolin et al., 2017; Worch, 2012

Dessa forma, surge a necessidade de se aplicar e desenvolver novos adsorventes de baixo custo, com elevada capacidade de adsorção, menos agressivos ao meio ambiente e, viáveis para a aplicação. A utilização de materiais naturais, resíduos agrícolas e industriais e seus subprodutos (Tabela 4), surgem como uma alternativa viável para aplicações no processo de adsorção, dando aplicabilidade para resíduos que apresentam dificuldade de disposição e 
descarte e de forma sustentável, uma vez que utiliza-se resíduos sem valor agregado (WORCH, 2012; CAROLIN et al., 2017; CEGłOWSKI et al., 2018; NGAH; TEONG; HANAFIAH, 2011).

Tabela 4 - Principais materiais e resíduos

\begin{tabular}{c|l}
\hline Adsorventes de baixo custo & \multicolumn{1}{c}{ Exemplos } \\
\hline Materiais naturais & Celulose, quitina, quitosana, zeólitas naturais, madeira, carvão. \\
\hline Resíduos agrícolas e subprodutos & $\begin{array}{l}\text { Resíduos lignocelulósicos no geral, como: palha de milho, sabugo de } \\
\text { milho, fibra de coco, bagaço de cana-de-açúcar, cascas de frutas e } \\
\text { castanhas, entre outros. }\end{array}$ \\
\hline $\begin{array}{c}\text { Resíduos industriais e } \\
\text { subprodutos }\end{array}$ & Cinzas, resíduos de alto forno, resíduos de queima de óleo e xisto. \\
\hline
\end{tabular}

Fonte: Autor “adapatado de” Worch, 2012; Cegłowski et al., 2018; Carolin et al., 2017; De Gisi et al., 2018

\subsection{ESTUDO DE VARIÁVEIS DO PROCESSO DE ADSORÇÃO}

Durante os processos de adsorção, vários fatores podem afetar a eficiência do tratamento destacando-se a temperatura utilizada durante a adsorção, o pH do efluente, a concentração do ín metálico presente na solução a ser tratada, bem como o tempo de tratamento necessário para se atingir o equilíbrio, o que mostra a importância de se estudar e otimizar esses parâmetros antes de se aplicar a técnicas na eliminação ou redução da concentração de diferentes íons metálicos (LI et al., 2019).

Dessa forma, estudos envolvendo a cinética de adsorção bem como relacionados a obtenção das isotérmicas de equilíbrio de adsorção dos íons metálicos como, por exemplo, os íons de cromo hexavalente, se tornam importantes fatores a serem estudos visando a verificação da eficiência de diferentes adsorventes em processos. Da mesma forma, estudos envolvendo a determinação do $\mathrm{pH}$ ideal a ser utilizado e, a determinação dos parâmetros termodinâmicos também se mostram primordiais em trabalhos envolvendo processos de adsorção. Neste contexto, no item 3.6.1 serão discutidos os parâmetros necessários para se compreender o processo de adsorção.

\subsubsection{Isotermas de adsorção}

O estudo de equilíbrio entre as concentrações do componente que se deseja retirar de uma determinada fase líquida e sua retenção na fase sólida se faz por meio das isotermas de 
adsorção, que oferecem as principais informações sobre o processo, descrevem a interação entre o adsorvato (contaminante) e o adsorvente e, auxiliam na compreensão do mecanismo envolvido no processo de adsorção (NERIS et al., 2019; RANGABHASHIYAM; BALASUBRAMANIAN, 2018; TRAN et al., 2017; FAUST; ALY, 1987).

Porém, ao contrário ao que é verificado, ao estudar-se equilíbrios líquido-líquido e liquido-vapor, os sistemas sólido-líquido não apresentam teorias aceitáveis e desenvolvidas que permitam estimar a distribuição do adsorvato entre fases. Dessa forma, se faz necessário a obtenção de dados experimentais de equilíbrio para um soluto presente em uma fase líquida a ser adsorvido em um determinado adsorvente. Para isso, os dados de equilíbrio devem ser coletados em um determinado intervalo de concentração, em uma temperatura constante e, utilizando-se uma quantidade fixa de adsorvente (NERIS et al., 2019; WORCH, 2012; SEADER; HENLEY, 1998).

Como resultados, a quantidade de soluto retido no adsorvente em função da concentração representa a isoterma de adsorção, que descrevem como o adsorvente interage com o adsorvato e, as mesmas, podem ser classificadas em favoráveis, desfavoráveis, linear e irreversível e, as formas representadas na figura 3 (LI et al., 2019; SEADER; HENLEY, 1998; WORCH, 2012).

As isotermas favoráveis são aquelas que representam uma adsorção mais rápida em baixas concentrações até atingirem um patamar caracterizado por uma capacidade de adsorção em que se atinge o equilíbrio. Apresentam uma curva caraterística com a concavidade voltada para baixo, também chamada de curva côncava. Em contrapartida, as isotermas desfavoráveis são curvas convexas, e recebem esse nome pelo fato de a adsorção apresentar resultados relevantes apenas em elevadas concentrações (SEADER; HENLEY, 1998; FAUST; ALY, 1987).

As isotermas irreversíveis apresentam uma adsorção instantânea e de alta interação adsorvato-adsorvente não sendo possível reverter o processo e ocorrem quando o processo se dá por quimissorção. As isotermas lineares apresentam uma adsorção diretamente linear a concentração de adsorvato (WORCH, 2012; SEADER; HENLEY, 1998; FAUST; ALY, 1987). 
Figura 3 - Representação dos tipos de isotermas de adsorção

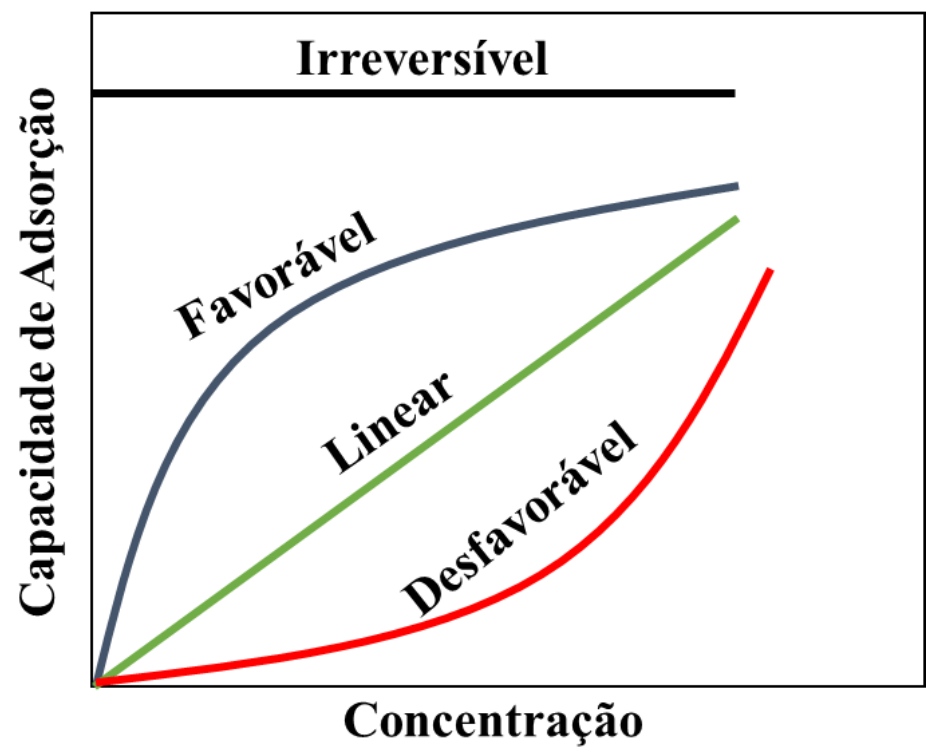

Fonte: Autor "adaptado de" Worch, 2012; Seader; Henley, 1998

De forma geral, o processo de adsorção no equilíbrio é verificado quando, na superfície do adsorvente, as taxas entre o processo de adsorção e seu processo inverso, a dessorção, se igualam (Figura 4), ou seja, a quantidade de adsorvato removida por adsorção torna-se igual à quantidade dessorvida (WORCH, 2012; SEADER; HENLEY, 1998; FAUST; ALY, 1987).

Figura 4 - Representação geral do equilíbrio em processo de adsorção

$$
\begin{aligned}
& \text { Adsorção }
\end{aligned}
$$

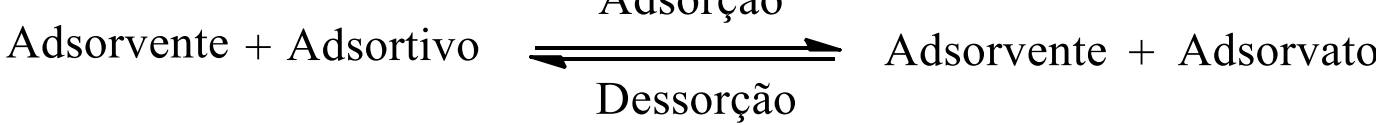

Fonte: Autor "adaptado de" Worch, 2012.

Para a realização desse estudo, as isotermas de adsorção são de vital importância para avaliação da distribuição do adsorvato na interface sólido-líquido, determinação do grau de interação entre adsorvato e adsorvente e, na estimativa da capacidade máxima de adsorção do material utilizado como adsorvente (RANGABHASHIYAM; BALASUBRAMANIAN, 2018; TRAN et al., 2017; WORCH, 2012; SEADER; HENLEY, 1998).

Dessa forma, diversos modelos empíricos são utilizados para representar os dados experimentais e descrever como o processo se comporta até atingir o equilíbrio, sendo possível destacar as isotermas de: Langmuir, Freundlich, Henry, Temkin, Giles, Redlich-Peterson, Dubinin-Radushkevich, Halsey, Jovanovic, Frumkin, Kiselev e Brunauer, Emmett, Teller 
(BET) (NERIS et al., 2019; RANGABHASHIYAM; BALASUBRAMANIAN, 2018; TRAN et al., 2017; WORCH, 2012; SEADER; HENLEY, 1998; FAUST; ALY, 1987).

Dentre as isotermas citadas, Langmuir, Freundlich e Temkin são as mais utilizadas por sua simplicidade e por fornecer parâmetros importantes que possibilitam a compreensão de como processo de adsorção ocorre e o nível de interação adsorvato-adsorvente dentro das condições especificas em que foram realizados os experimentos (TRAN et al., 2017; KUMAR et al., 2012; FAUST; ALY, 1987; SEADER; HENLEY, 1998).

\subsubsection{Isoterma de Langmuir}

A isoterma de Langmuir é um modelo teórico, originalmente aplicado em processos que envolvem adsorção em monocamada de gases em superfícies sólidas, admitindo a quimissorção porém, modificado por Sohn e Kim para aplicação em processos de adsorção envolvendo soluções aquosas (NERIS et al., 2019; ZHANG et al., 2019; RANGABHASHIYAM; BALASUBRAMANIAN, 2018; TRAN et al., 2017; SEADER; HENLEY, 1998; LANGMUIR, 1916). O mesmo é fundamentado por quatro hipóteses principais:

a) durante a realização dos estudos, um número fixo de sitios ativos estão disponíveis na superfície do adsorvente e todos os locais ativos apresentam a mesma energia;

b) o processo de adsorção é reversível;

c) uma vez que ocupado um sítio ativo pelo adsorvato, nenhuma adsorção adicional pode ocorrer nesse local (adsorção em monocamada);

d) não há interação entre as espécies adsorvidas.

Levando-se em consideração as hipóteses definidas e definindo-se, também, $\theta$ como a fração de superfície do adsorvente coberta pelo adsorvato e, (1- $\theta)$ a fração não coberta, a taxa de adsorção total é a diferença entre a taxa de adsorção e a taxa de dessorção, definida pela equação 1:

$$
\frac{\mathrm{dp}}{\mathrm{dt}}=\mathrm{k}_{\mathrm{a}} \mathrm{p}(1-\theta)-\mathrm{k}_{\mathrm{d}} \theta
$$

em que: q representa a capacidade de adsorção; p a pressão e, ka e kd as constantes cinéticas de adsorção e dessorção, respectivamente (SEADER; HENLEY, 1998; FAUST; ALY, 1987). 
Porém, no equilíbrio, as taxas de adsorção e dessorção são iguais e, considerando-se $\theta$ como a relação entre a capacidade de adsorção em um determinado tempo e, a capacidade máxima do adsorvente (q.q máx $^{-1}$ ), $\mathrm{K}$ descreve a constante de equilíbrio do processo de adsorção $\left(\mathrm{k}_{\mathrm{a}} \cdot \mathrm{k}_{\mathrm{d}}{ }^{-1}\right)$, determinada pela equação 2 (SEADER; HENLEY, 1998):

$$
\mathrm{q}=\frac{K q_{\text {máx }} p}{1+K p}
$$

Embora, inicialmente modelada para adsorção em gases pelo mecanismo de quimiossorção, o modelo de Langmuir foi expandido por analogia para descrever modelo de adsorção de líquidos e fisiossorção, descrito pela equação 3 que pode ser linearizada como demonstrado na equação 4 (RANGABHASHIYAM; BALASUBRAMANIAN, 2018; FAUST; ALY, 1987):

$$
\begin{aligned}
& \mathrm{q}_{\mathrm{e}}=\frac{\mathrm{q}_{\text {máx }} \mathrm{K}_{\mathrm{L}} \mathrm{C}_{\mathrm{e}}}{1+\mathrm{K}_{\mathrm{L}} \mathrm{C}_{\mathrm{e}}} \\
& \frac{\mathrm{C}_{\mathrm{e}}}{\mathrm{q}_{\mathrm{e}}}=\frac{\mathrm{C}_{\mathrm{e}}}{\mathrm{q}_{\text {máx }}}+\frac{1}{\mathrm{~K}_{\mathrm{L}} \mathrm{q}_{\text {máx }}}
\end{aligned}
$$

em que: $\mathrm{q}_{\mathrm{e}}$ representa a capacidade de adsorção no equilíbrio $\left(\mathrm{mg} \cdot \mathrm{g}^{-1}\right), \mathrm{C}_{\mathrm{e}}$ a concentração de adsorvato na fase fluida no equilíbrio $\left(\mathrm{mg} \mathrm{L}^{-1}\right)$ e, $\mathrm{K}_{\mathrm{L}}$ a constante de interação adsorvente-

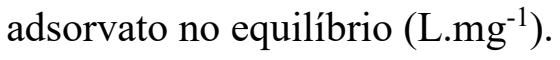

Levando-se em consideração as equações descritas anteriormente, a capacidade de adsorção é determinada pela equação (5) e, a constante $\mathrm{K}_{\mathrm{L}}$ pode ser relacionada com o chamado fator de separação $\left(\mathrm{R}_{\mathrm{L}}\right)$ determinado pela equação (6) (RANGABHASHIYAM; BALASUBRAMANIAN, 2018):

$$
\begin{aligned}
\mathrm{q}_{\mathrm{e}} & =\frac{\left(\mathrm{C}_{0}-\mathrm{C}_{\mathrm{e}}\right) \mathrm{V}}{\mathrm{W}} \\
\mathrm{R}_{\mathrm{L}} & =\frac{1}{1+\mathrm{K}_{\mathrm{L}} \mathrm{C}_{\mathrm{o}}}
\end{aligned}
$$

em que: V representa o volume da solução (L), W a massa de adsorvente (g) e, $\mathrm{C}_{0}$ a concentração inicial de adsorvato na fase fluida (g. $\left.\mathrm{L}^{-1}\right)$. 
Dessa forma, a construção de um gráfico de $\mathrm{C}_{\mathrm{e}} / \mathrm{q}_{\mathrm{e}}$ em função de $\mathrm{C}_{\mathrm{e}}$ por linearização fornecerá uma reta com coeficientes angular de $1 / \mathrm{q}_{\text {máx }}$ e, coeficiente linear de $1 / \mathrm{K}_{\mathrm{L}} \mathrm{q}_{\text {máx }}$ (RANGABHASHIYAM; BALASUBRAMANIAN, 2018; FAUST; ALY, 1987).

O fator de separação em processos de adsorção representa a afinidade pela fase sólida em relação a fase líquida, ou seja, quanto mais próximo de 0 for o valor de $\mathrm{R}_{\mathrm{L}}$, mais favorável a adsorção, o que indica uma elevada afinidade do adsorvato pelo sólido adsorvente. Em contrapartida se $\mathrm{R}_{\mathrm{L}}$ for maior que 1 a adsorção é desfavorável e, o adsorvato tem uma maior afinidade com a fase fluida e, quando $\mathrm{R}_{\mathrm{L}}$ for igual a 0 , a adsorção é linear (WANG et al., 2019; FAUST; ALY, 1987).

Assim, é possível a utilização de sua curva característica para classificação do tipo de isoterma identificada em processos de adsorção, como ilustrado na tabela 5.

Tabela 5 - Relação entre o fator de separação e o tipo de isoterma

\begin{tabular}{l|l|l}
\hline Fator de separação & Tipo de Isoterma & Característica Curva \\
\hline $\mathrm{R}_{\mathrm{L}}=0$ & Irreversível & Horizontal \\
$\mathrm{R}_{\mathrm{L}}<1$ & Favorável & Côncava \\
$\mathrm{R}_{\mathrm{L}}=1$ & Linear & Linear \\
$\mathrm{R}_{\mathrm{L}}>1$ & Não favorável & Convexa \\
\hline
\end{tabular}

Fonte: Autor "adaptado de" Tran et al., 2017; Worch, 2012

\subsubsection{Isoterma de Freundlich}

A isoterma de Freundlich é um outro modelo empírico comumente utilizado em estudos envolvendo processos de adsorção desenvolvido, inicialmente, para gases. O mesmo é capaz de relacionar a quantidade adsorvida de adsorvato com a concentração de adsorvato na fase tratada e pode ser aplicado para sistemas não ideais, reversíveis e, de superfícies heterogêneas (WANG et al., 2019; ZHANG et al., 2019; AMALRAJ et al., 2016).

O modelo considera o mecanismo de adsorção ocorrendo em multicamadas e, não prevê a ocupação de todos os sítios de adsorção. Assim, não ocorre saturação do material e, também, distribuição uniforme de calor de adsorção, o que caracteriza uma distribuição exponencial dos sítios de adsorção (WANG et al., 2019; RANGABHASHIYAM; BALASUBRAMANIAN, 2018; AMALRAJ et al., 2016; FAUST; ALY, 1987; SEADER; HENLEY, 1998). O mesmo pode ser descrito pela equação 7 : 


$$
\mathrm{q}_{\mathrm{e}}=\mathrm{K}_{\mathrm{F}} \mathrm{C}^{1 / \mathrm{n}}
$$

em que: $q_{e}$ representa a capacidade de adsorção $\left(m g \cdot g^{-1}\right), C_{e}$ a concentração de adsorvato na fase fluida no equilíbrio (mg. $\left.\mathrm{L}^{-1}\right) \mathrm{e}, \mathrm{n}$ e $\mathrm{K}_{\mathrm{F}}\left[\left(\mathrm{mg} \cdot \mathrm{g}^{-1}\right) /\left(\mathrm{mg} \cdot \mathrm{L}^{-1}\right)^{(1 / \mathrm{n})}\right]$ são constante empírica.

Já, a equação 8 representa a forma linear da isoterma de Freundlich:

$$
\log q_{e}=\log K_{F}+(1 / n) \log C_{e}
$$

em que: por regressão linear da curva de $\log \mathrm{q}_{\mathrm{e}}$ em função de $\log \mathrm{C}_{\mathrm{e}}$ é possível a obtenção de uma curva com coeficiente angular $(1 / \mathrm{n})$ e, coeficiente linear $\log \mathrm{K}_{\mathrm{F}}$ (TRAN et al., 2017; SEADER; HENLEY, 1998).

Em geral, ambos os parâmetros obtidos pela isoterma de Freundlich tendem a decrescer com o aumento da temperatura sendo que, $K_{F}$ descreve o valor da capacidade de adsorção para o modelo e, o processo é considerado favorável quando n encontra-se entre 1 e 5 (ARAÚJO et al., 2017; TRAN et al., 2017, KUMAR et al, 2012; SEADER; HENLEY, 1998).

O expoente obtido na isoterma Freundlich também é utilizado para classificar os tipos de isoterma, como demonstrado na tabela 6 .

Tabela 6 - Relação entre o fator de separação e o tipo de isoterma

\begin{tabular}{l|l|l}
\hline Expoente de Freundlich & Tipo de Isoterma & Característica Curva \\
\hline$(1 / \mathrm{n})=0$ & Irreversível & Horizontal \\
$(1 / \mathrm{n})<1$ & Favorável & Côncava \\
$(1 / \mathrm{n})=1$ & Linear & Linear \\
$(1 / \mathrm{n})>1$ & Não favorável & Convexa \\
\hline \multicolumn{2}{|l}{ Fonte: Autor “adaptado de" Tran et al., 2017; Worch, 2012 }
\end{tabular}

\subsubsection{Isoterma de Temkin}

A isoterma de Temkin consiste em um modelo que leva em consideração as interações entre as moléculas contaminantes e o adsorvato, assumindo que o calor de adsorção das mesmas diminui linearmente conforme ocorre o recobrimento causado pelo processo de adsorção. No mesmo, a distribuição de energias de ligação é uniforme. A representação matemática é dada pelas equações 9 e 10 : 


$$
\begin{aligned}
& \mathrm{q}_{\mathrm{e}}=\mathrm{B} \ln \mathrm{K}_{\mathrm{T}}+\mathrm{B} \ln \mathrm{C}_{\mathrm{e}} \\
& \mathrm{B}=\frac{\mathrm{RT}}{\mathrm{b}}
\end{aligned}
$$

em que: $\mathrm{R}$ representa a constante universal dos gases $\left(8,314 \mathrm{~J} \cdot \mathrm{K}^{-1} \cdot \mathrm{mol}^{-1}\right)$, T temperatura em kelvin $(\mathrm{K}), \mathrm{K}_{\mathrm{T}}$ constante de Temkin $\left(\mathrm{L}_{\mathrm{mg}}{ }^{-1}\right)$, b o calor de adsorção (J.mol ${ }^{-1}$ ) e, B a constante adimensional de Temkin (ARAÚJO et al., 2018; CHOUDHARY; PAUL, 2018; ARAÚJO et al., 2017; KUMAR et al, 2012).

$\mathrm{Na}$ isoterma de Temkin estima-se que o processo de adsorção deve ocorrer pelo mecanismo de quimiossorção quando o calor de adsorção encontrado é maior que $8 \mathrm{~kJ} . \mathrm{mol}^{-1}$. Caso contrário, ocorre via fisiossorção e, por se tratar de uma interação adsorvente-adsorvato mais fraca, necessita de uma menor energia para ocorrer (CHOUDHARY; PAUL, 2018; ARAÚJO et al., 2017; AMALRAJ et al., 2016).

\subsubsection{Cinética de adsorção}

Além das informações obtidas pelo estudo do equilíbrio, as informações relacionadas ao comportamento do processo de adsorção no decorrer do tempo também são importantes. Assim, a realização de estudos relacionados a adsorção em função do tempo possibilita a obtenção de dados muito importantes sendo, os mesmos, desenvolvidos por meio do estudo cinético de adsorção.

A cinética de adsorção pode ser definida como a taxa em que o adsorvato que é retirado da fase fluida por unidade de tempo, um processo que envolve basicamente 4 etapas, como ilustrado na figura 5 (TRAN et al., 2017; WORCH, 2012; WEBER; MORRIS, 1963):

1) transferência de massa do adsorvato da fase líquida para a camada limite;

2) transferência de massa na camada limite até o interior dos macroporos do adsorvente;

3) transferência de massa para o interior dos microporos por difusão do líquido nos poros e/ou por difusão no estado adsorvido ao longo da superfície interna;

4) interação energética entre o adsorvente e as moléculas do adosrvato, local em que de fato as partículas ficam adsorvidas. 
Figura 5 - Mecanismo de transferência de massa em adsorventes

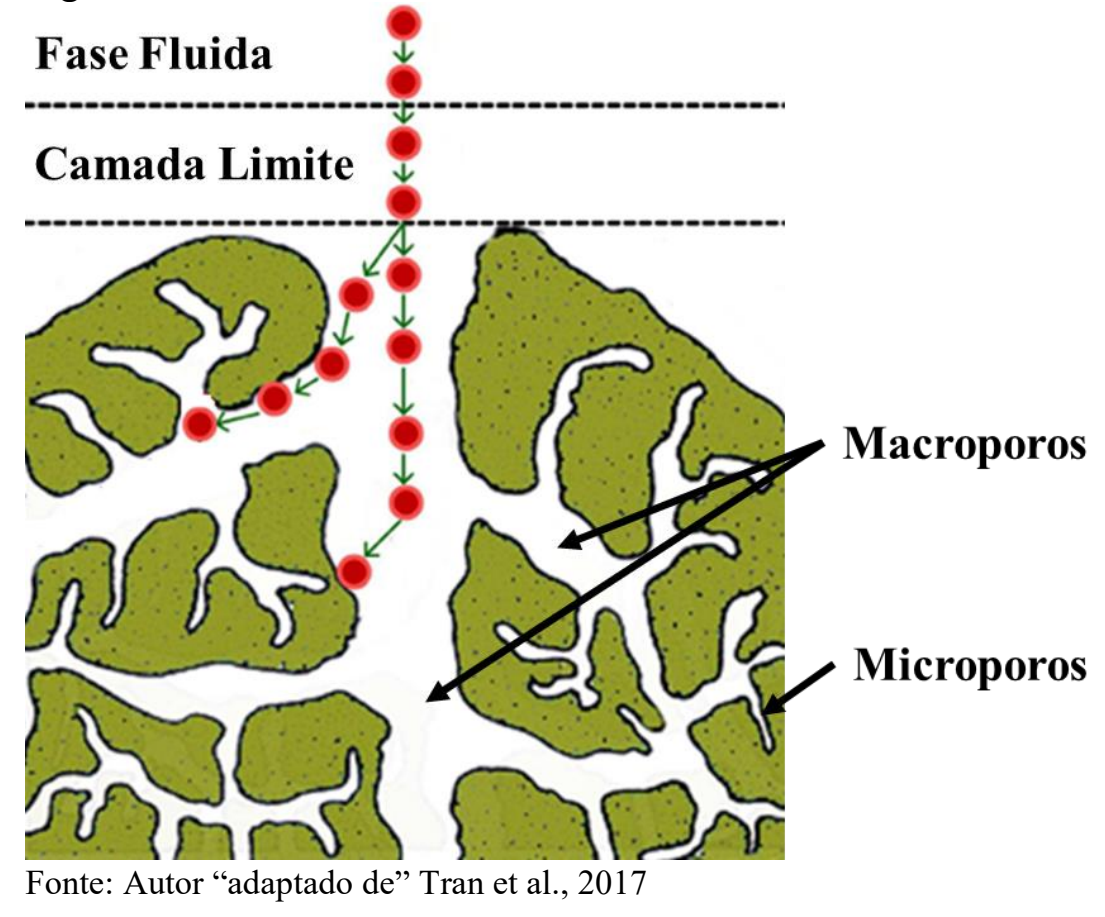

De forma geral, a primeira e a quarta etapa ocorrem de forma rápida, porém, quando o processo ocorre por quimiossorção, a etapa de interação energética adsorvato-adsorvente pode ser determinante e, até governar o processo. Em contrapartida, em processos de fisiossorção, a etapa de interação é praticamente instantânea, sendo as demais etapas de maior relevância para o processo. Com relação a etapa de transferência externa, a mesma é fortemente influenciada pela agitação e concentração da fase fluida (WORCH, 2012; SEADER; HENLEY, 1998).

A etapa de difusão intrapartícula controlam o processo sendo que, na região de macroporos, o processo de difusão é mais rápido, dado que as dimensões dos poros dos adsorventes são superiores aos dos adsorvatos. Porém, na região de microporos, a resistência a difusão é maior, sendo essa etapa responsável por controlar o processo que é fortemente influenciado pela interação adsorvente-adsorvato e, pela estrutura porosa do adsorvente (WORCH, 2012; WEBER; FAUST; ALY, 1987; MORRIS, 1963).

Assim, os principais modelos cinéticos utilizados para se compreender os mecanismos de transferência de massa envolvidos em processos de adsorção, como a transferência externa e, a difusão nos poros e na superfície determinantes no processo de adsorção são pseudoprimeira ordem, pseudo-segunda ordem, Weber e Morris, Boyd e, Elovich (TRAN et al, 2017). 


\subsubsection{Modelos cinéticos}

Os modelos cinéticos de adsorção são muito importantes na determinação da taxa de adsorção do processo, além disso, o estudo cinético fornece informações sobre o mecanismo de adsorção, que é baseado nas propriedades físico-químicas e de transferência de massa.

O primeiro modelo cinético utilizado para realização de estudos envolvendo processos de adsorção foi o descrito por Lagergren (1898) e ficou conhecido como modelo de pseudoprimeira. O mesmo é baseado na capacidade de adsorção do sólido levando-se em consideração que etapa determinante da taxa de adsorção é a difusão superficial. O mesmo pode ser descrito pela equação 11:

$$
\frac{\mathrm{dq}}{\mathrm{dt}}=\mathrm{k}_{1}\left(\mathrm{q}_{\mathrm{e}}-\mathrm{q}\right)
$$

em que: $k_{1}$ representa a constante de taxa de adsorção de primeira ordem $\left(\min ^{-1}\right)$ e, $\mathrm{q}_{\mathrm{e}}$ e $\mathrm{q}$ as capacidades de adsorção (mg. $\mathrm{g}^{-1}$ ) quando atingido o equilíbrio e em um determinado tempo t, respectivamente (TRAN et al, 2017; WORCH, 2012; RANGABHASHIYAM; BALASUBRAMANIAN, 2018).

Neste modelo, as formas não linear e linear podem ser expressas pelas equações 12 e 13 (RANGABHASHIYAM; BALASUBRAMANIAN, 2018; TRAN et al, 2017):

$$
\begin{aligned}
& \mathrm{q}=\mathrm{q}_{\mathrm{e}}\left(1-\mathrm{e}^{-\mathrm{k}_{1} \mathrm{t}}\right) \\
& \ln \left(\mathrm{q}-\mathrm{q}_{\mathrm{e}}\right)=\ln \mathrm{q}_{\mathrm{e}}-\mathrm{k}_{1} \mathrm{t}
\end{aligned}
$$

Porém, no processo de adsorção de sólidos, o modelo de pseudo-primeira ordem não apresenta um ajuste adequado para representar a cinética no processo, dessa forma, o modelo de pseudo segunda ordem é um modelo que se mostra mais apropriado para descrever a cinética. No mesmo, considera-se a etapa determinante da velocidade de adsorção a reação no sítio ativo entre o adsorvato e do adsorvente por meio adsorção química ou física, sendo descrito pela equação 14 (ZHANG et. al., 2017; RANGABHASHIYAM; BALASUBRAMANIAN, 2018):

$$
\frac{\mathrm{dq}}{\mathrm{dt}}=\mathrm{k}_{2}\left(\mathrm{q}_{\mathrm{e}}-\mathrm{q}\right)^{2}
$$


em que: $\mathrm{k}_{2}\left(\mathrm{~g} \cdot \mathrm{mg}^{-1} \cdot \mathrm{min}^{-1}\right)$ representa a constante de velocidade de pseudo-segunda ordem e, $\mathrm{q}_{\mathrm{e}}$ e $\mathrm{q}$ as capacidades de adsorção $\left(\mathrm{mg}_{\mathrm{g}} \mathrm{g}^{-1}\right.$ ) quando atingido o equilíbrio e em um determinado tempo $t$, respectivamente.

Para esse modelo, a forma linear é expressa pela equação 15 (TRAN et al, 2017; RANGABHASHIYAM; BALASUBRAMANIAN, 2018):

$$
\frac{t}{q}=\frac{1}{k_{2} q_{e}^{2}}+\frac{t}{q_{e}}
$$

Porém, quando a etapa determinante da velocidade de transferência de massa do processo de adsorção for a difusão intrapartícula, o modelo de Weber e Morris é considerado o que melhor representa a cinética envolvida no processo de adsorção. No mesmo, a adsorção é baseada no transporte do adsorvato por meio da estrutura interna do adsorvente por difusão no sólido, sendo que a capacidade de adsorção varia em função da raiz quadrada do tempo, e é descrita pela equação 16 (WEBER; MORRIS, 1963; RANGABHASHIYAM; BALASUBRAMANIAN, 2018; TRAN et al, 2017):

$$
\mathrm{q}=\mathrm{K}_{\mathrm{d}} \mathrm{t}^{0,5}+\mathrm{C}
$$

em que: $K_{d}$ representa o coeficiente de difusão intrapartícula $\left(\mathrm{mg}^{-1} \mathrm{~g}^{-1} \cdot \mathrm{min}^{-0,5}\right)$ e C a constante relacionada à resistência à difusão $\left(\mathrm{mg} \cdot \mathrm{g}^{-1}\right)$.

\subsubsection{Influência do pH}

$\mathrm{O}$ pH do meio tem uma forte influência na adsorção de íons de metais pesados como, por exemplo, os de cromo hexavalente, pois pode modificar tanto a forma como os íons se manifestam, quanto a carga superficial dos adsorventes (CAMPOS et al, 2019)

De uma maneira geral, os adsorventes podem sofrer protonação ou desprotonação dependendo do $\mathrm{pH}$ que é exposto. Porém, no caso de biopolímeros que apresentam capacidade de adsorver compostos relacionados a presença grupos funcionais, como aminas, hidroxilas e carboxilas, os mesmos, em meio ácido, sofrem protonação e conferem à superfície uma densidade de carga positivas que auxiliam na atração eletrostática das moléculas de adsorvato presentes na fase fluida (CAMPOS et al., 2019; JOBBY et al., 2018). 
No caso de poluentes como metais pesados os mesmos, em meio aquoso, não se manifestam na forma elementar ou de cátions simples dos elementos por apresentarem uma elevada reatividade. Dessa forma, geralmente são encontrados na forma de cátions e ânions compostos sendo que, o pH, determina a formação e estabilidades das espécies que se manifestam (SARODE et al., 2019; SHARMA et al, 2019; JOBBY et al., 2018)

Em relação ao cromo hexavalente, o mesmo pode se manifestar na forma de ácido crômico $\left(\mathrm{H}_{2} \mathrm{CrO}_{4}\right)$, cromato de hidrogênio $\left(\mathrm{HCrO}_{4}{ }^{-}\right)$, ânions cromato $\left(\mathrm{CrO}_{4}{ }^{2-}\right)$ e, dicromatos $\left(\mathrm{Cr}_{2} \mathrm{O}_{7}{ }^{2-}\right)$, dependendo do $\mathrm{pH}$ do meio (SU et al., 2019; JOBBY et al., 2018).

Como exemplo, em $\mathrm{pH}<1$, o cromo hexavalente se manifesta na forma de ácido crômico $\left(\mathrm{H}_{2} \mathrm{CrO}_{4}\right)$ e, na faixa de $\mathrm{pH}$ comprendida entre 1 e 7 , o ácido crômico se desprotona formando, predominatemente, cromato de hidrogênio $\left(\mathrm{HCrO}_{4}{ }^{-}\right)$. Porém, esses ânions podem formar íons como dicromato $\left(\mathrm{Cr}_{2} \mathrm{O}_{7}^{2-}\right)$ em meio ácido e, em $\mathrm{pH}>7$, o cromo hexavalente se manifesta unicamate na forma de ânions cromato $\left(\mathrm{CrO}_{4}{ }^{2-}\right)$. Dessa forma, conhecimento tanto do comportamento do adsorvente como dos poluentes em relação ao pH é de suma importância para maximizar as interações adsorvato-adsorvente e, assim, se obter elevadas taxas de remoção do adsorvato (ZHANG; FU; TANG, 2019; SU et al., 2019; SHARMA et al, 2019; JOBBY et al., 2018).

$$
\begin{aligned}
& \mathrm{H}_{2} \mathrm{CrO}_{4} \rightarrow \mathrm{H}^{+}+\mathrm{HCrO}_{4}^{-}(1 \leq \mathrm{pH} \leq 7) \\
& 2 \mathrm{HCrO}_{4}^{-} \rightarrow \mathrm{Cr}_{2} \mathrm{O}_{7}^{2-}+\mathrm{H}_{2} \mathrm{O}(1 \leq \mathrm{pH} \leq 7) \\
& \mathrm{HCrO}_{4}^{-} \rightarrow \mathrm{H}^{+}+\mathrm{CrO}_{4}{ }^{2-}(\mathrm{pH}>7)
\end{aligned}
$$

\subsubsection{Formalismo de termodinâmica de adsorção}

O estudo termodinâmico é indispensável para prever o comportamento do mecanismo de adsorção, principalmente quanto a distinção ente físiossorção e químiossorção, bem como características de espontaneidade, grau de desordem do processo e, como o sistema se comporta de modo geral frente a mudanças de temperatura (WORCH, 2012; TRAN et al., 2017)

$\mathrm{Na}$ termodinâmica, o estado do sistema é descrito por equações fundamentais escritas em função dos potenciais termodinâmicos, onde a energia de Gibbs $(\Delta \mathrm{G})$ é um desses potenciais que define se o processo é espontâneo ou não-espontâneo. Durante esses estudos, se $\Delta \mathrm{G}<0$, o processo é espontâneo e, se $\Delta \mathrm{G}>0$, o processo não é espontâneo e, como a adsorção é um processo de natureza físico-química, essa relação de espontaneidade também descreve esse processo (SMITH; VAN NESS; ABBOTT; 2013; WORCH, 2012). 
Para a realização desse estudo, se utiliza a equação fundamental de Gibbs em que, a variação da energia de Gibbs relaciona a variação de entalpia e entropia nos processos sendo, para adsorção, escrita segundo a equação 17 (SMITH; VAN NESS; ABBOTT; 2013; WORCH, 2012; TRAN, 2017):

$$
\Delta \mathrm{G}_{\mathrm{ads}}=\Delta \mathrm{H}_{\mathrm{ads}}-\mathrm{T} \Delta \mathrm{S}_{\mathrm{ads}}
$$

em que: $\Delta \mathrm{G}_{\mathrm{ads}}$ representa a variação da energia de Gibbs $\left(\mathrm{kJ} . \mathrm{mol}^{-1}\right), \Delta \mathrm{H}_{\mathrm{ads}}$ variação de entalpia $\left(\mathrm{kJ} \cdot \mathrm{mol}^{-1}\right), \Delta \mathrm{S}_{\mathrm{ads}}$ a variação de entropia $\left(\mathrm{kJ} \cdot \mathrm{mol}^{-1} \cdot \mathrm{K}^{-1}\right)$ e $\mathrm{T}$ a temperatura do processo $(\mathrm{K})$.

A variação da energia de Gibbs também pode ser estimada por meio da constante de equilíbrio do processo de adsorção, segundo a equação 18 (WORCH, 2012; TRAN, 2017):

$$
\Delta \mathrm{G}_{\mathrm{ads}}=-\mathrm{RT} \ln \mathrm{K}_{\mathrm{C}}
$$

em que: $\mathrm{K}_{C}$ representa a constante de equilíbrio, $\mathrm{R}$ a constante universal dos gases $(8,314$ $\left.\mathrm{kJ} \cdot \mathrm{mol}^{-1}\right)$ e $\mathrm{T}$ a temperatura do processo $(\mathrm{K})$.

Dessa forma, a combinação das equações 17 e 18 fornece a equação 19, também conhecida como equação Van't Hoff, que permite estimar os parâmetros termodinâmicos (CHOUDHARY; PAUL, 2018; RANGABHASHIYAM; BALASUBRAMANIAN, 2018; TRAN et al., 2017):

$$
\ln \mathrm{K}_{\mathrm{C}}=-\frac{\Delta \mathrm{G}_{\mathrm{ads}}}{\mathrm{RT}}=\frac{\Delta \mathrm{S}_{\mathrm{ads}}}{\mathrm{R}}-\frac{\Delta \mathrm{H}_{\mathrm{ads}}}{\mathrm{RT}}
$$

Esses parâmetros podem ser obtidos com base nas isotermas de equilíbrio, utilizando pelo menos três temperaturas distintas. Assim, construindo-se uma curva de $\ln K_{\mathrm{C}}$ em função de $1 / \mathrm{T}$ é possível a linearização da expressão, que fornece como coeficiente angular e linear $-\Delta \mathrm{H}_{\mathrm{ads}} /_{\mathrm{R}} \mathrm{e}^{\Delta \mathrm{S}_{\mathrm{ads}} / \mathrm{R}}$, respectivamente (TRAN et al., 2017; CHOUDHARY; PAUL, 2018; RANGABHASHIYAM; BALASUBRAMANIAN, 2018).

A constante de equilíbrio $\mathrm{K}_{C}$, pode ser estimada por meio da constante de interação adsorvato-adsorvente $\mathrm{K}_{\mathrm{L}}\left({\left.\mathrm{L} . \mathrm{mg}^{-1}\right)}\right.$ obtida pela isoterma de Langmuir, porém essas constantes apresentam dimensões e, a constante de equilíbrio é adimensional. Dessa forma, considera-se a 
solução utilizada com fase fluida como diluída, ou seja, a densidade da mesma é aproximadamente da água $\left(1,0 \mathrm{~g} \cdot \mathrm{mL}^{-1}\right)$ sendo, $\mathrm{K}_{C}$, obtido pela equação 20 :

$$
\mathrm{K}_{\mathrm{C}}=10^{6} \mathrm{~K}_{\mathrm{L}}
$$

em que: $K_{L}$ é representado em L.g ${ }^{-1}$ utilizando-se a densidade como 1000 g.L - $^{-1}$ (TRAN et al., 2017).

\subsection{POLÍMEROS NATURAIS EM PROCESSOS DE ADSORÇÃO}

A utilização de polímeros naturais como a carboximetilcelulose, a quitosana, o amido, a celulose ou, até mesmo, de materiais lignocelulósicos apresentam muitas vantagens para utilização em processos de adsorção tais como: biodegradabilidade, não toxicidade, fontes de obtenção abundantes, baixo custo e excelente capacidade de adsorção devido a presença de grupamentos funcionais como os amínicos, hidroxílicos e carboxílicos, tornando-os excelentes escolhas como adsorventes (VAKILI et al, 2018; JIANG et al., 2018; CEGŁOWSKI et al., 2018; DE GISI et al., 2018; LI et al., 2016).

\subsubsection{Quitosana}

A quitosana é um poliaminossacarídeo sintetizado industrialmente a partir da desacetilação da quitina (Figura 6), que é o polímero natural mais abundante após a celulose e, obtido, principalmente, de exoesqueleto de crustáceos, invertrebados e fungos. É um biopolímero, predominantemente constituído por cadeias não ramificadas de $\beta(1 \rightarrow 4)-2$ acetoamido-2-desoxi- $D$-glicose. (ZHANG et al., 2019; MOUSSOUT et al., 2018; ZHANG et al, 2018; JIANG et al., 2018; AHMAD, 2017; NGAH; TEONG; HANAFIAH, 2011). 
Figura 6 - Estrutura simplificada da quitina e quitosana

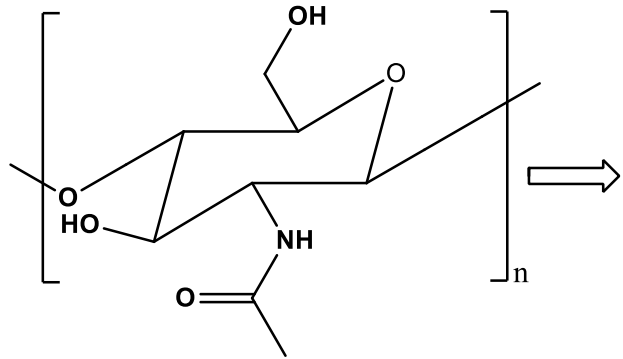

Quitina

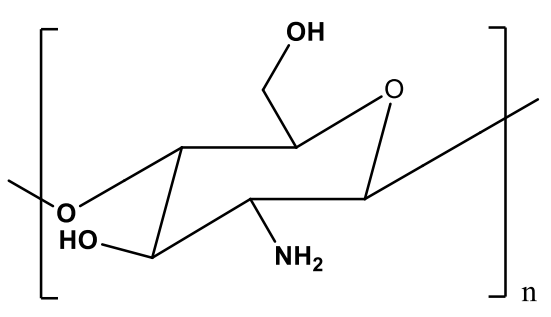

Quitosana

Fonte: Autor

A mesma se destaca por apresentar propriedade como hidrofobicidade, biocompatibilidade, não-toxidade, baixo custo e biodegradabilidade, que a torna um suporte natural para enzimas. Também tem se destacado os estudos envolvendo aplicações na obtenção de novos adsorventes devido a estabilidade química, elevada reatividade e capacidade de adsorção proporcionadas pela presença de grande quantidade de grupamentos amino $\left(-\mathrm{NH}_{2}\right)$ e hidroxila $(-\mathrm{OH})$, que funcionam com sítios ativos que apresentam grande seletividade a íons metálicos, como o cromo hexavalente (Figura 7), principalmente em meio ligeiramente ácido (VAKILI et al, 2018; HUANG, Y. et al., 2018; ZHANG et al, 2018; JIANG et al., 2018; AHMAD, 2017; ELIODÓRIO et al., 2017; NGAH; TEONG; HANAFIAH, 2011).

Figura 7 - Adsorção de íons cromo hexavalente pela quitosana

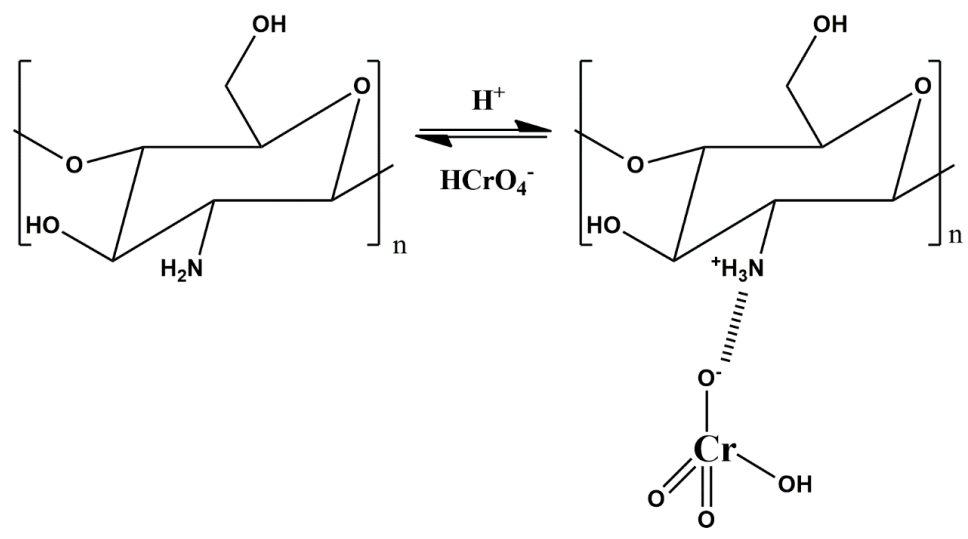

Fonte: Autor

No processo de adsorção, a quitosana é considerada um adsorvente catiônico pois, em meio ácido, os grupamentos amino presentes em sua estrutura são protonados formando cátions amônio, deixando moléculas carregadas positivamente. Nestas mesmas condições, o cromo hexavalente se manifesta na forma do ânion $\mathrm{HCrO}_{4}^{-}$, dessa forma, favorece o processo de 
adsorção via atração eletrostática devido as cargas positivas do grupo amino protonado $\left(-\mathrm{NH}_{3}{ }^{+}\right)$ frente a carga negativa do ânion (VAKILI et al, 2018; ZHANG et al, 2018; JIANG et al., 2018).

No entanto, a quitosana apresenta baixa estabilidade em meio ácido, pois pode formar gel ou dissolver-se totalmente, dependendo dos valores do $\mathrm{pH}$ que se encontra. Para melhorar o desempenho da quitosana como adsorvente, agentes de reticulação como o glioxal, formaldeído, glutaraldeído, epicloridrina, éter etilenoglicídico diglicidílico e isocianatos têm sido usados para com a finalidade, não apenas, de modificar a estrutura e estabilizar a quitosana em soluções ácidas, de modo a torná-la insolúvel mas, também, para aumentar suas propriedades mecânicas (CHEN et al., 2019; VAKILI et al, 2018; ZHANG et al, 2018; JIANG et al., 2018; HUANG, et al., 2018; AHMAD, 2017; ELIODÓRIO et al., 2017; KAHU et al., 2016).

Outras modificações podem envolver processos de graftização, reações com compostos orgânicos e inorgânicos que promovam mudanças no grupamentos amino livre ou nas hidroxilas e processos de tratamento com líquidos iônicos que proporcionam mudanças na carga da superfície, aumentando a efetividade na adsorção de íons de metais pesados, que podem promover o aumento da estabilidade da quitosana favorecendo a utilização da mesma nos mais diversos pH (MOUSSOUT et al, 2018; ZHANG et al, 2018; ELIODÓRIO et al., 2017; KAHU et al., 2016; KUMAR et al, 2012).

\subsubsection{Resíduos Lignocelulósicos}

Os materiais lignocelulósicos se caracterizam por serem materiais orgânicos provenientes de fontes vegetais, formados, principalmente, por três componentes poliméricos: 25-30 \% lignina (Figura 8) 30-35\% hemicelulose (Figura 9) e 40-45\% celulose (Figura 10) organizados em um complexo em que as fibras de celulose encontram-se envolvidas por uma estrutura de lignina e hemicelulose, como mostra a figura 11 (BRODIN et al., 2017; WANG et al, 2017; BISWAS et al, 2014; NEVÁREZ et al., 2011; TAHERZADEH; KARIMI, 2008). 
Figura 8 - Representação da estrutura da lignina

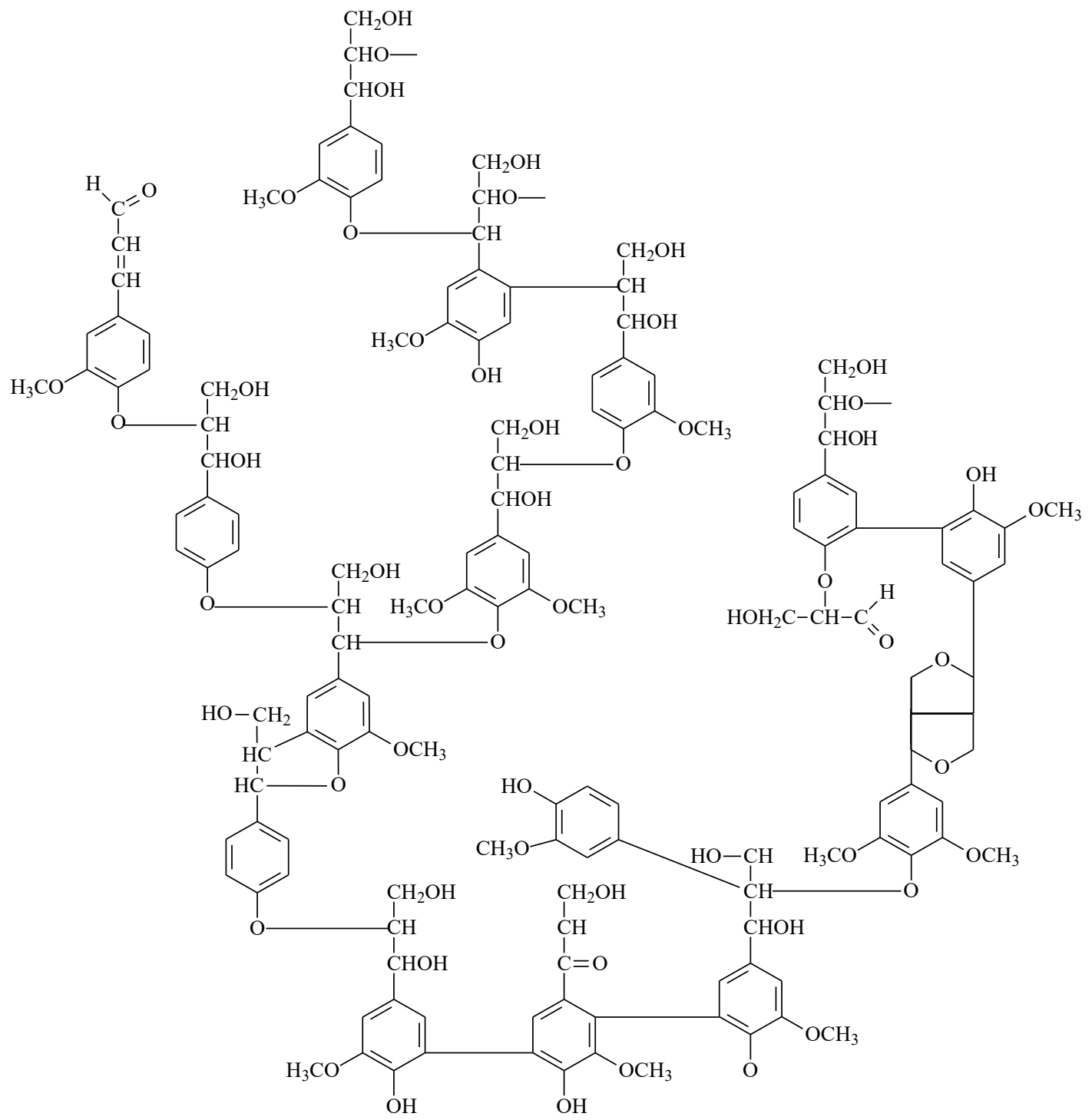

Fonte: Autor

Figura 9 - Representação da estrutura da hemicelulose

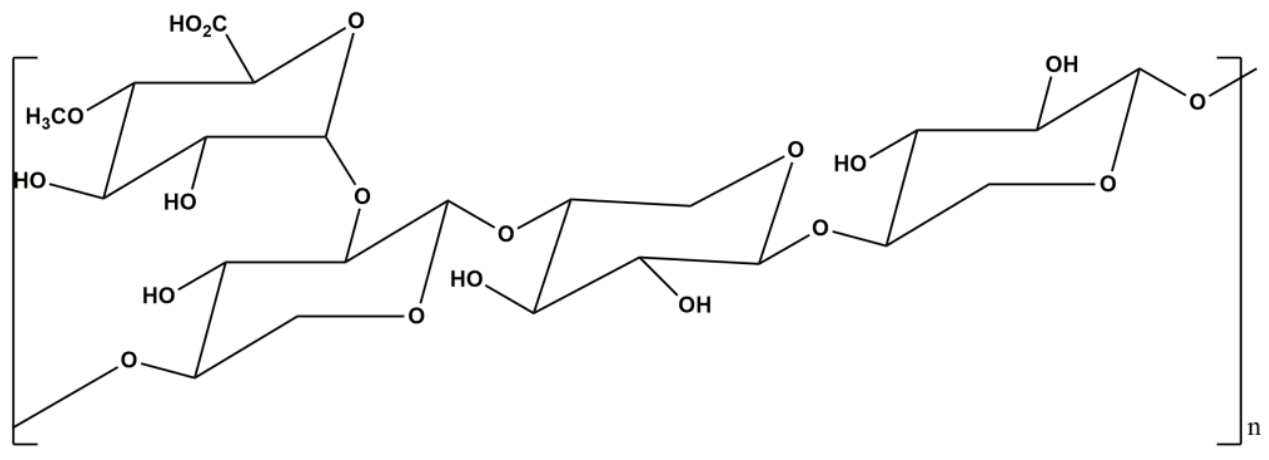

Fonte: Autor 
Figura 10 - Anel glicosídico presente na estrutura da celulose

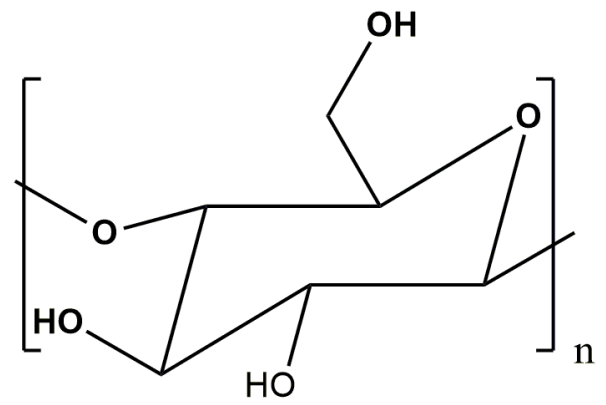

Fonte: Autor

Figura 11 - Estrutura dos resíduos lignocelulósicos

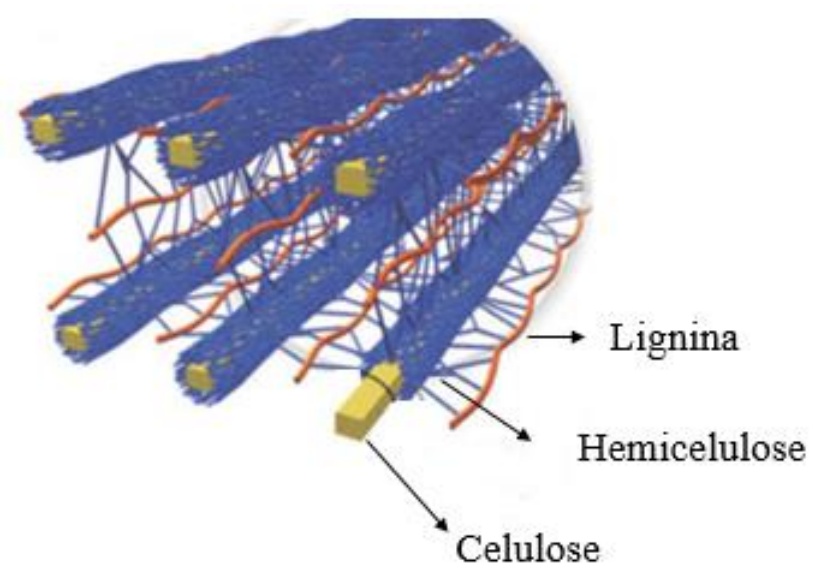

Fonte: Autor "adaptado de" Taherzadeh; Karimi, 2008

Os mesmos, devido a intensa atividade agrícola, tornaram-se resíduos com alta disponibilidade, custo relativamente baixo e seu perfil ambientalmente favorável, juntamente com a dificuldade de reutilização e disposição do mesmo têm despertado o interesse de pesquisadores na obtenção de produtos com valor agregado e de vasta aplicabilidade (WANG et al, 2017; BRODIN et al., 2017; BISWAS et al, 2014; BARAKAT; DE VRIES; ROUAU, 2013; NEVÁREZ et al., 2011).

Dentre os três componentes que compõem os resíduos lignocelulósicos, a celulose se destaca por ser o polímero natural mais abundante na natureza e, pelo elevado número de aplicações, devido a presença de grande quantidade de hidroxilas em sua estrutura passíveis de modificação, destacando-se a obtenção de ésteres e éteres de celulose, como a carboximetilcelulose, a metilcelulose e acetato de celulose (Figura 12) (WANG et al., 2017; BARAKAT; DE VRIES; ROUAU, 2013). 
Figura 12 - Representação simplificada da estrutura celulose e derivados
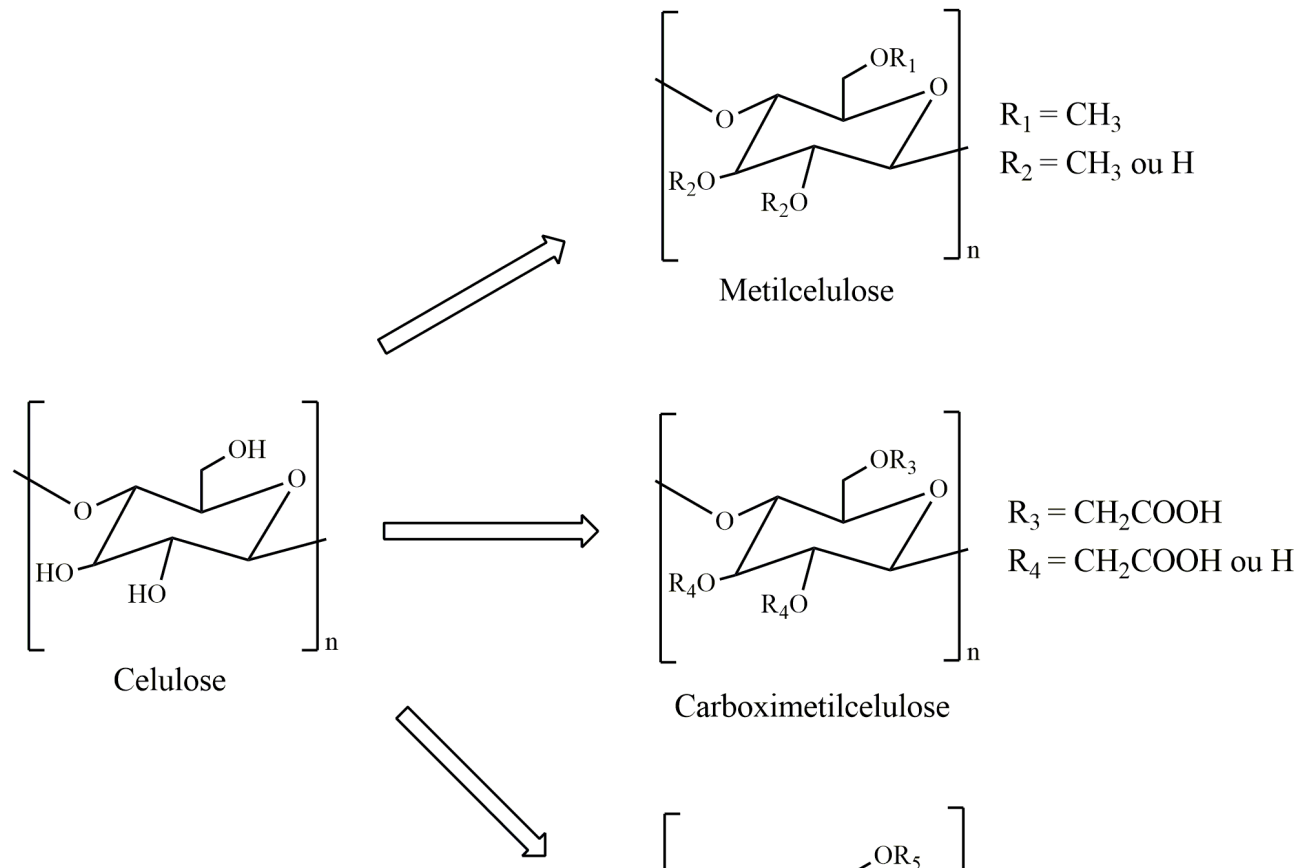

Carboximetilcelulose

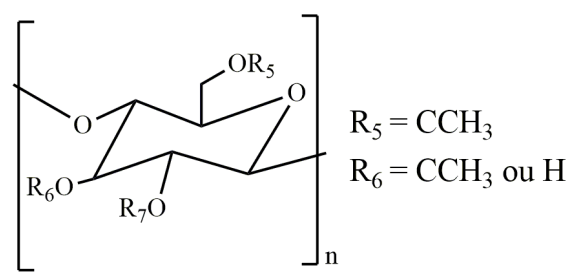

Acetato de Celulose

Fonte: Autor

Mas, para a utilização da celulose proveniente dos mais diversos materiais lignocelulósicos, são necessários pré-tratamento que possibilitem redução da quantidade de lignina, alteração da cristalinidade e, aumento da área específica possibilitando uma maior exposição da celulose presente no resíduo (BRODIN et al., 2017; BARAKAT; DE VRIES; ROUAU, 2013; MOSIER et al., 2005).

Para isso, são utilizados diversos tratamentos, como os descritos na tabela 7, sendo que, os pré-tratamento tradicionais envolvem a utilização de processos físicos no intuito de reduzir o tamanho de partícula aliado a um processo químico, ácido ou básico, que reduz o teor de lignina presente no resíduo (BRODIN et al., 2017; VENKATESWAR et al., 2016). 
Tabela 7 - Exemplos de processos de tratamento de materiais lignocelulósicos

\begin{tabular}{|c|c|}
\hline Tratamento & Mecanismos \\
\hline Mecânico (Físico) & edução do tamanho de partícula \\
\hline Irradiação gama (Físico) & $\begin{array}{l}\text { Quebras de ligações das cadeias da celulose e das interações entre hemiceluloses e } \\
\text { lignina }\end{array}$ \\
\hline Ultrassom (Físico) & Redução dos teores de lignina e hemicelulose aumento da porosidade \\
\hline Micro-ondas (Físico) & Quebra da interação presentes entre a estruturas da lignina, celulose e hemicelulose \\
\hline $\begin{array}{l}\text { Explosão a vapor } \\
\text { (Físico-químico) }\end{array}$ & $\begin{array}{l}\text { Quebra nas fibras lignocelulósicas e despolimerização, principalmente da lignina e } \\
\text { hemicelulose }\end{array}$ \\
\hline Ácido diluído (Químico) & $\begin{array}{l}\text { Utilizando-se baixa temperatura, promove a quebra da hemicelulose e lignina. Já, } \\
\text { em temperaturas elevadas, levam a ruptura da estrutura da celulose além da } \\
\text { hemicelulose e lignina }\end{array}$ \\
\hline Alcalino (Químico) & $\begin{array}{l}\text { Levam a deslignificação por oxidação da lignina (quebra oxidativa) e grande parte } \\
\text { da degradação da hemicelulose }\end{array}$ \\
\hline
\end{tabular}

Fonte: Autor "adaptado de" Brodin et al., 2017

Os derivados apresentam características como elevada área e superfície rapidamente modificável, boa resistência ao inchamento em diferentes solventes e, cinética de adsorção rápida e superficial, que conferem inúmeras aplicações industriais aos mesmos, sendo utilizado na indústria têxtil, produtos farmacêuticos, revestimentos, membranas poliméricas, filtros de cigarros, produção de filmes e processos de adsorção (WANG et al., 2017; CANDIDO, GONÇALVES, 2016; BISWAS et al., 2014; DAS; ALI; HAZARIKA, 2014; PEREDO et al., 2016; DAUD; DJUNED, 2015).

\subsubsection{Carboximetilcelulose}

A carboximetilcelulose $(\mathrm{CMC})$ é um polissacarídeo aniônico de cadeia longa e linear, que apresenta elevada solubilidade em água, obtido a partir da reação de eterificação da celulose com ácido monocloroacético em meio alcalino (Figura 13). O mesmo é um dos mais importantes éteres derivados da celulose e, durante a sua obtenção, são necessárias duas etapas: a primeira consiste em converter a celulose em um bom nucleófilo por meio da realização de um tratamento com hidróxido de sódio $(\mathrm{NaOH})$ e, em seguida, durante a segunda etapa, converte-se essa celulose em CMC por meio da reação de substituição nucleofílica no ácido monocloroacético (VELEMPINI et al., 2017; CANDIDO, GONÇALVES, 2016; BISWAS et al., 2014). 
Figura 13 - Reação de obtenção da carboximetilcelulose

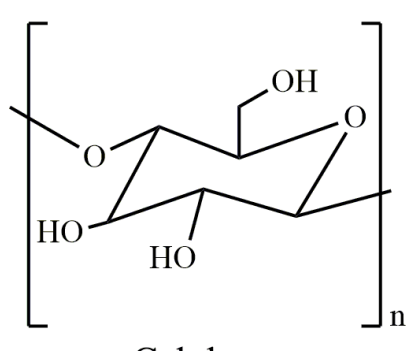

Celulose

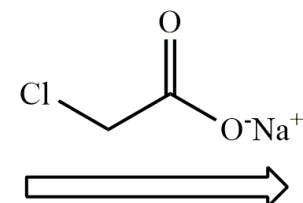

$\mathrm{NaOH}$

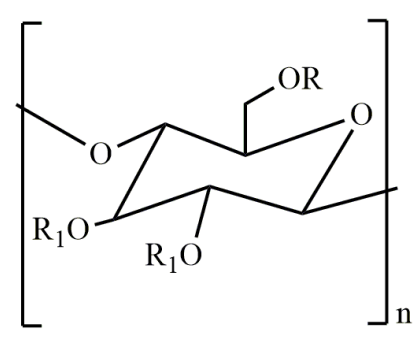

Carboximetilcelulose
$\mathrm{R}=\mathrm{CH}_{2} \mathrm{COOH}$

$\mathrm{R}_{1}=\mathrm{CH}_{2} \mathrm{COOH}$ ou $\mathrm{H}$

Fonte: Autor

A mesma se destaca pela aplicabilidade na indústria têxtil, de alimentos e farmacêutica devido a sua baixa toxicidade, baixa imunogenicidade, biodegradabilidade e baixo custo, porém a CMC atualmente tem sido alvo de estudos relacionados a sua aplicação em processos de tratamento de efluentes devido, principalmente, a presença de grupos carboxil e, dependendo do grau de substituição, de grupos hidroxil que são sítios favoráveis ao processo de adsorção (ZHANG et al., 2019; VELEMPINI et al., 2017; CANDIDO, GONÇALVES, 2016).

Porém, devido a sua elevada hidrofilicidade, apresenta aplicações restritas existindo a necessidade de realização de processos de reticulação anteriores, visando o aumento da estabilidade. Para isso, são utilizados compostos como polietilenoglicol, ácido fumárico, ácido dicloroacético, entre outros (WANG et al., 2017; VELEMPINI et al., 2017).

Neste contexto, no intuito de promover uma melhora nas propriedades de adsorção, busca-se a obtenção de blendas poliméricas da CMC com outros polímeros, como a quitosana, superando os problemas de solubilidade e estabilidade em meio ácido e, aumentando a quantidade de sítios ativos que proporcionariam um aumento na capacidade de adsorção, mesmo apresentando uma baixa área superficial (VELEMPINI et al., 2017)

Outra modificação na superfície de adsorventes é a utilização líquidos iônicos como agentes de ativação, que promovem um aumento na seletividade dos adsorventes em relação a remoção poluentes em efluentes (VELEMPINI et al., 2017).

\subsection{LÍQUIDOS IÔNICOS}

Líquidos iônicos (LIs) são definidos como sais líquidos ou sais fundidos composto unicamente de íons, a partir de um cátion orgânico, relativamente grande, e um ânion orgânico ou inorgânico, relativamente pequeno, e que apresenta ponto de fusão abaixo de $100{ }^{\circ} \mathrm{C}$. Dessa 
forma, inúmeras combinações entre cátions e ânions podem ocorrer para gerar uma infinidade de compostos sendo que, a seleção apropriada, permite a obtenção de líquidos iônicos com certas propriedades desejadas, tornando-os aplicáveis nos mais diversos processos (ACEITUNO et al., 2019; NAWAłA et al., 2018, MINEA; MURSHED; 2018; KIM, 2017).

Devido a sua síntese relativamente fácil e as suas várias propriedades como: elevada solubilidade, elevada polaridade, baixa toxicidade, miscibilidade em água e em solventes orgânicos, baixíssima pressão de vapor, baixa volatilidade, elevada estabilidade e condutividade térmica, elevada condutividade, não inflamabilidade, habilidade de dissolver compostos orgânicos, inorgânicos e organometálicos e pelo fato de se poder aplicar os mesmos em processos desenvolvidos em uma grande faixa de temperatura $\left(-40\right.$ até $\left.200{ }^{\circ} \mathrm{C}\right)$, os líquidos iônicos são cada vez mais utilizados na indústria e em vários campos da ciência e tecnologia (ACEITUNO et al., 2019; MINEA; MURSHED; 2018; NAWAłA et al., 2018; ANDRADE NETO et a, 2016).

Os LIs podem ser aplicados em processos de extração, separação, purificação de compostos, como substituto de solventes, como catalisador, eletrólitos eletroquímicos, solubilização de biopolímeros, adsorventes, fluidos refrigerantes e lubrificantes (NAWAłA et al., 2018, MINEA; MURSHED; 2018; KASPRZAK; STEPNIAK; GALINSKI, 2018; KIM, 2017; ANDRADE NETO et al., 2016).

A síntese dos líquidos iônicos, de forma geral envolve, primeiramente, a formação de um composto quaternário de uma amina, fosfina ou sulfina originando a formação de um cátion, e um ânion, que pode ou não ser substituído. Essa substituição pode ocorrer por meio da utilização do ácido de Lewis ou por troca de ânions utilizando-se sais metálicos ou ácidos de Bronsted-Lowry, como ilustrado na figura 14 (KASPRZAK; STEPNIAK; GALINSKI, 2018; MCLNTOSH; GRIFFITH; GRASVIK, 2016). 
Figura 14 - Rota de síntese dos líquidos iônicos

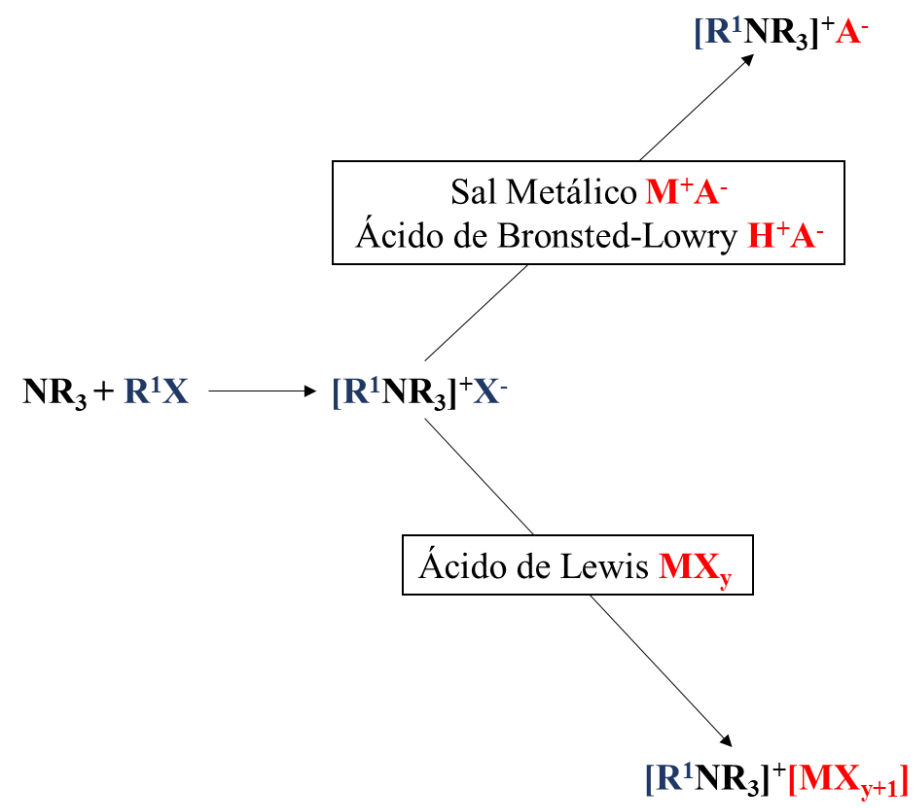

Fonte: Autor “adaptado de” Mclntosh; Griffith; Grasvik, 2016

Porém, essa rota de síntese de obtenção de líquidos iônicos envolve a aplicação de muitas etapas, utilização de reagentes químicos de difícil manipulação e, necessidade de purificação. Também necessita de controle de variáveis de processo rigorosas e utilização de equipamento mais robustos, o que torna o processo de elevado custo e não sustentável (KASPRZAK; STEPNIAK; GALINSKI, 2018; KIM, 2017; ANDRADE NETO et al., 2016).

Recentes estudos focam na obtenção de líquidos iônicos de baixo custo, uma vez que são obtidos por meio da neutralização ácido-base de compostos orgânicos, com aminas e ácidos carboxílicos, fazendo uso apenas da primeira etapa da rota de síntese convencional, utilizando, assim, sistemas menos complexos e ambientalmente favoráveis, podendo ampliar e difundir a utilização desses compostos (KASPRZAK; STEPNIAK; GALINSKI, 2018; KIM, 2017; ANDRADE NETO et al., 2016).

Levando-se em consideração a possibilidade de obtenção de líquidos iônicos de baixo custo, muitas pesquisas relacionadas a diversos processos começaram a ser desenvolvidas. Dessa forma, destacam-se os estudos envolvendo a utilização de líquidos iônicos na ativação de materiais visando a adsorção de metais pesados. Nesses estudos, os LIs são empregados, principalmente, no tratamento de biopolímeros como a quitosana, carboximetilcelulose ou mesmo blendas poliméricas, no intuito de melhorar a capacidade de adsorção e seletividade em relação aos íons de metais pesados (ELIODÓRIO et al., 2017; KUMAR et al., 2012). 
Esse aumento da capacidade de adsorção se deve à ligação entre os cátions amônio presentes nos líquidos iônicos com as hidroxilas livres presentes nas estruturas dos biopolímeros por meio dos elétrons disponíveis no oxigênio, que estabilizam as cargas positivas dos cátions do liquido iônico, por meio de interações eletrostáticas (Figura 15), deixando, assim, mais disponíveis e ativados os sítios reacionais (ELIODÓRIO et al., 2017; KAHU et al., 2016; KUMAR et al., 2012).

Figura 15 - Representação do processo de adsorção

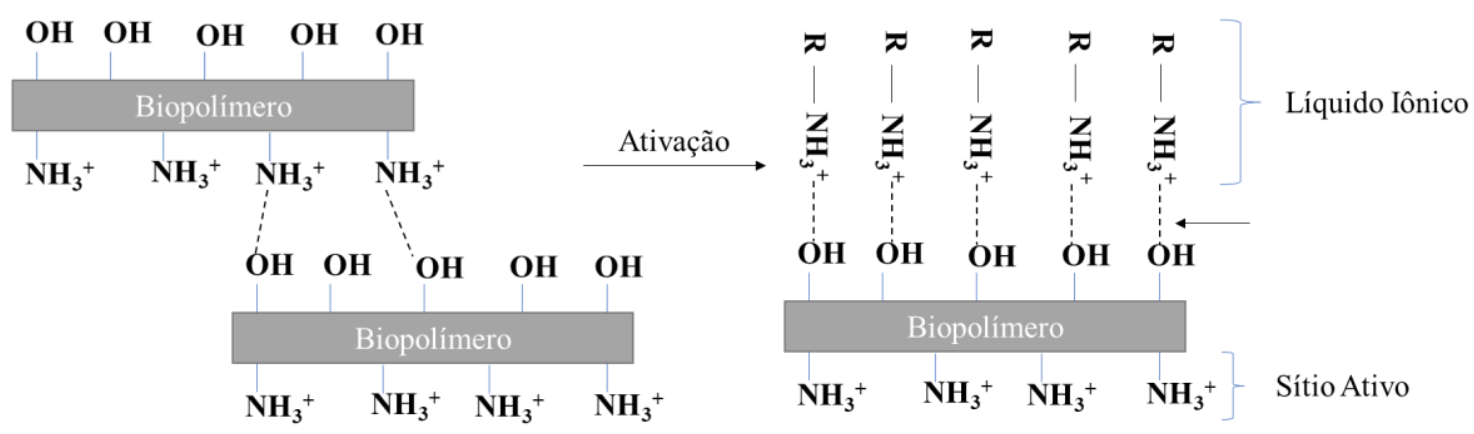

Fonte: Autor "adaptado de" Kumar et al., 2012

Esse fenômeno foi observado principalmente em quitosana sendo que, blendas poliméricas a base da mesma, devam apresentar comportamento semelhante e esse processo de ativação podendo auxiliar na melhoria das propriedades de adsorção desses materiais. 


\section{MATERIAIS E MÉTODOS}

No desenvolvimento do presente trabalho foram utilizados reagentes, equipamentos e metodologias descritas nos itens 4.1 a 4.3 .

\subsection{REAGENTES}

Durante o desenvolvimento do estudo os seguintes reagentes foram utilizados:

a) palha de milho (adquirida na CEGESP);

b) hidróxido de sódio (Dinâmica - 98\% em escamas);

c) peróxido de hidrogênio (Dinâmica - 35\%);

d) clorito de sódio (Sigma-Aldrich - 80\%);

e) ácido monocloroacético (Sigma-Aldrich - $\geq 99 \%$ );

f) isopropanol (Dinâmica - 99,5\%);

g) metanol (Dinâmica - 99,8\%);

h) etanol absoluto (Dinâmica - 99,5\%);

i) ácido sulfúrico (Dinâmica - 95\%);

j) ácido acético glacial (Dinâmica - 99,7\%);

k) ácido ferúlico (Sigma-Aldrich - $\geq 99 \%$ );

1) N,N'-diisopropilcarbodiimida (Sigma-Aldrich - 99\%);

m) dimetilformamida (Merk $-\geq 99,8 \%$;);

n) ácido nítrico (Merk - 65\%;);

o) difenilcarbazida (Sigma-Aldrich $-\geq 98 \%$ );

p) carboximetilcelulose (Sigma-Aldrich $-\mathrm{M}_{\mathrm{w}} \sim 700.000$ );

q) óxido de deutério (Sigma-Aldrich);

r) clorofórmio deuterado (Sigma-Aldrich);

s) quitosana de média massa molar (Sigma-Aldrich - 75 a 85\% de desacetilação);

t) ácido láctico (Sigma-Aldrich - Mín. 90\% e Máx.100 \%);

u) ácido acético (Dinâmica - 99,7\%);

v) sec-butilamina (Sigma Aldrich - 99\%);

w) terc-butilamina (Sigma aldrich - 99,5\%). 


\subsection{EQUIPAMENTOS}

Para a realização das sínteses e caracterizações envolvidas no estudo os seguintes equipamentos foram utilizados:

a) moinho de facas tipo Willye (TE-6500 da Tecnal);

b) reator de 5 L DA Metalquim;

c) estufa modelo $515 \mathrm{~A}$ da Fanem;

d) shaker Innova 43-Incubator Shaker Series;

e) espectrofotômetro na região do infravermelho (FTIR) NICOLET 670;

f) difratômetro de Raio X, (Modelo XRD-7000), Shimadzu;

g) espectrofotômetro UV visível Spectronic Gensys 5.

h) ultrasson Ultracleaner modelo USC $1600 \mathrm{~A}$;

i) calorímetro de Varredura Diferencial Shimadzu DSC-60;

j) espectrômetro de RMN Bruker Avance III 600 HD (14,1 T) equipado com criossonda de $5 \mathrm{~mm}$ com detecção inversa;

k) espectrômetro de RMN para realização de análise de amostras no estado sólido Bruker Avance III 400 WB (9,4 T) equipado com uma sonda CP/MAS de 4 mm;

1) micorscópio Eletrônico de Varredura de Alta Resolução - MEV/FEG JSM-7500F (JEOL);

m) evaporador Baltec SCD050;

n) bomba T-station 75 Edwards;

o) balança Mettler Toledo AG 204;

p) pipeta eletrônica Brand 0,5-5 mL;

q) analisador de umidade por infra-vermelho IV2000 (GEHAKA);

r) equipamento Accupys II 1340 Micromeritics;

s) equipamento Microtrac Bluewave;

t) micromeritics Gemini VII.

\subsection{METODOLOGIA}

Os métodos utilizados para realização dos experimentos necessários para 0 desenvolvimento do estudo encontram-se descritos nos itens a seguir. 


\subsubsection{Tratamento da palha de milho}

Inicialmente, foi realizado um tratamento da palha de milho visando a redução do teor de lignina e hemicelulose. Para isso, a mesma foi moída com o auxílio do moinho de facas Willye (TE-6500 da Tecnal) e, posteriormente, submetida a processo de polpação utilizando-se um reator batelada de $5 \mathrm{~L}$ Metalquim (Figura 16), em que $430 \mathrm{~g}$ de palha de milho moída foram submetidas ao tratamento com $3 \mathrm{~L}$ de solução de hidróxido de sódio $9 \%$ em massa. A temperatura utilizada durante o tratamento foi de $137^{\circ} \mathrm{C}$, a pressão de $2,5 \mathrm{~atm}$, a rotação de 120 rpm e, o tempo de reação, de $6 \mathrm{~h}$. Finalizado o processo, o material foi lavado e seco em estufa a $70{ }^{\circ} \mathrm{C}$ (ANDRADE NETO et al., 2016).

Figura 16 - Reator Batelada de $5 \mathrm{~L}$

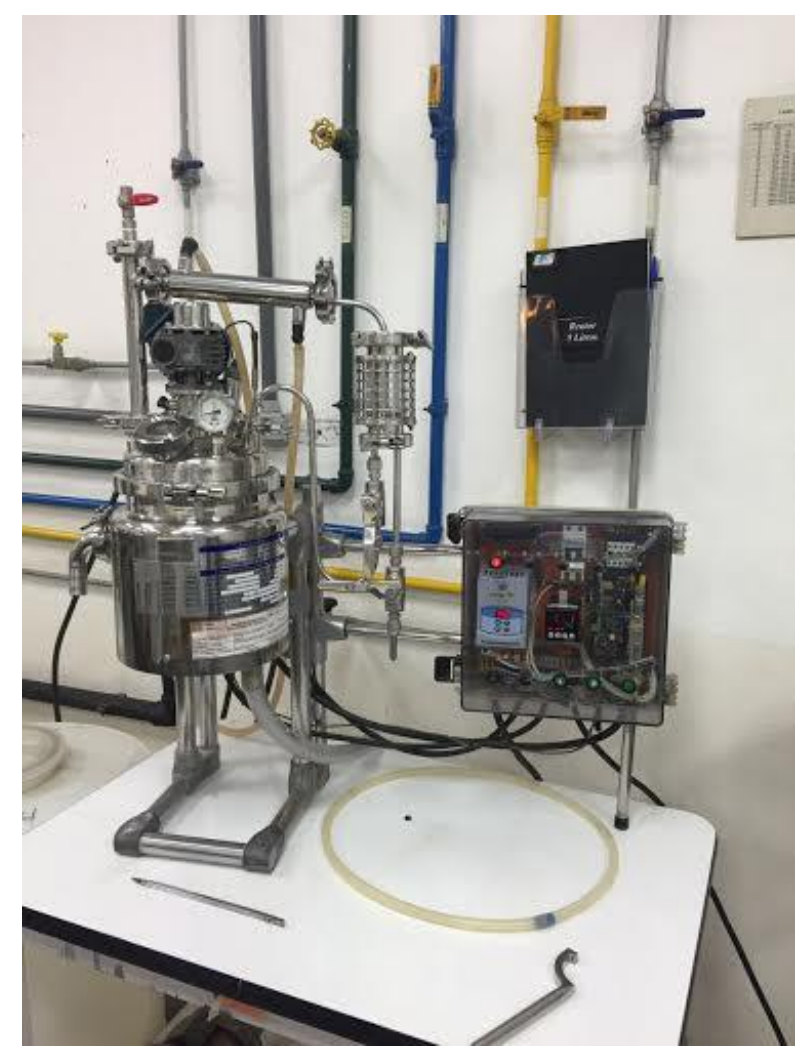

Fonte: Autor

Em seguida, a palha de milho polpada foi submetida a um processo de branqueamento (Figura 17) em um meio reacional constituído de uma solução de 4,2\% em massa de peróxido de hidrogênio e $\mathrm{pH} 12$, utilizando uma proporção de $5 \mathrm{~g}$ palha de milho polpada para cada 100 g de solução. A temperatura de reação foi de $40^{\circ} \mathrm{C}$, a rotação de $200 \mathrm{rpm}$ e, o tempo reacional 
de $6 \mathrm{~h}$. Após esse período, a palha de milho branqueada foi lavada para retirada de todo o resíduo do meio reacional e seca em estufa a $70{ }^{\circ} \mathrm{C}$ (MORANDIM-GIANNETTI et al., 2013).

Figura 17 - Sistema reativo utilizado no branqueamento

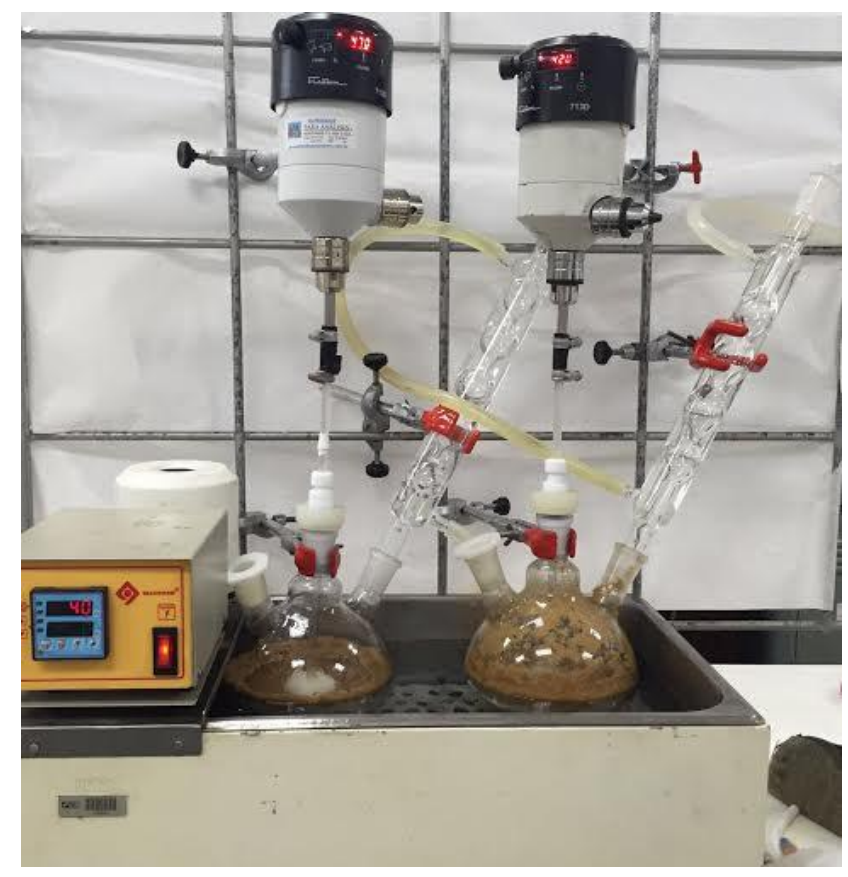

Fonte: Autor

A palha de milho bruta e os produtos após cada etapa de tratamento, foram caracterizados quanto aos teores de cinzas, umidade, celulose, hemicelulose, lignina, e com auxílio de espectroscopia na região do infravermelho (FTIR) e difração de raios X (DRX).

\subsubsection{Obtenção da carboximetilcelulose (CMC) a partir da palha de milho}

A obtenção da carboximetilcelulose $(\mathrm{CMC})$ foi realizada com a palha de milho após o tratamento inicial (polpação e branqueamento). Para isso, inicialmente, $15 \mathrm{~g}$ da palha branqueada foram misturadas com $400 \mathrm{~mL}$ de isopropanol e $40 \mathrm{~mL}$ de água sob agitação constante por 30 min à temperatura ambiente. Em seguida, $100 \mathrm{~mL}$ de solução de soda $40 \% \mathrm{em}$ massa foram adicionados lentamente ao sistema, sendo o mesmo mantido sob agitação por 90 min. Decorrido esse período, $40 \mathrm{~g}$ de ácido monocloroacético dissolvidos em $50 \mathrm{~mL}$ de isopropanol foram adicionados ao sistema que foi mantido a $55^{\circ} \mathrm{C}$ durante $4 \mathrm{~h}$, sob agitação.

Finalizada a reação, o produto foi filtrado e o sólido suspenso em solução metanólica $80 \%$, neutralizado com ácido acético, filtrado novamente e, seco em estufa a $50{ }^{\circ} \mathrm{C}$. 
O produto da reação (CMC) foi caracterizado via espectroscopia na região do infravermelho (FTIR) e grau de substituição, bem como DRX, ${ }^{13} \mathrm{C}-\mathrm{RMN}$ e ${ }^{1} \mathrm{H}-\mathrm{RMN}$ de hidrogênio.

\subsubsection{Modificação da carboximetilcelulose (CMC) com quitosana}

A carboximetilcelulose foi modificada com quitosana utilizando três metodologias distintas, descritas nos itens subsequentes, no intuito de verificar mudanças na capacidade de adsorção desses compostos em relação a quitosana pura e decidir quais seriam utilizados como adsorventes no estudo de adsorção de cromo hexavalente proposto.

\subsubsection{Modificação da CMC utilizando-se o ácido ferúlico}

Durante a obtenção do adsorvente CMCQF, inicialmente, foram dissolvidos, separadamente, a CMC e a quitosana em água, utilizando-se uma proporção de 1:2 \% em massa de cada composto, porém a solução de quitosana adicionou-se ácido acético até o pH 3. Em seguida, ambas as soluções foram misturadas e introduziu-se o ácido ferúlico como agente de reticulação na proporção de $4 \%$ em massa, sendo o sistema reativo mantido em agitação constante à temperatura ambiente por $60 \mathrm{~min}$. Posteriormente, o produto foi filtrado, lavado com etanol e seco em estufa a $50{ }^{\circ} \mathrm{C}$ (WONGKOM; JIMTAISONG, 2017).

\subsubsection{Modificação da CMC utilizando-se a N,N'-diisopropilcarbodiimida}

Durante a obtenção do adsorvente CMCQDIC, inicialmente, foram dissolvidos, separadamente, a quitosana e a CMC na proporção de 1:1 em $100 \mathrm{~mL}$ de dimetilformamida (DMF) e um equivalente de 1,8 de $N, N^{\prime}$-diisopropilcarbodiimida (DIC) em relação a CMC. Após essa etapa, o sistema foi mantido sob agitação constante a $50^{\circ} \mathrm{C}$ de temperatura por $24 \mathrm{~h}$. Finalizada a reação, o sistema foi filtrado, lavado e seco em estufa a $50{ }^{\circ} \mathrm{C}$ (CORTI, 2004).

\subsubsection{Modificação da CMC utilizando-se álcool polivinílico}

Durante a obtenção do adsorvente CMCQPVA, inicialmente, foram dissolvidos, separadamente, o PVA, a CMC e a quitosana em água, utilizando-se uma proporção de 1:1:1 em massa, onde para dissolução o PVA foi utilizado um sistema de refluxo com duração de 2 
h a $80^{\circ} \mathrm{C}$ e, para a dissolução da quitosana, adicionou-se ácido acético até pH 3. Em seguida, misturou-se as soluções e o sistema foi mantido sob agitação por $30 \mathrm{~min}$. Após essa etapa, a mistura foi transferida para uma placa de petri e seca em estufa a $50{ }^{\circ} \mathrm{C}$ para formar um filme que, posteriormente, foi triturado para ser utilizado com adsorvente (HU; QIANGA; WANG, 2017).

\subsubsection{Teste inicial de adsorção de cromo hexavalente}

Após a síntese das carboximetilcelulose modificadas foi realizado um teste de adsorção de íons de cromo hexavante no intuito de verificar se os compostos obtidos apresentavam uma melhora na capacidade de adsorção quando comparados a quitosana pura e se eram relevantes essas modicações para um estudo mais aprofundado de adsorção. Para isso, adicionou-se 25 $\mathrm{mL}$ de solução de $250 \mathrm{ppm}$ de cromo hexavalente a cerca $0,05 \mathrm{~g}$ de adsorvente, sendo essa mistura mantida sob agitação de $250 \mathrm{rpm}$ a temperatura ambiente por $3 \mathrm{~h}$ em um shaker orbital. Após esse período, o sistema foi filtrado e a solução resultante analisada via método colorimétrico da difenilcarbazida, para a determinação da quantidade de cromo hexavalente presente na solução.

Durante a realização dos testes iniciais de adsorção, verificou-se uma maior eficiência ao utilizar-se os adsorventes CMCQF e CMCQDIC, assim, os mesmos foram sintetizados em maior quantidade para realização de todos os experimentos de adsorção bem como das caracterizações via DRX, FTIR, ${ }^{13} \mathrm{C}-\mathrm{RMN}$ e Análise Térmica (TGA e DSC).

\subsubsection{Estudo de adsorção de cromo hexavalente com os adsorventes selecionados}

Os estudos de adsorção foram realizados no intuito de estabelecer as melhores condições, determinando-se o pH ótimo de adsorção, a temperatura ideal do processo, a concentração máxima de cromo adsorvido por grama de adsorvente e, também, do tempo ótimo de reação com esses adsorventes.

Os estudos referentes ao tempo de reação foram utilizados para a determinação da cinética de reação e, os dados referentes a variação da concentração de cromo em diferentes temperaturas foram utilizados para a obtenção das isotermas de adsorção, e com isso, determinar a eficiência de cada um dos adsorventes selecionados (CMCQF e CMCQDIC). 


\subsubsection{Cinética de adsorção}

Para a obtenção do tempo ótimo utilizado durante o tratamento do efluente de cromo, bem como para a realização do estudo de cinética de reação foram realizados experimentos utilizando-se tempos de 1, 2, 4, 5 a $30 \mathrm{~min}$ (variando-se o tempo de 5 em $5 \mathrm{~min}$ ), de 30 até 120 min (variando-se o tempo de 15 em $15 \mathrm{~min}$ ), de 120 a 300 (variando-se o tempo de 30 em 30 min), além de experimentos de 12 e $24 \mathrm{~h}$.

Em cada experimento utilizou-se $0,05 \mathrm{~g}$ de adsorventes e $25 \mathrm{~mL}$ de solução de cromo hexavelente com concentração de $250 \mathrm{ppm}$. A temperatura utilizada foi de $25^{\circ} \mathrm{C}$ e, a rotação de $250 \mathrm{rpm}$. Após a finalização de cada experimento, os sistemas foram filtrados e, a fase líquida analisada para determinação da concentração de cromo.

Obtidos todos os dados, os mesmos foram utilizados para a realização do estudo da cinética de reação, sendo a mesma avaliada utilizando-se os modelos de pseudo-primeira ordem, pseudo-segunda ordem e Weber-Morris.

\subsubsection{Avaliação do pH da solução}

A influência do pH foi analisada utilizando-se 7 valores diferentes, 2,5, 3, 4, 5, 6, 7 e 8. Para isso, os pHs foram ajustados utilizando-se soluções de ácido clorídrico e hidróxido de sódio $0,5 \mathrm{~mol} . \mathrm{L}^{-1}$. Todos os experimentos foram realizados utilizando-se $25 \mathrm{~mL}$ de cada uma das soluções de cromo preparadas sendo a concentrações das mesmas de $250 \mathrm{rpm}, 0,05 \mathrm{~g}$ de adsorvente e os tempos estipulados durante o estudo da cinética para cada adsorvente (60 min para CMCQF e 180 min para o CMCQDIC).

\subsubsection{Construção das Isotermas de Langmuir, Freundlich e Temkin}

Para construção das isotermas foram utilizadas dez soluções de diferentes concentrações de cromo hexavalente, 25, 50 a 450 (variando-se de 50 em 50 ppm) e, cinco temperaturas, 20, $25,30,40,50{ }^{\circ} \mathrm{C}$. A rotação utilizada foi de 250 ppm e, os tempos de adsorção de 60 min para o adsorvente CMCQF e 180 min para o CMCQDIC. Finalizados os experimentos, as soluções foram analisadas via espectrofotometria UV/VIS, os dados obtidos utilizados para a realização dos estudos utilizando-se três modelos de isotermas: a de Langmuir, Freundlich e Temkin. 


\subsubsection{Síntese dos líquidos iônicos}

Os líquidos iônicos lactato de sec-butilamônio, acetato de sec-butilamônio, lactato de terc-butilamônio e acetato de terc-butilamônio (Figura 18) foram obtidos a partir da neutralização ácido-base 1:1 (molar) do ácido láctico ou ácido acético com a sec-butilamina ou terc-butilamina, respectivamente. Para isso, a amina foi adicionada em um balão de três bocas equipado com um condensador de refluxo. Para a produção dos líquidos iônicos, a adição do ácido foi realizada, gota a gota, por meio de um funil de separação, controlando-se a temperatura entre 20 e $40{ }^{\circ} \mathrm{C}$, com auxílio de um banho de gelo (ANDRADE NETO et al., 2016).

Figura 18 - Estrutura dos LIs sintetizados

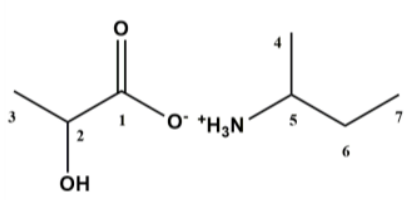

lactato de $s e c$-butilamônio

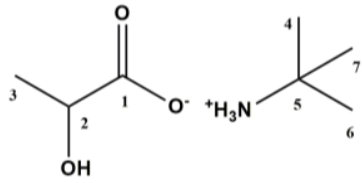

lactato de terc-butilamônio

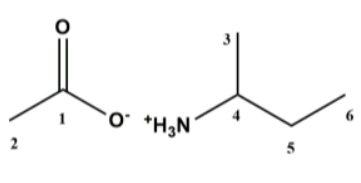

acetato de sec-butilamônio

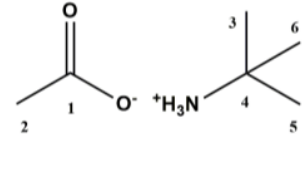

acetato de terc-butilamônio

Fonte: Autor

Após a obtenção dos líquidos iônicos, os mesmos foram caracterizados via Ressonância Magnética Nuclear de hidrogênio $\left({ }^{1} \mathrm{H}-\mathrm{RMN}\right)$ e de carbono $\left({ }^{13} \mathrm{C}-\mathrm{RMN}\right)$ em fase líquida utilizando-se como solvente o clorofórmio deuterado.

\subsubsection{Tratamento da CMC modificada com os líquidos iônicos}

Os adsorventes CMCQF e CMCQDIC foram submetidos a um tratamento com os líquidos iônico (lactato de sec-butilamônio, acetato de sec-butilamônio, lactato de tercbutilamônio e, acetato de terc-butilamônio) utilizando-se, para isso, uma proporção de $0,5 \mathrm{~g}$ de adsorvente para 0,5 g de líquido iônico e $5 \mathrm{ml}$ de metanol. Após a realização de cada uma das misturas, os sistemas foram introduzidos em aparelho de ultrassom por 2 horas (15 minutos de ultrassom/5min repouso) e, após esse período, os materiais foram filtrados, secos em dessecador à vácuo e utilizados em testes de adsorção visando a verificação do aumento da capacidade de adsorção em função desse tratamento (KUMAR et al., 2012; ELIODORIO et al, 2017).

Para o adsorvente CMCQF as condições de realização dos testes de adsorção foram de $60 \mathrm{~min}, \mathrm{pH} 3$ e $20^{\circ} \mathrm{C}$ de temperatura e, para o CMCQDIC, $180 \mathrm{~min}, \mathrm{pH} 2,5$ e $20^{\circ} \mathrm{C}$ temperatura, 
condições essas estabelecidas realizando-se os estudos de adsorção para os materiais adsorventes antes da realização do tratamento com líquido iônicos. Para ambos foi utilizada uma solução de 250 ppm, 0,05 g de adsorvente e agitação de $250 \mathrm{rpm}$.

\subsubsection{Caracterizações}

Nos itens 4.3.7.1 a 4.3.7.11 encontram-se descritos os procedimentos utilizados para caracterizar os reagentes e produtos.

\subsubsection{Determinação da composição da palha de milho}

As palhas de milho bruta, polpada e branqueada foram caracterizadas por meio dos teores de umidade, cinzas, lignina, celulose e hemicelulose, com a finalidade de determinar a composição desses compostos, como descritos nos itens 4.3.7.1.1 a 4.3.7.1.4.

\subsection{Teor de umidade}

O teor de umidade foi determinado com auxílio de um analisador de umidade por infravermelho IV 2000 (Figura 19) com controle de temperatura de 50 a $200^{\circ} \mathrm{C}$, faixa de medida de 0 a $100 \%$ e, sensibilidade de $\pm 0,1 \%$, onde cerca de $1,0 \mathrm{~g}$ de amostra foi colocado sob a balança do equipamento e mantido por aquecimento até a massa constante.

Figura 19 - Analisador de umidade

por infravermelho

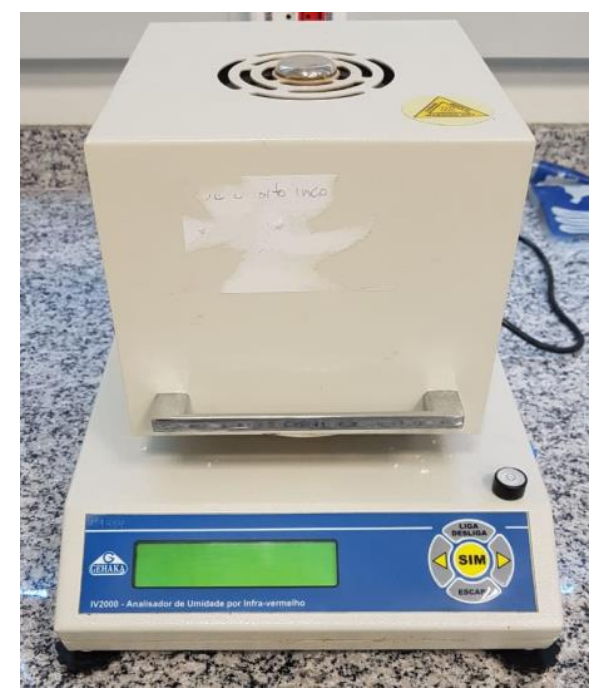

Fonte: Autor 


\subsection{Teor percentual de cinzas}

Para determinação teor percentual de cinzas adicionou-se em um cadinho, previamente calcinado a $600{ }^{\circ} \mathrm{C}$ por $30 \mathrm{~min}$ resfriado em dessecador e pesado, 1,5 g do material lignocelulósico, sendo esse conjunto aquecido em um forno mufla partindo da temperatura ambiente até $600{ }^{\circ} \mathrm{C}$. A rampa de aquecimento foi de $9,6^{\circ} \mathrm{C} / \mathrm{min}$ em 60 minutos, sendo essa temperatura mantida por três horas. Após essa etapa, a temperatura foi reduzida para $200{ }^{\circ} \mathrm{C}$ durante uma hora e, ao atingir esse ponto, o conjunto foi transferido para um dessecador até seu completo resfriamento e mantido até obter-se massa constate, sendo o teor de cinzas calculado utilizando-se a equação 21 (MORAIS; ROSA; MARCONCINI, 2010):

$$
\% \mathrm{TC}=\frac{\mathrm{MC}}{\mathrm{MA}} \times 100
$$

em que: MC descreve a massa de cinzas após a calcinação, MR a massa do cadinho, MA a massa de amostra antes da calcinação e, \%TC o teor percentual de cinzas (\%).

\subsection{Teor de lignina}

A determinação do teor de lignina foi realizada seguindo a norma TAPPI T222 os-76 (1976). Assim, durante a caracterização, 1,0 g de resíduo foi submetido ao tratamento com 20 $\mathrm{mL}$ de ácido sulfúrico $72 \%$ em massa durante $2 \mathrm{~h}$ sob agitação constante à temperatura ambiente. Em seguida, o sistema foi diluído em $560 \mathrm{~mL}$ de água e mantido em refluxo por $4 \mathrm{~h}$. Decorrido esse período, o sólido que restou foi lavado e seco em estufa à $80{ }^{\circ} \mathrm{C}$, sendo o teor obtido seguindo a equação 22 :

$$
\% \operatorname{Lig}=\left(\frac{m_{\text {lig }}}{m_{t}} \times 100\right)-\% \mathrm{TC}
$$

em que: $m_{\text {lig }}$ é massa de lignina, $m_{t}$ é a massa inicial utilizada e \%Lig é o teor de lignina.

\subsection{Teor de holocelulose, celulose e hemicelulose}

Durante a determinação do teor de holocelulose foi utilizada a metodologia descrita por Wise; Murphy (1946). Para isso, 1,0 g do resíduo lignocelulósico foi misturado com $60 \mathrm{~mL}$ de água e mantido sob agitação constante à $70^{\circ} \mathrm{C}$ durante $30 \mathrm{~min}$. Após essa etapa, adicionou-se 
ao sistema 1,5 g de clorito de sódio e $2 \mathrm{~mL}$ de ácido acético glacial e, a mistura foi mantida sob agitação por mais $1 \mathrm{~h}$, sendo esse processo repetido mais duas vezes após 1 e $2 \mathrm{~h}$ da primeira adição. Em seguida, o sólido foi filtrado e lavado com água gelada, etanol e acetona e seco em estufa à $75^{\circ} \mathrm{C}$, sendo o teor de determinado pela equação 23 :

$$
\% \text { Holo }=\frac{\mathrm{m}_{\text {holo }}}{\mathrm{m}_{\mathrm{m}}} \times 100
$$

em que: $\mathrm{m}_{\mathrm{m}}$ é a massa de material analisado, $\mathrm{m}_{\text {holo }}$ é a massa holocelulose e \%Holo é o teor de holocelulose.

O teor de celulose foi determinado a partir da massa de holocelulose (TAPPI T203 cm99, 1979). Para isso, a holocelulose obtida foi diluída em solução de hidróxido de potássio (KOH) $24 \%$ (m/m), na proporção de $1,0 \mathrm{~g}$ de holocelulose para cada $15 \mathrm{~mL}$ de solução de $\mathrm{KOH}$, e mantido sob agitação à temperatura ambiente por $15 \mathrm{~h}$ em um shaker orbital a $250 \mathrm{rpm}$. Posteriormente, o material foi filtrado, lavado com água e etanol e seco em estufa à $75^{\circ} \mathrm{C}$, sendo o teor determinado pela equação 24 :

$$
\% \text { Cel }_{\text {Holo }}=\frac{\mathrm{m}_{\text {cel }}}{\mathrm{m}_{\text {holo }}} \times 100
$$

em que: $\mathrm{m}_{\text {cel }}$ é a massa de celulose obtida, $\mathrm{m}_{\text {holo }}$ é a massa de holocelulose utilizada e $\% \mathrm{Cel}_{\text {holo }}$ o teor de celulose em relação a massa de holocelulose.

Para determinação do teor de celulose em relação a massa de amostra inicial utilizada na quantificação da holocelulose, utilizou-se a equação 25 :

$$
\% \text { Cel }=\frac{\% \text { Cel }_{\text {Holo }} \times \text { Holo }}{100}
$$

em que: \%Cel ${ }_{\text {Holo }}$ é o teor de celulose em relação a massa de holocelulose, \%Holo é teor de holocelulose e \%Cel é o teor de celulose corrigido em relação a massa de amostra inicial.

Como a holocelulose descreve a quantificação total de celulose e hemicelulose, o teor de hemicelulose foi determinado pela equação 26 :

$$
\% \text { Hemi }=100-\% \text { Cel }
$$


em que: \%Hemi é o teor de hemicelulose e \% $\%$ el o teor de celulose.

\subsubsection{Difratometria de raios $X(D R X)$}

Técnica importante que possibilita a determinação na mudança de cristalinidade das amostras em análise, por meio da incidência de raios $\mathrm{X}$ que interagem com os elétrons presentes no material e como consequência ocorre o espelhamento culminando no fenômeno de difração que consiste na interferências construtivas e destrutivas de ondas, e, também, permite a determinação dos índices de cristalinidade dos materiais.

Durante a análise via difração de raios $\mathrm{X}$ foi utilizado um difratômetro modelo XRD7000 (Figura 20). Para a realização das análises, as amostras foram colocadas no suporte sendo utilizados $5 \mathrm{~s}$ para cada período de contagem de tempo e uma taxa de $0,015^{\circ} / \mathrm{min}$ em uma escala de $5^{\circ}$ a $40^{\circ}$ em $2 \theta$. O índice de cristalinidade foi calculado pelo método da área, sendo a cristalinidade calculada pela razão entre a área das regiões cristalinas e a área total do material (amorfo e cristalino) x 100, como descreve a equação 27:

$$
I C(\%)=\frac{(\text { área cristalina })}{(\text { área total })} \cdot 100
$$


Figura 20 - Difratômetro de Raios X

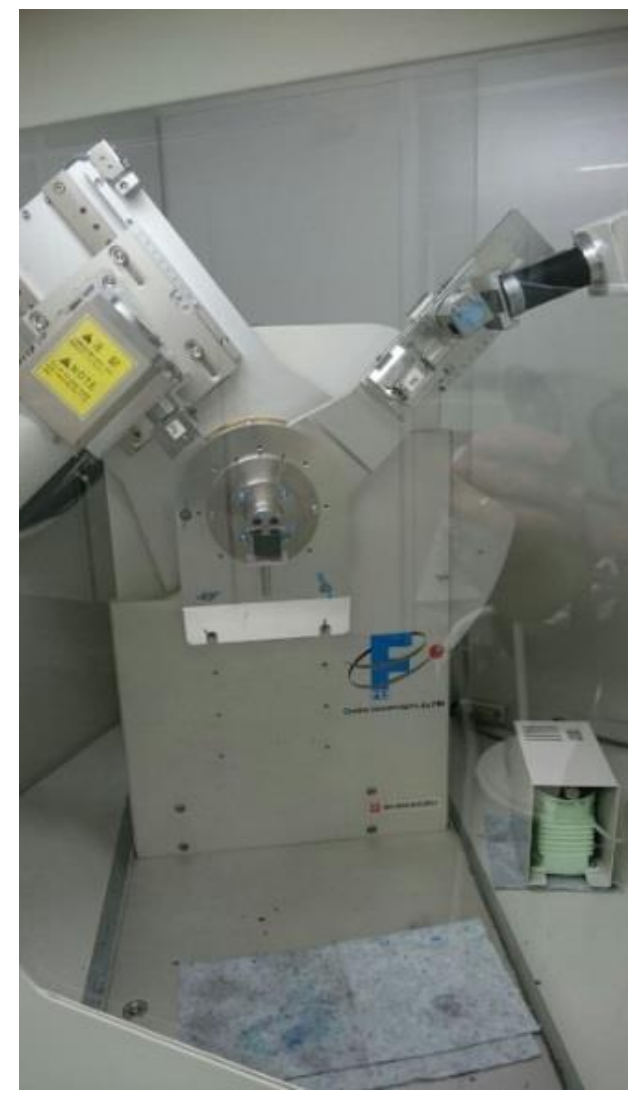

Fonte: Autor

\subsubsection{Microscopia eletrônica de varredura de alta resolução (MEV-FEG)}

A microscopia eletrônica é uma técnica que utiliza elétrons para a formação de imagens de superfícies de elevada resolução e, ainda, quando aliado a um modelo de alta resolução, devido ao modo com ocorre a emissão de elétrons, que pode modificar a relação entre o sinal emitido e o ruído gerado e, também, a resolução tridimencinal, fornece resultados com elevada qualidade.

A análise via MEV-FEG foi realizada utilizando o microscópio eletrônico de varredura de alta eficiência JEOL modelo JSM-7500F (Figura 21) com emissão de elétrons por canhão de aplicação de campo elétrico. As imagens foram obtidas utilizando-se uma voltagem de aceleração $2,00 \mathrm{kV}$ e uma deposição com fio de carbono para possibilitar a condução elétrica.

As micrografias foram obtidas utilizando elétrons secundários, aumentos de 50, 200, $1.000,3.000,10.000$ e $25.000 x$ com resolução de $1 \mu \mathrm{m}$ que possibilitassem a análise de superfícies dos materiais sólidos em alta resolução e tridimensionalmente.

A análise foi realizada em parceria com o Instituto de Química - UNESP - Araraquara. 
Figura 21 - Microscópio eletrônico de varredura de alta resolução

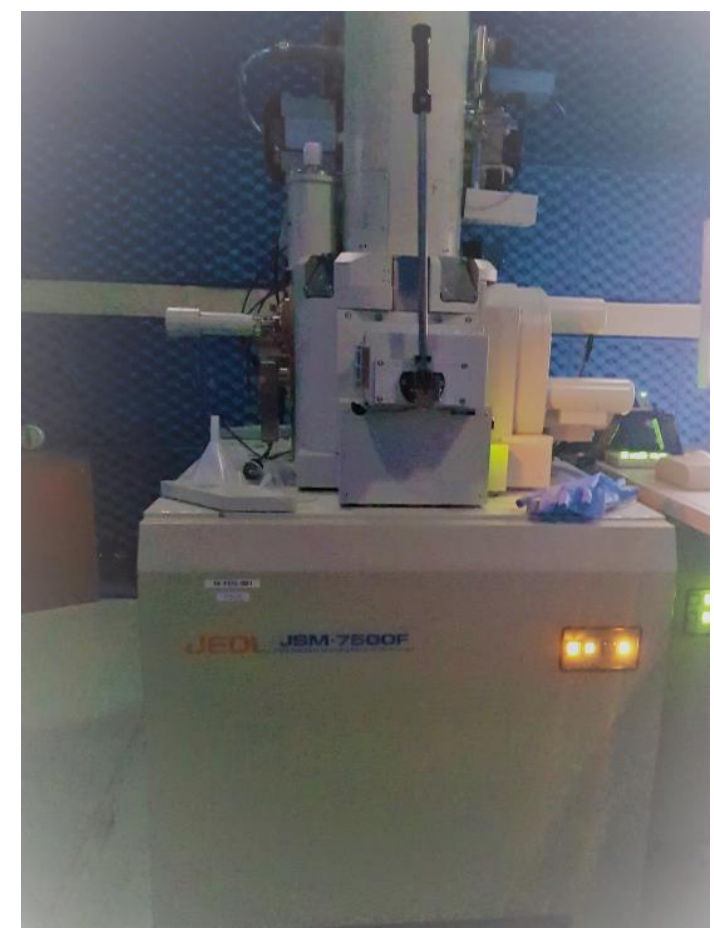

Fonte: Autor

\subsubsection{Espectoscopia na região do infravermelho (FTIR)}

A espectroscopia na região do infravermelho é uma importante técnica que permite a identificação de diferentes tipos de ligações moleculares, uma vez que cada tipo de ligação vibra em uma frequência natural própria e característica que corresponde a um nível energético, dessa forma quando a amostra recebe energia na mesma frequência do estado vibracional, por meio da incidência feixes de ondas de diferentes comprimentos, ocorre o fenômeno de adsorção que gera uma banda característica única referente a cada ligação permitindo a identificação de compostos químicos.

As análises via FTIR foram realizadas utilizando um espectrofotômetro na região do infravermelho Nicolet 6700 (Figura 22) utilizando-se o acessório de reflexão total atenuada (ATR), visando a identificação de modificações químicas dos produtos obtidos em relação aos compostos utilizadas para síntese, utilizando-se 128 scans sendo as amostras analisadas em porcentagem de transmitância com resolução de $4 \mathrm{~cm}^{-1}$. 
Figura 22 - Espectrofotômetro na região do infravermelho

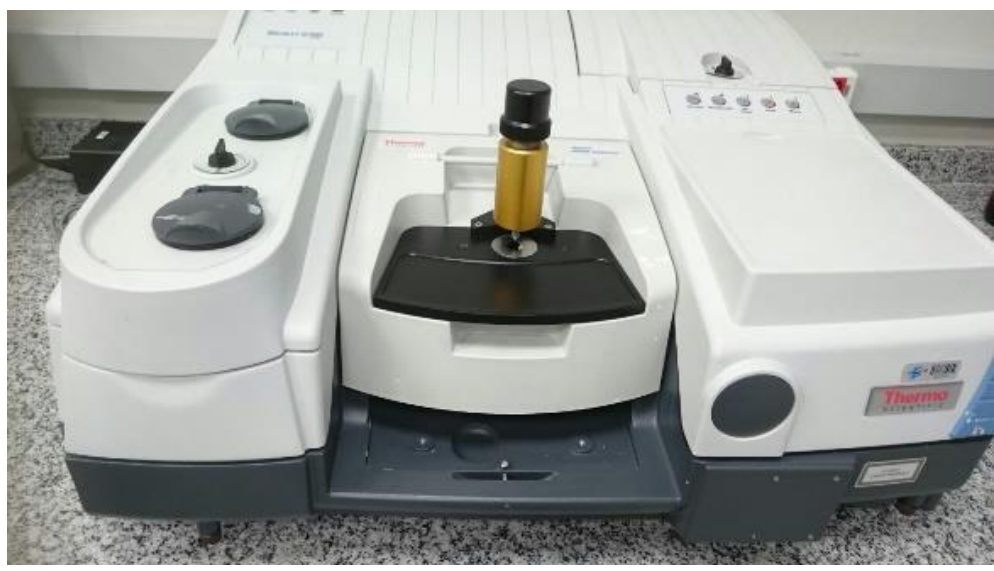

Fonte: Autor

\subsubsection{Determinação do grau de substituição (GS)}

Para determinação do grau de substituição da $\mathrm{CMC}$, inicialmente foi preparado $1 \mathrm{~L}$ de solução dissolvendo-se $108 \mathrm{~mL}$ de ácido nítrico concentrado em metanol. Em seguida, 0,5 g de CMC foram colocados em refluxo com $100 \mathrm{~mL}$ da solução por 3 h. Após essa etapa, o resíduo foi filtrado, lavado com metanol e seco em estufa a $60^{\circ} \mathrm{C}$.

Posteriormente, cerca $0,25 \mathrm{~g}$ do material obtido na etapa anterior foram dissolvidos em 22,5 mL de água e 62,5 mL de solução de $\mathrm{NaOH} \mathrm{0,05} \mathrm{M,} \mathrm{sendo} \mathrm{a} \mathrm{solução} \mathrm{titulada} \mathrm{com} \mathrm{solução}$ de $\mathrm{HCl}$ 0,05 M utilizando fenolftaleína como indicador, sendo o GS determinado por meio das equações 28 e 29 ,

$$
\begin{aligned}
& \mathrm{A}=\frac{\left(\mathrm{V}_{\mathrm{NaOH}} \mathrm{C}_{\mathrm{NaOH}} \mathrm{f}_{\mathrm{NaOH}}-\mathrm{V}_{\mathrm{HCl}} \mathrm{C}_{\mathrm{HCl}} \mathrm{f}_{\mathrm{HCL}}\right)}{\mathrm{m}} \\
& G S=\frac{0,162 A}{(1-0,0058 A)}
\end{aligned}
$$

em que: $\mathrm{V}_{\mathrm{NaOH}}, \mathrm{C}_{\mathrm{NaOH}}$ e $\mathrm{f}_{\mathrm{NaOH}}$ representam o volume utilizado (em $\mathrm{mL}$ ), a concentração e o fator de correção, respectivamente, da solução de $\mathrm{NaOH} ; \mathrm{V}_{\mathrm{HCl}}, \mathrm{C}_{\mathrm{HCL}}$ e $\mathrm{f}_{\mathrm{HCL}}$ são o volume utilizado (em mL), a concentração e o fator de correção, respectivamente, da solução de $\mathrm{HCl}$; m é a massa de amostra utilizada; GS é o grau de substituição da carboximetilcelulose e pode variar de 0 a 3 (ASTM, 2008; ÜNLÜ, 2013). 


\subsubsection{Caracterização via $R M N$}

A espectroscopia de ressonância magnética nuclear (RMN) é uma técnica que permite a identificar o número, o tipo e a posição de certos átomos nos compostos em análise, por meio da análise das frequências específicas que átomos, como o hidrogênio e o carbono, absorvem radiação eletromagnética, sendo que baseia-se no fato dos átomos de uma molécula não apresentarem mesma densidade eletrônica que geram regiões magnéticas diferentes e, consequentemente, frequência de sinais diferentes.

Assim, a CMC obtida foi caracterizada via RMN sendo utilizado como solvente para obtenção do espectro de hidrogênio $\left({ }^{1} \mathrm{H}-\mathrm{RMN}\right)$ o óxido de deutéreo. Já, o espectro de carbono $\left({ }^{13} \mathrm{C}-\mathrm{RMN}\right)$ foi obtido em estado sólido.

Por meio da análise da relação entre as áreas dos hidrogênios referentes aos $-\mathrm{CH}_{2}$ dos grupos carboximetílicos e dos hidrogênios ligados aos carbonos glicosídicos, foi possível a determinação do grau de substituição (Equação 30).

$$
\mathrm{GS}=\frac{7 x I_{\mathrm{CH}_{2}}}{2 x I_{H A}} \times 100
$$

em que: GS representa o grau de substituição, $\mathrm{I}_{\mathrm{CH}_{2}}$ a integração referente aos hidrogênios carboximetílicos e $\mathrm{I}_{\mathrm{HA}}$ a integração referente aos hidrogênios do anel glicosídico.

Os líquidos iônicos sintetizados foram caracterizados via ${ }^{1} \mathrm{H}-\mathrm{RMN}$ e ${ }^{13} \mathrm{C}-\mathrm{RMN}$, utilizando-se como solvente o clorofórmio deuterado.

Todas as caracterizações via ${ }^{1} \mathrm{H}-\mathrm{RMN}$ foram realizadas em um Espectrômetro de RMN Bruker Avance III 600 HD (14,1 T) equipado com criossonda de detecção inversa de 5 mm (Figura 23), bem como as análises via ${ }^{13} \mathrm{C}-\mathrm{RMN}$ dos LIs. 
Figura 23 - Espectrômetro de RMN Bruker Avance III 600 HD
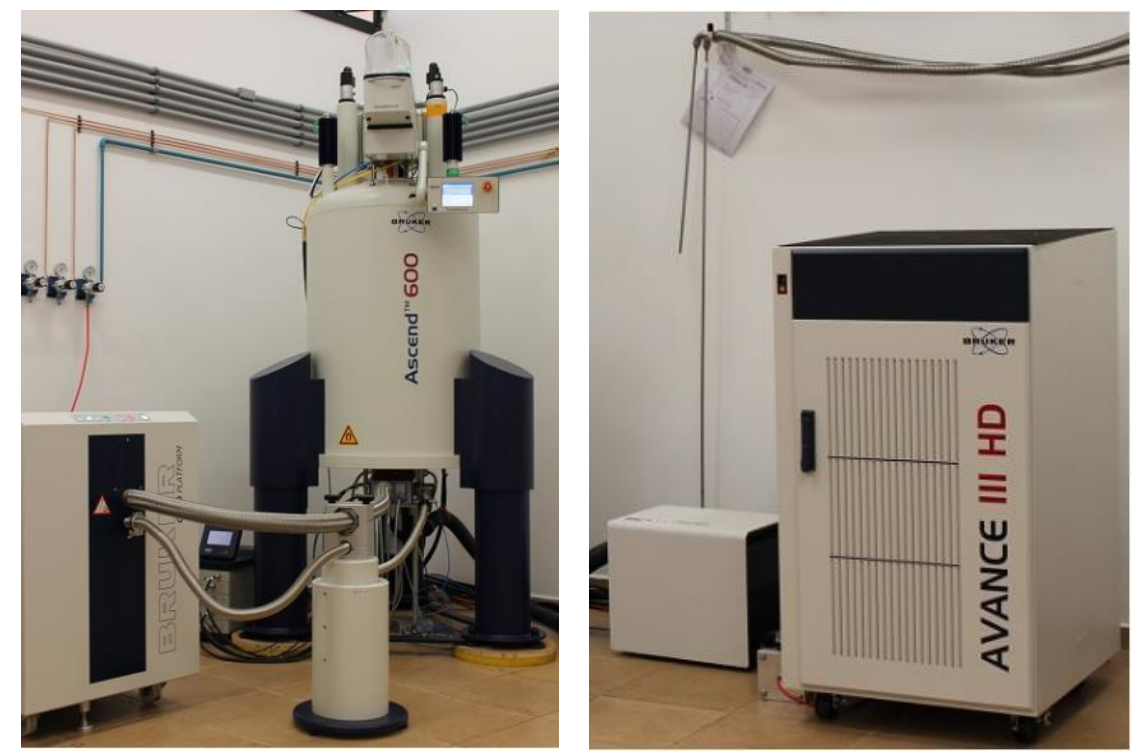

Fonte: Marconcini, 2018

Já, os espectros de ${ }^{13} \mathrm{C}-\mathrm{RMN}$ da $\mathrm{CMC}$, quitosana e adsorventes foram realizadas no estado sólido em um espectrômetro de RMN Bruker Avance III 400 WB (9,4 T) equipado com uma sonda CP/MAS de $4 \mathrm{~mm}$ (Figura 24).

Ambas as análises foram realizadas em parceria com o Instituto de Química - UNESP - Araraquara.

Figura 24 - Espectrômetro de RMN Bruker Avance III 400 WB

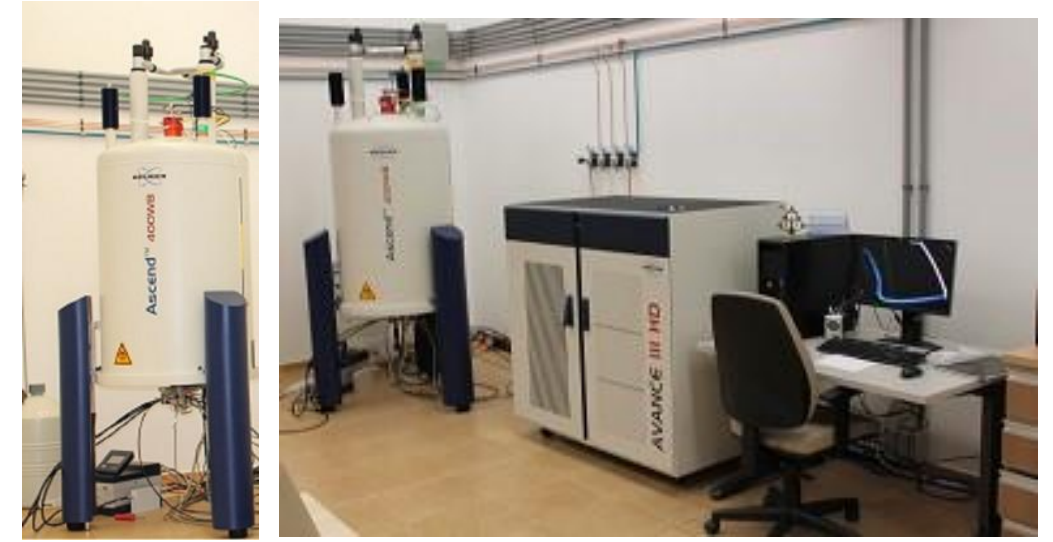

Fonte: Marconcini, 2018 


\subsubsection{Análise Térmica}

Durante a realização das análises térmicas, as amostras (CMC, quitosana, CMCQF e CMCQDIC) foram caracterizadas por calorimetria diferencial exploratória (DSC) e por análise termogravimétrica (TGA) utilizando o analisador térmico Setaram SetSys Evolution 16 (Figura 25), são técnicas que permitem a análise eventos endotérmicos e exotérmicos, bem como a perda de massa relacionadas a esses eventos, quando as amostras são submetidas a aquecimento gradativo a uma taxa constante, permitindo determinar a estabilidade e temperatura de aplicação dos compostos.

Figura 25 - Analisador térmico

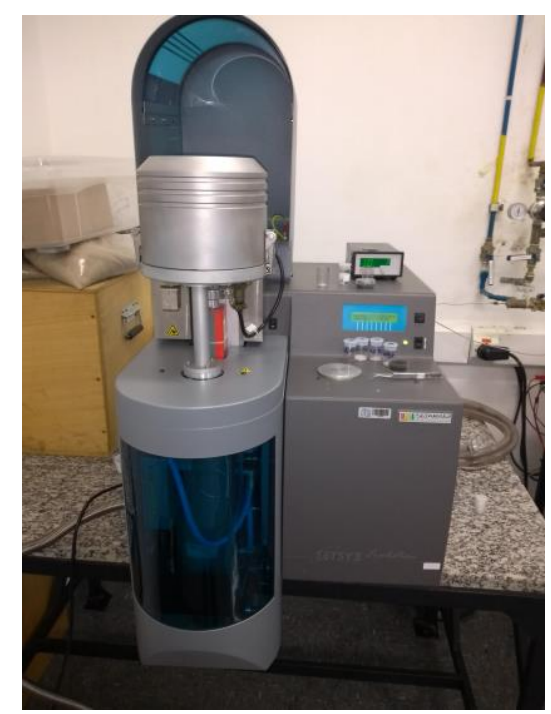

Fonte: Autor

Durante essas análises, utilizou-se uma rampa de aquecimento de 25 a $450{ }^{\circ} \mathrm{C}$ e uma razão de aquecimento de $10{ }^{\circ} \mathrm{C} \cdot \mathrm{min}^{-1}$ com uma atmosfera inerte de nitrogênio com fluxo de 40 $\mathrm{mLmin}^{-1}$ e cadinhos de alumina sem tampa, contendo de 2-3 mg de amostra. Em cada análise as amostras foram reaquecidas e, antes dos ensaios, a célula foi calibrada no eixo da temperatura com índio $\left(\mathrm{T}_{\text {melting }}=156,6^{\circ} \mathrm{C}\right)$ e zinco $\left(\mathrm{T}_{\text {melting }}=419,6^{\circ} \mathrm{C}\right)$ e o eixo de fluxo de calor somente

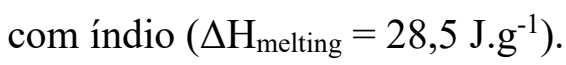




\subsubsection{Distribuição do tamanho de partícula}

A distribuição do tamanho de partícula foi realizada com o equipamento para determinação de tamanho de partícula Microtrac Bluewave (Figura 26), utilizando-se modo de análise via seco e ar como fluido da câmara contendo o sólido.

Figura 26 - Analisador de tamanho de partícula

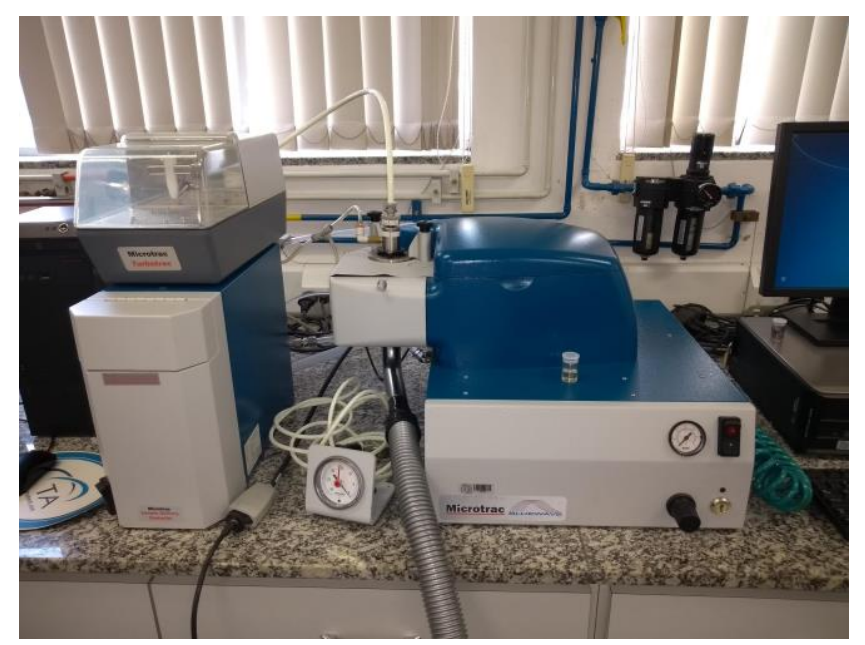

Fonte: Autor

Durante a análise, por meio da incidência de laser na amostra e da medida de espalhamento e, da intensidade da radiação residual com sensores localizados em diferentes posições, foram obtidos os resultados de distribuição média do tamanho de partícula, que permitiu comparar o tamanho de grão entre os adsorventes sintetizados, bem como com os reagentes utilizados na síntese.

\subsubsection{Densidade real}

As densidades reais das amostras foram determinadas por picnometria de gás utilizandose o equipamento Accupys II 1340 Micromeritics (Figura 27). Durante as análises foi utilizado o hélio como gás inerte. Dessa forma, por meio da variação de pressão entre dois recipientes de volumes conhecidos ligados por uma válvula de expansão, um contendo a amostra e, outra onde se realiza a expansão do gás, determinou-se o do volume da amostra e, sabendo-se a massa utilizada, o equipamento realiza o cálculo da densidade real. Com a finalidade de apresentar um resultado com maior precisão foram realizados dez ciclos de medidas. 
Figura 27 - Picnômetro

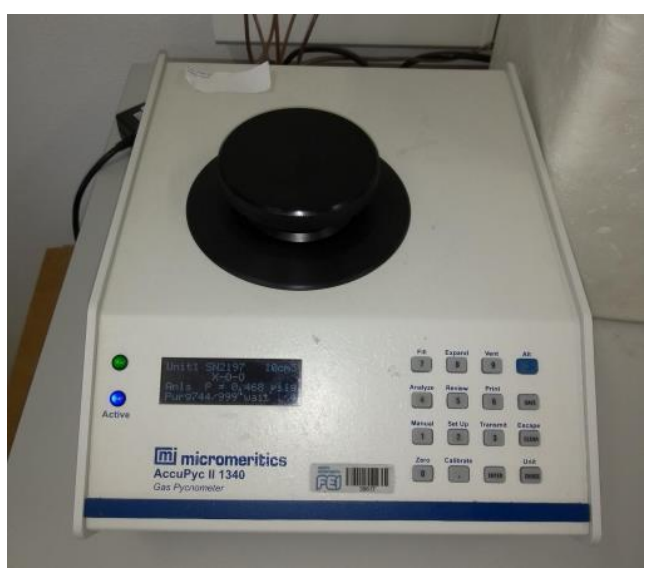

Fonte: Autor

Salienta-se que antes de realizar a análise as amostras são submetidas a purgas de desgaseificação utilizando-se gás hélio com a finalidade de retirar umidade e impurezas, assim foram utilizadas trinta purgas de desgaseificação, não havendo a necessidade de tratamentos prévios nas amostras antes de realizar a medida.

\subsubsection{0 Área superficial}

A área superficial foi determinada no equipamento Micromeritics Gemini VII (Figura 28), de acordo com o tratamento matemático proposto por Brunauer, Emmett e Teller (método B.E.T) a partir da adsorção de gás nitrogênio na superfície da amostra em função da pressão relativa gerada por esse processo. Sendo uma técnica importante, pois a área superficial tornase um importante parâmetros em estudos de adsorção que permite se determinar a efíciência da aplicação do mesmo, bem como aliados a análise de superfície pode fornecer informação sobre mecanismos de transferência de massa e como a adsorção ocorrer nos adsorventes utilizados. 
Figura 28 - Analisador de área superficial

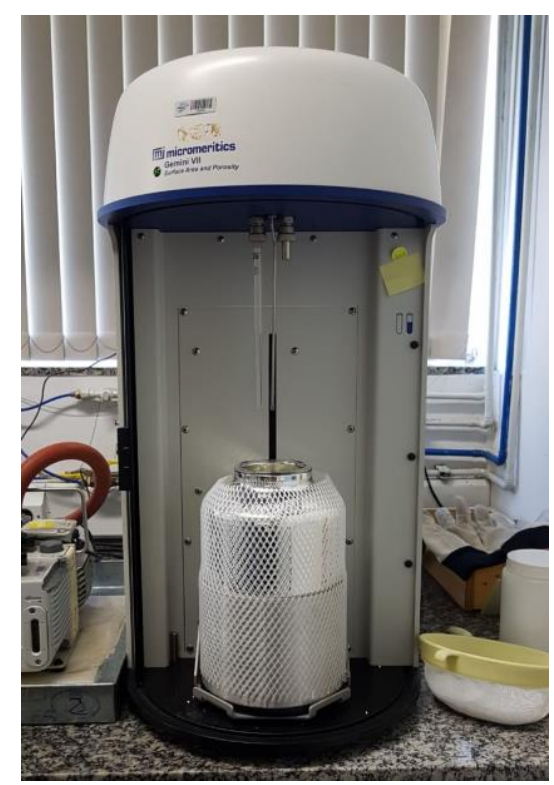

Fonte: Autor

Dessa forma, forma utilizados 5 pontos para determinar a área superficial específica $\left(\mathrm{m}^{2} \cdot \mathrm{g}^{-1}\right)$, sendo que a amostras foram submetidas a um tratamento prévio para retirada de impurezas e umidades, onde as amostras foram mantidas sob vácuo a $80{ }^{\circ} \mathrm{C}$ por 12 horas utilizando-se o equipamento Micromeritics VacPrep.

\subsubsection{Método colorimétrico da difenilcarbazida}

Para a determinação da quantidade de cromo hexavalente das soluções, inicialmente preparou-se a solução de difenilcarbazida diluindo-se $0,125 \mathrm{~g}$ do composto em $25 \mathrm{~mL}$ de acetona e 10 gotas de ácido sulfúrico 72\%, sendo essa solução mantida sem contato com a luz.

Em seguida, $0,2 \mu \mathrm{L}$ da amostra a ser quantificada foram colocados para reagir com 0,2 $\mu \mathrm{L}$ de solução de difenilcarbazida, $10 \mathrm{~mL}$ de água e, uma gota de ácido sulfúrico $72 \%$. O tempo de reação foi de 10 min para que o cromo reagir com a difenilcarbazida, como mostra a figura 29, após esse período, essa solução foi analisada via espectroscopia na região do ultravioleta lendo-se a absorbância a $540 \mathrm{~nm}$. 
Figura 29 - Reação de caracterização do cromo hexavalente

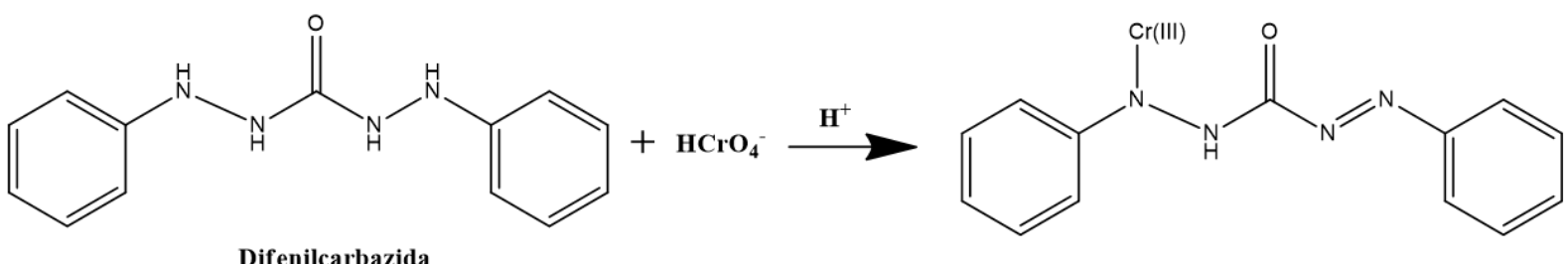

Fonte: Autor

A quantidade de cromo foi calculada mediante uma preparação previa de uma curva de calibração utilizando-se soluções de concentrações de 0 a 250 ppm e realizando-se o mesmo procedimento anteriormente descrito, frente a um branco de preparado com $0,2 \mu \mathrm{L}$ de água como amostra. 


\section{RESULTADOS E DISCUSSÕES}

A seguir encontram-se a discussão dos principais resultados obtidos durante o desenvolvimento do presente trabalho que envolveu, inicialmente, a obtenção da carboximetilcelulose a partir da palha de milho, seguida da síntese dos adsorventes e, por último, a realização dos estudos envolvendo a adsorção de cromo hexavalente.

\subsection{OBTENÇÃO DA CARBOXIMETILCELULOSE (CMC)}

Durante a primeira etapa de desenvolvimento do presente trabalho, foi realizada a obtenção da CMC a partir da palha de milho, sendo necessário, para isso, a realização de tratamentos da mesma visando a redução dos teores de lignina e hemicelulose. Onde, foram utilizados dois processos, um de polpação em meio básico e, outro, de branqueamento utilizando-se peróxido de hidrogênio também em meio básico.

\subsubsection{Tratamento e caracterização da palha de milho}

Durante a realização do tratamento inicial da palha de milho, a mesma foi submetida a dois processos de deslignificação e redução do teor de hemicelulose sendo que, as ilustrações referentes a cada etapa encontram-se na figura 30. Onde, na figura 30A temos a palha de milho bruta, na figura 30B, a mesma após a moagem, bem como as obtidas após cada etapa de tratamento: palha de milho polpada (Figura 30C) e, palha de milho polpada e branqueada (Figura 30D).

Figura 30 - Características da palha de milho no decorrer do tratamento

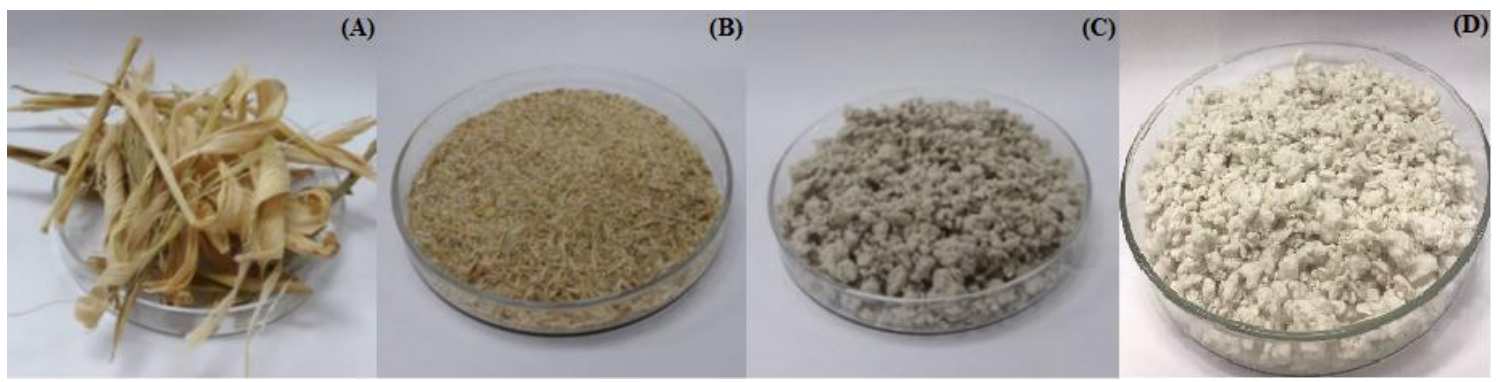

Fonte: Autor

Legenda: (A), (B), (C) e (D) referem-se as palhas bruta, moída, polpada e branqueada, respectivamente. 
Os materiais brutos e tratados foram caracterizados via determinação dos teores de umidade, cinzas, lignina, celulose e hemicelulose, bem como por meio da realização de análises via FTIR, ${ }^{13} \mathrm{C}-\mathrm{RMN}$, DRX e MEV-FEG.

Analisando-se o teor de umidade dos materiais, obtido segundo o item 4.3.7.1.1, verifica-se que as amostras mostraram um baixo teor de umidade, como ilustrado na tabela 8 e que, não ocorreram mudanças significativas no decorrer de cada um dos processos de tratamento.

Tabela 8 - Teores de umidades referentes a cada etapa do processo

\begin{tabular}{c|c}
\hline Amostra & Teor de umidade (\%) \\
\hline Palha de milho bruta & $4,00 \pm 0,04$ \\
\hline Palha de milho polpada & $4,60 \pm 0,06$ \\
\hline Palha de milho branqueada & $4,40 \pm 0,07$ \\
\hline
\end{tabular}

Fonte: Autor

Porém, ao analisar-se o teor de cinzas, obtido pela equação 21 descrita no item 4.3.7.1.2, que descreve a quantidade de compostos inorgânicos presentes na composição de materiais lignocelulósicos, verifica-se uma redução significativa que chega, ao comparar-se a palha de milho bruta com a tratada, em aproximadamente $50 \%$ (Tabela 9).

Tabela 9 - Teores percentuais de cinzas referentes a cada etapa de tratamento

\begin{tabular}{|c|c|c|c|c|}
\hline Amostra & $\mathrm{MC}(\mathrm{g})$ & MA (g) & $\% \mathrm{TC}$ & $\% \mathrm{TC}_{\text {média }}$ \\
\hline \multirow{2}{*}{ Palha de milho bruta } & 1,8557 & 0,0221 & 1,1909 & \multirow{2}{*}{$1,148 \pm 0,043$} \\
\hline & 1,8191 & 0,0201 & 1,1049 & \\
\hline \multirow{2}{*}{ Palha de milho polpada } & 1,8537 & 0,0163 & 0,8793 & \multirow{2}{*}{$0,807 \pm 0,072$} \\
\hline & 1,8646 & 0,0137 & 0,7347 & \\
\hline \multirow{2}{*}{ Palha de milho branqueada } & 1,8311 & 0,0114 & 0,6226 & \multirow{2}{*}{$0,580 \pm 0,042$} \\
\hline & 1,8777 & 0,0101 & 0,5379 & \\
\hline
\end{tabular}

Fonte: Autor

Esse fato se deve, principalmente, a eliminação dos mesmos devido à realização dos tratamentos que promovem a solubilização de diversos compostos inorgânicos e, dessa forma, favorecem a eliminação desses resíduos durante as etapas de polpação e branqueamento.

Com relação ao teor de lignina (Tabela 10), obtida a partir da equação 22 descrita no item 4.3.7.1.3, sendo que do valor original calculado foi necessário descontar a quantidade de 
compostos inorgânicos, percentual de cinzas, uma vez que o método de quantificação de lignina não é capaz de eliminar esses compostos.

Tabela 10 - Teores de lignina referentes a cada etapa de tratamento

\begin{tabular}{c|c|c|c|c}
\hline Amostra & $\mathrm{m}_{\mathrm{t}}$ & $\mathrm{m}_{\text {lig }}$ & \%Lig & \%Lig \\
\hline \multirow{2}{*}{ Palha de milho bruta } & 1,0014 & 0,1278 & 11,61 & \multirow{2}{*}{$11,85 \pm 0,23$} \\
\cline { 2 - 4 } & 1,0033 & 0,1327 & 12,08 & \\
\hline \multirow{2}{*}{ Palha de milho polpada } & 1,0790 & 0,0085 & 0,43 & \multirow{2}{*}{$0,448 \pm 0,017$} \\
\cline { 2 - 4 } & 1,0454 & 0,0086 & 0,46 & \\
\hline \multirow{2}{*}{ Palha de milho branqueada } & 1,0738 & 0,0025 & 0,17 & \multirow{2}{*}{$0,1589 \pm 0,0064$} \\
\cline { 2 - 4 } & 1,0458 & 0,0023 & 0,15 & \\
\hline
\end{tabular}

Fonte: Autor

Assim, analisando os resultados após cada etapa do tratamento, quando comparado a palha de milho bruta com a polpada e a branqueada ocorreu uma deslignificação de $96,22 \%$ e $98,66 \%$, respectivamente, mostrando que o processo de tratamento foi efetivo, pois a lignina, componente do resíduo lignocelulósico responsável por conferir proteção mecânica e, também, inibir reações com agentes externos e esse composto foi praticamente eliminado. Esse fato é de suma importância, pois permite uma maior exposição da celulose para posterior conversão em carboximetilcelulose.

Com relação à porcentagem de holocelulose, que representa a quantificação da celulose e hemicelulose presente na palha de milho, como verificado na tabela 11, nota-se que, conforme avança no processo de tratamento, ocorre o aumento da quantidade de holocelulose. Isso se deve ao fato de a quantidade de lignina diminuir, tendo em vista que as quantidades celulose, hemicelulose e lignina representam quase que a totalidade da massa do resíduo lignocelulósico.

Tabela 11 - Teores de holocelulose referentes a cada etapa do processo de tratamento

\begin{tabular}{c|c|c|c|c}
\hline Amostra & $\mathrm{m}_{\mathrm{m}}(\mathrm{g})$ & $\mathrm{m}_{\text {holo }}(\mathrm{g})$ & \%Holo & \multirow{2}{*}{ \%Holomédia } \\
\hline \multirow{2}{*}{ Palha de milho bruta } & 1,0012 & 0,7756 & 77,47 & \multirow{2}{*}{$77,27 \pm 0,20$} \\
\cline { 2 - 4 } & 1,0019 & 0,7722 & 77,07 & \\
\hline \multirow{2}{*}{ Palha de milho polpada } & 1,0082 & 0,9351 & 92,75 & \multirow{2}{*}{$92,38 \pm 0,37$} \\
\cline { 2 - 4 } & 1,0493 & 0,9654 & 92,00 & \\
\hline \multirow{2}{*}{ Palha de milho branqueada } & 1,0089 & 0,9608 & 95,23 & \multirow{2}{*}{$94,61 \pm 0,63$} \\
\cline { 2 - 4 } & 1,0229 & 0,9613 & 93,98 & \\
\hline
\end{tabular}


Em seguida, com a massa obtida de holocelulose quantificou-se a celulose e a hemicelulose por meio das equações 24,25 e 26 descritas no item 4.3.7.1.4, como demonstrado nas tabelas 12 e 13 .

Tabela 12 - Teores de celulose referentes a cada etapa do processo de tratamento

\begin{tabular}{|c|c|c|c|c|c|c|}
\hline Amostra & $\mathrm{m}_{\text {holo }}$ & $\mathrm{m}_{\mathrm{cel}}$ & $\% \mathrm{Cel}_{\text {holo }}$ & \%Holo & $\% \mathrm{Cel}$ & $\% \mathrm{Cel}_{\text {Médio }}$ \\
\hline \multirow{2}{*}{ Palha de milho bruta } & 0,8101 & 0,7446 & 91,91 & 77,47 & 71,20 & \multirow{2}{*}{$71,79 \pm 0,59$} \\
\hline & 0,7931 & 0,7448 & 93,91 & 77,07 & 72,38 & \\
\hline \multirow{2}{*}{ Palha de milho polpada } & 0,9192 & 0,8082 & 87,92 & 92,75 & 81,55 & \multirow{2}{*}{$81,16 \pm 0,39$} \\
\hline & 0,9658 & 0,8479 & 87,79 & 92,01 & 80,77 & \\
\hline \multirow{2}{*}{$\begin{array}{l}\text { Palha de milho } \\
\text { branqueada }\end{array}$} & 0,9462 & 0,8336 & 88,10 & 95,23 & 83,90 & \multirow{2}{*}{$83,42 \pm 0,48$} \\
\hline & 0,9591 & 0,8465 & 88,26 & 93,98 & 82,94 & \\
\hline
\end{tabular}

Fonte: Autor

Tabela 13 - Teores de hemicelulose referentes a cada etapa de tratamento

\begin{tabular}{c|c|c|c}
\hline Amostra & \%Cel & \%Hemi & \%Hemi \\
\hline \multirow{2}{*}{ Palha de milho bruta } & 71,20 & 28,80 & \multirow{2}{*}{$28,21 \pm 0,59$} \\
\cline { 2 - 3 } & 72,38 & 27,62 & \\
\hline \multirow{2}{*}{ Palha de milho polpada } & 81,55 & 18,45 & \multirow{2}{*}{$18,84 \pm 0,39$} \\
\cline { 2 - 3 } & 80,77 & 19,23 & \\
\hline \multirow{2}{*}{ Palha de milho branqueada } & 83,90 & 16,10 & \multirow{2}{*}{$16,58 \pm 0,48$} \\
\cline { 2 - 3 } & 82,94 & 17,06 & \\
\hline
\end{tabular}

Fonte: Autor

Com relação aos teores de celulose e hemicelulose, que juntas representam a holocelulose, verifica-se que, após a realização dos dois tratamentos, ocorreu um aumento de $16,20 \%$ no teor de celulose e, uma redução de 41,23 \% no teor de hemicelulose, o que reafirma a efetividade do tratamento de deslignificação adotado e corroborando com os dados obtidos por Candido; Gonçalves (2016), que obtiveram valores semelhantes ao trabalhar com processos de deslignificação do bagaço de cana visando a produção de acetato de celulose.

Também foram realizadas caracterizações via FTIR, ${ }^{13} \mathrm{C}-\mathrm{RMN}$ no estado sólido e DRX sendo que, os dados obtidos corroboram com os resultados iniciais referentes a caracterização química para a celulose proveniente da palha de milho (Figura 31). 
Figura 31 - Unidade glicosídica

da celulose

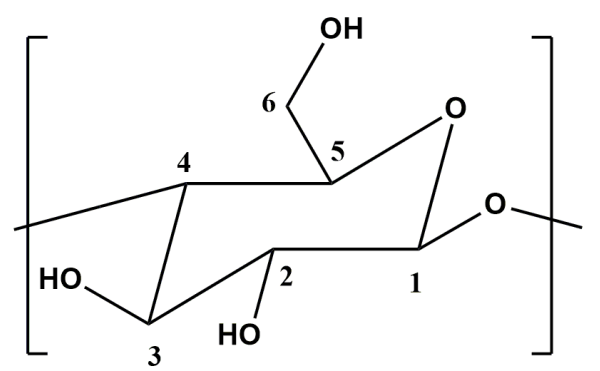

Fonte: Autor

Dessa forma, por meio da análise do espectro obtido via FTIR-ATR é possível verificar a redução das bandas referentes a presença de aromáticos, na região de 1500 a $1650 \mathrm{~cm}^{-1}$ e de 1440 a $1500 \mathrm{~cm}^{-1} \mathrm{e}$, o aumento da banda na região entre 3400 a 3000, referente à ligação $\mathrm{OH}$ da celulose e, referente às ligações $\mathrm{C}-\mathrm{O}$ e C-C da celulose entre, aproximadamente, 900-1200 $\mathrm{cm}^{-1}$ (Figura 32) (FONTES et al., 2018; YANG et al., 2017; CANDIDO; GONÇALVES, 2016; MASTRANTONIO et al., 2015).

Figura 32 - Comparação entre os espectros de FTIR da palha de milho bruta e tratada

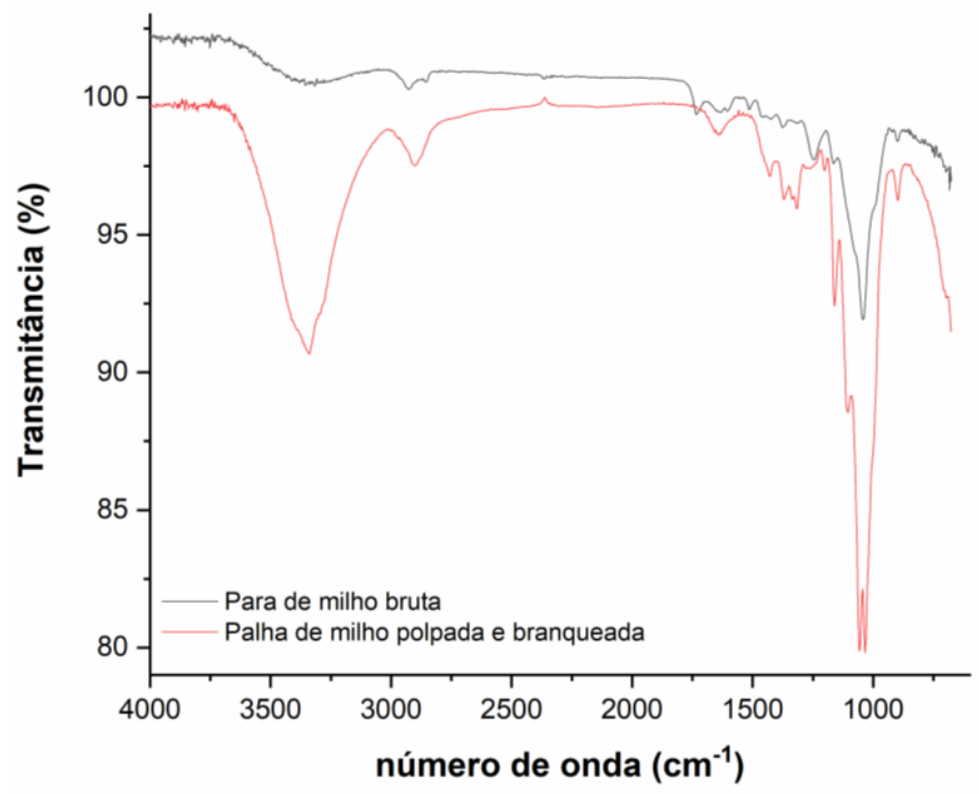

Fonte: Autor

Com relação a análise via ${ }^{13} \mathrm{C}-\mathrm{RMN}$, que foi realizada com as amostras no estado sólido, (Figura 33) verifica-se ausência de sinais referentes a aromáticos na região entre 120 e 140 ppm, bem como a presença de sinais característicos da celulose em 105, 94; 70 a 75; 58 a 63 e; 
89 ppm, referentes as posições 1, 2, 3, 5, 6 e 4, respectivamente, confirmando a redução dos teores de lignina e, assim, obtenção da celulose.

Figura 33 - Espectro de ${ }^{13} \mathrm{C}-\mathrm{RMN}$ no estado sólido da palha de milho após o tratamento a $9,4 \mathrm{~T}$

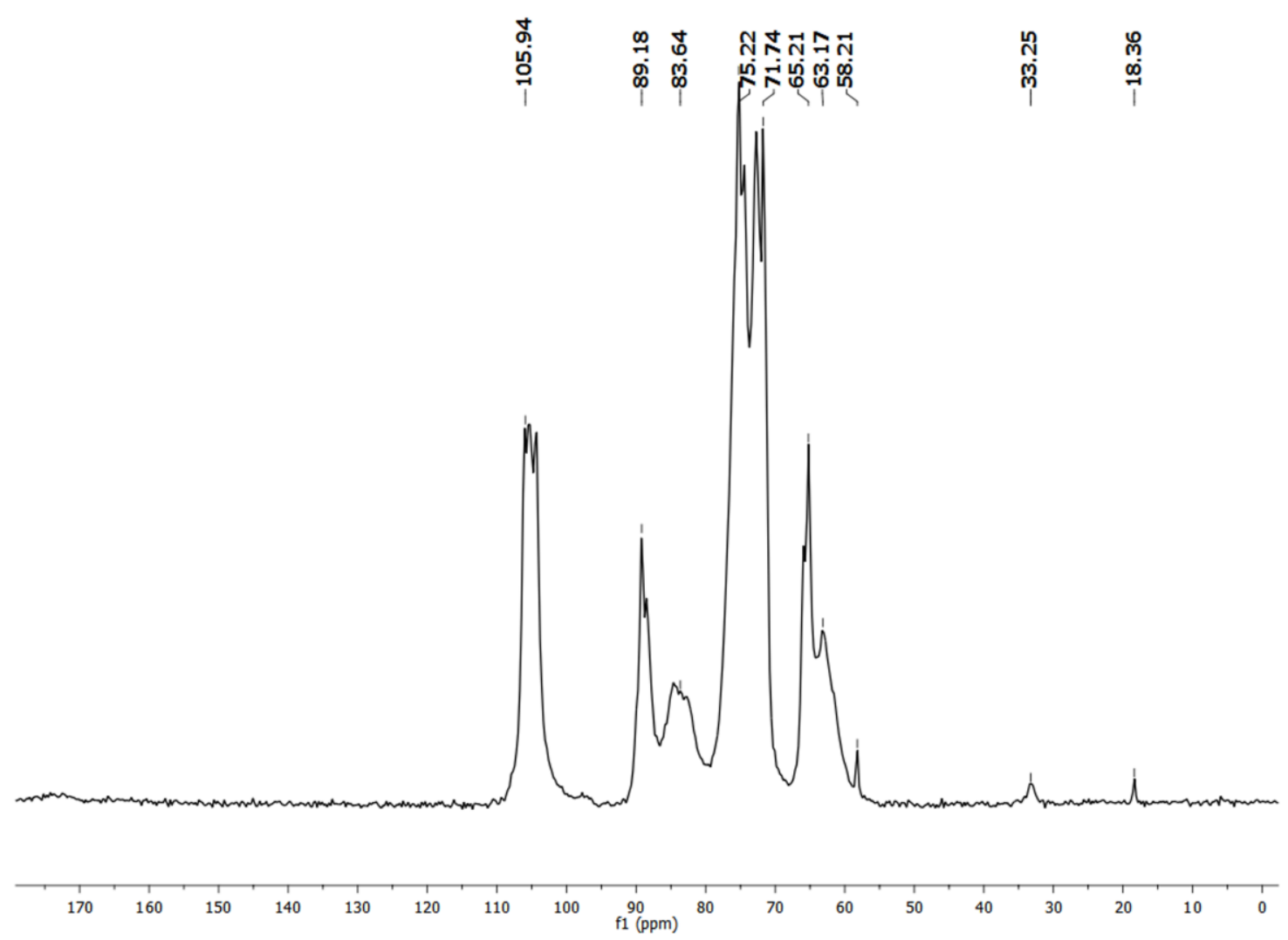

Fonte: Autor

Já, por meio da caracterização realizada via DRX (Figura 34), verifica-se a presença de picos em aproximadamente $2 \theta=16^{\circ}$ e $22^{\circ}$ correspondente aos planos (101) e (002) da celulose tipo 1 em ambos os difratogramas porém, com intensidades diferentes sendo verificada um aumento no índice de cristalinidade após a realização dos tratamentos (Tabela 14) corroborando com resultados observados por Yang e colaboradores (2017) e, Fontes et al. (2018). 
Figura 34 - Comparação entre os difratogramas obtidos para as palhas bruta e tratadas

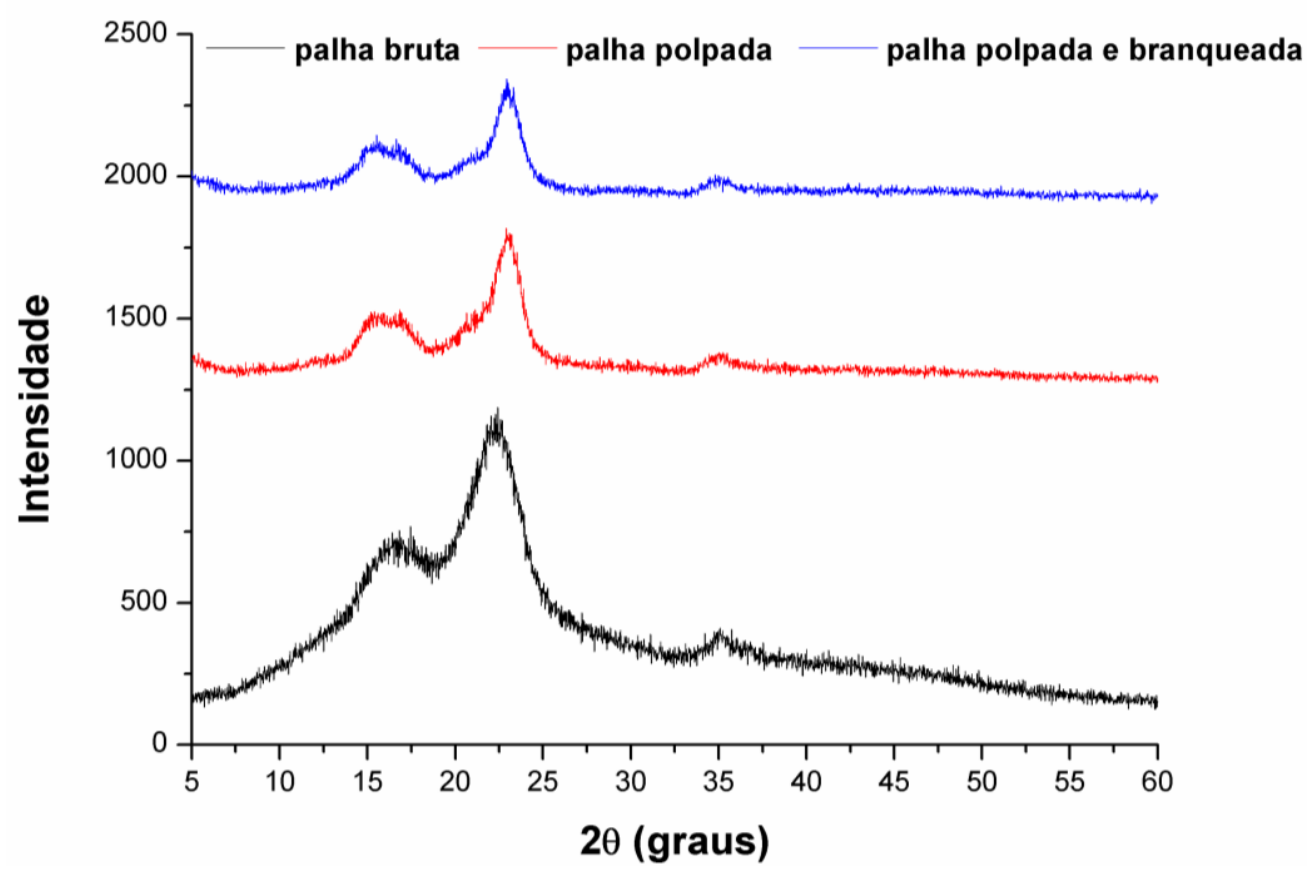

Fonte: Autor

Tabela 14 - Índice de cristalinidade para as palhas bruta e tratadas

\begin{tabular}{c|c}
\hline Amostra & IC (\%) \\
\hline Palha Bruta & 40,30 \\
Palha Polpada & 48,30 \\
Palha Polpada e Branqueada & 63,38
\end{tabular}

Fonte: Autor

Portanto, pode-se verificar que quanto menor a quantidade de lignina e hemicelulose presente no material lignocelulósico, maior o índice de cristalinidade da amostra, já que a fase cristalina está relacionada com o arranjo molecular típico da celulose.

Por meio das micrografias obtidas via MEV-FEG (Figura 22) pode-se notar mudanças na morfologia da palha bruta (Figura 35A) em relação a palha polpada (Figura 22B) e branqueada (Figura 22C), devido a ruptura no complexo cristalino do resíduo lignocelulósico com o ataque e redução dos teores de lignina e hemicelulose. 
Figura 35 - Micrografias referentes a cada etapa de tratamento da ampliação de 10.000x

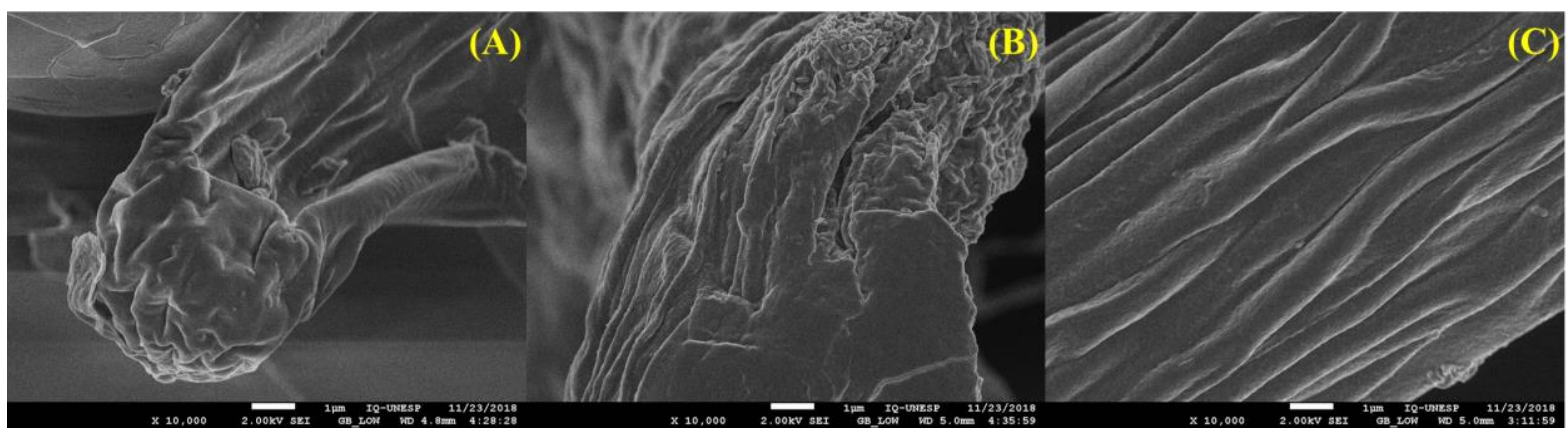

Fonte: Autor

Legenda: (A), (B) e (C) referem-se a micrografias das palhas bruta, polpada e, branqueada, respectivamente.

Assim, conforme necessário para a realização da primeira etapa do projeto, que consiste na obtenção da carboximetilcelulose $(\mathrm{CMC})$, o processo de pré-purificação da celulose proveniente da palha de milho foi efetivo, promovendo a redução dos teores de lignina e hemicelulose, que foram praticamente solubilizados, conforme reportado por outros autores e, assim, foi possível a síntese do derivado celulósico, a CMC. (FONTES et al., 2018; YANG et al., 2017; CANDIDO; GONÇALVES, 2016; MASTRANTONIO et al., 2015)

\subsubsection{Síntese e caracterização da carboximetilcelulose}

Tendo em vista os resultados obtidos anteriormente, a palha de milho encontrou-se apta para ser convertida em carboximetilcelulose (CMC), pois atingiu-se níveis significativos de deslignificação que contribui para melhor contato entre celulose e os reagentes necessários para a conversão.

Dessa forma, utilizando a metodologia anteriormente descrita, foi possível a síntese da CMC, como demostrado pelo mecanismo representado na figura 36 , em que a adição da base propiciou a abstração do hidrogênio da hidroxila que, em seguida, promoveu a reação de substituição nucleofílica do cloro presente no monocloroacetato de sódio. 
Figura 36 - Representação do mecanismo de síntese da carboximetilcelulose
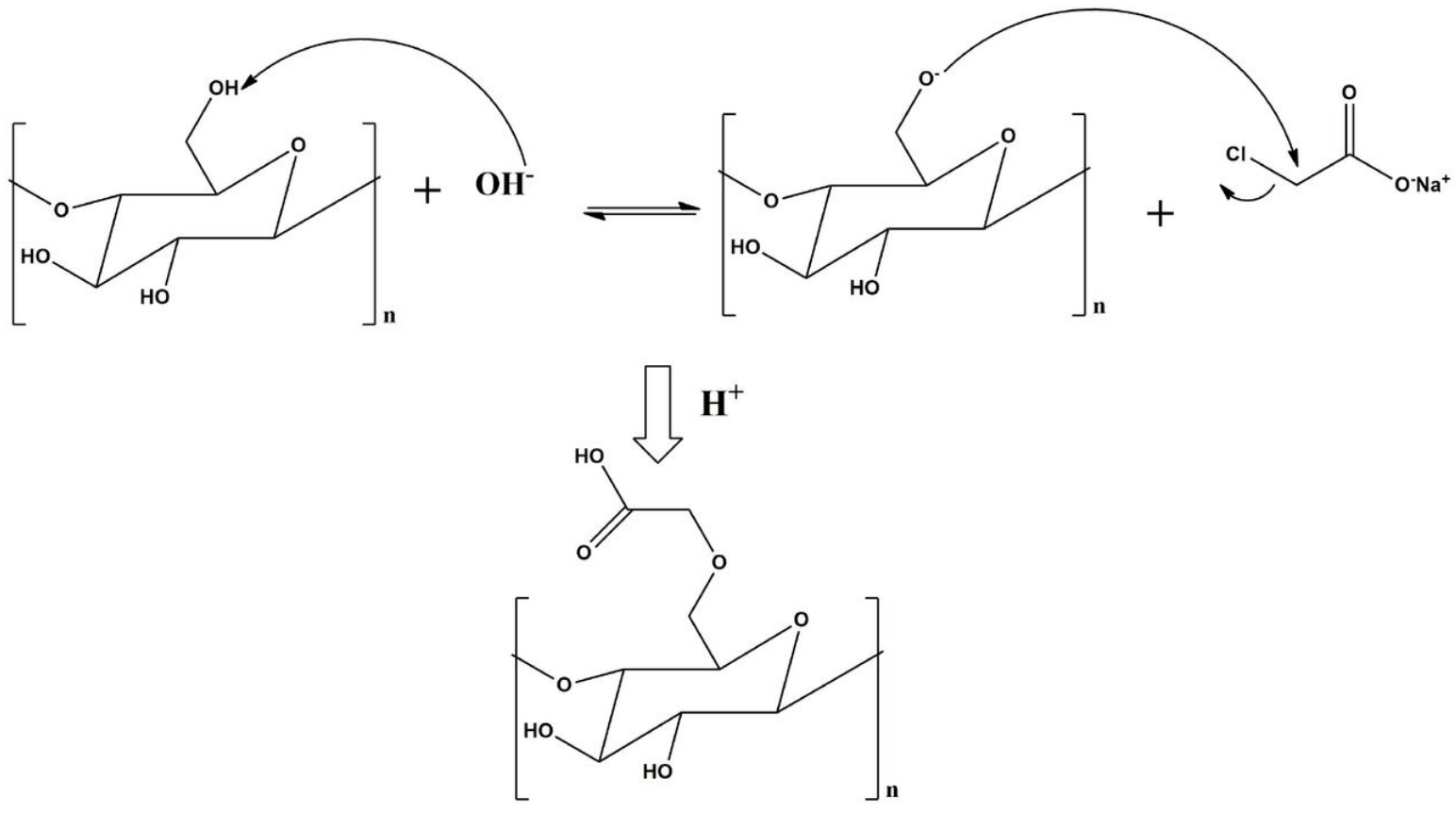

Fonte: Autor

Porém, no intuito verificar a formação da $\mathrm{CMC}$, realizou-se a análise via $\mathrm{FTIR},{ }^{13} \mathrm{C}$ RMN utilizando-se a amostra no estado sólido, ${ }^{1} \mathrm{H}-\mathrm{RMN}$ utilizando-se como solvente óxido de deutério e, determinação do grau de substituição.

Ao analisar-se os dados de FTIR (Figura 37), verifica-se a presença das principais bandas características do composto desejado, a CMC, sendo possível observar a presença de bandas referentes a ligação O-H entre 3250 a $3500 \mathrm{~cm}^{-1}$, porém com intensidade reduzida quando em relação ao espectro da palha branqueada, de $\mathrm{C}=\mathrm{O}$ em $1650 \mathrm{~cm}^{-1}$, de C-O e C-C entre 900 e $1200 \mathrm{~cm}^{-1}$, o que caracteriza a eterificação da celulose presente na palha de milho branqueada (FONTES et a., 2018; CERRUTTI et al., 2017, CANDIDO; GONÇALVES, 2016; PAVIA et al., 2015) 
Figura 37 - FTIR comparativo entre CMC sintetizada, comercial e da palha de milho.

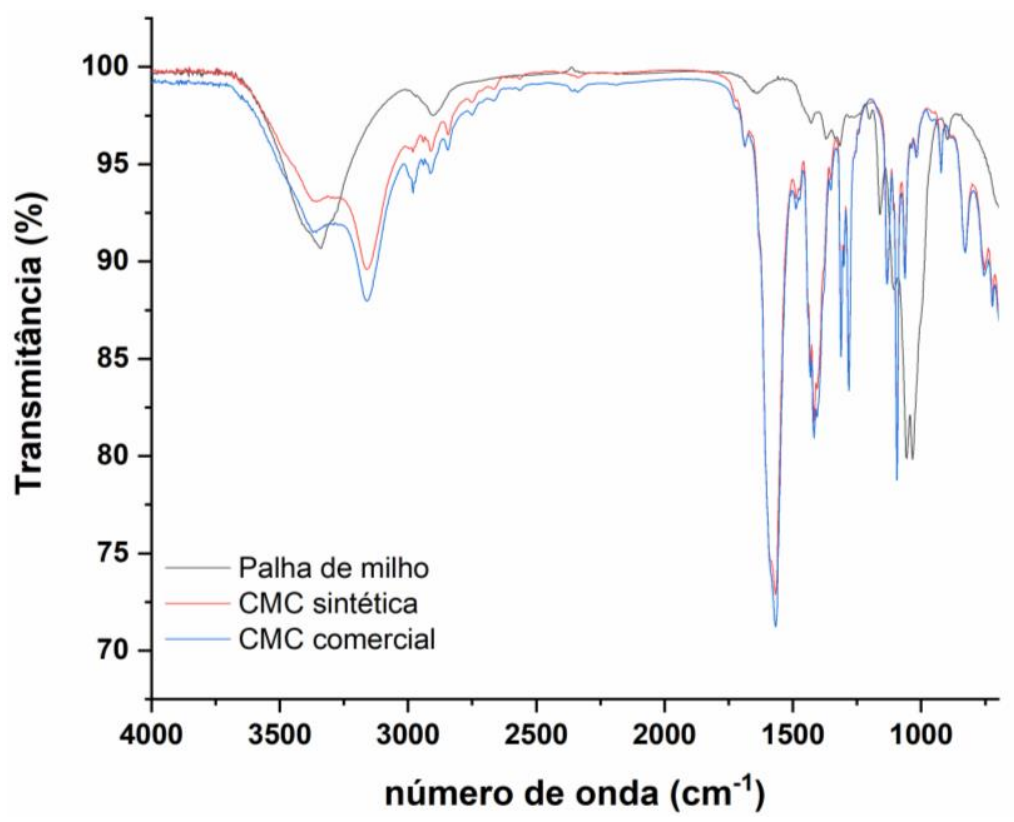

Fonte: Autor

Com relação a análise via RMN, comparando os espectros da CMC e da palha de milho branqueada (Figura 38), no espectro de ${ }^{13} \mathrm{C}-\mathrm{RMN}$ da carboximetilcelulose nota-se a presença de sinais entre 175 e 185 ppm e, também, em 75 ppm ausentes na espectro de ${ }^{13} \mathrm{C}-\mathrm{RMN}$ da celulose, referentes a presença carbonilas e do grupo carboximetílico $\left(-\mathrm{CH}_{2}\right)$, respectivamente, como demostrado pelo mecanismo de reação (Figura 36), comprovando a formação efetiva do derivado celulósico, a CMC (BISWAS et al., 2014; PAVIA et al., 2015).

Análises via ${ }^{1} \mathrm{H}-\mathrm{RMN}$ (Figura 39) corroboraram com os dados de carbono e mostraram a presença de sinais entre 3,20 e 3,81 ppm e, também, um sinal em 4,53 referentes aos hidrogênios das posições de 1 a 6 (Figura 40) e, dois sinais em 4,08 e, 4,25 ppm atribuídos aos hidrogênios dos grupos carboximetílicos $\left(-\mathrm{CH}_{2}\right)$ da $\mathrm{CMC}$ e um grau de substituição de 2,01, confirmando a obtenção da carboximetilcelulose substituída em duas posições (PAVIA et al., 2015; ÜNLÜ, 2013). 
Figura 38 - Comparação entre os espectros de ${ }^{13} \mathrm{C}-\mathrm{RMN}$ para a CMC e celulose no estado sólido a 9,4 T

Carboximetilcelulose

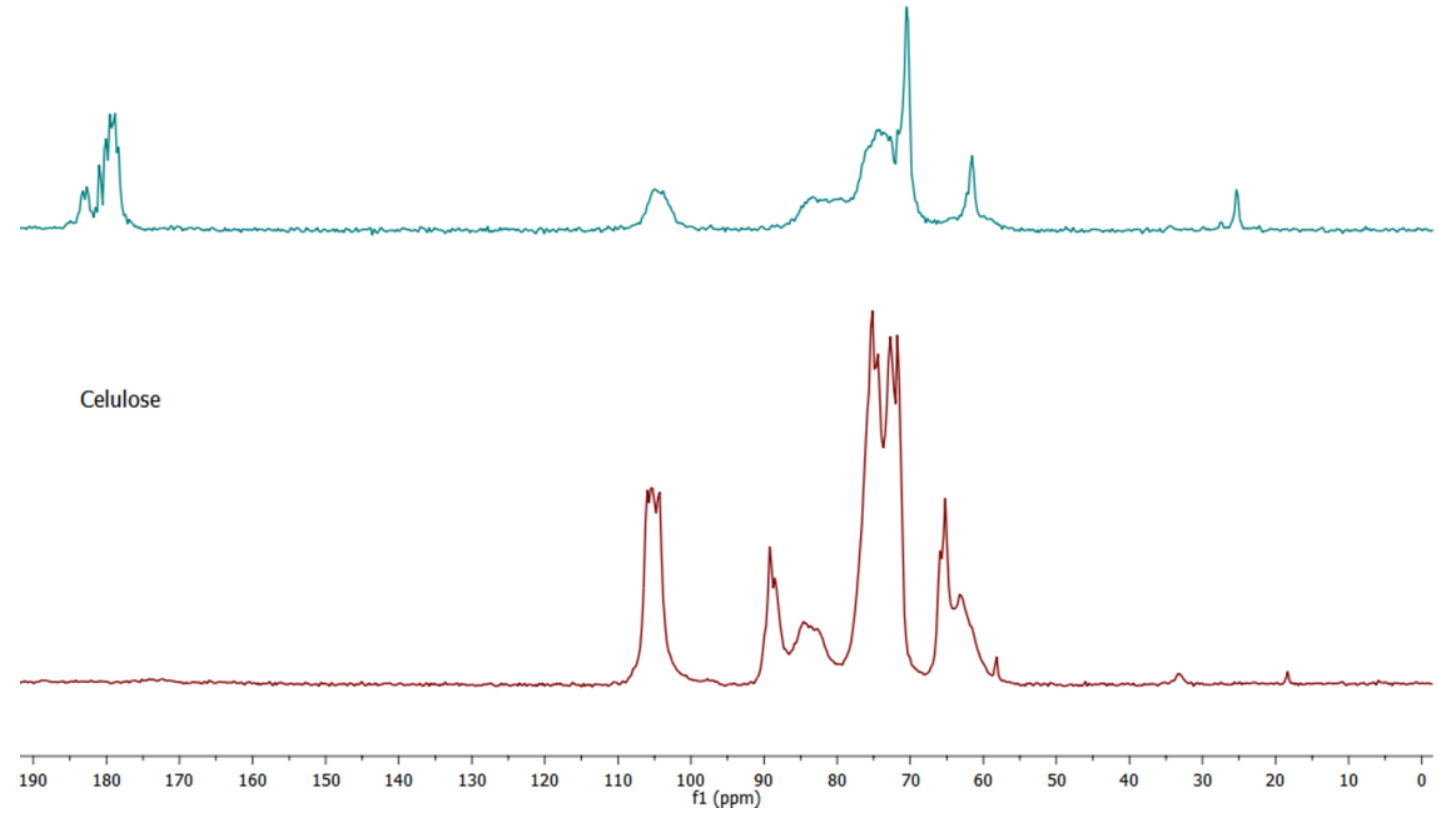

Fonte: Autor

Figura 39 - Ampliação do espectro de ${ }^{1} \mathrm{H}-\mathrm{RMN}$ para a CMC utilizando como solvente $\mathrm{D}_{2} \mathrm{O}$ a $14,1 \mathrm{~T}$

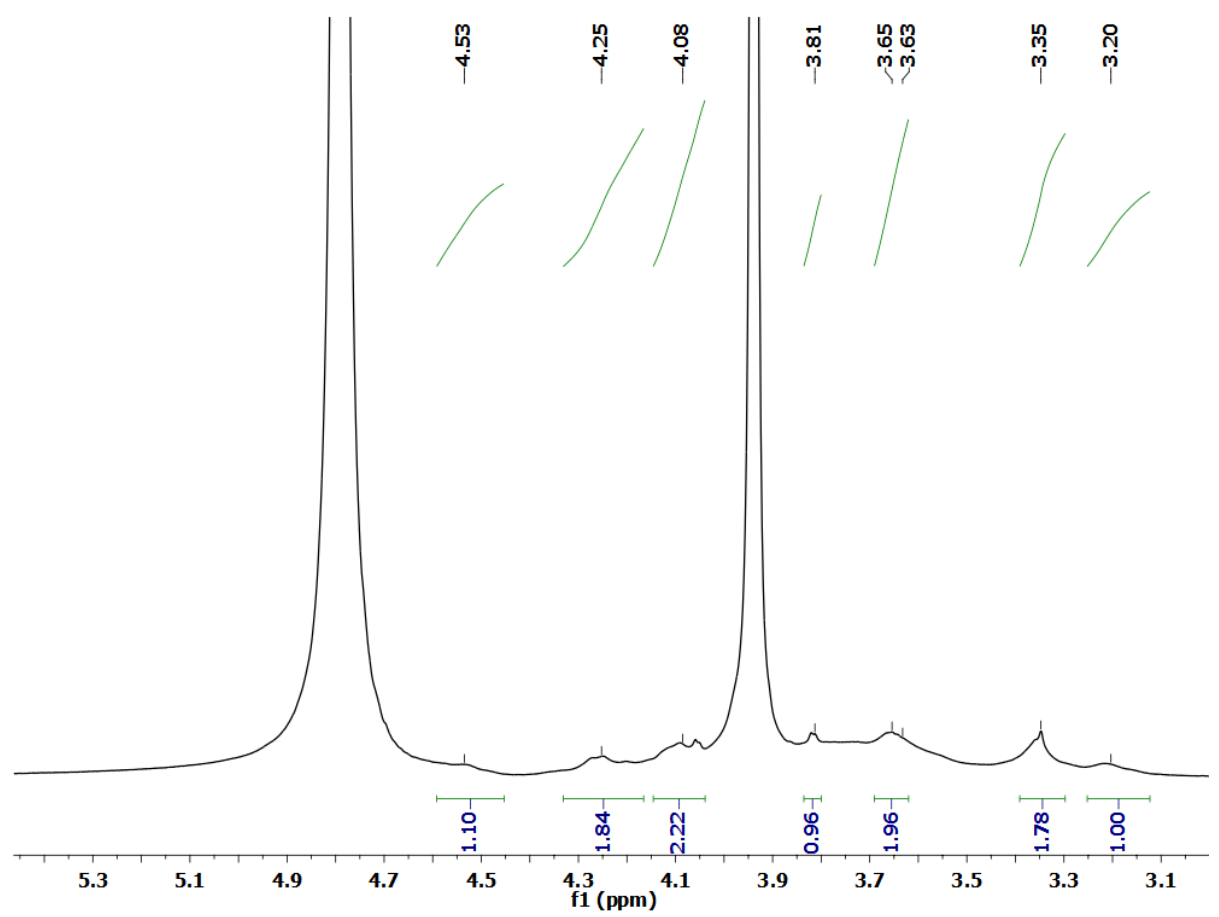

Fonte: Autor 
Figura 40 - Representação da unidade de repetição da celulose e CMC
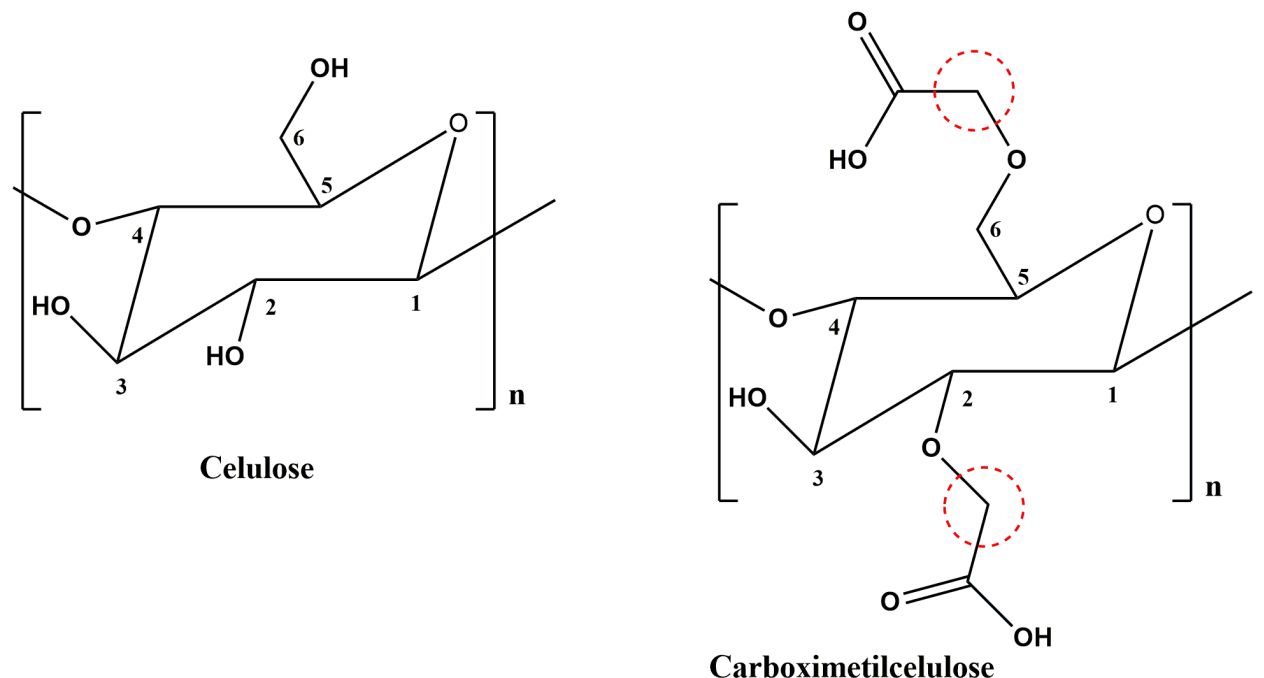

Fonte: Autor

Uma vez que, cada unidade de repetição da celulose apresenta três hidroxilas livres que são passíveis de sofrerem reações, a CMC sintetizada foi submetida a caracterização via titulação para confirmação do grau de substituição (GS), sendo que os resultados são apresentados na tabela 17.

Para o cálculo do método de titulação foram utilizadas uma solução de $\mathrm{HCl}$ e $\mathrm{NaOH}$ de 0,05 mol. $\mathrm{L}^{-1}$, com fatores de correção de 1,005 e 1,000, respectivamente. A massa de amostra utilizada e volume de titulante $(\mathrm{HCl})$ encontram-se na tabela 15 , sendo os cálculos realizados utilizando as equações 28 e 29 descritas no item 4.3.7.5. O volume de $\mathrm{NaOH}$ utilizado em cada amostra foi de $62,5 \mathrm{~mL}$.

Tabela 15 - Dados de empregados no cálculo do GS por titulometria

\begin{tabular}{c|c|c}
\hline Amostra & Massa de amostra $(\mathrm{g})$ & Volume de titulante $(\mathrm{mL})$ \\
\hline 1 & 0,2549 & 10,5 \\
\hline 2 & 0,2574 & 9,3 \\
\hline 3 & 0,2583 & 9,1 \\
\hline
\end{tabular}

Fonte: Autor

Para a realização do cálculo do grau de substituição por meio da análise do espectro de ${ }^{1} \mathrm{H}-\mathrm{RMN}$, foi utilizada a relação entre a soma das integrais referentes aos sinais dos hidrogênios glicosídicos e os sinais dos hidrogênios carboximetílicos (Tabela 16), utilizando a equação 30 descrita no item 4.3.7.6. 
Tabela 16 - Deslocamentos químicos e integrais referentes ao espectro de ${ }^{1} \mathrm{H}-\mathrm{RMN}$ para a $\mathrm{CMC}$

\begin{tabular}{c|c|c}
\hline & $\delta \mathrm{H}$ & $\mathrm{I}_{\mathrm{HA}}$ \\
\hline \multirow{3}{*}{ Hidrogênios } & 3,20 & 1,00 \\
Glicosídicos & 3,35 & 1,78 \\
& $3,65-3,63$ & 1,96 \\
& 3,81 & 0,96 \\
& 4,53 & 1,10 \\
\hline & $\delta \mathrm{H}$ & $\mathrm{I}_{\mathrm{CH}_{2}}$ \\
\hline Hidrogênios & 4,08 & 2,22 \\
Carboximetílicos & 4,25 & 1,84 \\
\hline
\end{tabular}

Fonte: Autor

Como o valor do grau de substituição GS pode variar de 0 a 3 , onde 0 seria para a celulose pura e 3 para uma conversão total da celulose em carboximetilcelulose e o resultado encontrado foi próximo a 2 para ambas a análises (Tabela 17), sugere-se que a reação de eterificação ocorreu em duas hidroxilas (ÜNLÜ, 2013).

Tabela 17 - Resultados Referentes ao GS da CMC

\begin{tabular}{c|c}
\hline Metodologia & Grau de substituição \\
\hline RMN & 2,01 \\
Titulação & $1,83 \pm 0,01$ \\
\hline
\end{tabular}

Fonte: Autor

\subsection{OBTENÇÃO DOS ADSORVENTES E TESTE INICIAL DE ADSORÇÃO}

Uma vez confirmada a obtenção da carboximetilcelulose, foi possível, em seguida, a obtenção dos novos adsorventes modificados pela introdução da quitosana. Para isso, foram utilizadas três metodologias diferentes, uma utilizando o PVA (Figura 41), outra utilizando o ácido ferúlico (Figura 42) e, a última, utilizando o DIC (Figura 43) sendo obtidos os adsorventes CMCQPVA, CMCQF e CMCQDIC.

Analisando-se as propostas de mecanismos envolvidas em cada caso verifica-se, na formação do adsorvente CMCQPVA, a provável reação entre as hidroxilas do PVA e as carboxilas tanto da CMC, quanto da CMQ, favorecidas em meio ácido. 
Já, na formação do material CMCQF, verifica-se a reação entre a hidroxila posição 5 da quitosana com a carboxila do ácido ferúlico, seguida da reação de substituição eletrofílica no anel aromático do ácido ferúlico e, com isso, introdução da CMC.

Com relação ao último material sintetizado, a CMCQDIC, verifica-se a reação entre o grupo amino da quitosana com o DIC e, também, a reação de esterificação entre as hidroxilas livres da quitosana com as carboxilas da CMC.

Figura 41 - Proposta de mecanismo para a obtenção do adsorvente CMCQPVA
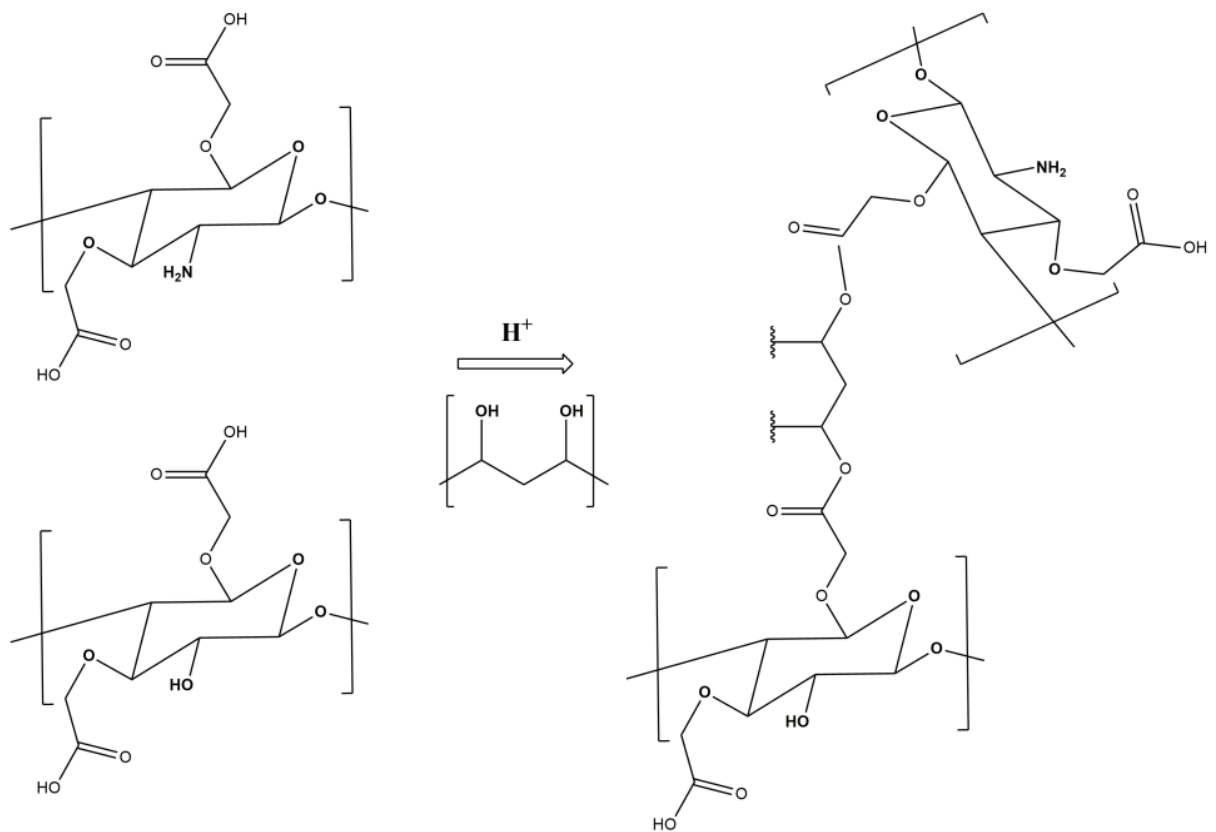

Fonte: Autor 
Figura 42 - Proposta de mecanismo para a obtenção do adsorvente CMCQF
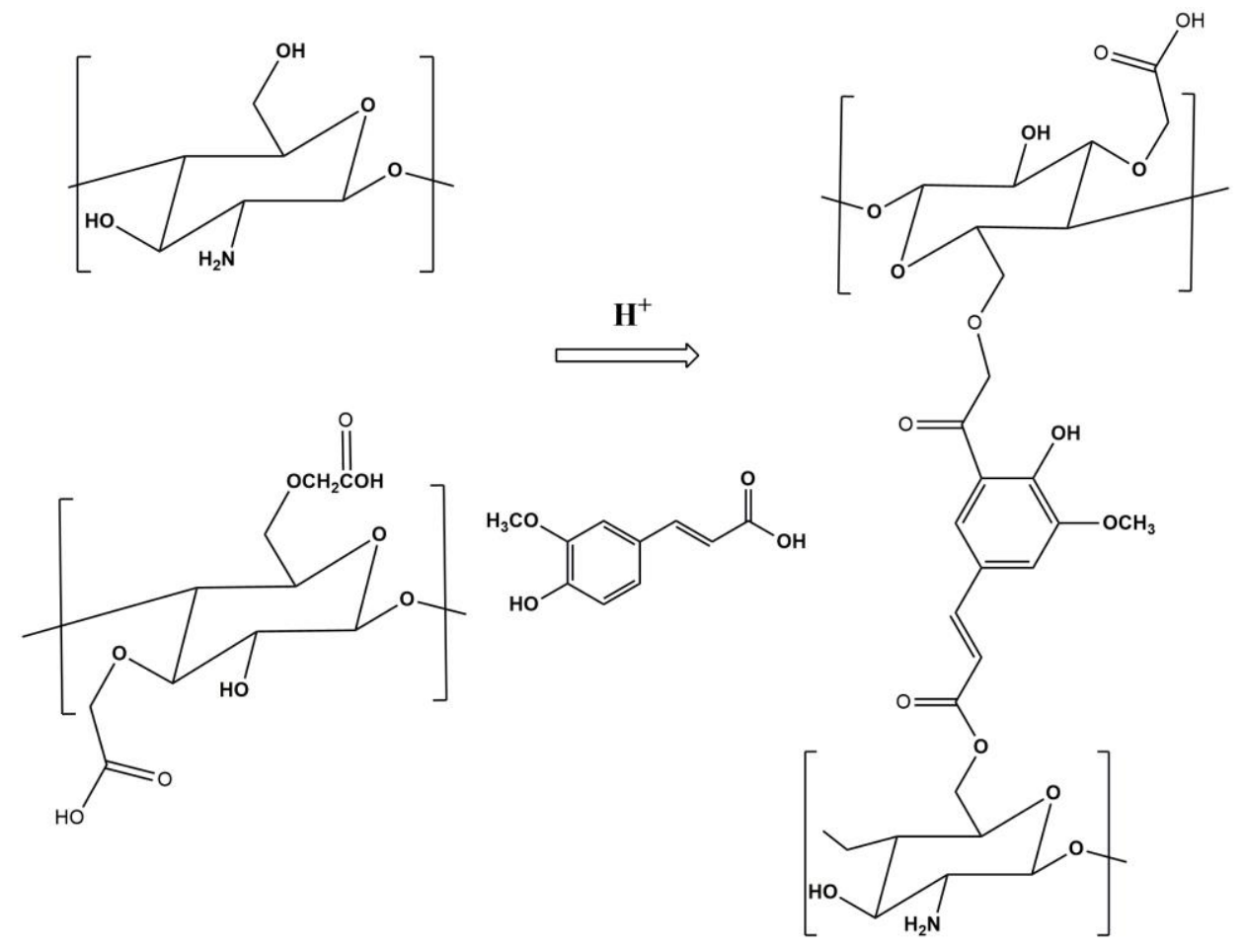

Fonte: Autor

Figura 43 - Proposta de mecanismo para a obtenção do adsorvente CMCQDIC
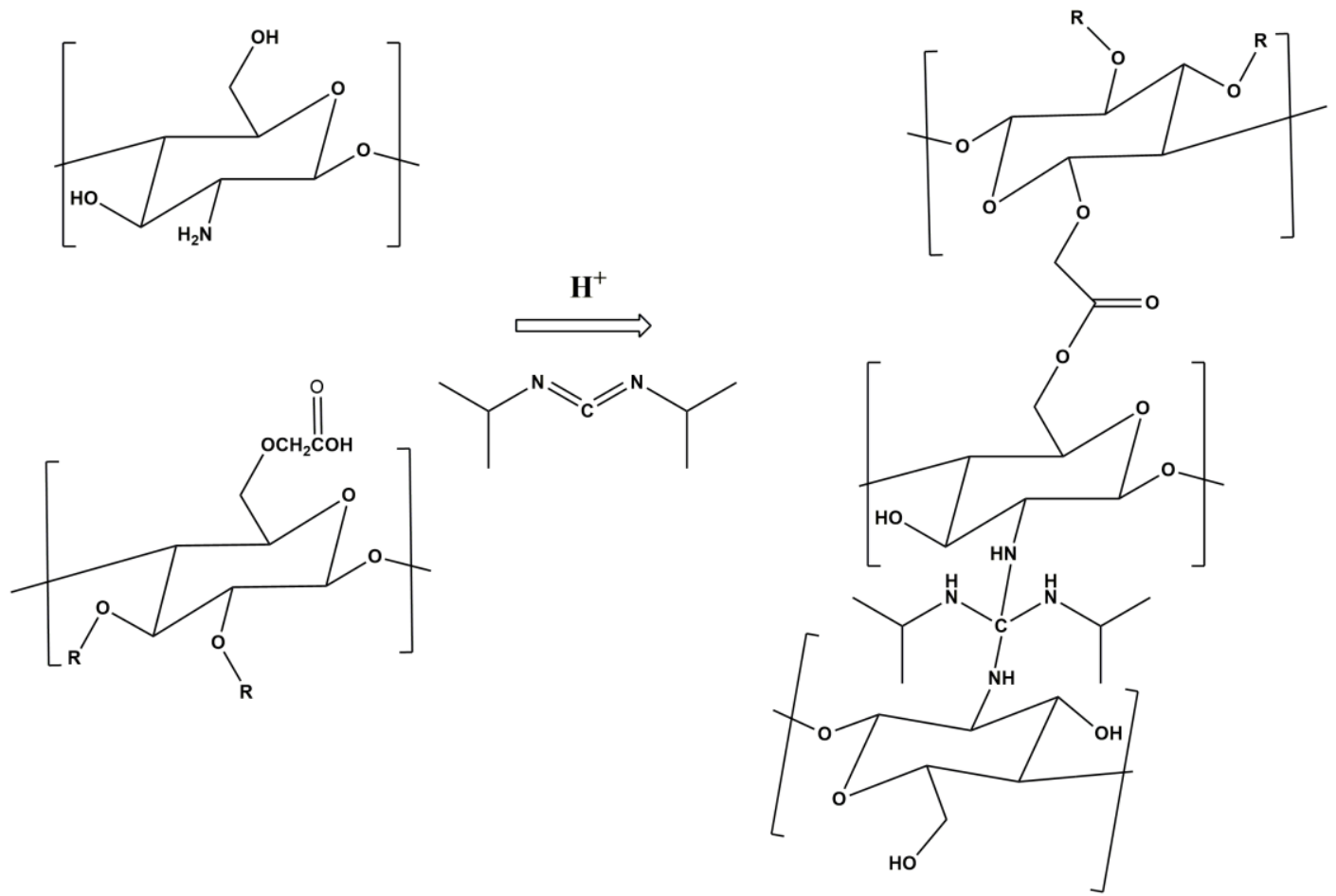

Fonte: Autor 
Após a obtenção dos três novos materiais, com o intuito de verificar a eficiência dos novos adsorventes, quando comparado a quitosana, que é um material muito utilizado nesta operação, foram realizados testes preliminares de adsorção de cromo hexavalente e, conforme resultados apresentados na tabela 18, nota-se um aumento da capacidade de adsorção em relação aos adsorventes CMCQDIC e CMCQF, respectivamente, sendo esses os adsorventes que passaram a ser objeto de estudo no presente trabalho.

Tabela 18 - Resultados preliminares de capacidade de adsorção

\begin{tabular}{c|c|c|c}
\hline Amostras & $\begin{array}{c}\text { Concentração } \\
\text { Inicial }(\mathrm{ppm})\end{array}$ & $\begin{array}{c}\text { Concentração final } \\
(\mathrm{ppm})\end{array}$ & $\begin{array}{c}\text { Capacidade de adsorção } \\
\left(\mathrm{mg} \cdot \mathrm{g}^{-1}\right)\end{array}$ \\
\hline Quitosana & & $202,13 \pm 0,00$ & $50,34 \pm 2,59$ \\
CMCQDIC & $307,10 \pm 1,23$ & $143,50 \pm 1,15$ & $80,81 \pm 3,62$ \\
CMCQPVA & & $275,53 \pm 1,23$ & $15,50 \pm 1,00$ \\
CMCQF & & $148,01 \pm 1,64$ & $77,24 \pm 1,76$ \\
\hline
\end{tabular}

Fonte: Autor

Quanto ao material CMCQPVA, houve uma piora na capacidade de adsorção devido ao fato de a quitosana não ter reagido de forma significativa para a formação do composto desejado.

Salienta-se também que, possivelmente, a maior capacidade de adsorção observada para adsorvente CMCQDIC se deve a introdução de novos grupos aminos na estrutura uma vez que, conforme reportado na literatura, a adsorção de íons de metais pesados como os de cromo hexavalente ocorrem devido a presença de grupos aminos presentes em quitosana e derivados (ELEIODÓRIO et al., 2017, KUMAR et al., 2012).

Assim, os materiais escolhidos para a realização da próxima etapa, CMCQF e, CMCQDIC, foram caracterizados via ${ }^{13} \mathrm{C}-\mathrm{RMN}$, FTIR, DSC, TGA, determinação da densidade, determinação da área superficial e, do tamanho de partícula e, após essa etapa, foi iniciada a etapa final de aplicação dos adsorventes e determinação das condições ideais de tratamento de efluentes contendo íons cromo hexavalente.

\subsection{CARACTERIZAÇÃO DOS ADSORVENTES ESCOLHIDOS}

Os adsorventes obtidos após a modificação da carboximetilcelulose com ácido ferúlico ou DIC foram caracterizados via análise termodravimetrica (TGA e DSC), FTIR e ${ }^{13} \mathrm{C}$-RMN. 
Dessa forma, durante as análises por TGA e DSC, como mostra as figuras 44 e 45 verifica-se, pela análise via TGA a presença de eventos característicos da perda de água até $120^{\circ} \mathrm{C}$ para todas as amostras, sendo que, para a CMC, verifica-se dois eventos de perdas de massa de aproximadamente $10 \%$ em $245-310^{\circ} \mathrm{C}$ e $345-390^{\circ} \mathrm{C}$ e, para a quitosana, uma perda de massa de $30 \%$ entre $265-320^{\circ} \mathrm{C}$.

Figura 44 - Análise via TGA e DSC para a CMC

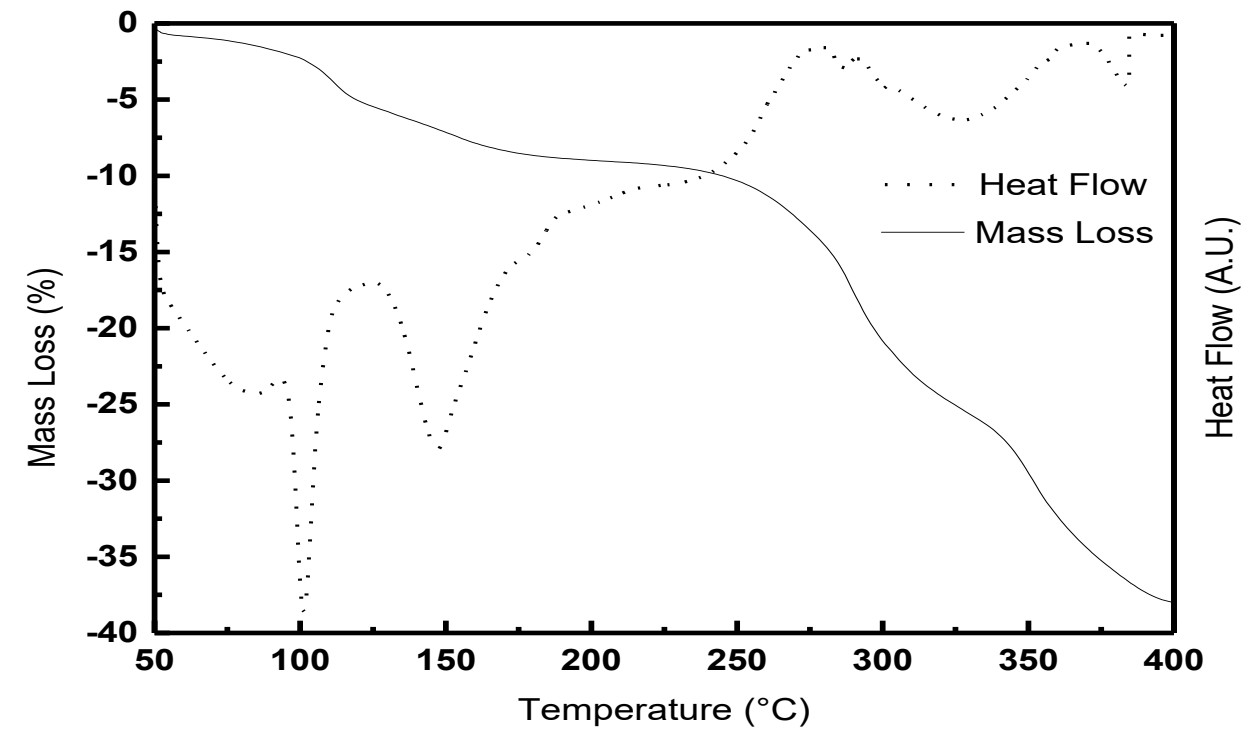

Fonte: Autor

Figura 45 - Análise via TGA e DSC para a quitosana

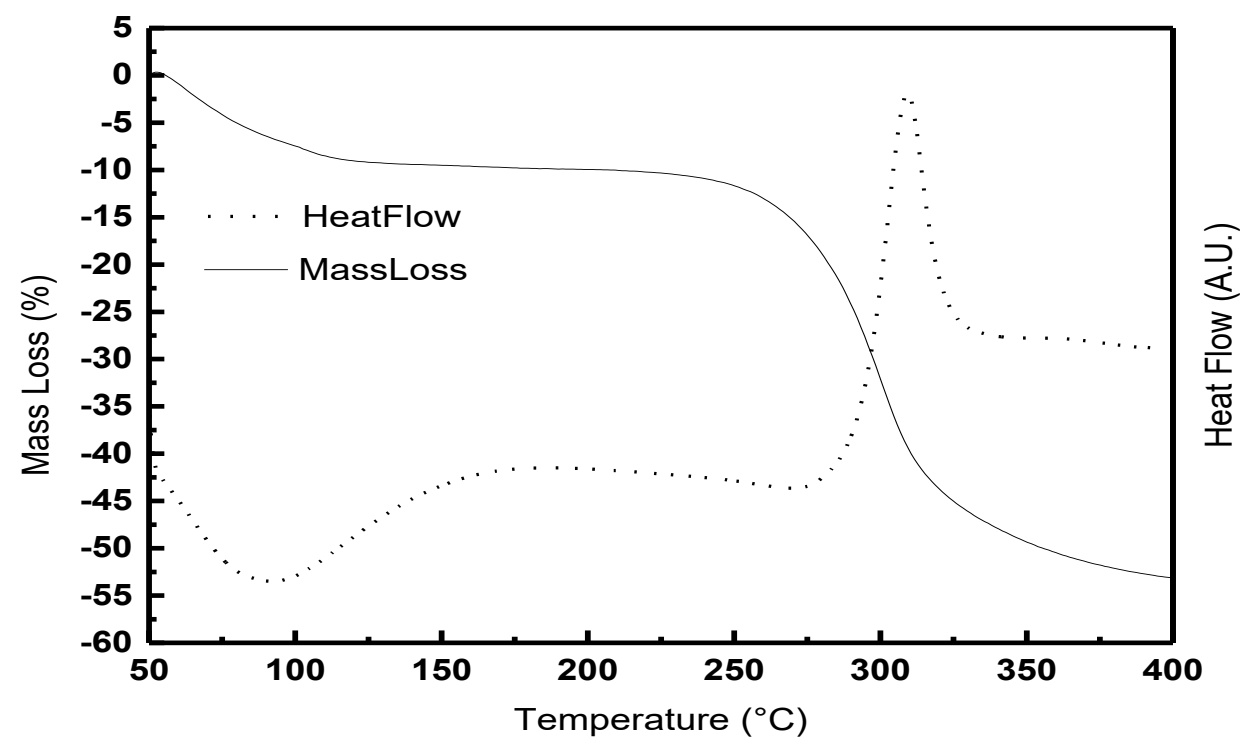

Fonte: Autor 
Já, a análise via DSC mostrou, para a CMC, um evento endotérmico entre $120^{\circ} \mathrm{C}$ e $170^{\circ} \mathrm{C}$, referentes a perda de voláteis e, dois eventos exotérmicos em $279^{\circ} \mathrm{C}$ e $300^{\circ} \mathrm{C}$, que indicam degradação da mesma e, para a quitosana pura, verifica-se um evento exotérmico em $302^{\circ} \mathrm{C}$, que indicou a degradação do material (Tabela 19).

Após a caracterização dos principais reagentes de partida, foram realizadas análises dos adsorventes obtidos por meio da reação entre CMC, quitosana e ácido ferúlico (CMCQF) e CMC, quitosana e DIC (CMCQDIC).

Por meio da análise da TGA dos adsorventes, verifica-se dois eventos de perda de massa, um entre $225-250^{\circ} \mathrm{C}$ de $13 \%$ e, outro, entre $257-290^{\circ} \mathrm{C}$ de $10,2 \%$, para o CMCQF (Figura 46) e, para o outro adsorvente (CMCQDIC), verifica-se um único evento entre $259-320^{\circ} \mathrm{C}$ com perda de massa de 23,8\% (Figura 47). A análise via DSC mostrou uma redução na temperatura de degradação com eventos em $236^{\circ} \mathrm{C}$ e $262^{\circ} \mathrm{C}$ para o $\mathrm{CMCQF}$ e, em $297^{\circ} \mathrm{C}$ para o CMCQDIC, que, possivelmente, estão relacionadas com a redução das interações eletrostáticas entre as cadeias do polímero, pela presença do ácido ferúlico e/ou DIC (Tabela 19).

Figura 46 - Análise termogravimétrica referente ao CMCQF

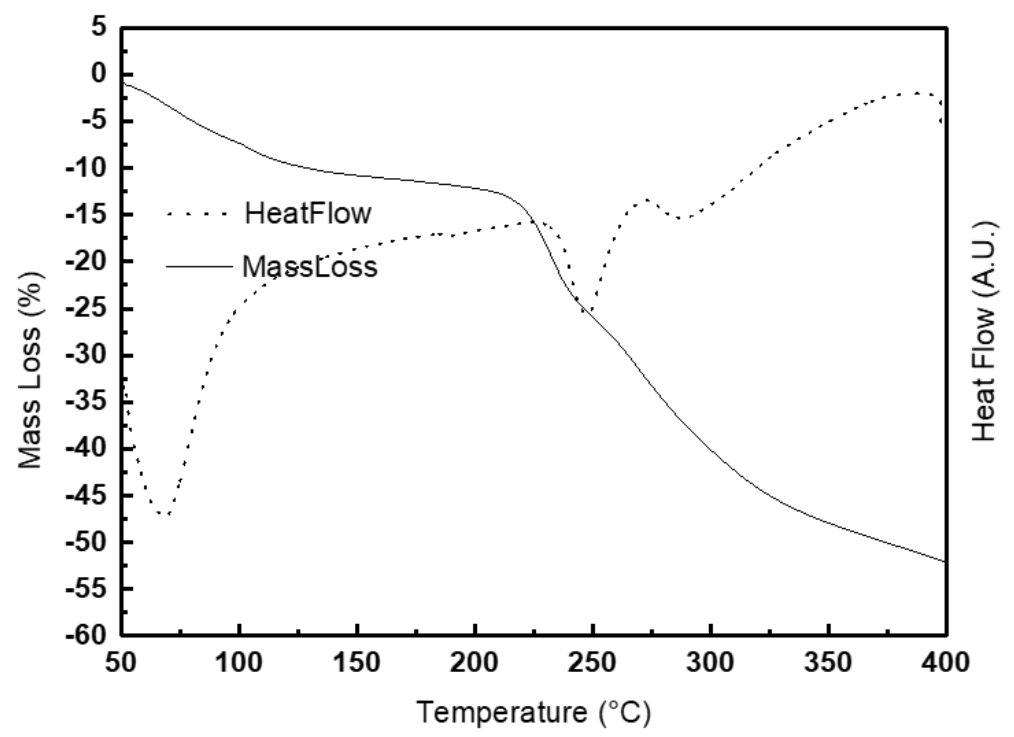

Fonte: Autor 
Figura 47 - Análise termogravimétrica referente ao CMCQDIC

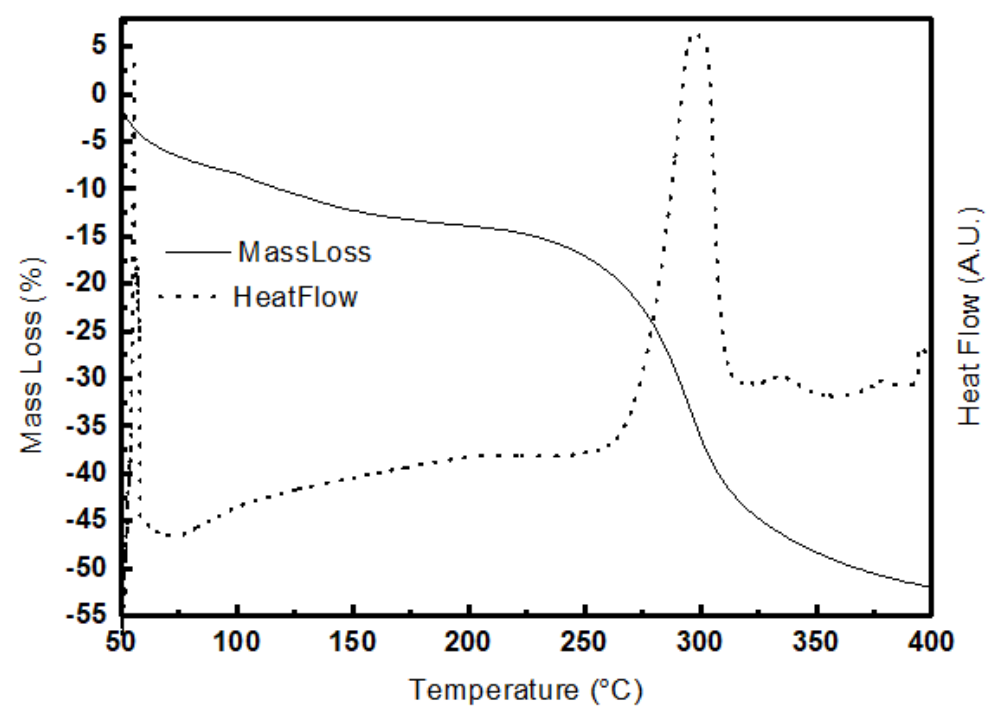

Fonte: Autor

Tabela 19 - Análise DSC para a CMC, quitosana e adsorventes CMCQF e CMCQDIC

\begin{tabular}{c|c|c}
\hline Material & Temperatura $\left({ }^{\circ} \mathrm{C}\right)$ & $\Delta \mathrm{H}\left(\mathrm{J} \mathrm{g}^{-1}\right)$ \\
\hline \multirow{3}{*}{ CMC } & 86 & 20,33 \\
& 129 & 52,10 \\
& 258 & $-15,86$ \\
& 290 & $-5,90$ \\
\hline Q & 355 & $-33,74$ \\
\hline \multirow{2}{*}{ CMCQF } & 286 & $-259,00$ \\
\hline \multirow{2}{*}{ CMCQDIC } & 230 & 60,00 \\
& 327 & $-25,74$ \\
\hline
\end{tabular}

Fonte: Autor

Legenda: valores em itálico referem-se a eventos exotérmicos

Além da análise via TGA/DSC, as análises via FTIR mostraram a presença das principais bandas de absorção características, tanto da CMC e da quitosana, quanto do ácido ferúlico e DIC, nos espectros referentes aos adsorventes CMCQF e CMCQDIC.

Assim, ao analisar-se o espectro referente ao adsorvente CMCQDIC e, comparando-se o mesmo com os espectros dos reagentes quitosana, CMC e DIC (Figura 48), verifica-se a presença de bandas referentes a cada um dos reagentes presentes no CMCQDIC sendo as principais bandas observada em: 1600 e $1400 \mathrm{~cm}^{-1}(\mathrm{C}=\mathrm{O}), 1220 \mathrm{~cm}^{-1}(\mathrm{C}-\mathrm{O})$ referentes a $\mathrm{CMC}$, 
bandas em e $1040 \mathrm{~cm}^{-1}(\mathrm{C}-\mathrm{N}), 1580$ e $1415 \mathrm{~cm}^{-1}(\mathrm{~N}-\mathrm{H}$ e C-H) referentes a quitosana e, bandas em $3000 \mathrm{~cm}^{-1}\left(-\mathrm{CH}_{3}\right)$ e em 3300 e $1200 \mathrm{~cm}^{-1}$ (C-N) referentes ao DIC, melhor observadas na figura 49 (PAVIA et al., 2015).

Figura 48 - Comparativos entre os espectros de FTIR para o CMCQDIC

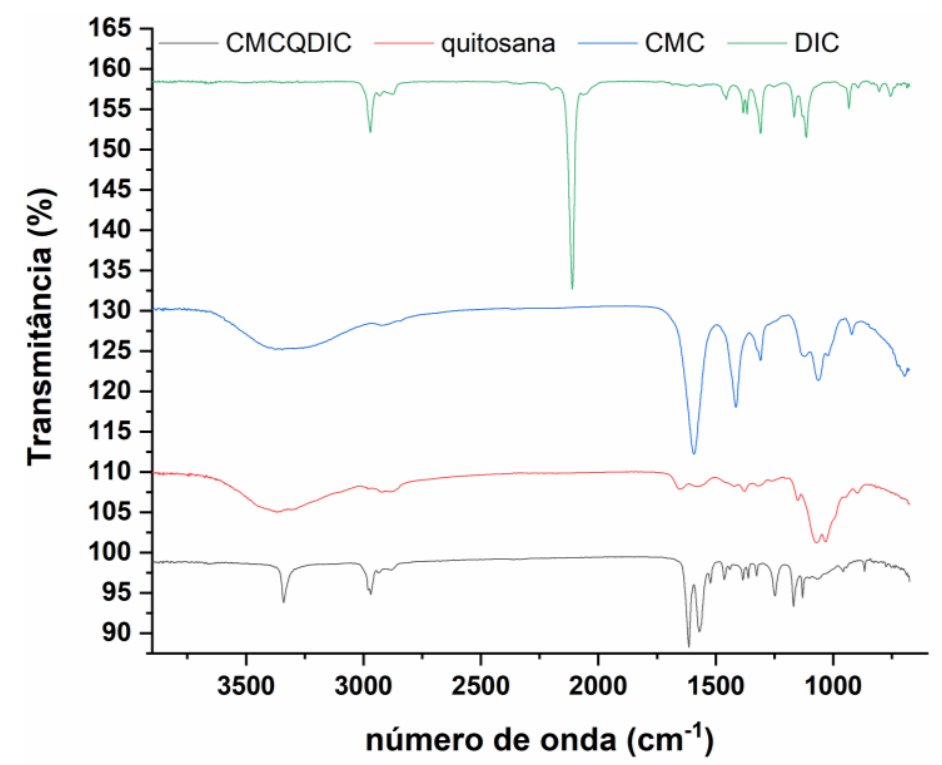

Fonte: Autor

Figura 49 - Espectro de FTIR referente ao CMCQDIC

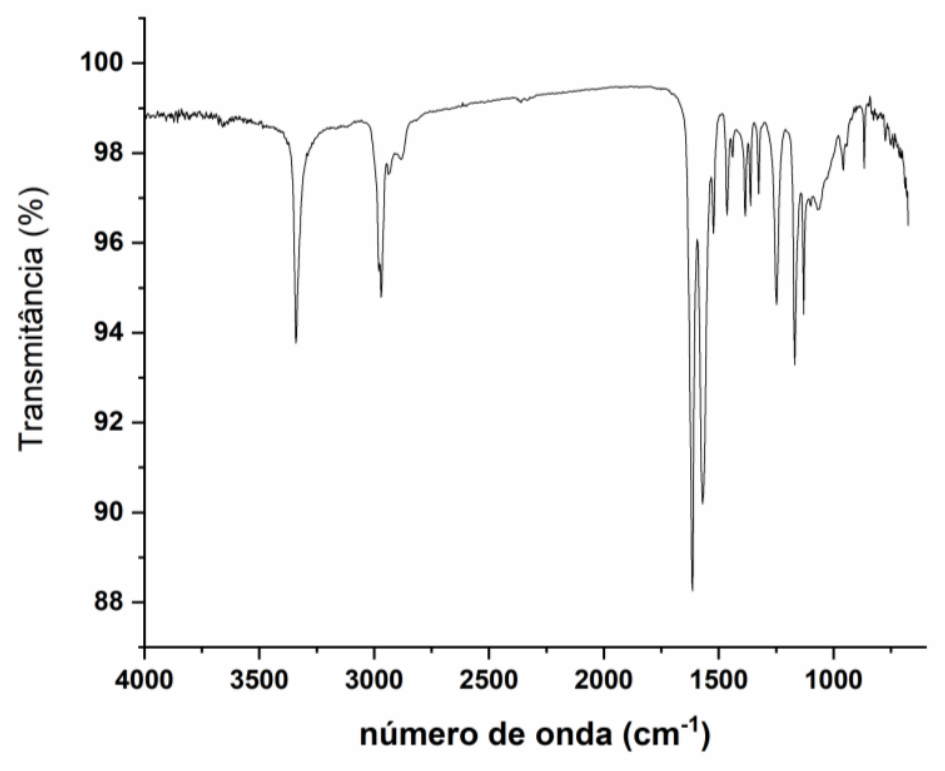

Fonte: Autor

Da mesma forma, ao analisar-se o espectro de FTIR obtido para o CMCQF, verifica-se bandas características de cada um dos reagentes no espectros porém, não de forma nítida na 
comparação entre todos os reagentes envolvido com o espectro do adsorvente (Figura 50), porém, analisando o espectro do CMCQF ampliado (Figura 51) foi possível identificar a presença de banda em $1600 \mathrm{~cm}^{-1}(\mathrm{C}=\mathrm{O})$ referentes a CMC, bandas em $1250 \mathrm{~cm}^{-1}(\mathrm{~N}-\mathrm{H})$ e 1040 $\mathrm{cm}^{-1}(\mathrm{C}-\mathrm{N})$ referentes a quitosana e, bandas entre 1800 e $1600 \mathrm{~cm}^{-1}$, referentes a presença de aromáticos e em 1400 e $1300 \mathrm{~cm}^{-1}$ (C-O), referentes ao ácido ferúlico (PAVIA et al., 2015).

Figura 50 - Comparativos entre os espectros de FTIR para o CMCQF

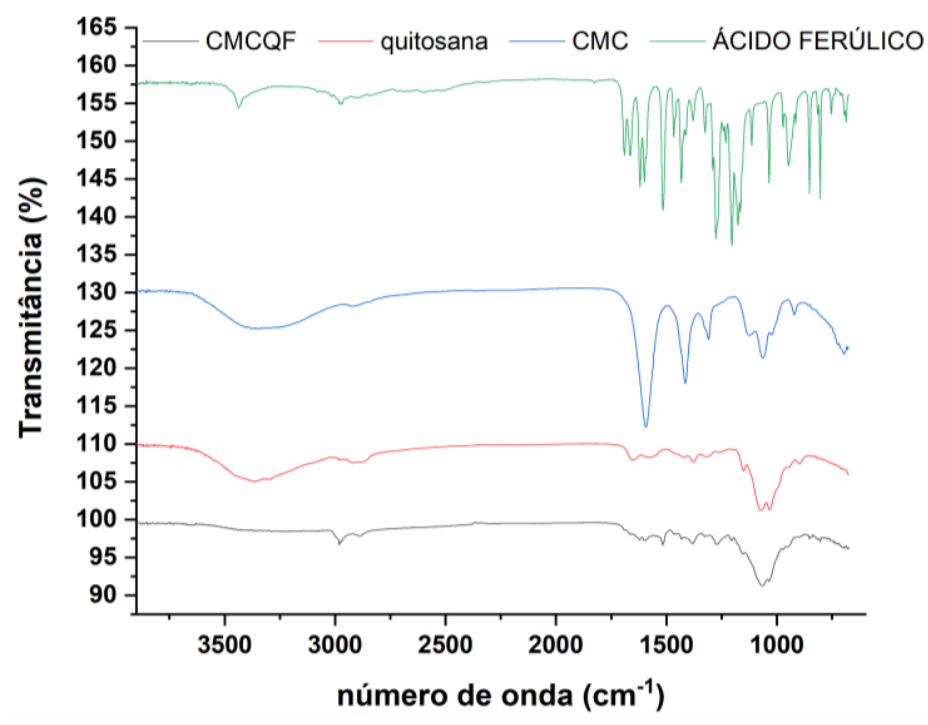

Fonte: Autor

Figura 51 - Espectro de FTIR referente ao CMCQF

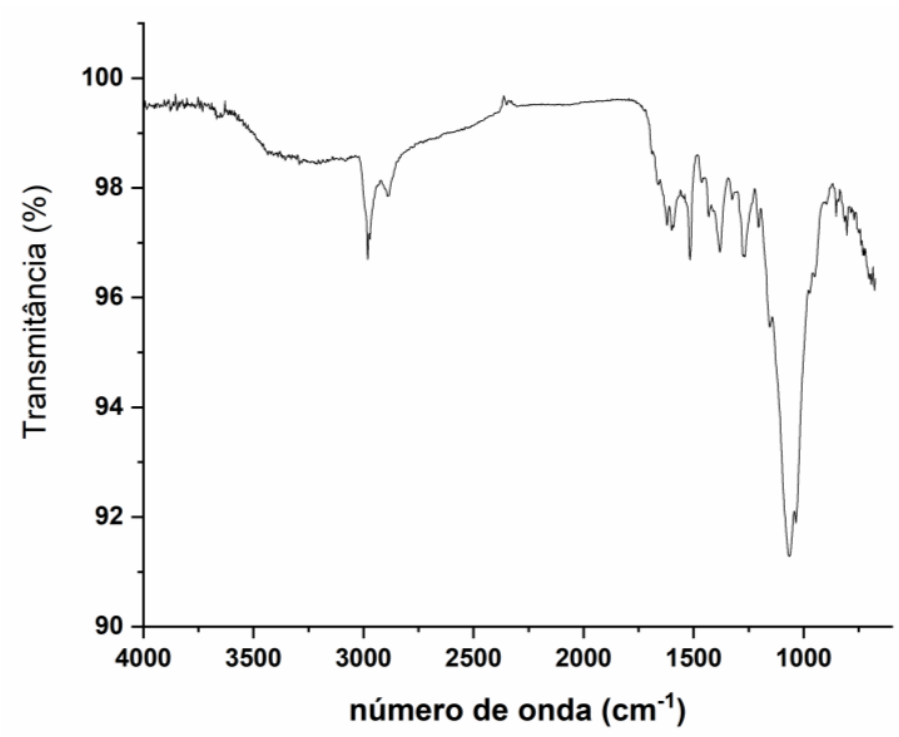

Fonte: Autor 
Também foram realizadas caracterizações via ${ }^{13} \mathrm{C}-\mathrm{RMN}$ utilizando-se as amostras no estado sólido sendo que, ao analisar-se o espectro referente ao primeiro adsorvente, o CMCQF (Figuras 52 e 53), verifica-se sinais em aproximadamente $175 \mathrm{ppm}$, referente as carboxilas da CMC. É possível verificar a presença do ácido ferúlico na estrutura, uma vez que são observados sinais em aproximadamente 148 ppm, referentes aos carbonos do anel aromático, além dos demais sinais referentes tanto a CMC, quanto da quitosana (PAVIA et al., 2015).

Figura 52 - Comparação entre os espectros de ${ }^{13} \mathrm{C}-\mathrm{RMN}$ no estado sólido para a quitosana, CMC e o adsorvente CMCQF a 9,4 T

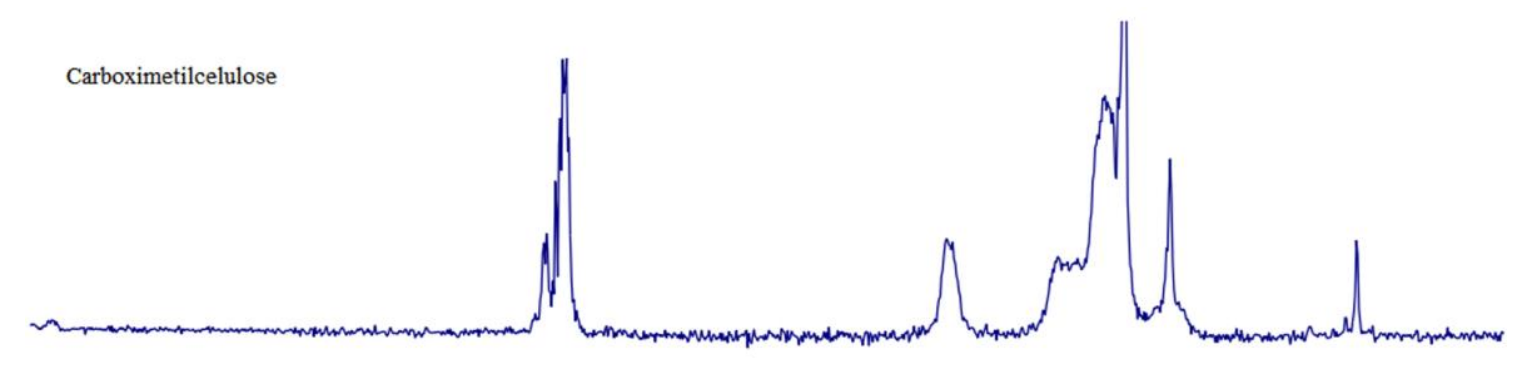

Adsorvente

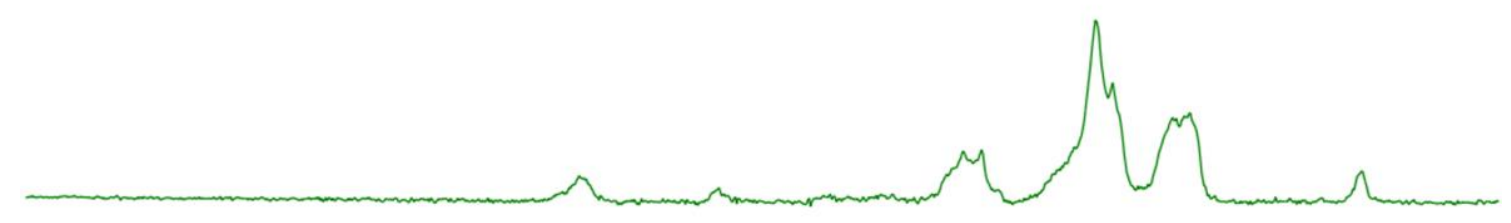

Quitosana

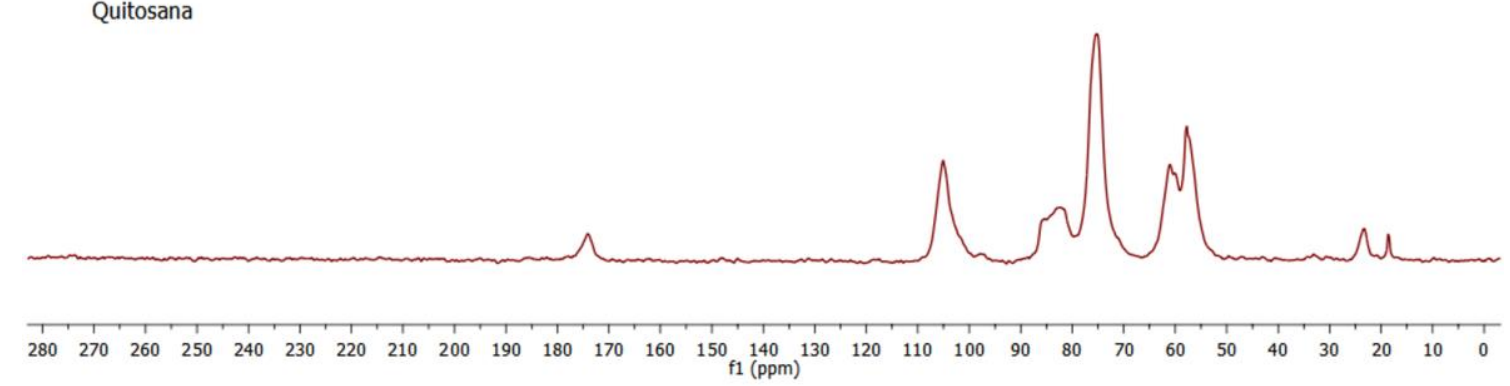

Fonte: Autor 
Figura 53 - Espectros de ${ }^{13} \mathrm{C}-\mathrm{RMN}$ no estado sólido para o adsorvente CMCQF a 9,4 T

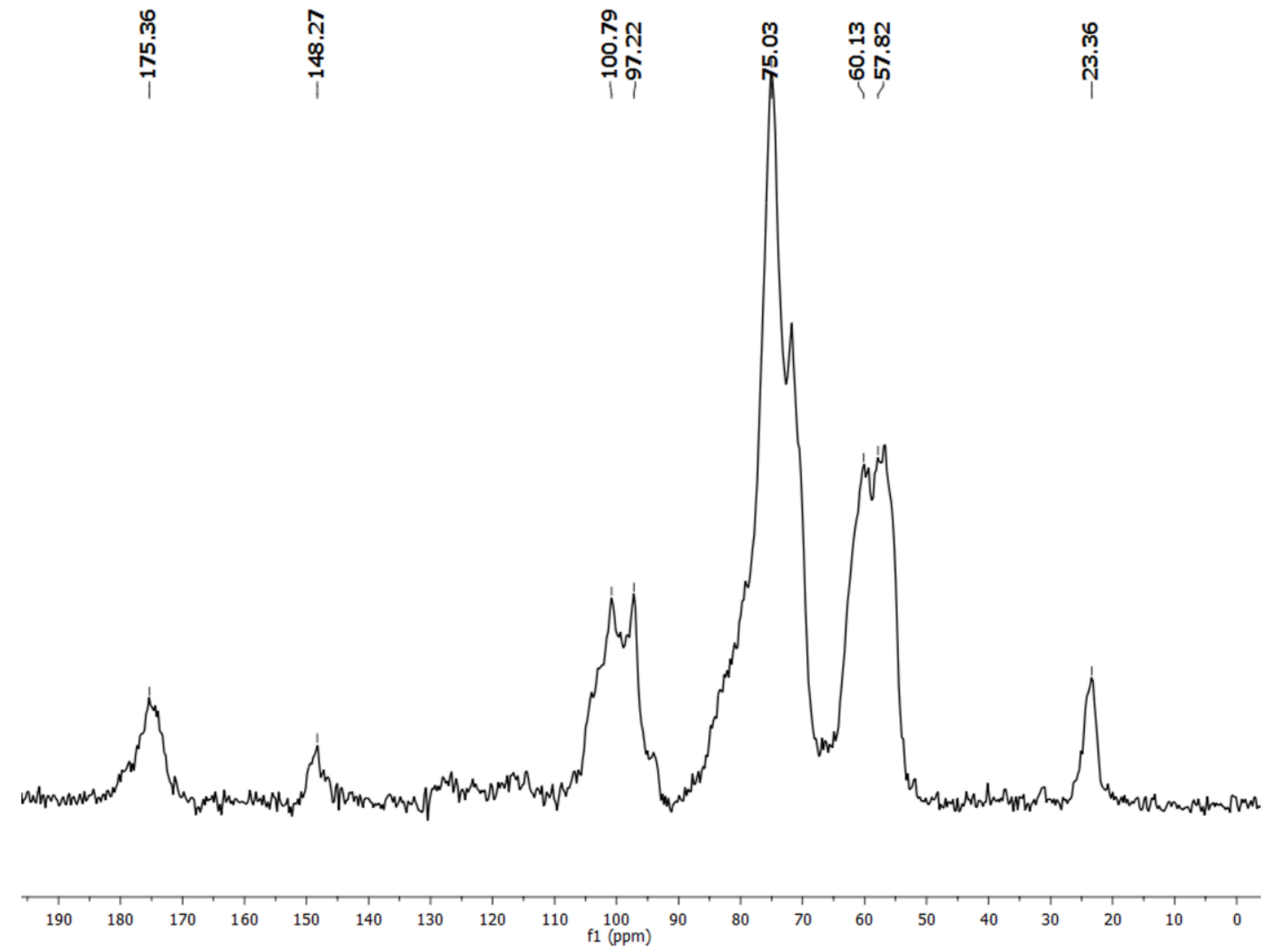

Fonte: Autor

Com relação a análise do adsorvente CMCQDIC, é possível verificar a presença de sinais referentes a presença de carbonilas em aproximadamente $175 \mathrm{ppm}$, em $42,68 \mathrm{ppm}$ possivelmente devido a presença do carbono originalmente ligado aos nitrogênios do DIC e que, após a formação do adsorvente, se encontra ligado a quatro nitrogênios conforme proposto no mecanismo de reação (Figuras 54 e 55) (PAVIA et al., 2015).

Também é possível verificar a presença dos demais sinais referentes aos carbonos da CMC e da quitosana, corroborando com a formação do produto desejado. 
Figura 54 - Comparação entre os espectros de ${ }^{13} \mathrm{C}-\mathrm{RMN}$ no estado sólido para a quitosana, CMC e o adsorvente CMCQDIC a 9,4 T

CMC

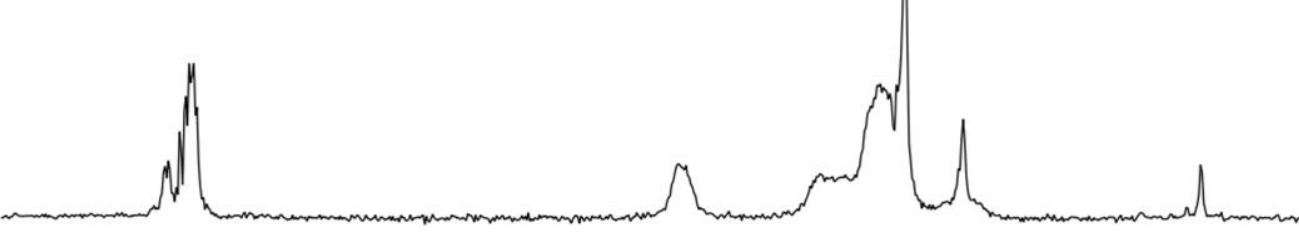

Quitosana

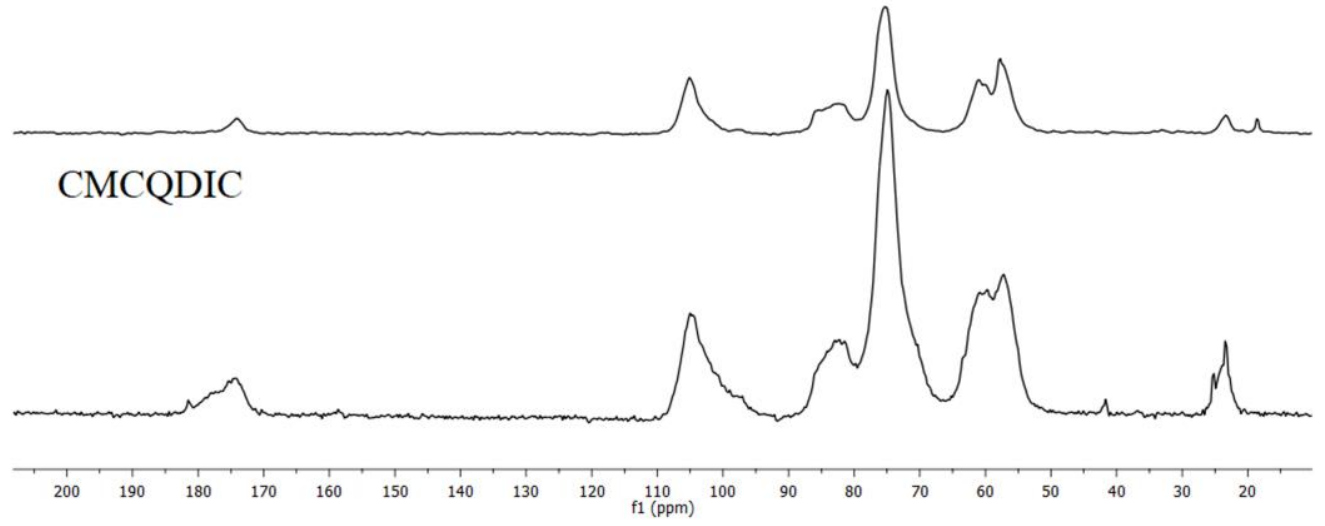

Fonte: Autor

Figura 55 - Espectros de ${ }^{13} \mathrm{C}-\mathrm{RMN}$ no estado sólido para o adsorvente CMCQDIC a 9,4 T

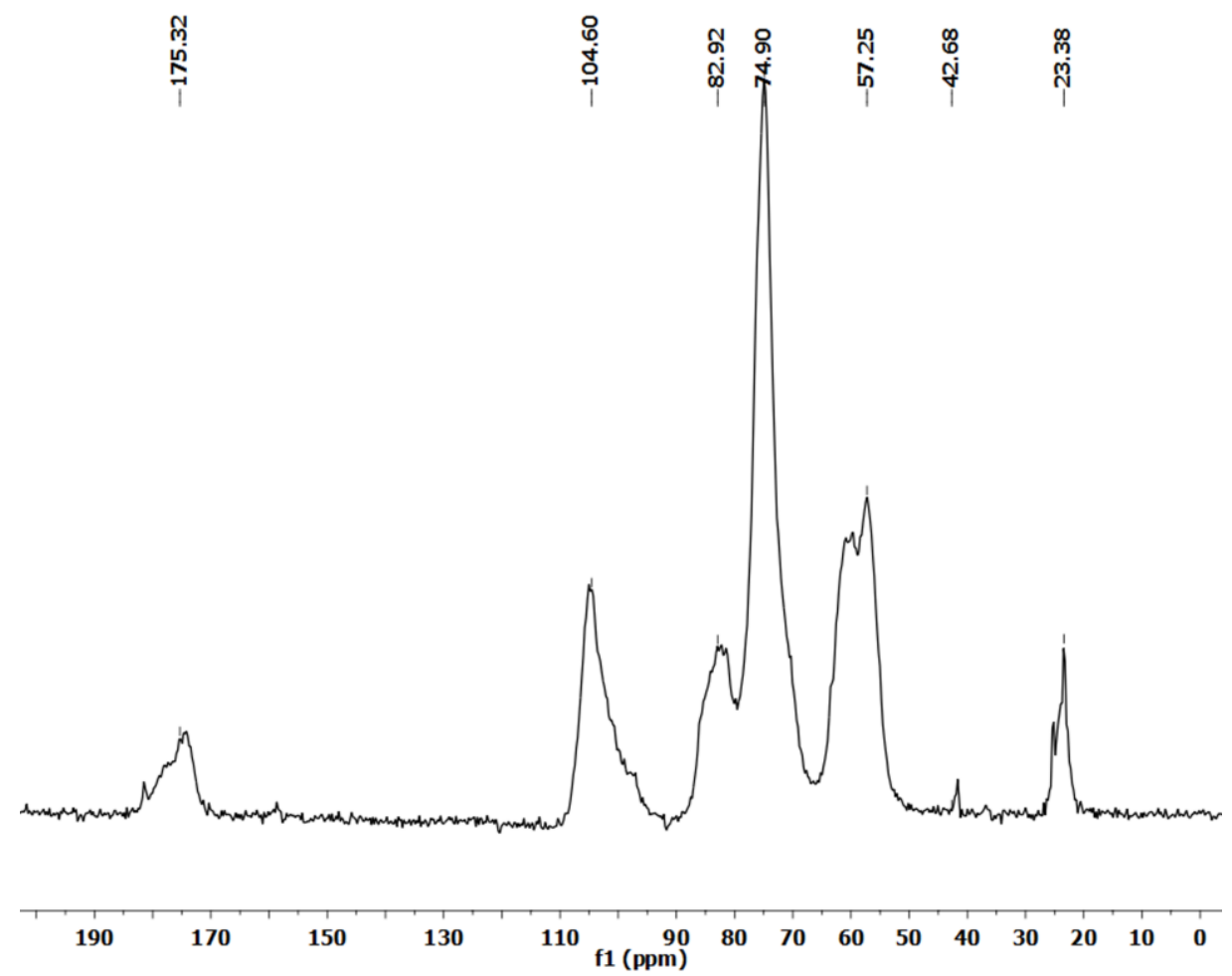

Fonte: Autor 
Outra característica muito importante ao realizar-se a síntese de novos adsorventes são as análises superficiais dos mesmos.

Dessa forma, foram realizadas análises via determinação da área superficial B.E.T distribuição do tamanho de partícula e densidade real.

A área superficial, determinada utilizando-se os métodos de isoterma de B.E.T, mostrou que os adsorventes apresentam baixa área de superfície sendo, a mesma de 0,1229 e 0,5912 $\mathrm{m}^{2} \cdot \mathrm{g}^{-1}$ para o CMCQF e CMCQDIC, respectivamente. E, inferiores aos valores obtidos para a $\operatorname{CMC}\left(0,6010 \mathrm{~m}^{2} \cdot \mathrm{g}^{-1}\right)$.

Analisando-se os resultados obtidos, verifica-se que os valores não foram tão elevados, um ponto negativo para aplicação em processos de adsorção pois, em geral, adsorventes com elevada área específica apresentam maior capacidade de adsorção. Porém, já era um resultado esperado, em se tratando de biopolímeros, sendo importante para confirmar o fato de que, nesse tipo de material, o processo de adsorção ocorre devido a presença de grupos funcionais específicos que interagem com os poluentes, não sendo toda a superfície capaz de reter as moléculas de adsorvato. Dessa forma, a adsorção será mais eficiente quanto maior número de grupos que agem como sítios ativos (DOTTO; CAPANHA-FILHO; PINTO, 2017).

Em relação a densidade real, ambos os adsorventes apresentaram resultados muito semelhantes, 1,397 $\pm 0,001$ g.cm $\mathrm{cm}^{-3}$ para o CMCQF e de 1,355 $\pm 0,003 \mathrm{~g} . \mathrm{cm}^{-3}$ para o CMCQDIC, porém, inferiores aos valores observados para a CMC $(1,747 \pm 0,003)$ e, reforçando a hipótese de obtenção de novos materiais que levam a mudanças na densidade devido a ocorrência de alterações nas interações entre as cadeias poliméricas finais (Tabela 20) (GIERSZEWSKA; OSTROWSKA-CZUBENKO; KWIATKOWSKA, 2013).

Tabela 20 - Densidade real obtida para a CMC, quitosana e, adsorventes

\begin{tabular}{c|c}
\hline Material & Densidade real $\left(\mathrm{g} . \mathrm{cm}^{-3}\right)$ \\
\hline CMC & $1,747 \pm 0,003$ \\
Quitosana & $1,342 \pm 0,002$ \\
CMCQF & $1,397 \pm 0,001$ \\
CMCQDIC & $1,355 \pm 0,003$ \\
\hline
\end{tabular}

Fonte: Autor

A distribuição do tamanho de partícula mostrou uma redução do tamanho médio em relação a quitosana para ambos os adsorventes (CMCQF e CMCQDIC) porém, em relação a CMC, verifica-se um aumento ao comparar-se com CMCQDIC e, uma redução levando-se em consideração CMCQF (Tabela 21, Apêndice B). 
Tabela 21 - Tamanho de partícula médio observado para a CMC, quitosana e, adsorventes

\begin{tabular}{c|c}
\hline Material & Tamanho médio de partícula $(\mu \mathrm{m})$ \\
\hline CMC & $303,30 \pm 148,60$ \\
Quitosana & $361,10 \pm 92,34$ \\
CMCQF & $276,90 \pm 76,93$ \\
CMCQDIC & $360,60 \pm 126,20$ \\
\hline
\end{tabular}

Fonte: Autor

\subsection{ESTUDO DE ADOSRÇÃO DE CROMO HEXAVALENTE}

A partir da escolha das carboximetilcelulose modificadas, CMCQF e CMCQDIC, foram realizados os estudos de adsorção de cromo hexavalente e otimização dos parâmetros, para ambos os adsorventes, referentes ao tempo ideal de contato com estudo cinético, $\mathrm{pH}$ ideal, temperatura ideal por meio das isotermas de adsorção, e termodinâmica, como descrito nos itens 5.4.1 a 5.4.4.

\subsubsection{Cinética de adsorção}

O estudo de cinética de adsorção foi realizado segundo o procedimento descrito no item 4.3.4.1. Dessa forma foram, inicialmente, obtidos os valores de capacidade de adsorção para cada tempo estipulado (Tabela 22, Apêndice A) e, em seguida, os modelos cinéticos propostos foram aplicados aos dados, com a finalidade de compreender os mecanismos determinantes no processo de adsorção utilizando-se, para isso, os modelos de pseudo-primeira ordem, pseudosegunda ordem e Weber-Morris, descritos no item 3.6.2.1. 
Tabela 22 - Resultados referentes ao ensaio de cinética de adsorção

\begin{tabular}{|c|c|c|c|c|}
\hline Adsorvente & \multicolumn{2}{|r|}{ CMCQF } & \multicolumn{2}{|c|}{ CMCQDIC } \\
\hline Tempo (min) & $\begin{array}{c}\text { Concentração } \\
(\mathrm{ppm})\end{array}$ & $\begin{array}{c}\text { Capacidade de adsorção } \\
\left(\mathrm{mg} \cdot \mathrm{g}^{-1}\right)\end{array}$ & $\begin{array}{c}\text { Concentração } \\
(\mathrm{ppm})\end{array}$ & $\begin{array}{c}\text { Capacidade de adsorção } \\
\left(\mathrm{mg} \cdot \mathrm{g}^{-1}\right)\end{array}$ \\
\hline 0 & $253,30 \pm 1,09$ & - & $266,22 \pm 0,71$ & - \\
\hline 1 & $176,05 \pm 0,00$ & $38,40 \pm 0,15$ & $238,52 \pm 3,20$ & $13,78 \pm 1,55$ \\
\hline 2 & $169,79 \pm 1,49$ & $41,47 \pm 2,34$ & $231,06 \pm 3,20$ & $17,63 \pm 1,59$ \\
\hline 4 & $169,79 \pm 1,05$ & $41,48 \pm 3,92$ & $201,75 \pm 1,60$ & $32,14 \pm 0,83$ \\
\hline 5 & $167,10 \pm 1,68$ & $43,18 \pm 1,34$ & $190,03 \pm 1,60$ & $37,83 \pm 0,76$ \\
\hline 10 & $155,92 \pm 1,92$ & $48,55 \pm 2,50$ & $187,89 \pm 0,53$ & $38,66 \pm 0,30$ \\
\hline 15 & $139,81 \pm 1,92$ & $56,75 \pm 2,57$ & $184,16 \pm 0,00$ & $40,91 \pm 0,04$ \\
\hline 20 & $145,63 \pm 1,79$ & $53,41 \pm 1,09$ & $182,57 \pm 0,00$ & $41,37 \pm 0,30$ \\
\hline 25 & $138,02 \pm 0,45$ & $57,47 \pm 0,39$ & $180,97 \pm 1,07$ & $42,25 \pm 0,13$ \\
\hline 30 & $133,10 \pm 1,05$ & $59,90 \pm 3,72$ & $179,90 \pm 0,53$ & $43,12 \pm 0,04$ \\
\hline 45 & - & - & $177,77 \pm 0,53$ & $44,36 \pm 0,04$ \\
\hline 60 & $135,79 \pm 1,05$ & $58,18 \pm 3,99$ & $174,57 \pm 0,00$ & $45,92 \pm 0,72$ \\
\hline 75 & $139,37 \pm 0,00$ & $56,46 \pm 0,17$ & $174,04 \pm 1,60$ & $45,77 \pm 0,22$ \\
\hline 90 & - & - & $172,98 \pm 0,53$ & $46,76 \pm 0,22$ \\
\hline 105 & $142,50 \pm 1,34$ & $55,07 \pm 0,45$ & $171,38 \pm 0,53$ & $47,00 \pm 0,05$ \\
\hline 120 & $132,66 \pm 1,19$ & $60,00 \pm 5,39$ & $171,91 \pm 1,07$ & $47,06 \pm 0,70$ \\
\hline 150 & $138,92 \pm 3,13$ & $56,90 \pm 1,78$ & $171,91 \pm 0,53$ & $47,49 \pm 0,22$ \\
\hline 180 & $138,02 \pm 3,13$ & $57,41 \pm 1,44$ & $169,78 \pm 0,53$ & $48,27 \pm 0,22$ \\
\hline 210 & $138,92 \pm 2,24$ & $56,68 \pm 1,05$ & $168,18 \pm 1,07$ & $48,54 \pm 0,43$ \\
\hline 240 & $142,95 \pm 3,58$ & $55,01 \pm 1,62$ & $168,71 \pm 0,53$ & $48,76 \pm 0,27$ \\
\hline 270 & $136,68 \pm 2,47$ & $58,20 \pm 2,35$ & $169,78 \pm 0,53$ & $48,37 \pm 0,32$ \\
\hline 300 & $138,02 \pm 1,34$ & $57,47 \pm 0,84$ & $169,78 \pm 0,53$ & $48,47 \pm 0,32$ \\
\hline 720 & $142,95 \pm 0,00$ & $54,80 \pm 0,05$ & $184,70 \pm 0,53$ & $40,72 \pm 0,23$ \\
\hline 1440 & $148,76 \pm 3,13$ & $51,81 \pm 1,71$ & $209,74 \pm 0,53$ & $28,18 \pm 0,06$ \\
\hline
\end{tabular}

Fonte: Autor

Assim, durante a realização dos estudos utilizando-se o primeiro modelo, o de pseudoprimeira, inicialmente, foi determinada, inicialmente, a capacidade de adsorção no equilíbrio $\left(\mathrm{q}_{\mathrm{e}}\right)$, calculado pela média das capacidades de adsorção do processo a partir do momento em que não houve mais mudança significativa no valor da capacidade de adsorção. Dessa forma, para os adsorventes CMCQF e CMCQDIC notou-se que o processo atingiu o equilíbrio a partir de 60 e 180 minutos, (Figura 56) com capacidades de equilíbrio de $(57,1 \pm 1,1)$ e, $(48,48 \pm 0,13)$ mg. $\mathrm{g}^{-1}$, respectivamente. 
Figura 56 - Capacidade de adsorção em função do tempo

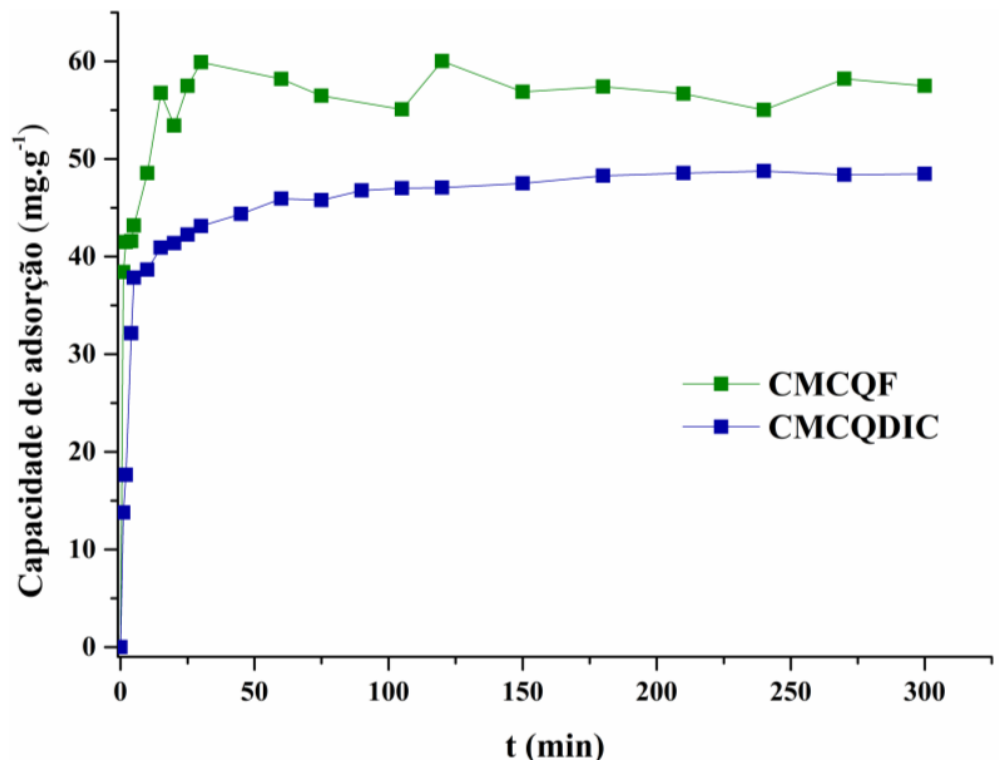

Fonte: Autor

Após determinação da capacidade de adsorção no equilíbrio para ambos os adsorventes, foi realizado o ajuste para o modelo de pseudo-primeira ordem (Figuras 57 e 58) sendo obtidas as constantes cinética de primeira ordem $\mathrm{k}_{1}$ iguais a 0,0866 e $0,0183 \mathrm{~min}^{-1}$ e, capacidades de adsorção no equilíbrio de 11,24 e 10,11 mg.g ${ }^{-1}$, para os adsorventes CMCQF e CMCQDIC, respectivamente.

Ao analisar-se os resultados, verifica-se que os valores obtidos experimentalmente ficaram bem distantes dos teóricos e que, analisando-se os coeficientes de correlação $\mathrm{R}^{2}$, o modelo não se ajustou bem aos dados obtidos e, portanto, o mesmo não descreveu a cinética do processo de adsorção de cromo hexavalente para os adsorventes estudados. 
Figura 57 - Modelo de pseudo-primeira ordem para CMCQF

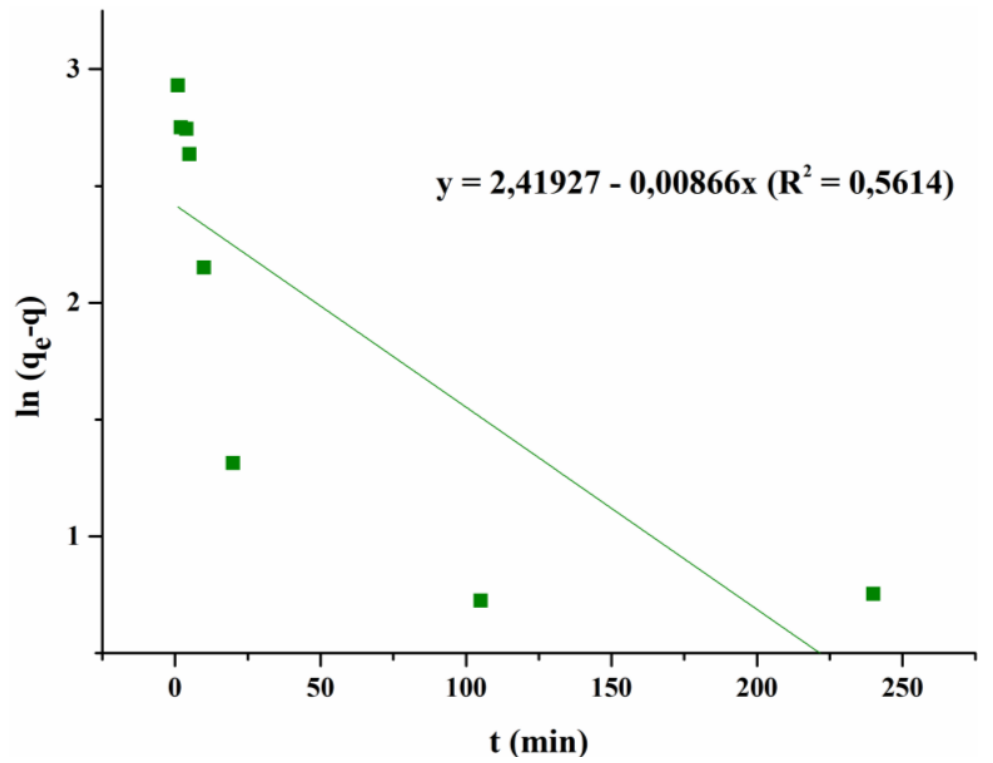

Fonte: Autor

Figura 58 - Modelo de pseudo-primeira ordem para CMCQDIC

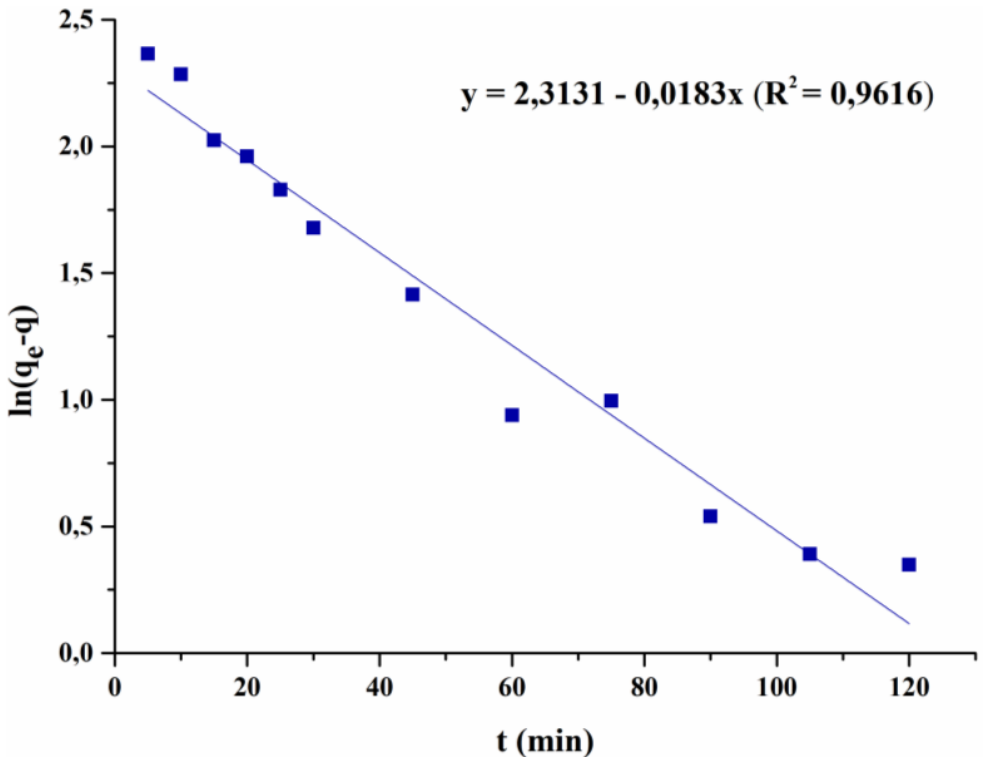

Fonte: Autor

Já, durante a análise utilizando-se o modelo de pseudo-segunda ordem (Figura 59 e 60), foram obtidas capacidades de adsorção no equilíbrio de 57,14 e 49,26 mg.g ${ }^{-1}$ e, constantes cinéticas de pseudo-segunda ordem $\mathrm{k}_{2}$ de 0,0278 e 0,00522 g.min.mg ${ }^{-1}$, para CMCQF e CMCQDIC, respectivamente, mostrando que o modelo descrever melhor a cinética de adsorção, uma vez que o coeficiente de correlação $\mathrm{R}^{2}$ foi bem próximo de 1 e que os valores de $\mathrm{q}_{\mathrm{e}}$ encontrados foram próximos dos obtidos experimentalmente. 
Figura 59 - Modelo de pseudo-segunda ordem para CMCQF

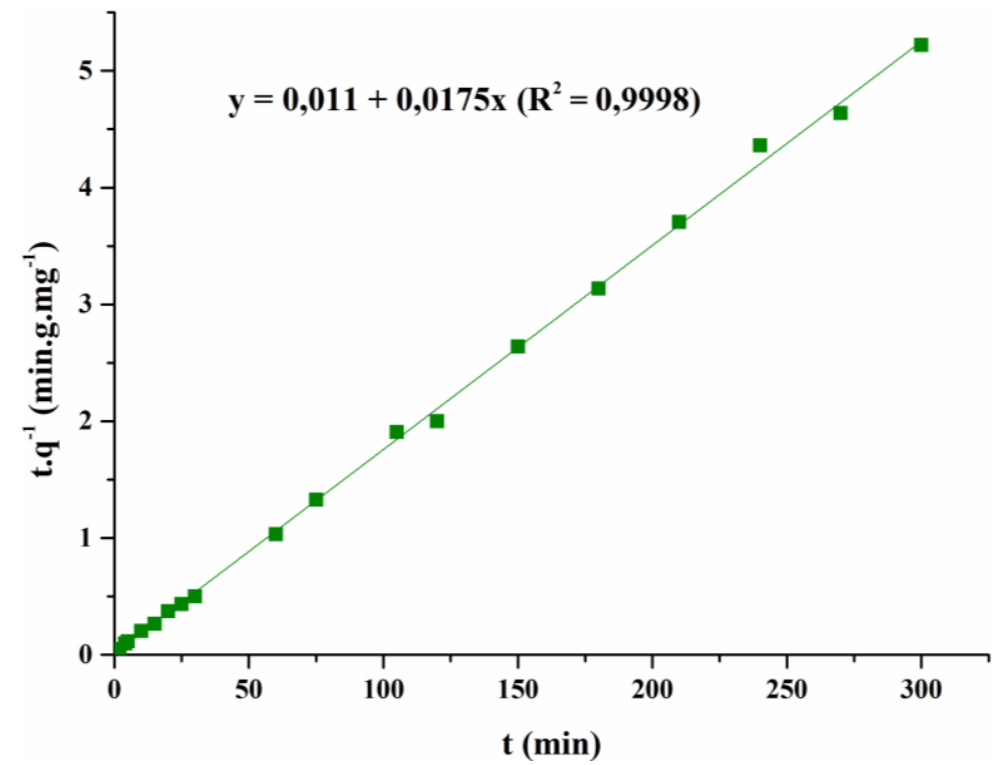

Fonte: Autor

Figura 60 - Modelo de pseudo-segunda ordem para CMCQDIC

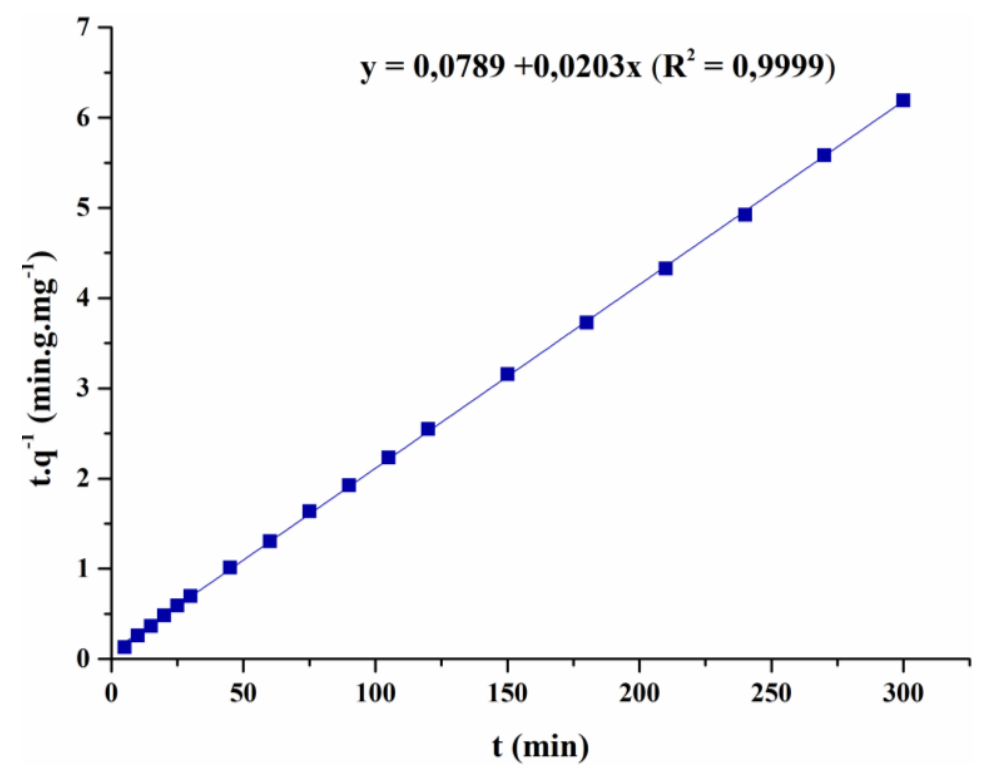

Fonte: Autor

Salienta-se também que modelo cinético de pseudo-segunda ordem tem sido utilizado com sucesso para investigar a adsorção de muitos poluentes de soluções aquosas (metais pesados, compostos orgânicos compostos, corantes químicos, produtos farmacêuticos) quando a sua concentração é baixa, estando em conformidade com os resultados reportados na literatura (CAMPOS et al, 2019).

O último modelo utilizado foi o de Weber-Morris (Figura 61 e 62) que, possibilitou a verificação do mecanismo predominante de transferência de massa no processo de adsorção é a difusão intrapartícula. 
Figura 61 - Modelo de Weber-Morris para CMCQF

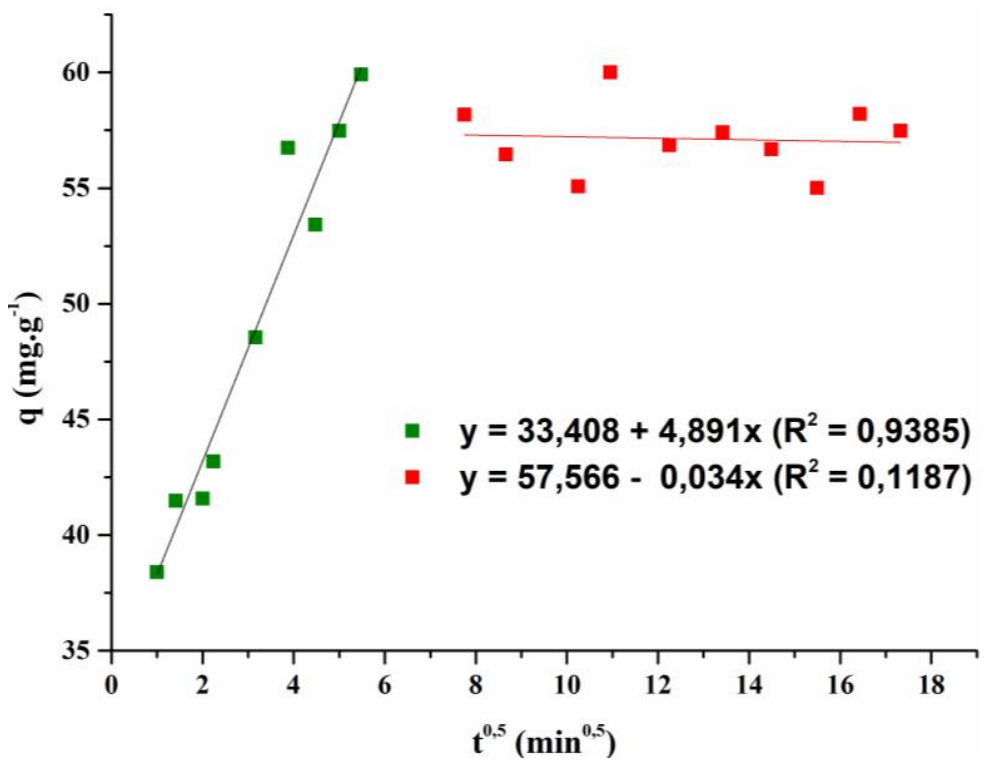

Fonte: Autor

Figura 62 - Modelo de Weber-Morris para CMCQDIC

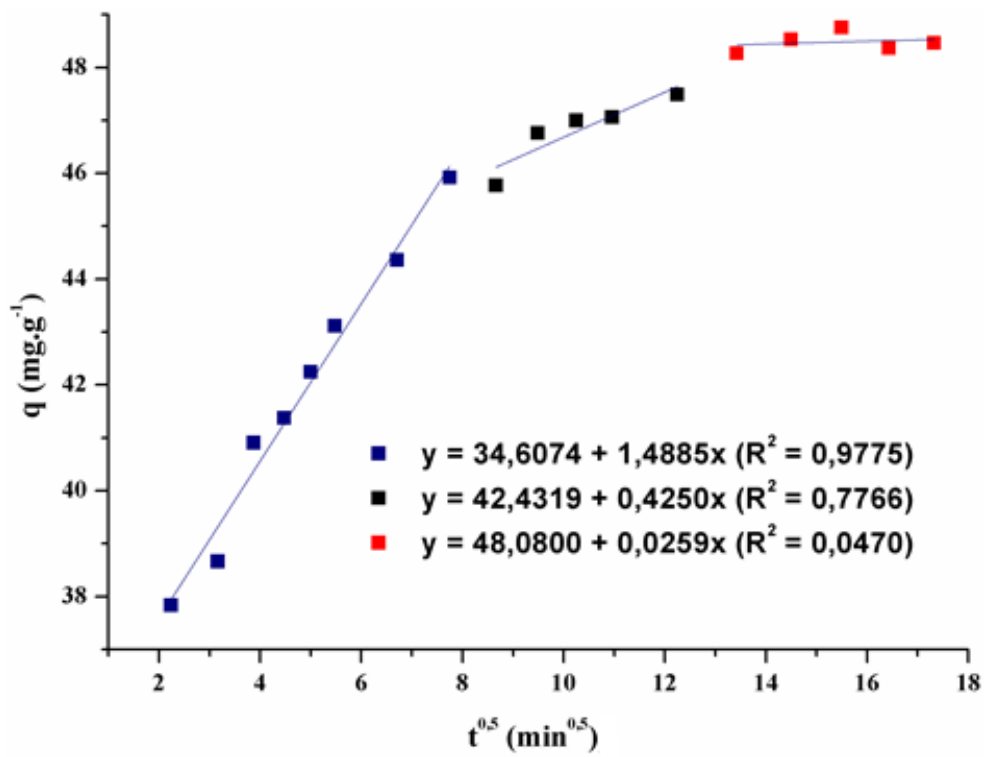

Fonte: Autor

Assim, por meio da análise dos gráficos obtidos, nota-se a presença de, pelo menos, duas retas, que são as etapas envolvidas no processo de adsorção. Destas, a última curva representa a etapa em que o equilíbrio é atingido e fornece a capacidade de adsorção no equilíbrio pelo coeficiente linear e, as demais curvas, representam as etapas em que ocorrem variações das capacidades de adsorção com a raiz do tempo e, quando essas curvas passam pela origem, o mecanismo controlador da transferência de massa é a difusão intrapartícula, ou seja, coeficiente linear nulo. 
Dessa forma, para CMCQF o coeficiente de difusão $\mathrm{K}_{d}$ foi $4,891 \mathrm{mg} \cdot \mathrm{g}^{-1} \cdot \mathrm{t}^{-0,5}$ e a constante C, de 33,41 mg.g-1 ${ }^{-1}$ que no modelo de Weber-Morris está relacionada a espessura da camada limite formada ao redor do adsorvente e a resistência a difusão e, como a mesma é diferente de zero, a difusão intrapartícula não é controladora da cinética de adsorção.

Como observado na figura 61, o mecanismo de adsorção ocorre em uma única etapa, pois na região onde a capacidade de adsorção varia com o tempo, é ajustado por uma única curva, o que indica que a transferência de massa ocorre da fase fluida para a camada limite, também chamada de difusão em filme, onde é adsorvida na superfície do adsorvente.

Para o adsorvente estudado (CMCQF), na região de equilíbrio nota-se um coeficiente de difusão muito baixo indicando que de fato não há mobilidade das moléculas de adsorvato, ocorrendo a saturação do adsorvente e a capacidade de adsorção pelo modelo de Weber-Morris foi de $57,57 \mathrm{mg} \cdot \mathrm{g}^{-1}$.

Porém, o modelo de Weber-Morris para o adsorvente CMCQDIC indica que o processo ocorre em dois estágios (Figura 62) onde, no primeiro, se tem a representação da difusão da fase fluida para a camada limite (difusão em filme). No segundo, verifica-se a difusão intrapartícula e, posteriormente, o estágio de equilíbrio caracterizado por um baixo coeficiente de difusão e que apresentou capacidade de adsorção de 48,08 mg.g-1 (KONG et al, 2019).

O aumento do valor da constante C para os dois primeiros estágios de 34,61 e 42,43 $\mathrm{mg} \cdot \mathrm{g}^{-1}$, respectivamente, indicam que, conforme a adsorção progride, a espessura da camada limite aumenta, resultando em uma desaceleração na taxa de adsorção, o que se confirma pela redução dos coeficientes de difusão $K_{d} 1,4885$ e $0,4250 \mathrm{mg} \cdot \mathrm{g}^{-1} \cdot \mathrm{t}^{-0,5}$, sendo o estágio onde ocorre a difusão intraparticula mais lento (KONG et al, 2019).

O fato do adsorvente CMCQF não apresentar difusão intrapartícula está relacionado a sua estrutura, onde nota-se que os sítios ativos não apresentam impedimentos devido as características observadas por meio da micrografia obtida via MEV-FEG (Figura 63), onde observa-se uma superfície com certa uniformidade e continua (Figura 63A), porém no caso do adsorvente CMCQDIC a micrografia mostra a uma superfície não uniforme (Figura 63B) e também devido a própria estrutura onde observa-se regiões com grande impedimento, porém com grandes quantidades de sítios ativos, principalmente grupos amônios, e regiões onde os esses mesmos grupos encontram-se mais disponíveis, como mostra a figura 64 . 
Figura 63 - Micrografias dos adsorventes com ampliação de 3.000x

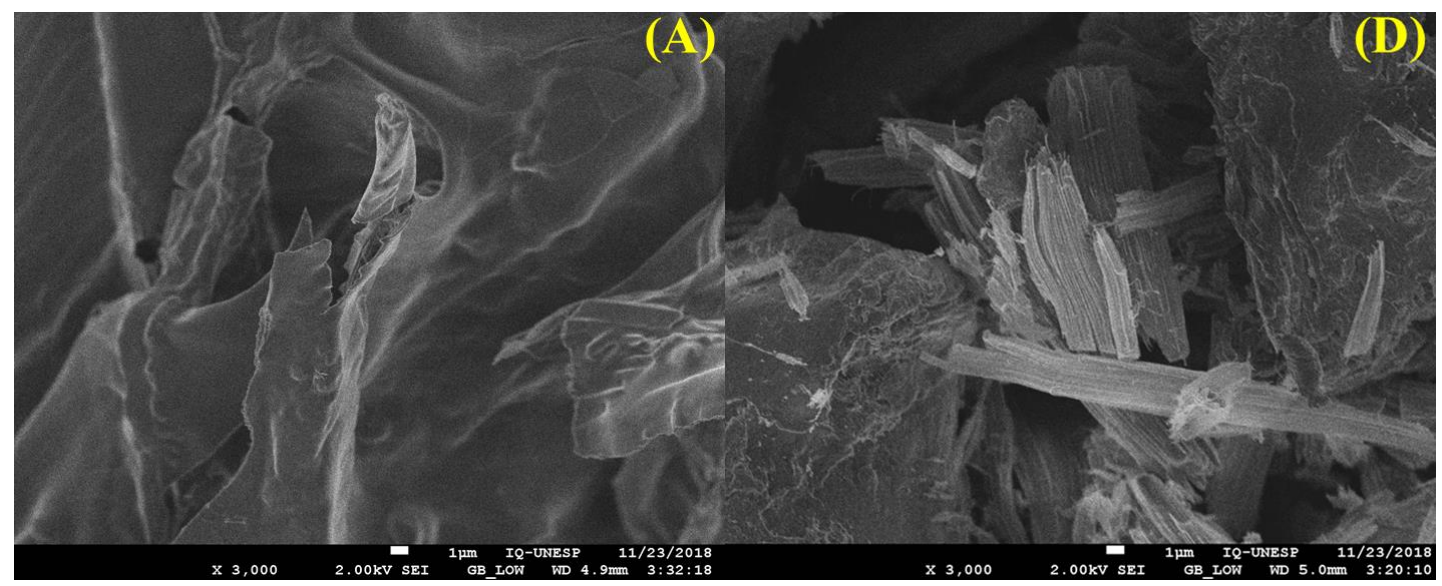

Fonte: Autor

Legenda: (A) e (D) referem-se aos adsorventes CMCQF e CMCQDIC, respectivamente

Figura 64 - Estrutura do adsorvente CMCQDIC

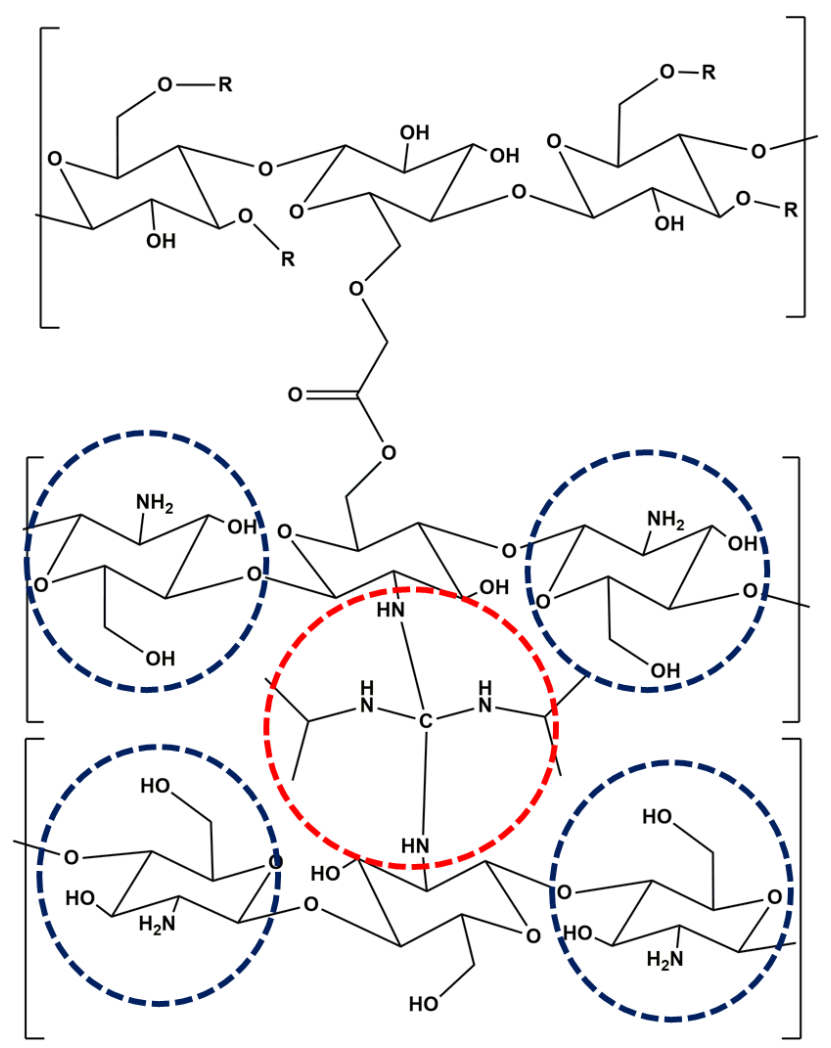

Fonte: Autor

Legenda: _ - - Região de menor impedimento

- - - Região de maior impedimento

Assim, no ponto onde ocorreu a reação entre os polímeros para a formação do adsorvente, os sítios ativos encontram-se em uma área de maior impedimento, enquanto as demais unidades de repetição apresentam maior liberdade para interagir com o adsorvato. Dessa 
forma, os processos de adsorção ocorrem em tempo e taxas diferentes entre essas duas regiões, como foi observado pelo modelo de Weber-Moris.

Realizados os estudos utilizando-se os três modelos, ao comparar-se os resultados obtidos (Tabela 23), o de pseudo-segunda ordem apresentou melhores ajustes devido ao elevado coeficiente de correlação $\left(\mathrm{R}^{2}\right)$ para ambos os adsorventes e, mostrou resultados semelhantes de capacidade de adsorção no equilíbrio em relação ao valor observado experimentalmente, sendo esse o modelo cinético que se aplica ao processo de adsorção utilizando-se esses adsorventes (CMCQF e CMCQDIC).

Tabela 23 - Comparação dos parâmetros obtidos pelos três modelos cinéticos

\begin{tabular}{|c|c|c|}
\hline Método/Adsorvente & CMCQF & CMCQDIC \\
\hline \multicolumn{3}{|l|}{ Pseudo-primeira order } \\
\hline $\mathrm{q}_{\mathrm{e}}(\exp )\left(\mathrm{mg} \cdot \mathrm{g}^{-1}\right)$ & 57,10 & 48,48 \\
\hline $\mathrm{q}_{\mathrm{e}}(\mathrm{calc})\left(\mathrm{mg} \cdot \mathrm{g}^{-1}\right)$ & 11,24 & 10,11 \\
\hline $\mathrm{k}_{1}\left(\min ^{-1}\right)$ & 0,0866 & 0,0183 \\
\hline $\mathrm{R}^{2}$ & 0,56 & 0,96 \\
\hline \multicolumn{3}{|l|}{ Pseudo-segunda order } \\
\hline $\mathrm{q}_{\mathrm{e}}(\exp )\left(m g \cdot \mathrm{g}^{-1}\right)$ & 57,10 & 48,48 \\
\hline $\mathrm{q}_{\mathrm{e}}(\mathrm{calc})\left(\mathrm{mg} \cdot \mathrm{g}^{-1}\right)$ & 57,14 & 49,26 \\
\hline $\mathrm{k}_{2}\left(\mathrm{~g} \cdot \mathrm{min} \cdot \mathrm{mg}^{-1}\right)$ & 0,0278 & 0,00522 \\
\hline $\mathrm{R}^{2}$ & 0,99 & 0,99 \\
\hline \multicolumn{3}{|l|}{ Weber-Morris } \\
\hline $\mathrm{q}_{\mathrm{e}} \exp \left(\mathrm{mg} \cdot \mathrm{g}^{-1}\right)$ & 57,10 & 48,48 \\
\hline $\mathrm{q}_{\mathrm{e}}$ calc $\left(\mathrm{mg} \cdot \mathrm{g}^{-1}\right)$ & 57,57 & 48,08 \\
\hline $\mathrm{C}\left(\mathrm{mg} \cdot \mathrm{g}^{-1}\right)$ & 33,41 & $34,61-42,43$ \\
\hline $\mathrm{K}_{\mathrm{d}}\left(\mathrm{mg} \cdot \mathrm{g}^{-1} \cdot \mathrm{min}^{-0.5}\right)$ & 4,891 & $1,4885-0,4250$ \\
\hline $\mathrm{R}^{2}$ & 0,93 & $0,98-0,78$ \\
\hline
\end{tabular}

Fonte: Autor

Pode-se também afirmar que a etapa de controle da velocidade de adsorção é a reação no sítio ativo que envolve, principalmente, forças de valência entre o adsorvente e o adsorvato, também chamado de difusão superficial, pois é uma das hipóteses admitidas pelo método e, a taxa de adsorção, é diretamente proporcional ao número de sítios ativos presentes no adsorvente (CAMPOS et al, 2019; RANGABHASHIYAM; BALASUBRAMANIAN, 2018).

Dessa forma, indica que para que o processo ocorra de maneira eficiente, a interação adsorvato-adsorvente deve ser otimizada, sendo o pH um fator de grande importância, uma vez 
que auxilia na maximização dessas interações e nenhum dos métodos apresentam parâmetros que prevejam esse tipo de interação.

Apesar de o modelo de Weber e Morris não se ajustar ao processo com tanta eficiência, a realização de estudos utilizando-se o mesmo é de grande importância para verificação do mecanismo de transporte de massa do processo, sendo que verificou-se que para ambos os adsorventes a difusão intrapartícula que, embora presente, não foi determinante para o processo, uma vez que o coeficiente linear (C) do ajuste do modelo não foi nulo para região que se variou o capacidade de adsorção com tempo. Essa observação pode ser justificada pelo fato de que, em polímeros naturais e seus derivados, que apresentam cadeia longa e lineares, a adsorção ocorre na superfície, indicando que o mecanismo de transporte ocorre por meio da camada limite, difusão externa ou em filme e, a partir desse ponto, fica retido por difusão superficial (SHARMA et al., 2019)

Contudo, a difusão intrapartícula, característica de adsorventes porosos, é a etapa de transferência de massa que ocorre da região da camada limite para a estrutura interna desses adsorventes (macroporos e microporos). A mesma encontra-se presente no processo, uma vez que a matriz polimérica do adsorvente pode apresentar regiões onde as macromoléculas do polímero apresentem uma conformidade que dificulta a passagem do adsorvato e, este, deve se movimentar entre as cadeias poliméricas para atingir o maior número de sítios. Sendo assim, apesar de não apresentar uma estrutura porosa, o adsorvato encontra resistência para o transporte relacionada com a organização das cadeias poliméricas, o que caracteriza uma difusão intrapartícula.

\subsubsection{Influência do pH}

Após determinação do tempo ótimo a ser utilizado nos processos de adsorção, foi realizada a avaliação da variação do $\mathrm{pH}$ no processo (Tabela 24, Apêndice A), como descrito no item 4.3.4.2, uma vez que esse parâmetro afeta a eficiência da atração adsorvato-adsorvente. Assim, foi avaliada a capacidade de adsorção em diferentes pH de soluções. 
Tabela 24 - Dados da influência no $\mathrm{pH}$ no processo de adsorção referente ao CMCQF

\begin{tabular}{|c|c|c|c|c|c|c|}
\hline Adsorvente & \multicolumn{3}{|c|}{ CMCQF } & \multicolumn{3}{|c|}{ CMCQDIC } \\
\hline $\mathrm{pH}$ & $\begin{array}{l}\text { Concentração } \\
\text { inicial (ppm) }\end{array}$ & $\begin{array}{l}\text { Concetração } \\
\text { final (ppm) }\end{array}$ & $\begin{array}{l}\text { Capacidade } \\
\text { de adsorção } \\
\left(\mathrm{mg} \cdot \mathrm{g}^{-1}\right)\end{array}$ & $\begin{array}{l}\text { Concentração } \\
\text { inicial (ppm) }\end{array}$ & $\begin{array}{l}\text { Concetração } \\
\text { final (ppm) }\end{array}$ & $\begin{array}{l}\text { Capacidade de } \\
\text { adsorção } \\
\left(\mathrm{mg} \cdot \mathrm{g}^{-1}\right)\end{array}$ \\
\hline 2 & - & - & - & $230,99 \pm 0,47$ & $94,26 \pm 0,35$ & $67,62 \pm 0,24$ \\
\hline 2,5 & $238,71 \pm 1,47$ & $108,06 \pm 1,58$ & $65,00 \pm 1,60$ & $228,53 \pm 0,70$ & $94,26 \pm 0,35$ & $67,20 \pm 0,24$ \\
\hline 3 & $247,21 \pm 0,30$ & $117,45 \pm 1,71$ & $64,80 \pm 3,30$ & $229,94 \pm 0,70$ & $135,03 \pm 1,05$ & $47,74 \pm 0,63$ \\
\hline 4 & $241,84 \pm 1,49$ & $124,16 \pm 1,37$ & $58,50 \pm 2,50$ & $232,75 \pm 0,70$ & $155,42 \pm 1,49$ & $38,70 \pm 1,30$ \\
\hline 5 & $229,76 \pm 1,19$ & $134,01 \pm 1,58$ & $47,60 \pm 1,80$ & $230,64 \pm 0,23$ & $158,58 \pm 1,81$ & $36,10 \pm 1,40$ \\
\hline 6 & $227,52 \pm 1,49$ & $159,06 \pm 1,58$ & $34,10 \pm 1,60$ & $236,26 \pm 0,23$ & $173,34 \pm 1,81$ & $31,20 \pm 1,40$ \\
\hline 7 & $220,36 \pm 0,89$ & $188,59 \pm 0,00$ & $15,87 \pm 0,02$ & $226,42 \pm 0,23$ & $219,74 \pm 1,51$ & $3,40 \pm 1,80$ \\
\hline 8 & $204,26 \pm 0,89$ & $188,15 \pm 1,34$ & $8,04 \pm 0,69$ & $223,61 \pm 0,23$ & $218,34 \pm 1,81$ & $2,60 \pm 1,40$ \\
\hline
\end{tabular}

Fonte: Autor

Analisando os resultados, nota-se que a capacidade de adsorção aumenta conforme o pH é reduzido para ambos os adsorventes (Figuras 65 e 66). O resultado observado se deve ao fato dos íons de cromo hexavalente se manifestarem em efluentes, independente do $\mathrm{pH}$, na forma de ânions, sendo que para $\mathrm{pH}$ neutro e alcalino na forma de cromato $\left(\mathrm{CrO}_{4}{ }^{2-}\right)$ e, predominantemente, na forma de cromato de hidrogênio $\left(\mathrm{HCrO}_{4}^{-}\right)$para $\mathrm{pH}$ ácido.

Figura 65 - Capacidade de adsorção em função do pH (CMCQF)

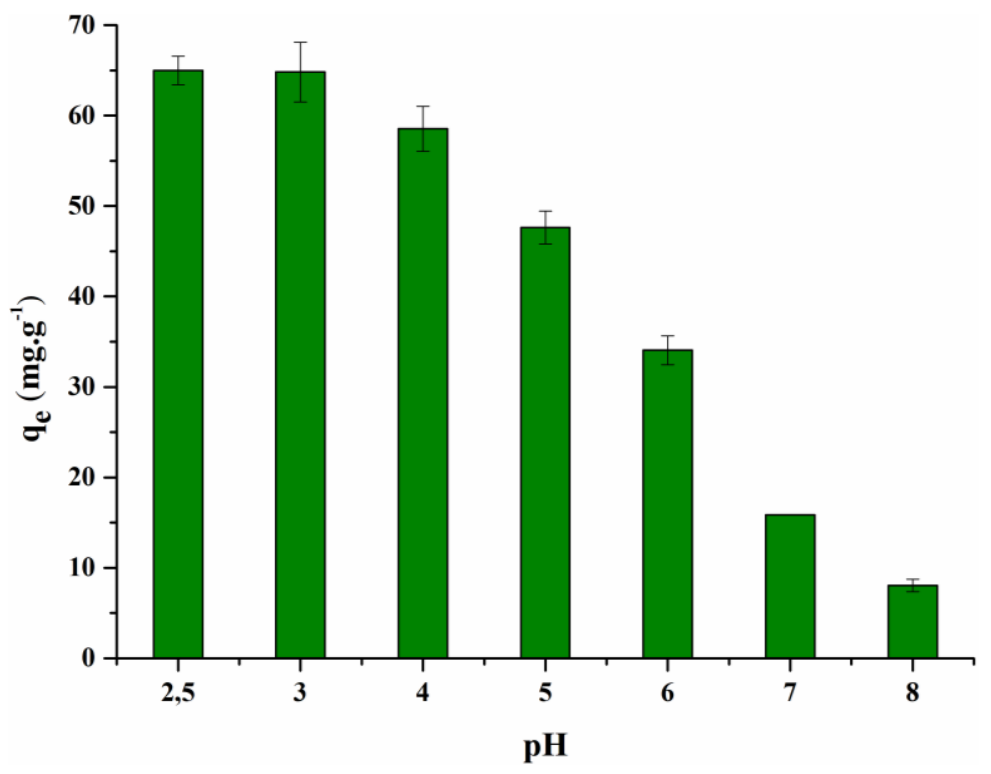

Fonte: Autor 
Figura 66 - Capacidade de adsorção em função do pH (CMCQDIC)

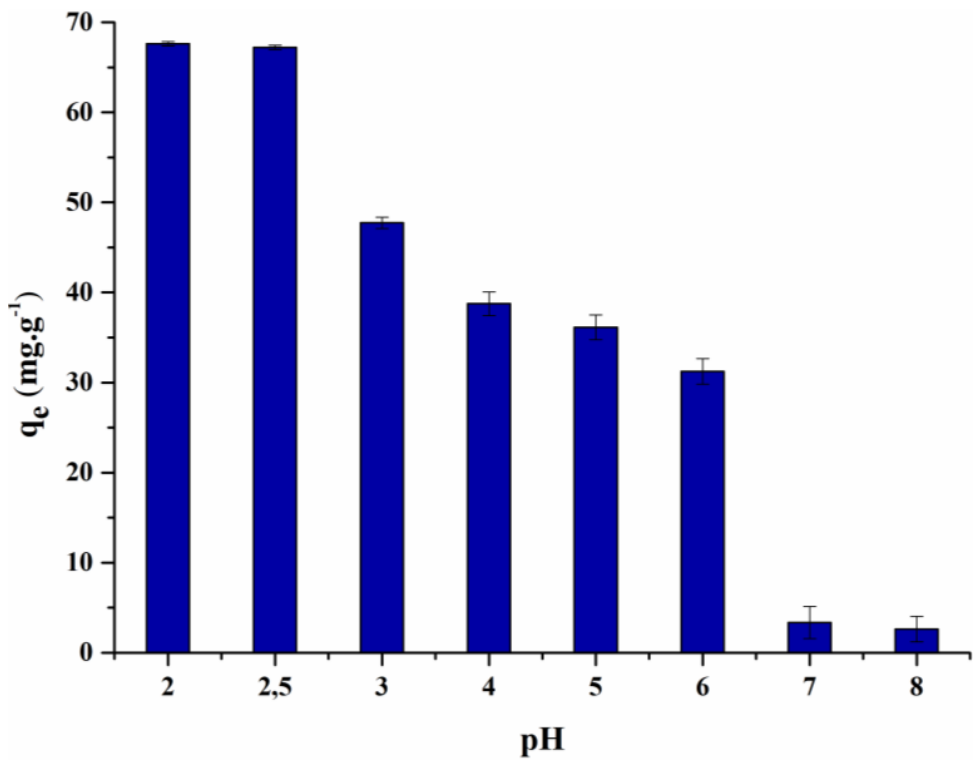

Fonte: Autor

Dessa forma, em meio ácido, as superfícies dos adsorventes encontram-se carregadas positivamente, pois as aminas provenientes da quitosana encontram-se protonadas na forma de íons amônios $\left(\mathrm{NH}_{3}{ }^{+}\right)$que favorece a atração eletrostática entre esses íons e o ânion de cromato de hidrogênio obtendo-se, assim, aumento da capacidade de adsorção conforme se reduz o pH (Figura 67 e 68) (CAMPOS et al., 2019; JOBBY et a., 2018).

Figura 67 - Mecanismos de adsorção do cromo hexavalente para o CMCQF

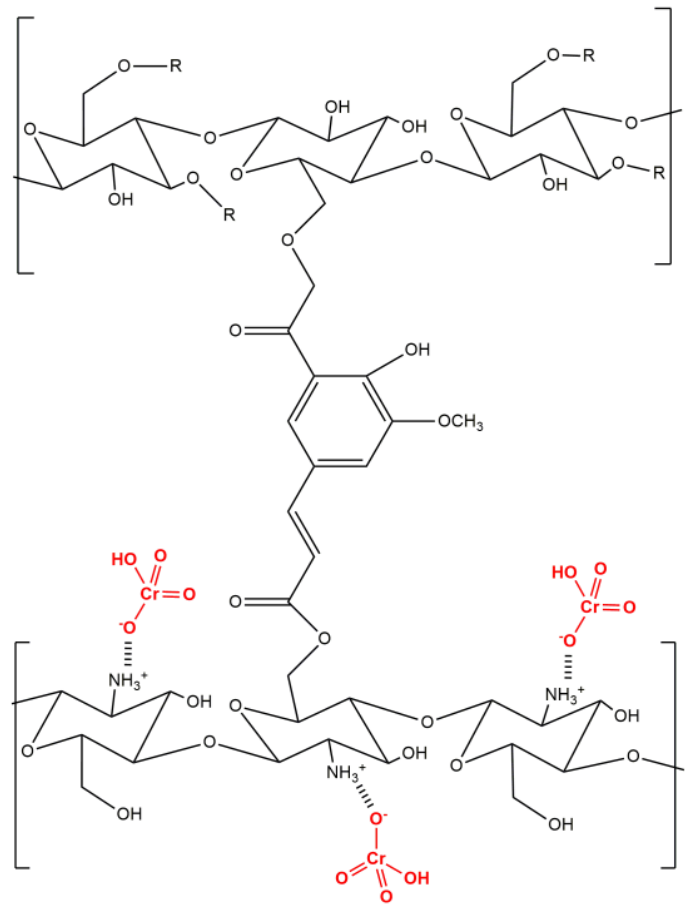

Fonte: Autor 
Figura 68 - Mecanismos de adsorção do cromo hexavalente para o CMCQDIC

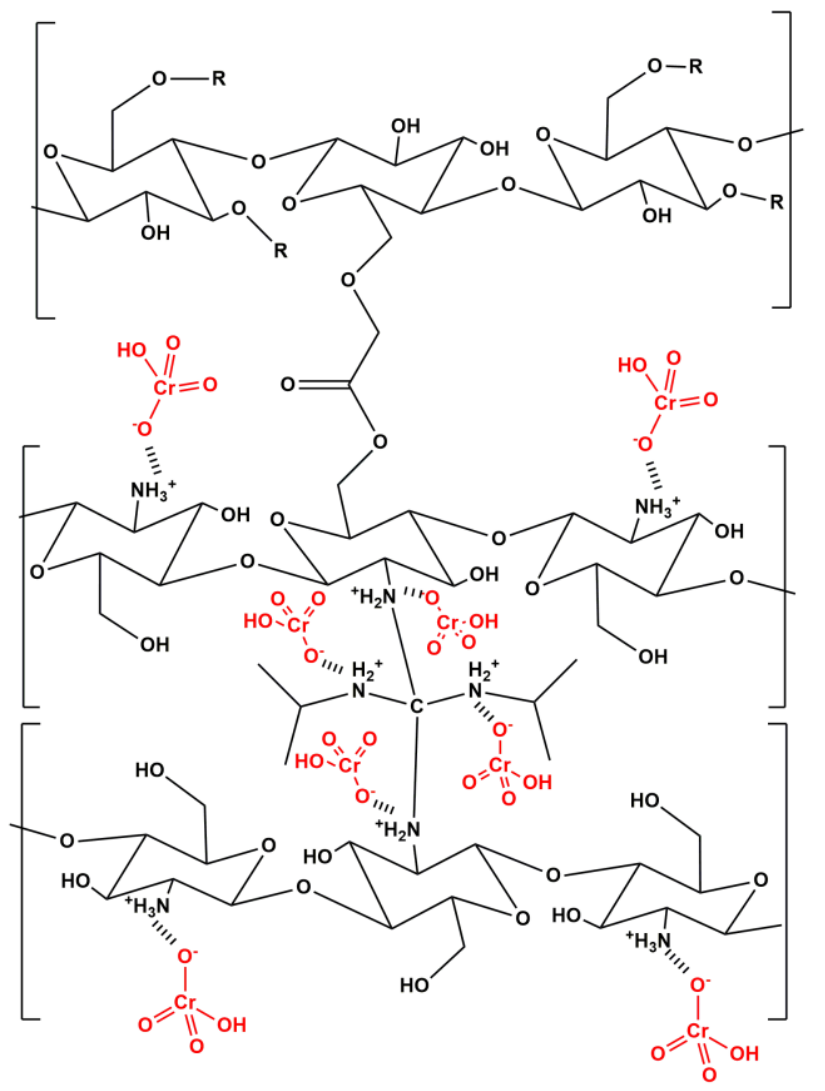

Fonte: Autor

Para o adsorvente CMCQF, embora tenha sido observada uma maior capacidade de adsorção em pH igual a 2,5, estabeleceu-se como $\mathrm{pH}$ ótimo 3, uma vez que foi observado, abaixo desse $\mathrm{pH}$, início da degradação do adsorvente, não sendo ideal para o processo.

Já, o adsorvente CMCQDIC apresentou uma maior resistência ao $\mathrm{pH}$ 2,0 não apresentando sinais de degradação, porém para $\mathrm{pH}$ menor que 2,5 não ocorreu mudança significativa na capacidade de adsorção, sendo o mesmo estabelecido como ótimo.

Essa mudança de $\mathrm{pH}$ ideal pode ser explicada pelo fato do adsorvente CMCQDIC apresentar uma quantidade maior de nitrogênios presentes na estrutura em relação ao CMCQF, acarreta na necessidade de uma maior quantidade de íons $\mathrm{H}^{+}$, para formar íons amônios, e, consequentemente, um menor $\mathrm{pH}$.

\subsubsection{Isotermas de adsorção}

Estabelecido o tempo ideal de 60 e 180 min e o $\mathrm{pH}$ ideal 3 e 2,5 para os adsorventes CMCQF e CMCQDIC, respectivamente, realizou-se o estudo referente a influência da temperatura no processo de adsorção, como descrito no item 4.3.4.3. Para isso, foram utilizadas 
as isotermas de adsorção sendo que, os valores de concentração e capacidade obtidos durante a realização dos experimentos encontram-se presentes nas tabelas 25 a 29 e apêndice A.

Tabela 25 - Dados para o estudo de isotermas à temperatura de $20^{\circ} \mathrm{C}$

\begin{tabular}{c|c|c|c|c|c}
\hline \multicolumn{5}{c}{ CMCQF } & \multicolumn{3}{c}{ CMCQDIC } \\
\hline $\begin{array}{c}\text { Concentração } \\
\text { Inicial (ppm) }\end{array}$ & $\begin{array}{c}\text { Concentração } \\
\text { final (ppm) }\end{array}$ & $\begin{array}{c}\text { Capacidade de } \\
\text { adsorção }\left(\mathrm{mg} . \mathrm{g}^{-1}\right)\end{array}$ & $\begin{array}{c}\text { Concentração } \\
\text { Inicial (ppm) }\end{array}$ & $\begin{array}{c}\text { Concentração } \\
\text { final (ppm) }\end{array}$ & $\begin{array}{c}\text { Capacidade de } \\
\text { adsorção (mg.g-1) }\end{array}$ \\
\hline $24,59 \pm 0,01$ & $3,59 \pm 0,00$ & $10,49 \pm 0,05$ & $24,06 \pm 0,35$ & $0,53 \pm 0,00$ & $11,86 \pm 0,21$ \\
$48,91 \pm 0,03$ & $9,11 \pm 0,37$ & $19,94 \pm 0,26$ & $48,45 \pm 0,71$ & $1,78 \pm 0,00$ & $23,24 \pm 0,09$ \\
$99,02 \pm 0,02$ & $19,43 \pm 0,37$ & $39,72 \pm 0,10$ & $98,64 \pm 0,71$ & $5,32 \pm 1,41$ & $46,47 \pm 0,52$ \\
$149,14 \pm 0,05$ & $43,01 \pm 0,37$ & $53,17 \pm 0,03$ & $149,19 \pm 0,35$ & $12,04 \pm 1,06$ & $68,30 \pm 0,53$ \\
$199,99 \pm 0,07$ & $61,44 \pm 0,37$ & $68,59 \pm 0,18$ & $197,98 \pm 0,35$ & $28,09 \pm 0,00$ & $83,69 \pm 0,12$ \\
$249,73 \pm 0,10$ & $93,13 \pm 0,37$ & $78,30 \pm 0,18$ & $249,23 \pm 0,00$ & $48,97 \pm 0,35$ & $100,13 \pm 0,03$ \\
$299,11 \pm 0,00$ & $126,66 \pm 1,47$ & $85,88 \pm 0,39$ & $295,90 \pm 0,71$ & $75,70 \pm 1,41$ & $109,44 \pm 0,21$ \\
$349,86 \pm 0,04$ & $158,72 \pm 1,79$ & $95,10 \pm 2,10$ & $350,00 \pm 0,00$ & $117,05 \pm 1,41$ & $116,48 \pm 0,47$ \\
$399,97 \pm 0,04$ & $193,63 \pm 0,74$ & $103,18 \pm 0,57$ & $397,37 \pm 0,71$ & $129,07 \pm 0,00$ & $133,88 \pm 0,27$ \\
$449,35 \pm 0,03$ & $240,05 \pm 1,47$ & $104,23 \pm 0,94$ & $443,32 \pm 1,41$ & $159,83 \pm 1,06$ & $139,79 \pm 0,52$ \\
\hline
\end{tabular}

Fonte: Autor

Tabela 26 - Dados para o estudo de isotermas à temperatura de $25^{\circ} \mathrm{C}$

\begin{tabular}{c|c|c|c|c|c}
\hline \multicolumn{2}{c}{ CMCQF } & \multicolumn{3}{c}{ CMCQDIC } \\
\hline Concentração & $\begin{array}{c}\text { Concentração } \\
\text { final (ppm) }\end{array}$ & $\begin{array}{c}\text { Capacidade de } \\
\text { adsorção }\left(\mathrm{mg}^{-} \mathrm{g}^{-1}\right)\end{array}$ & $\begin{array}{c}\text { Concentração } \\
\text { Inicial (ppm) }\end{array}$ & $\begin{array}{c}\text { Concentração } \\
\text { final (ppm) }\end{array}$ & $\begin{array}{c}\text { Capacidade de } \\
\left.\text { adsorção (mg.g }{ }^{-1}\right)\end{array}$ \\
\hline $24,59 \pm 0,01$ & $4,69 \pm 0,37$ & $10,01 \pm 0,17$ & $24,06 \pm 0,35$ & $1,78 \pm 0,00$ & $11,13 \pm 0,01$ \\
$48,91 \pm 0,03$ & $9,85 \pm 0,37$ & $19,47 \pm 0,16$ & $48,45 \pm 0,71$ & $2,14 \pm 0,35$ & $23,02 \pm 0,13$ \\
$99,02 \pm 0,02$ & $28,28 \pm 1,11$ & $35,16 \pm 0,48$ & $98,64 \pm 0,71$ & $7,80 \pm 0,35$ & $45,29 \pm 0,22$ \\
$149,14 \pm 0,05$ & $47,81 \pm 1,47$ & $50,72 \pm 0,89$ & $149,19 \pm 0,35$ & $19,11 \pm 1,77$ & $64,59 \pm 0,94$ \\
$199,99 \pm 0,07$ & $69,91 \pm 0,74$ & $64,78 \pm 0,11$ & $197,98 \pm 0,35$ & $35,37 \pm 0,35$ & $80,66 \pm 0,30$ \\
$249,73 \pm 0,10$ & $103,81 \pm 0,00$ & $72,45 \pm 0,07$ & $249,23 \pm 0,00$ & $56,23 \pm 1,13$ & $96,02 \pm 0,80$ \\
$299,11 \pm 0,00$ & $139,19 \pm 0,00$ & $80,20 \pm 0,56$ & $295,90 \pm 0,71$ & $81,54 \pm 1,95$ & $106,33 \pm 0,01$ \\
$349,86 \pm 0,04$ & $165,35 \pm 1,11$ & $92,4 \pm 1,10$ & $350,00 \pm 0,00$ & $117,05 \pm 0,00$ & $116,36 \pm 0,12$ \\
$399,97 \pm 0,04$ & $210,58 \pm 0,00$ & $94,33 \pm 0,94$ & $397,37 \pm 0,71$ & $141,44 \pm 0,35$ & $126,32 \pm 0,30$ \\
$449,35 \pm 0,03$ & $243,74 \pm 0,74$ & $102,19 \pm 0,04$ & $443,32 \pm 1,41$ & $173,97 \pm 1,30$ & $133,48 \pm 0,66$ \\
\hline
\end{tabular}

Fonte: Autor 
Tabela 27 - Dados para o estudo de isotermas à temperatura de $30{ }^{\circ} \mathrm{C}$

\begin{tabular}{c|c|c|c|c|c}
\hline \multicolumn{3}{c|}{ CMCQF } & \multicolumn{3}{c}{ CMCQDIC } \\
\hline $\begin{array}{c}\text { Concentração } \\
\text { Inicial (ppm) }\end{array}$ & $\begin{array}{c}\text { Concentração } \\
\text { final (ppm) }\end{array}$ & $\begin{array}{c}\text { Capacidade de } \\
\text { adsorção }\left(\mathrm{mg} \cdot \mathrm{g}^{-1}\right)\end{array}$ & $\begin{array}{c}\text { Concentração } \\
\text { Inicial (ppm) }\end{array}$ & $\begin{array}{c}\text { Concentração } \\
\text { final (ppm) }\end{array}$ & $\begin{array}{c}\text { Capacidade de } \\
\left.\text { adsorção (mg.g }{ }^{-1}\right)\end{array}$ \\
\hline $24,59 \pm 0,01$ & $6,54 \pm 0,00$ & $9,06 \pm 0,05$ & $24,06 \pm 0,35$ & $3,03 \pm 0,35$ & $10,55 \pm 0,19$ \\
$48,91 \pm 0,03$ & $9,11 \pm 0,37$ & $19,98 \pm 0,23$ & $48,45 \pm 0,71$ & $6,38 \pm 0,71$ & $20,91 \pm 0,13$ \\
$99,02 \pm 0,02$ & $30,49 \pm 2,58$ & $34,30 \pm 1,30$ & $98,64 \pm 0,71$ & $9,56 \pm 0,71$ & $44,45 \pm 0,00$ \\
$149,14 \pm 0,05$ & $53,70 \pm 0,00$ & $48,10 \pm 0,00$ & $149,19 \pm 0,35$ & $19,82 \pm 0,35$ & $64,75 \pm 0,95$ \\
$199,99 \pm 0,07$ & $67,70 \pm 0,00$ & $66,14 \pm 0,00$ & $197,98 \pm 0,35$ & $45,98 \pm 0,35$ & $75,77 \pm 0,20$ \\
$249,73 \pm 0,10$ & $107,50 \pm 1,47$ & $70,76 \pm 0,52$ & $249,23 \pm 0,00$ & $66,49 \pm 0,00$ & $91,83 \pm 0,44$ \\
$299,11 \pm 0,00$ & $139,19 \pm 0,74$ & $79,88 \pm 0,19$ & $295,90 \pm 0,71$ & $83,81 \pm 0,71$ & $105,90 \pm 1,20$ \\
$349,86 \pm 0,04$ & $168,30 \pm 0,37$ & $90,51 \pm 0,45$ & $350,00 \pm 0,00$ & $126,22 \pm 0,00$ & $111,22 \pm 0,39$ \\
$399,97 \pm 0,04$ & $214,26 \pm 0,74$ & $92,76 \pm 0,09$ & $397,37 \pm 0,71$ & $160,18 \pm 0,71$ & $118,25 \pm 0,83$ \\
$449,35 \pm 0,03$ & $254,06 \pm 2,21$ & $97,26 \pm 0,71$ & $443,32 \pm 1,41$ & $193,41 \pm 1,41$ & $124,46 \pm 0,10$ \\
\hline
\end{tabular}

Fonte: Autor

Tabela 28 - Dados para o estudo de isotermas à temperatura de $40{ }^{\circ} \mathrm{C}$

\begin{tabular}{c|c|c|c|c|c}
\hline \multicolumn{5}{c|}{ CMCQF } & \multicolumn{3}{c}{ CMCQDIC } \\
\hline $\begin{array}{c}\text { Concentração } \\
\text { Inicial (ppm) }\end{array}$ & $\begin{array}{c}\text { Concentração } \\
\text { final (ppm) }\end{array}$ & $\begin{array}{c}\text { Capacidade de } \\
\text { adsorção (mg.g-1) }\end{array}$ & $\begin{array}{c}\text { Concentração } \\
\text { Inicial (ppm) }\end{array}$ & $\begin{array}{c}\text { Concentração } \\
\text { final (ppm) }\end{array}$ & $\begin{array}{c}\text { Capacidade de } \\
\text { adsorção (mg.g-1) }^{-1}\end{array}$ \\
\hline $24,59 \pm 0,01$ & $5,80 \pm 0,00$ & $9,38 \pm 0,08$ & $24,06 \pm 0,35$ & $3,45 \pm 0,00$ & $10,36 \pm 0,00$ \\
$48,91 \pm 0,03$ & $10,59 \pm 0,37$ & $19,30 \pm 0,17$ & $48,45 \pm 0,71$ & $7,09 \pm 0,35$ & $20,62 \pm 0,11$ \\
$99,02 \pm 0,02$ & $32,70 \pm 1,84$ & $33,23 \pm 0,92$ & $98,64 \pm 0,71$ & $12,75 \pm 0,35$ & $42,74 \pm 0,05$ \\
$149,14 \pm 0,05$ & $53,70 \pm 1,47$ & $47,29 \pm 0,59$ & $149,19 \pm 0,35$ & $18,40 \pm 0,35$ & $65,14 \pm 0,08$ \\
$199,99 \pm 0,07$ & $69,91 \pm 1,47$ & $64,27 \pm 0,73$ & $197,98 \pm 0,35$ & $48,81 \pm 2,12$ & $73,99 \pm 0,32$ \\
$249,73 \pm 0,10$ & $99,39 \pm 0,74$ & $74,88 \pm 0,81$ & $249,23 \pm 0,00$ & $80,71 \pm 0,35$ & $83,76 \pm 0,04$ \\
$299,11 \pm 0,00$ & $134,77 \pm 0,00$ & $81,20 \pm 0,32$ & $295,90 \pm 0,71$ & $99,08 \pm 2,12$ & $97,72 \pm 0,08$ \\
$349,86 \pm 0,04$ & $168,67 \pm 0,74$ & $90,06 \pm 0,01$ & $350,00 \pm 0,00$ & $138,26 \pm 0,00$ & $104,51 \pm 0,10$ \\
$399,97 \pm 0,04$ & $212,05 \pm 1,47$ & $93,68 \pm 0,83$ & $397,37 \pm 0,71$ & $160,89 \pm 0,35$ & $118,00 \pm 0,35$ \\
$449,35 \pm 0,03$ & $256,27 \pm 1,47$ & $96,16 \pm 0,93$ & $443,32 \pm 1,41$ & $195,54 \pm 2,83$ & $123,28 \pm 0,02$ \\
\hline
\end{tabular}

Fonte: Autor 
Tabela 29 - Dados para o estudo de isotermas à temperatura de $50{ }^{\circ} \mathrm{C}$

\begin{tabular}{c|c|c|c|c|c}
\hline \multicolumn{3}{c|}{ CMCQF } & \multicolumn{3}{c}{ CMCQDIC } \\
\hline $\begin{array}{c}\text { Concentração } \\
\text { Inicial (ppm) }\end{array}$ & $\begin{array}{c}\text { Concentração } \\
\text { final (ppm) }\end{array}$ & $\begin{array}{c}\text { Capacidade de } \\
\text { adsorção }\left({\mathrm{mg} . \mathrm{g}^{-1}}^{-1}\right)\end{array}$ & $\begin{array}{c}\text { Concentração } \\
\text { Inicial (ppm) }\end{array}$ & $\begin{array}{c}\text { Concentração } \\
\text { final (ppm) }\end{array}$ & $\begin{array}{c}\text { Capacidade de } \\
\left.\text { adsorção (mg.g }^{-1}\right)\end{array}$ \\
\hline $24,59 \pm 0,35$ & $6,17 \pm 0,37$ & $9,09 \pm 0,23$ & $24,06 \pm 0,35$ & $4,29 \pm 0,00$ & $9,94 \pm 0,02$ \\
$48,91 \pm 0,71$ & $10,59 \pm 0,37$ & $19,05 \pm 0,07$ & $48,45 \pm 0,71$ & $6,38 \pm 0,35$ & $20,97 \pm 0,20$ \\
$99,02 \pm 0,71$ & $31,59 \pm 3,68$ & $33,90 \pm 1,90$ & $98,64 \pm 0,71$ & $18,40 \pm 0,35$ & $39,84 \pm 0,10$ \\
$149,14 \pm 0,35$ & $56,28 \pm 0,37$ & $46,52 \pm 0,09$ & $149,19 \pm 0,35$ & $32,54 \pm 1,06$ & $58,85 \pm 0,48$ \\
$199,99 \pm 0,35$ & $73,23 \pm 0,37$ & $63,51 \pm 0,18$ & $197,98 \pm 0,35$ & $59,77 \pm 0,71$ & $69,73 \pm 0,29$ \\
$249,73 \pm 0,00$ & $103,08 \pm 0,00$ & $73,11 \pm 0,07$ & $249,23 \pm 0,00$ & $80,63 \pm 0,35$ & $84,56 \pm 0,26$ \\
$299,11 \pm 0,71$ & $139,19 \pm 0,74$ & $80,52 \pm 0,29$ & $295,90 \pm 0,71$ & $112,45 \pm 1,06$ & $92,18 \pm 0,07$ \\
$349,86 \pm 0,00$ & $171,98 \pm 0,37$ & $89,84 \pm 0,01$ & $350,00 \pm 0,00$ & $143,76 \pm 0,53$ & $101,79 \pm 0,73$ \\
$399,97 \pm 0,71$ & $217,21 \pm 0,74$ & $92,31 \pm 0,37$ & $397,37 \pm 0,71$ & $185,11 \pm 0,35$ & $105,08 \pm 0,62$ \\
$449,35 \pm 1,41$ & $259,95 \pm 0,74$ & $95,18 \pm 0,11$ & $443,32 \pm 1,41$ & $203,06 \pm 2,83$ & $119,30 \pm 0,30$ \\
\hline
\end{tabular}

Fonte: Autor

Todos os dados obtidos foram analisados por meio dos modelos Langmuir, Freundlich e Temkin, descritos nos itens 3.6.1.1, 3.6.1.2 e 3.6.1.3, respectivamente, com o intuito de determinar o comportamento de adsorção, o nível de interação adsorvato-adsorvente e, compreender o mecanismo de adsorção, frente a alteração de temperaturas.

Assim, analisando-se os dados utilizando-se a isoterma de Langmuir foi possível a determinação de dois parâmetros, a constante de equilíbrio entre a adsorção e seu processo inverso, a dessorção $\left(\mathrm{K}_{\mathrm{L}}\right)$ e, a máxima capacidade de adsorção que o sistema pode atingir, qmáx., sendo que, com esses dois parâmetros, foi possível estimar o fator de separação $\mathrm{R}_{\mathrm{L}}$, que mostra a relação de afinidade entre o adsorvato na fase liquida e na fase sólida.

Dessa forma, para cada temperatura foi traçada uma isoterma (Figura 69 e 70) e, os parâmetros encontra-se descritos na tabela 30, Apêndice D e E. 
Figura 69 - Isotermas de Langmuir para CMCQF

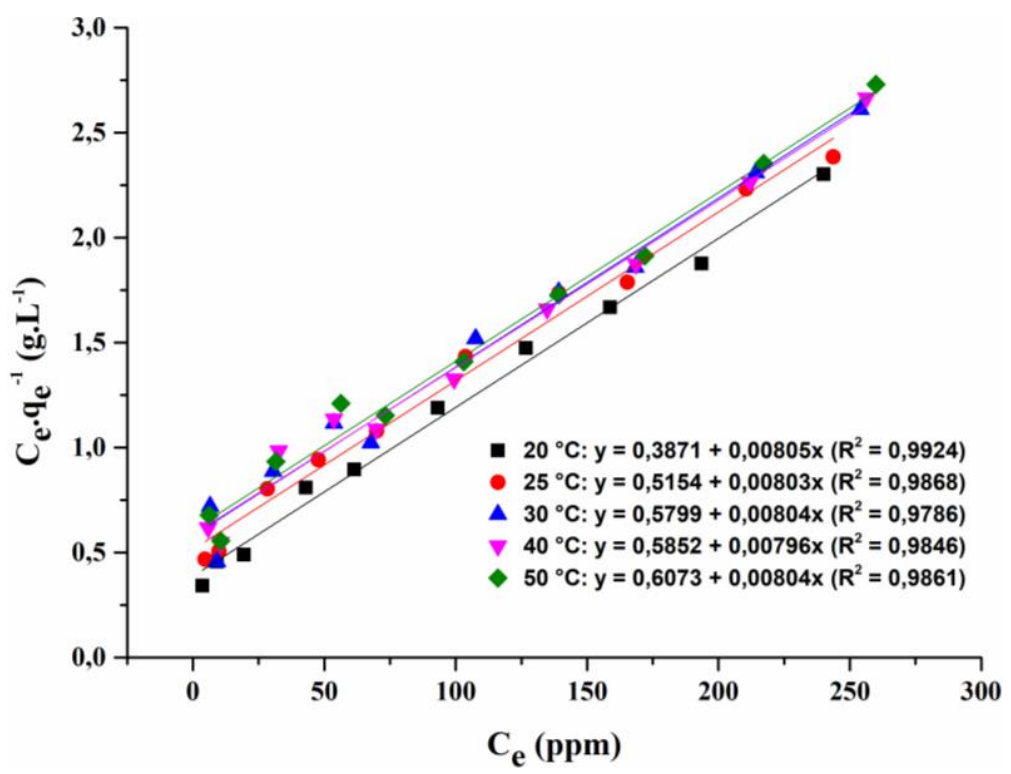

Fonte: Autor

Figura 70 - Isotermas de Langmuir para CMCQDIC

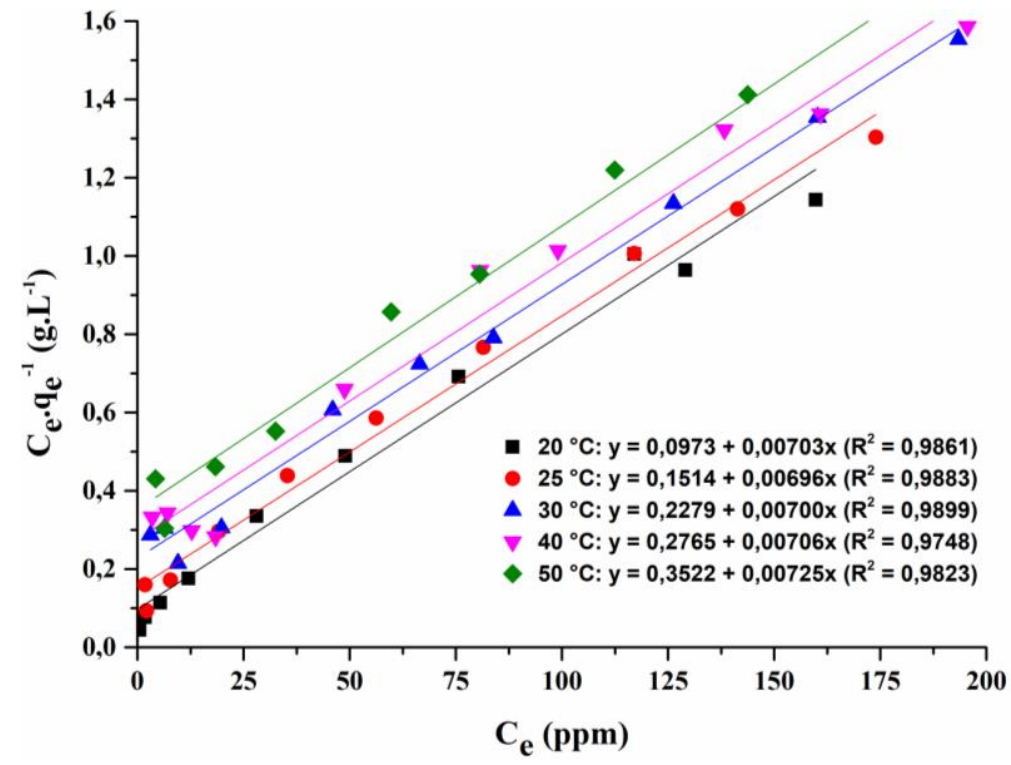

Fonte: Autor 
Tabela 30 - Parâmetros para a isoterma de Langmuir

\begin{tabular}{|c|c|c|c|c|c|c|}
\hline Adsorventes & Temperatura $\left({ }^{\circ} \mathrm{C}\right)$ & 20 & 25 & 30 & 40 & 50 \\
\hline \multirow{5}{*}{ CMCQF } & $\mathrm{q}_{\operatorname{máx}}\left(\mathrm{mg} \cdot \mathrm{g}^{-1}\right)$ & 124,220 & 124,530 & 124,380 & 125,630 & 124,380 \\
\hline & $\mathrm{K}_{\mathrm{L}}\left(\mathrm{L} \cdot \mathrm{mg}^{-1}\right)$ & 0,021 & 0,016 & 0,014 & 0,014 & 0,013 \\
\hline & $\mathrm{R}_{\mathrm{L}}{ }^{\text {Máx }}$ & 0,66 & 0,72 & 0,75 & 0,75 & 0,75 \\
\hline & $\mathrm{R}_{\mathrm{L}}{ }^{\operatorname{Min}}$ & 0,097 & 0,125 & 0,138 & 0,141 & 0,144 \\
\hline & $\mathrm{R}^{2}$ & 0,992 & 0,987 & 0,979 & 0,985 & 0,986 \\
\hline \multirow{5}{*}{ CMCQDIC } & $\mathrm{q}_{\text {máx }}\left(\mathrm{mg} \cdot \mathrm{g}^{-1}\right)$ & 142,250 & 143,68 & 142,860 & 141,640 & 137,930 \\
\hline & $\mathrm{K}_{\mathrm{L}}\left(\mathrm{L} \cdot \mathrm{mg}^{-1}\right)$ & 0,072 & 0,046 & 0,031 & 0,026 & 0,021 \\
\hline & $\mathrm{R}_{\mathrm{L}}{ }^{\text {Máx }}$ & 0,365 & 0,475 & 0,575 & 0,620 & 0,669 \\
\hline & $\mathrm{R}_{\mathrm{L}}{ }^{\mathrm{Min}}$ & 0,030 & 0,047 & 0,068 & 0,0812 & 0,099 \\
\hline & $\mathrm{R}^{2}$ & 0,986 & 0,988 & 0,990 & 0,975 & 0,982 \\
\hline
\end{tabular}

Fonte: Autor

Assim, pela análise dos valores descritos tabela 30, para ambos os adsorventes é possível verificar que, conforme a temperatura aumenta, o processo de adsorção se torna desfavorável e, o valor da constante de interação adsorvato-adsorvente $\left(\mathrm{K}_{\mathrm{L}}\right)$ diminui sendo que, quanto menor esse fator, menor a quantidade de adsorvato retido no adsorvente.

Com relação aos fatores de separação, que foram calculados com as concentrações iniciais $\left(\mathrm{R}_{\mathrm{L}}{ }^{\text {Máx }}\right)$ e finais $\left(\mathrm{R}_{\mathrm{L}}{ }^{\text {Mín }}\right)$ nota-se que, conforme aumenta-se a temperatura, os valores tendem a ficais mais próximos de 1 , ou seja, a afinidade do soluto pelo sólido diminui, sendo que, para processos de adsorção, valores próximos a 0 demostram uma maior predisposição do soluto ficar retido na superfície do adsorvente.

Outro fator importante é que as isotermas obtidas são praticamente paralelas, o que se torna mais um indicio que o aumento da temperatura diminui a interação adsorvato-adsorvente, pois as capacidades máximas de adsorção são semelhantes independente da temperatura para ambos os adsorventes.

Já, por meio da análise dos resultados utilizando-se a isoterma de Freundlich foi possível estimar dois parâmetros, a constante adimensional de interação entre o adsorvato e adsorvente (n) e, $K_{f}\left(m g . g^{-1}\right) /\left(\text { mg.L }{ }^{-1}\right)^{(1 / n)}$ (Figura 71 e 72 , Tabela 31). Salienta-se que $n$ deve apresentar valores entre 1 e 5 em processo de adsorção favoráveis. 
Figura 71 - Isoterma de Freundlich para CMCQF

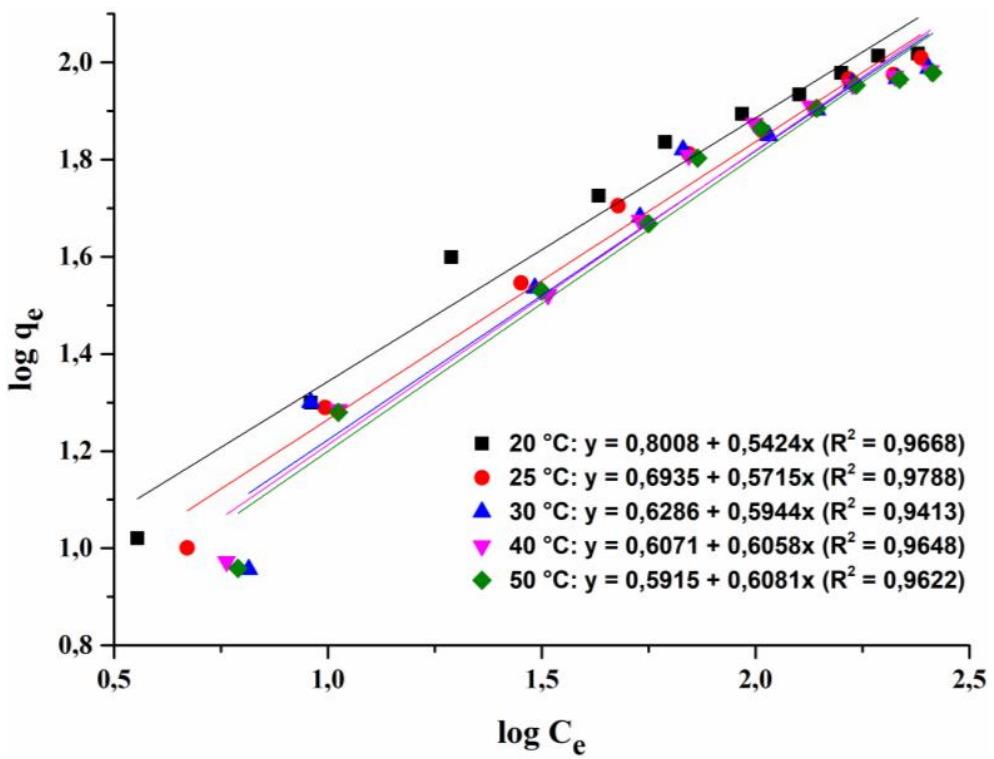

Fonte: Autor

Figura 72 - Isoterma de Freundlich para CMCQDIC

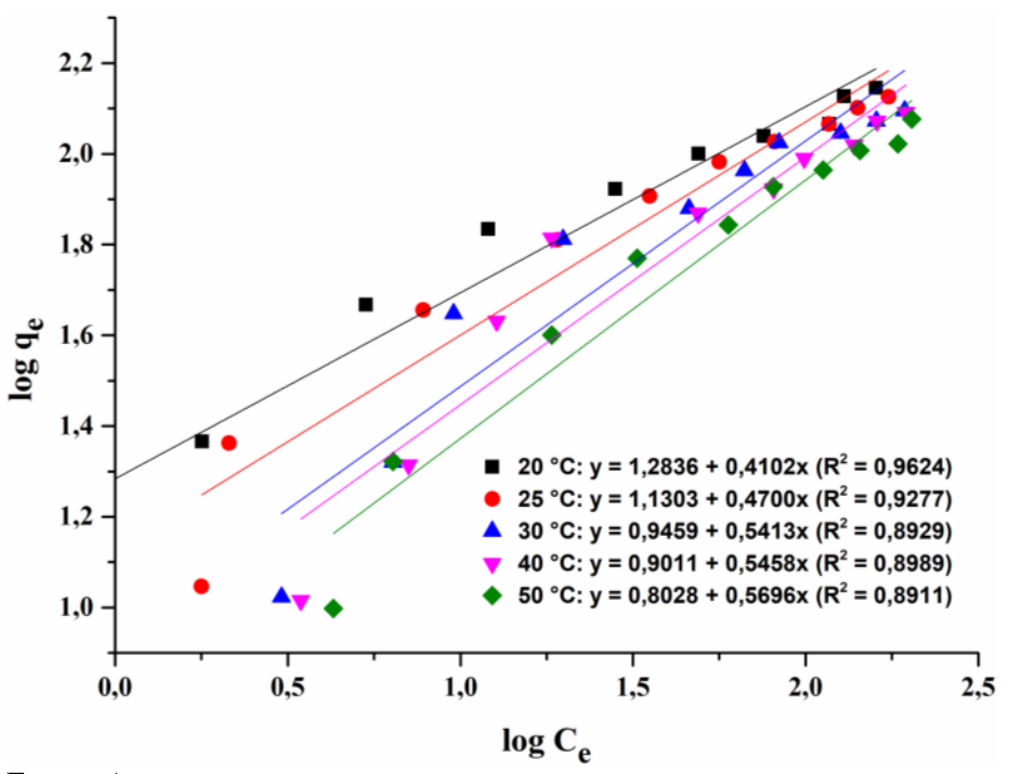

Fonte: Autor

Tabela 31 - Parâmetros para a isoterma de Freundlich

\begin{tabular}{c|c|c|c|c|c|c}
\hline Adsorventes & Temperatura $\left({ }^{\circ} \mathrm{C}\right)$ & 20 & 25 & 30 & 40 & 50 \\
\hline \multirow{3}{*}{$\mathrm{CMCQF}$} & $\mathrm{n}$ & 1,840 & 1,75 & 1,680 & 1,650 & 1,64 \\
& $\mathrm{~K}_{\mathrm{F}}\left(\mathrm{mg}^{(1-1 / \mathrm{n})} \cdot \mathrm{L}^{1 / \mathrm{n}} \cdot \mathrm{g}^{-1}\right)$ & 2,227 & 2,001 & 1,875 & 1,835 & 1,807 \\
& $\mathrm{R}^{2}$ & 0,967 & 0,979 & 0,941 & 0,965 & 0,962 \\
\hline \multirow{3}{*}{$\mathrm{CMCQDIC}$} & $\mathrm{n}$ & 2,44 & 2,130 & 1,850 & 1,830 & 1,760 \\
& $\mathrm{~K}_{\mathrm{F}}\left(\mathrm{mg}^{(1-1 / \mathrm{n})} \cdot \mathrm{L}^{1 / \mathrm{n}} \cdot \mathrm{g}^{-1}\right)$ & 3,610 & 3,097 & 2,575 & 2,462 & 2,232 \\
& $\mathrm{R}^{2}$ & 0,962 & 0,928 & 0,893 & 0,899 & 0,891 \\
\hline
\end{tabular}

Fonte: Autor 
A análise dos resultados contidos na tabela 31 mostra a diminuição das constantes para ambos os adsorventes com o aumento da temperatura, ou seja, ocorre a diminuição da interação adsorvato-adsorvente, mesmo que para todos os ensaios o parâmetro tenho ficado na faixa que favorece o processo de adsorção.

Por último, utilizando-se a isoterma de Temkin, foi possível a obtenção de dois parâmetros, a constante isotérmica de Temkin $\left(\mathrm{K}_{\mathrm{T}}\right)$ que representa a afinidade do adsorvato pelo adsorvente, ou seja, quanto maior essa constante maior a tendência de a superfície sólida reter as moléculas de adsorvato e, o calor de adsorção (b) (Figura 72 e 73, Tabela 32).

Figura 73 - Isoterma de Temkin para CMCQF

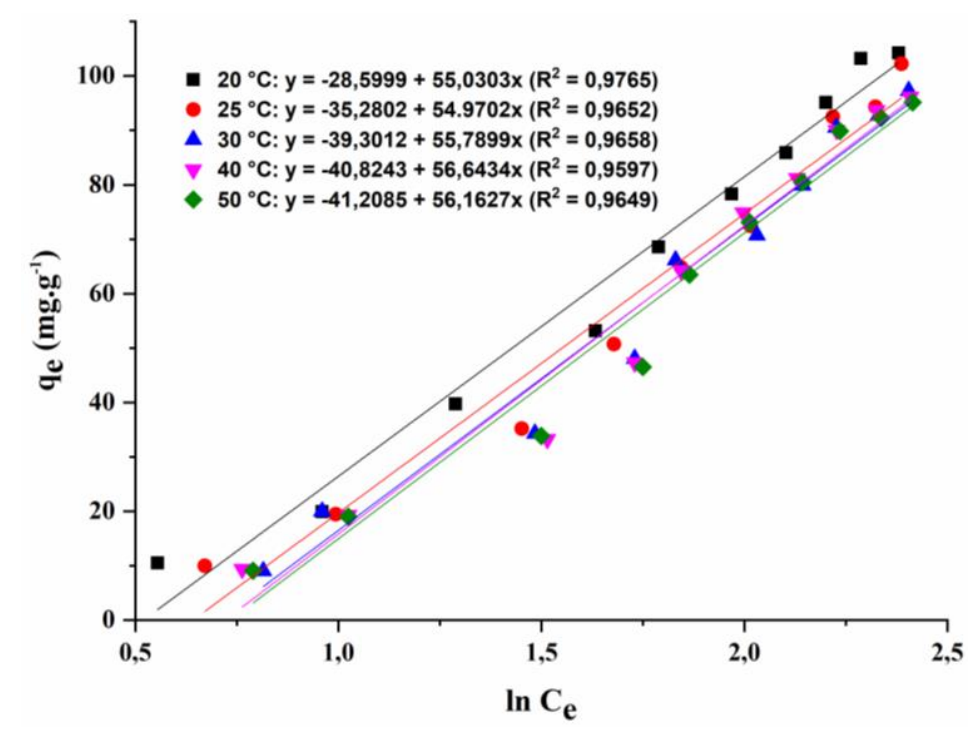

Fonte: Autor

Figura 74 - Isoterma de Temkin para CMCQDIC

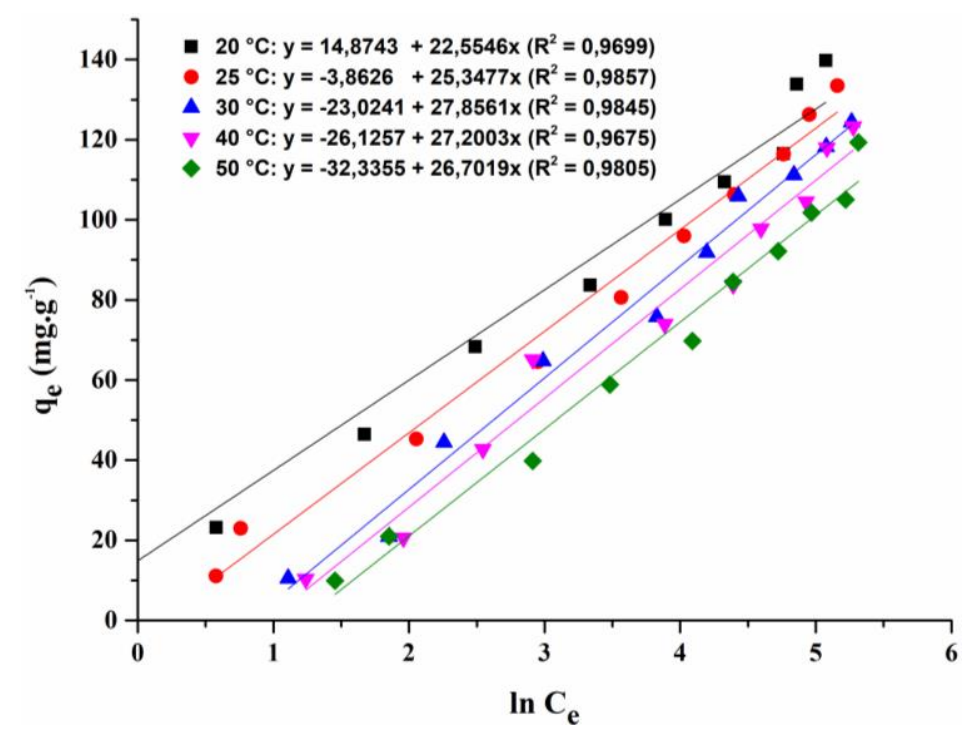

Fonte: Autor 
Tabela 32 - Parâmetros para a isoterma de Temkin obtidos para o CMCQF

\begin{tabular}{c|c|c|c|c|c|c}
\hline Adsorventes & Temperatura $\left({ }^{\circ} \mathrm{C}\right)$ & 20 & 25 & 30 & 40 & 50 \\
\hline \multirow{5}{*}{$\mathrm{CMCQF}$} & $\mathrm{B}$ & 55,030 & 54,970 & 55,790 & 56,640 & 56,160 \\
& $\mathrm{~b}\left(\mathrm{~kJ} \cdot \mathrm{mol}^{-1}\right)$ & 0,044 & 0,045 & 0,045 & 0,046 & 0,048 \\
& $\mathrm{~K}_{\mathrm{T}}\left({\left.\mathrm{L} \cdot \mathrm{mg}^{-1}\right)}^{*}\right.$ & 0,595 & 0,526 & 0,494 & 0,486 & 0,480 \\
& $\mathrm{R}^{2}$ & 0,977 & 0,965 & 0,966 & 0,960 & 0,965 \\
\hline \multirow{5}{*}{$\mathrm{CMCQDIC}$} & $\mathrm{B}$ & 22,550 & 25,350 & 27,860 & 27,200 & 26,700 \\
& $\mathrm{~b}\left(\mathrm{~kJ} \cdot \mathrm{mol}^{-1}\right)$ & 0,108 & 0,098 & 0,091 & 0,096 & 0,101 \\
& $\mathrm{~K}_{\mathrm{T}}\left({\left.\mathrm{L} \cdot \mathrm{mg}^{-1}\right)}^{*}\right.$ & 1,934 & 0,859 & 0,438 & 0,383 & 0,298 \\
& $\mathrm{R}^{2}$ & 0,970 & 0,986 & 0,985 & 0,968 & 0,981 \\
\hline
\end{tabular}

Fonte: Autor

A análise dos parâmetros obtidos (Tabela 32) também mostra que o aumento de temperatura desfavorece o processo de adsorção, uma vez que ocorreu a diminuição de $\mathrm{K}_{\mathrm{T}}$, onde para CMCQDIC essa redução foi mais significativa quando comparado ao CMCQF, mostrando que a interação entre o adsorvato e o adsorventes é afetada.

Nota-se também que os valores dos calores de adsorção são baixos e estima-se que, como os mesmos são menores que $8 \mathrm{~kJ} \mathrm{~mol}^{-1}$, o processo em questão ocorre pelo mecanismo de fisiossorção. Dessa forma, para ambos os adsorventes a adsorção ocorre por meio de interações eletrostáticas entre o adsorvato-adsorventes, como reportado na literatura quando se utiliza biopolímeros e derivados como adsorventes (CHOUDHARY; PAUL, 2018; ARAÚJO et al., 2017).Salienta-se que, dentre os três modelos de isoterma utilizados, a isoterma de Langmuir ajusta-se melhor ao processo em estudo, para ambos os adsorventes, devido aos fatores de correlação $\left(\mathrm{R}^{2}\right)$ maiores apresentados em relação a isoterma de Freundlich e Temkin.

Dessa forma, isso sugere que preferencialmente o processo ocorre em monocamada, não apresentando diferença de energia e a afinidade adsorvato-adsorvente que é a mesma em cada sítio ativo. Importante destacar também que, por se tratar de compostos poliméricos, que apresentam umas unidades de repetição base, a distribuição de sítios ativos ocorre de forma homogênea (ANIRUDHAN; LEKSHMI; SHAINY, 2019).

Estas características estão relacionadas ao fato do processo ocorrer por fisiossorção, onde cada sítio ativo, no caso preferencialmente os grupos aminos presente na cadeias dos poliméricas dos adsorventes, são iguais, apresentam mesmo tipo de interação e, não apresentam elevada energia para capturar um grande quantidade de moléculas de adsorvato, uma vez que o processo se dá por interação eletrostática entre esses grupos, que apresentam carga positiva, com o ânions que apresentam carga negativa (SARODE et al., 2019). 
Aliado a isso, o processo de adsorção também é reversível sendo que, após submetidos a elevado tempo de contato, o processo tende a se reverter sendo, o processo de dessorção, favorecido, como mostra a figura 75 .

Figura 75 - Processo de adsorção até elevados tempos de contato

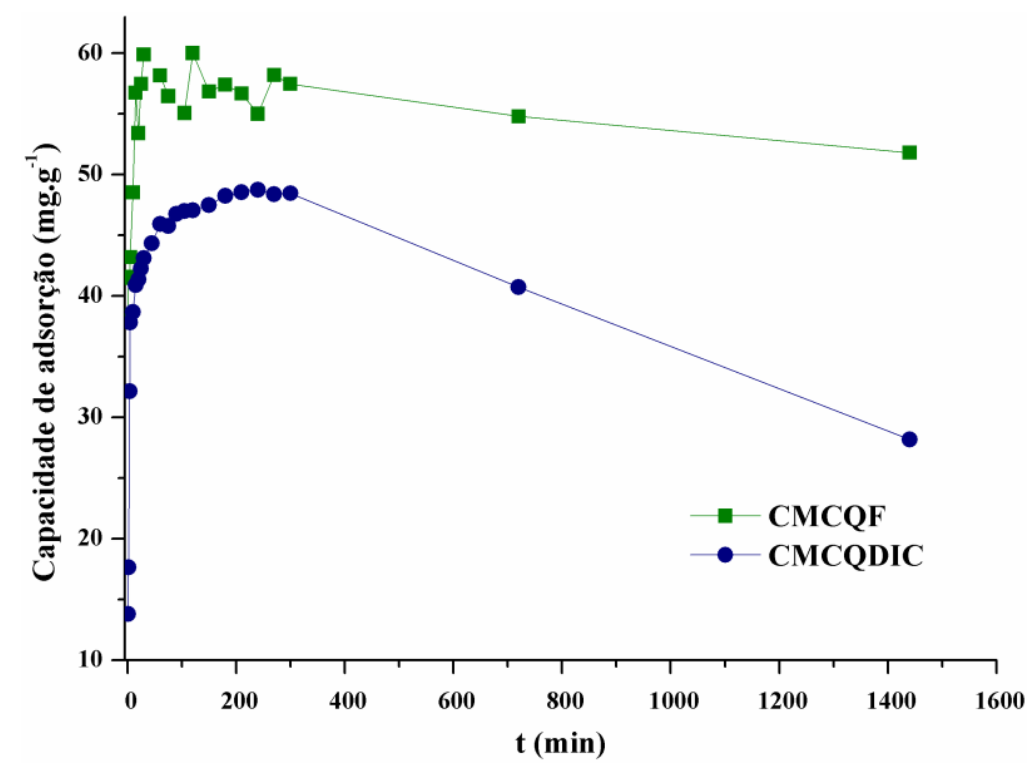

Fonte: Autor

Outra característica importante das isotermas de adsorção se refere ao tipo e característica da curva sendo que, a mesma, pode ser classificada com irreversível, favorável, linear e não favorável. Dessas, os chamados processos favoráveis de adsorção são os mais comuns e muitas isotermas partem do pressuposto que o processo será favorável, como no caso da isoterma de Langmuir.

Esse tipo de isoterma apresenta como característica curvas com remoção crescente de adsorvato conforme aumenta a concentração do mesmo na fase fluida até a saturação do adsorvente, devido ao elevado número de sítios ativos disponíveis em concentrações mais baixas e, a menor disponibilidade dos mesmos em concentrações mais elevadas sendo que, a concavidade da curva é voltada para baixo (SU et al., 2019; TRAN et al, 2017; WORCH, 2012)

Neste contexto, ambos os adsorventes apresentam essas características como mostram as figuras 76 e 77, para CMCQF e CMCQDID, respectivamente. Os fatores $\mathrm{R}_{\mathrm{L}}$ e (1/n), obtidos a partir do estudo de isotermas de adsorção também são utilizados para nessa classificação, sendo que, quando menores que 1, caracterizam isotermas favoráveis e curvas côncavas, como é o caso de ambos os adsorventes no intervalo de temperatura utilizado (TRAN et al, 2017; WORCH, 2012). 
Figura 76 - Capacidade em função da concentração para o CMCQF

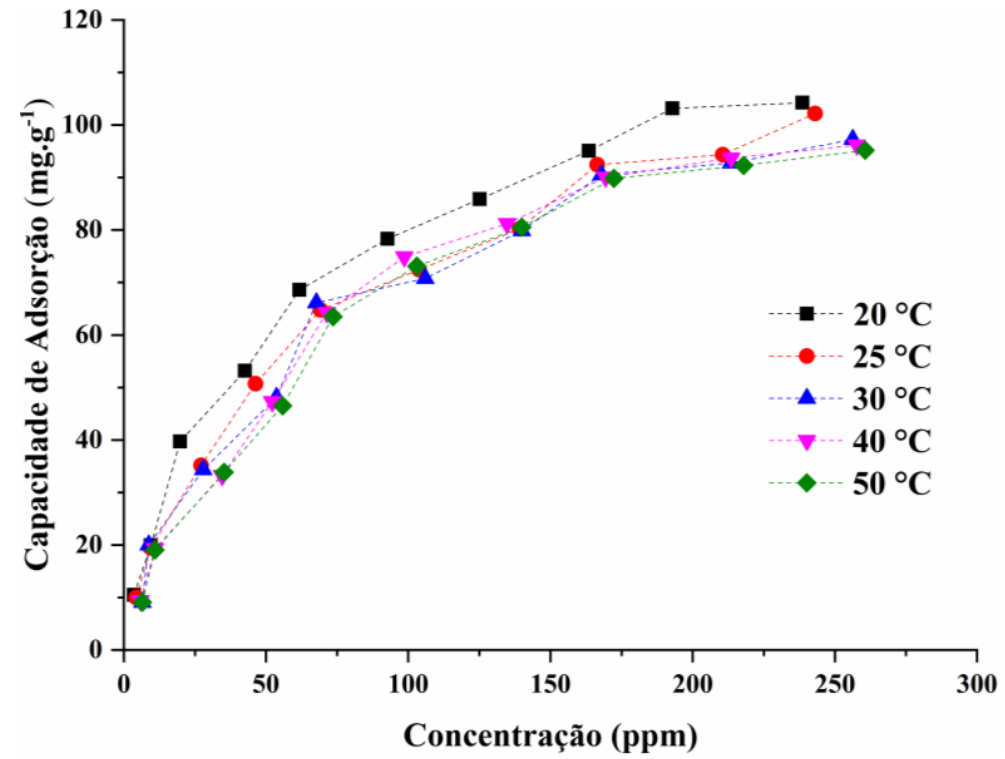

Fonte: Autor

Figura 77 - Capacidade em função da concentração para o CMCQDIC

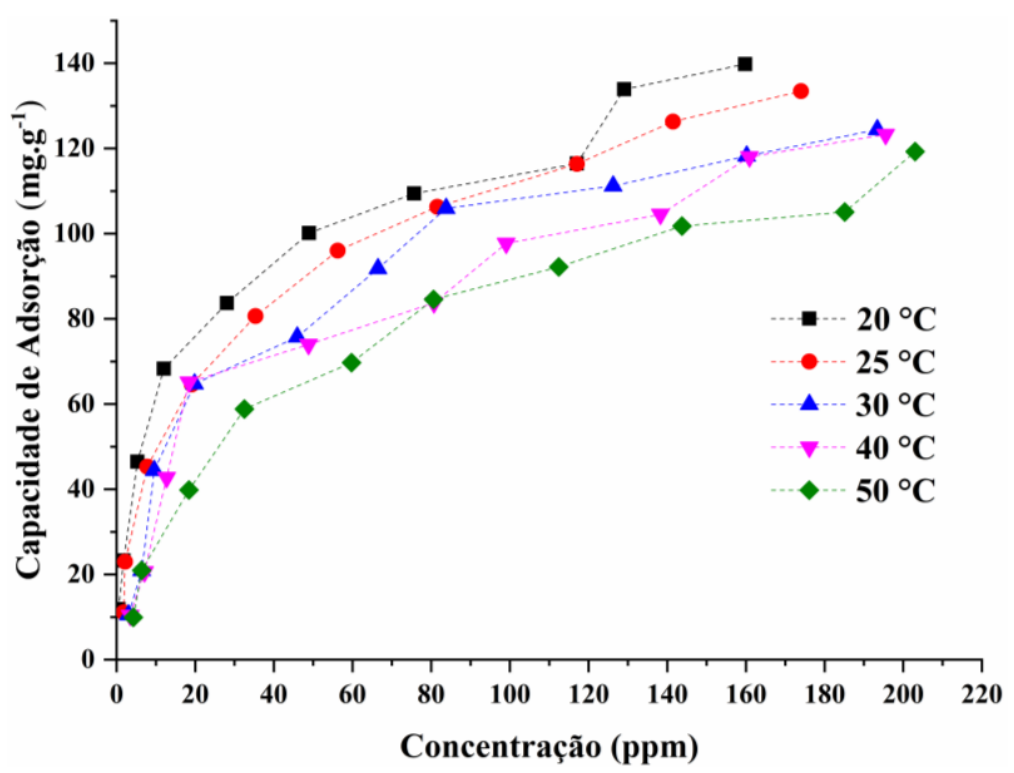

Fonte: Autor

Portanto, ambos os adsorventes se enquadram nas principais hipóteses propostas pela isoterma de Langmuir e, a mesma, melhor descreve o processo de adsorção, sendo que a temperatura que maximiza a interação adsorvato-adsorvente é a de $20^{\circ} \mathrm{C}$, pois apresenta maior $\left(\mathrm{K}_{\mathrm{L}}\right)$ e fator de separação $\left(\mathrm{R}_{\mathrm{L}}\right)$ mais próximo de 0 .

Com os resultados apresentados pode-se estabelecer, então, que as condições de processo de adsorção para a CMCQF foram de $20{ }^{\circ} \mathrm{C}$ de temperatura, $\mathrm{pH} 3 \mathrm{e}$, tempo de contato 
de $60 \mathrm{~min}$. Do mesmo modo, para o adsorvente CMCQDIC foram de $20{ }^{\circ} \mathrm{C}$ de temperatura, $\mathrm{pH}$ 2,5 e, tempo de contato de $180 \mathrm{~min}$.

\subsubsection{Termodinâmica de adsorção}

Além da determinação das condições ideais para de processo de adsorção, também foram determinados os parâmetros termodinâmicos referentes a aplicação de cada adsorvente, descrito no item 3.6.4, utilizando a equação de Van't Hoff, que relaciona a constante de equilíbrio com a temperatura do processo. Para isso, a partir da construção da curva de $\ln \mathrm{K}_{\mathrm{C}}$ em função de $\mathrm{T}^{-1}$ (Figura 78 e 79 ), foram determinadas as variações de entalpia $\left(\Delta \mathrm{H}_{\mathrm{ads}}\right)$, entropia $\left(\Delta \mathrm{S}_{\mathrm{ads}}\right)$ e, energia de Gibbs $\left(\Delta \mathrm{G}_{\mathrm{ads}}\right)$ verificados na tabela 33.

A constante de equilíbrio foi estimada a partir da constante de $\mathrm{K}_{\mathrm{L}}$ obtida pela isoterma de Langmuir, uma vez que o modelo se adequou melhor ao processo de adsorção para os adsorventes CMCQF e CMCQDIC.

Figura 78 - Linearização da equação de Van't Hoff para o CMCQF

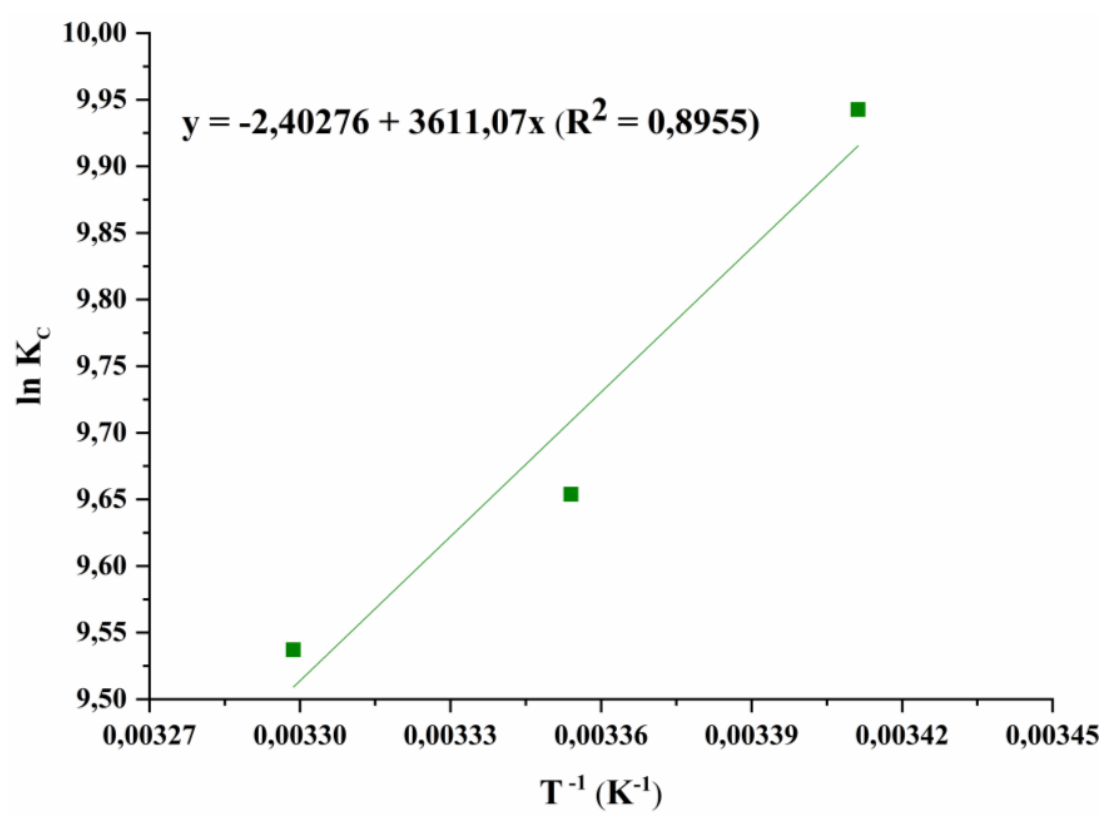

Fonte: Autor 
Figura 79 - Linearização da equação de Van’t Hoff para o CMCQDIC

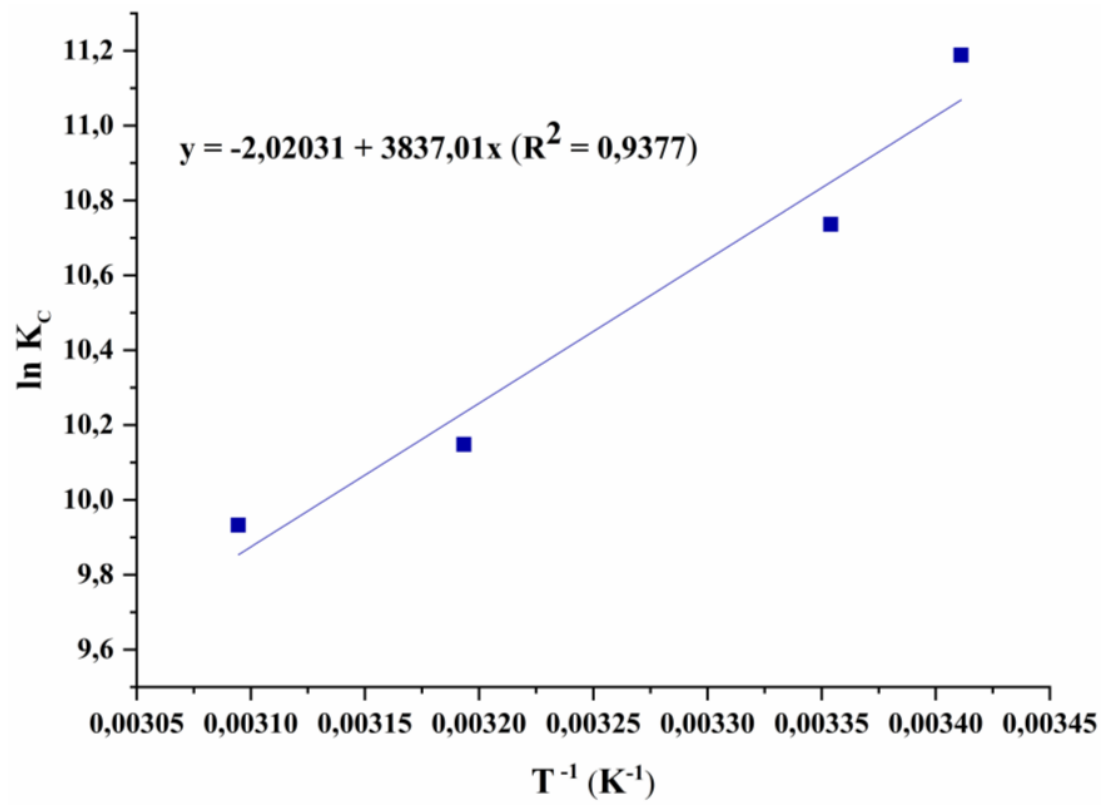

Fonte: Autor

Tabela 33 - Parâmetros termodinâmicos obtidos

\begin{tabular}{c|c|c|c|c|c|c}
\hline Adsorvente & $\mathrm{T}(\mathrm{K})$ & $\mathrm{K}_{\mathrm{L}}\left(\mathrm{L} \cdot \mathrm{mg}^{-1}\right)$ & $\mathrm{Kc}$ & $\Delta \mathrm{G}_{\mathrm{ads}}\left(\mathrm{kJ}^{\mathrm{mol}} \mathrm{mol}^{-1}\right)$ & $\Delta \mathrm{H}_{\mathrm{ads}}\left(\mathrm{kJ} \cdot \mathrm{mol}^{-1}\right)$ & $\Delta \mathrm{S}_{\mathrm{ads}}\left(\mathrm{kJ} \cdot \mathrm{mol}^{-1} \cdot \mathrm{K}^{-1}\right)$ \\
\hline \multirow{3}{*}{ CMCQF } & 293,15 & 0,021 & 20796 & $-24,2$ & & \\
& 298,15 & 0,016 & 15580 & $-23,9$ & $-30,0$ & $-0,020$ \\
& 303,15 & 0,014 & 13864 & $-24,0$ & & \\
CMCQDIC & 293,15 & 0,072 & 72251 & $-27,3$ & & $-0,017$ \\
& 298,15 & 0,046 & 45971 & $-26,6$ & $-31,9$ & \\
& 313,15 & 0,026 & 25533 & $-26,4$ & & \\
& 323,15 & 0,021 & 20585 & $-26,7$ & & \\
\hline
\end{tabular}

Fonte: Autor

Dessa forma, analisando-se os parâmetros obtidos, nota-se que o processo ocorre de maneira espontânea, pois a variação da energia de Gibbs foi menor que zero e, também, praticamente constante de uma temperatura para outra, uma vez que apresentou mudanças de valores muito baixas, o que indica que o processo, de modo geral, é espontâneo e independente da temperatura (CAMPOS et al., 2019).

Em relação entalpia de adsorção, nota-se que o processo é exotérmico, pois a variação desse parâmetro é negativa, indicando que a diminuição da temperatura favorece o processo e confirmando o que foi observado anteriormente, por meio das isotermas de adsorção.

Também é possível verificar, por meio da variação da entalpia da adsorção $\left(\Delta \mathrm{H}_{\mathrm{ads}}\right)$, que o processo adsorção ocorre por físiossorção, pois os valores encontrados de 30,0 e 31,9 kJ.mol ${ }^{1}$ para CMCQF e CMCQDIC, respectivamente, são menores que $50 \mathrm{~kJ} . \mathrm{mol}^{-1}$, confirmando o 
que é reportado na literatura para processo de adsorção utilizando-se biomateriais e, por meio do observado na isoterma de Temkin (CHOUDHARY, PAUL, 2018).

Com relação a variação de entropia, o processo apresenta uma redução da aleatoriedade na interface sólido-líquido ao longo do processo de adsorção por apresentar valores negativos para esse parâmetro $\left(\Delta \mathrm{S}_{\mathrm{ads}}<0\right)$ (SAMUEL et al., 2019).

\subsubsection{Comparação entre os adsorventes}

No geral, os adsorventes CMCQF e CMCQDIC apresentaram resultados semelhantes, porém com algumas diferenças, sendo os principais resultados e parâmetros otimizados apresentados de maneira resumida na tabela 34.

Tabela 34 - Comparação entre condições de cada adsorvente

\begin{tabular}{c|c|c}
\hline Adsorvente/Parâmetros & CMCQF & CMCQDIC \\
\hline Tempo de contato & $60 \mathrm{~min}$ & $180 \mathrm{~min}$ \\
$\mathrm{pH}$ & 3 & 2,5 \\
Modelo cinético & $2^{\mathrm{a}}$ Ordem & $2^{\mathrm{a}}$ Ordem \\
Modelo de Isoterma de adsorção & Langmuir & Langmuir \\
Temperatura & $20^{\circ} \mathrm{C}$ & $20^{\circ} \mathrm{C}$ \\
Capacidade Máxima & $124,22 \mathrm{mg} \cdot \mathrm{g}^{-1}$ & $142,25 \mathrm{mg} \cdot \mathrm{g}^{-1}$ \\
\hline
\end{tabular}

Fonte: Autor

Basicamente, as diferenças observadas em relação aos adsorventes se devem, principalmente, a mudanças na estrutura, uma vez que o adsorvente CMCQDIC apresenta uma maior quantidade de nitrogênios que, de acordo com a literatura, é o maior responsável por interagir e remover moléculas de adsorvato apresentando, dessa forma, um maior número de sítios ativos, o que justifica os tempos mais longos para atingir o equilíbrio.

Essa maior disponibilidade de nitrogênios também afeta o $\mathrm{pH}$, uma vez que o processo é favorecido com a protonação dos nitrogênios da estrutura dos adsorventes que geram uma carga positiva na superfície do adsorvente, favorecendo a atração e remoção do cromo hexavalente presentes na solução na forma de ânions, como discutido anteriormente. Neste contexto, uma maior quantidade de cátion hidrogênio são necessários para protonar os centros ativos, o que implica em um menor $\mathrm{pH}$.

Sendo assim, foram realizados experimentos utilizando-se as condições ideias de processo: tempo ideal, $\mathrm{pH}$ ideal e temperatura ideal, sendo que os valores encontram-se 
disponíveis na tabela 35 e figura 80 , com a finalidade de comparar ambos os adsorventes frente a quitosana. Dessa forma, o experimento com a quitosana foi realizado para cada condição determina para os adsorventes.

Tabela 35 - Dados de capacidade obtidos na condição ideal

\begin{tabular}{c|c|c|c}
\hline Adsorvente & $\begin{array}{c}\text { Concentração } \\
\text { Inicial }(\mathrm{ppm})\end{array}$ & $\begin{array}{c}\text { Concentração } \\
\text { final }(\mathrm{ppm})\end{array}$ & $\begin{array}{c}\text { Capacidade de } \\
\text { adsorção }\left(\mathrm{mg} \cdot \mathrm{g}^{-1}\right)\end{array}$ \\
\hline Quitosana & $233,27 \pm 0,47$ & $122,31 \pm 1,41$ & $55,04 \pm 0,84$ \\
CMCQF & & $71,53 \pm 0,47$ & $80,31 \pm 0,67$ \\
\hline Quitosana & $248,79 \pm 0,47$ & $119,96 \pm 0,94$ & $63,78 \pm 0,48$ \\
CMCQDIC & & $17,93 \pm 0,47$ & $115,78 \pm 0,17$ \\
\hline
\end{tabular}

Fonte: Autor

Figura 80 - Capacidades obtidas nas condições ideais

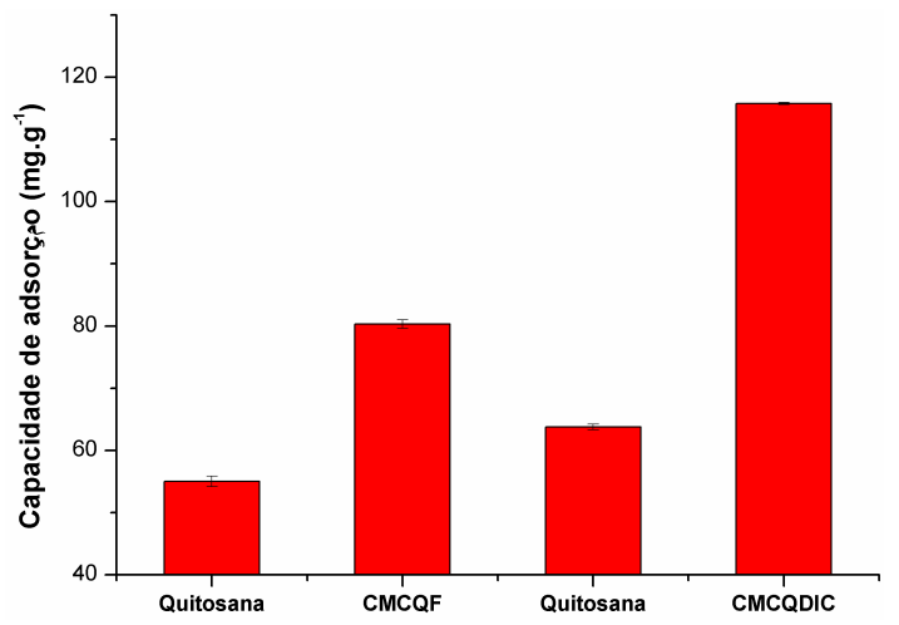

Fonte: Autor

Com base nos resultados obtidos para as condições ideais, pode-se afirmar que a obtenção desses adsorventes promoveu uma melhora no processo de adsorção, superando os problemas que cada uma dos biopolímeros utilizados na síntese apresentam como, por exemplo, a elevada solubilidade da carboximetilcelulose em meio aquoso e, a baixa estabilidade em meio ácido da quitosana.

Nesse contexto, foram obtidos dois adsorventes com elevada capacidade de adsorção e não solúvel em meio aquoso. Salienta-se também que, o CMCQDIC apresentou elevada resistência ao $\mathrm{pH}$ e, embora o CMCQF exibisse sinais de degradação em $\mathrm{pH}$ baixo de 3, encontra-se dentro da faixa de $\mathrm{pH}$ de efluentes industriais contendo cromo hexavalente, que varia de 2 a 3. 
Esses resultados também são importantes para comprovar os mecanismos de adsorção propostos pela literatura, em que o sitio ativo preferencial se dá pelos nitrogênios presentes na estrutura e, tendo em vista que o CMCQDIC apresenta uma maior quantidade de nitrogênios em sua estrutura em relação a quitosana e ao CMCQF, o mesmo apresentou melhores resultados.

Do mesmo modo, pode-se comprovar que outros grupos funcionais também podem auxiliar o processo de adsorção, pois para o CMCQF não houve um aumento na quantidade de nitrogênios na estrutura, porém, houve um aumento na capacidade de adsorção desse material em relação a quitosana.

\subsection{INFLUENCIA DOS LÍQUIDOS IÔNICOS NO PROCESSO DE ADSORÇÃO}

Com o intuito de verificar a influencias dos líquidos iônicos no processo de adsorção, foram sintetizados quatro líquidos iônicos diferentes, como descrito no item 4.3.5: acetato de sec- butilamônio (AS), acetato de terc- butilamônio (AT), lactato de sec-butilamônio (LS) e lactato de terc-butilamônio (LT), a partir de ácidos carboxílicos (ácido acético e ácido láctico) e aminas (sec-butilamina e terc-butilamina)

Após a síntese os LIs foram caracterizados via ${ }^{13} \mathrm{C}-\mathrm{RMN}$ e ${ }^{1} \mathrm{H}-\mathrm{RMN}$ em fase líquida, os adsorventes CMCQF e CMCQDIC foram submetidos ao processo de ativação com os mesmos e os experimentos de adsorção foram realizados nas condições otimizadas, determinadas anteriormente, e a nível de comparação o mesmo processo foi realizado para a quitosana.

Esse processo de ativação ocorreu por meio da interação do ânion do líquido iônico com as hidroxilas livre presentes na composição do adsorvente, fazendo com que a interações intra e intermolecular dos adsorventes diminuíssem deixando os grupos amino mais disponíveis para capturar os íons cromo.

\subsubsection{Obtenção e caracterização dos líquidos iônicos}

Durante o processo de ativação dos adsorventes CMCQF e, CMCQDIC, inicialmente foi realizada a síntese e caracterização via RMN dos LIs acetato de sec-butilamônio (AS), acetato de terc-butilamônio (AT), lactato de sec-butilamônio (LS) e lactato de terc-butilamônio (LT) (Figura 81). 
Figura 81 - Estruturas dos ácidos, aminas e LIs sintetizados<smiles>CC(O)C(=O)O</smiles>

ácido láctico<smiles>CC(=O)O</smiles>

ácido acético<smiles>CCC(C)N</smiles>

sec-butilamina

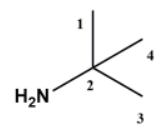

terc-butilamina<smiles>CCC(C)NOC(=O)C(C)O</smiles>

lactato de sec-butilamônio<smiles>CC(O)C(=O)ONC(C)(C)C</smiles>

lactato de terc-butilamônio<smiles>CCC(C)NOC(C)=O</smiles>

acetato de sec-butilamônio<smiles>CC(=O)ONC(C)(C)C</smiles>

acetato de terc-butilamônio

Fonte: Autor

Analisando-se os espectros obtidos via ${ }^{1} \mathrm{H}-\mathrm{RMN}$ e ${ }^{13} \mathrm{C}-\mathrm{RMN}$ (Apêndice C), verifica-se, em todos os casos, mudança de deslocamento químico referente ao grupo amino após a protonação e formação do grupo amônio, confirmado pela integração do sinal referente ao mesmo em cada LI produzido, bem como a correlação dos demais sinais que evidenciam a formação dos LIs, conforme destacado nas tabelas 36 a 39. (PAVIA et al., 2015)

Tabela 36 - Deslocamentos químicos $\left({ }^{1} \mathrm{H},{ }^{13} \mathrm{C}\right)$, multiplicidade $\left({ }^{1} \mathrm{H}\right)$, número de hidrogênios, constantes de acoplamento $(J)$ referentes aos espectros ${ }^{1} \mathrm{H}-\mathrm{RMN}$ e ${ }^{13} \mathrm{C}-\mathrm{RMN}$ para o AS e precursores

\begin{tabular}{|c|c|c|c|c|c|c|}
\hline \multirow[t]{2}{*}{ Posição } & \multicolumn{2}{|c|}{ Ácido acético } & \multicolumn{2}{|c|}{ sec-butilamina } & \multicolumn{2}{|c|}{ Acetato de sec-butilamônio } \\
\hline & $\delta \mathrm{H}\left(\mathrm{m}, \mathrm{n}^{\circ} \mathrm{H}, J\right)$ & $\delta \mathrm{C}$ & $\delta \mathrm{H}\left(\mathrm{m}, \mathrm{n}^{\circ} \mathrm{H}, J\right)$ & $\delta \mathrm{C}$ & $\delta \mathrm{H}\left(\mathrm{m}, \mathrm{n}^{\circ} \mathrm{H}, J\right)$ & $\delta \mathrm{C}$ \\
\hline 1 & - & 177,985 & $\begin{array}{c}1,032(\mathrm{~d}, 3 \mathrm{H}, 6,6 \\
\mathrm{Hz})\end{array}$ & 23,693 & - & 178,791 \\
\hline 2 & $2,097(\mathrm{~s}, 3 \mathrm{H})$ & 20,814 & $\begin{array}{c}2,778(\mathrm{~m}, 2 \mathrm{H}, \\
6,6 \mathrm{~Hz})\end{array}$ & 48,844 & $1,898(\mathrm{~s}, 3 \mathrm{H})$ & 28,438 \\
\hline 3 & & & $1,336(\mathrm{~m}, 1 \mathrm{H})$ & 32,903 & $\begin{array}{c}1,230(\mathrm{~d}, 3 \mathrm{H}, 6,6 \\
\mathrm{Hz})\end{array}$ & 18,420 \\
\hline 4 & & & $\begin{array}{c}0,890(\mathrm{t}, 3 \mathrm{H}, 7,2 \\
\mathrm{Hz})\end{array}$ & 10,814 & $\begin{array}{c}3,034(\mathrm{~m}, 1 \mathrm{H}, 6 \\
\mathrm{Hz})\end{array}$ & 48,519 \\
\hline 5 & & & & & $\begin{array}{c}1,502 / 1,692(\mathrm{~m} \\
1 \mathrm{H}, 7,2 \mathrm{~Hz})\end{array}$ & 24,410 \\
\hline 6 & & & & & $\begin{array}{c}0,945(\mathrm{t}, 3 \mathrm{H}, 7,2 \\
\mathrm{Hz})\end{array}$ & 10,120 \\
\hline $\mathrm{NH}_{2} / \mathrm{NH}_{3}{ }^{+}$ & & & $1,336(\mathrm{~m}, 2 \mathrm{H})$ & - & 7,417 (s,3H,) & - \\
\hline
\end{tabular}

Fonte: Autor 
Tabela 37 - Deslocamentos químicos $\left({ }^{1} \mathrm{H},{ }^{13} \mathrm{C}\right)$, multiplicidade $\left({ }^{1} \mathrm{H}\right)$, número de hidrogênios, constantes de acoplamento $(J)$ referentes aos espectros ${ }^{1} \mathrm{H}$-RMN e ${ }^{13} \mathrm{C}-\mathrm{RMN}$ para o AT e precursores

\begin{tabular}{c|c|c|c|c|c|c}
\hline \multirow{2}{*}{ Posição } & \multicolumn{2}{|c|}{ Ácido acético } & \multicolumn{2}{c|}{ terc-butilamina } & \multicolumn{2}{c}{ Acetato de terc-butilamônio } \\
\cline { 2 - 7 } & $\delta \mathrm{H}\left(\mathrm{m}, \mathrm{n}^{\circ} \mathrm{H}, J\right)$ & $\delta \mathrm{C}$ & $\delta \mathrm{H}\left(\mathrm{m}, \mathrm{n}^{\circ} \mathrm{H}, J\right)$ & $\delta \mathrm{C}$ & $\delta \mathrm{H}\left(\mathrm{m}, \mathrm{n}^{\circ} \mathrm{H}, J\right)$ & $\delta \mathrm{C}$ \\
\hline 1 & - & 177,985 & $1,146(\mathrm{~s}, 3 \mathrm{H})$ & 32,620 & - & 177,637 \\
2 & $2,097(\mathrm{~s}, 3 \mathrm{H})$ & 20,814 & - & 47,501 & $1,940(\mathrm{~s}, 3 \mathrm{H})$ & 23,261 \\
3 & & & $1,146(\mathrm{~s}, 3 \mathrm{H})$ & 32,620 & $1,301(\mathrm{~s}, 3 \mathrm{H})$ & 27,536 \\
4 & & & $1,146(\mathrm{~s}, 3 \mathrm{H})$ & 32,620 & - & 51,329 \\
5 & & & & & $1,301(\mathrm{~s}, 3 \mathrm{H})$ & 27,536 \\
6 & & & & & $1,301(\mathrm{~s}, 3 \mathrm{H})$ & 27,536 \\
$\mathrm{NH}_{2} / \mathrm{NH}_{3}{ }^{+}$ & & & $1,383(\mathrm{~s}, 2 \mathrm{H})$ & - & $7,982(\mathrm{~s}, 3 \mathrm{H})$ & - \\
\hline
\end{tabular}

Fonte: Autor

Tabela 38 - Deslocamentos químicos $\left({ }^{1} \mathrm{H},{ }^{13} \mathrm{C}\right)$, multiplicidade $\left({ }^{1} \mathrm{H}\right)$, número de hidrogênios, constantes de acoplamento $(J)$ referentes aos espectros ${ }^{1} \mathrm{H}-\mathrm{RMN}$ e ${ }^{13} \mathrm{C}-\mathrm{RMN}$ para o LS e precursores

\begin{tabular}{|c|c|c|c|c|c|c|}
\hline \multirow[t]{2}{*}{ Posição } & \multicolumn{2}{|c|}{ Ácido lactico } & \multicolumn{2}{|c|}{ sec-butilamina } & \multicolumn{2}{|c|}{ Lactato de sec-butilamônio } \\
\hline & $\delta \mathrm{H}\left(\mathrm{m}, \mathrm{n}^{\circ} \mathrm{H}, J\right)$ & $\delta \mathrm{C}$ & $\delta \mathrm{H}\left(\mathrm{m}, \mathrm{n}^{\circ} \mathrm{H}, J\right)$ & $\delta \mathrm{C}$ & $\delta \mathrm{H}\left(\mathrm{m}, \mathrm{n}^{\circ} \mathrm{H}, J\right)$ & $\delta \mathrm{C}$ \\
\hline 1 & - & 179,399 & $\begin{array}{c}1,032(\mathrm{~d}, 3 \mathrm{H}, \\
6,6 \mathrm{~Hz})\end{array}$ & 23,693 & - & 181,915 \\
\hline 2 & $\begin{array}{c}4,376(\mathrm{q}, 1 \mathrm{H}, \\
6,6 \mathrm{~Hz})\end{array}$ & 66,662 & $\begin{array}{c}2,778(\mathrm{~m}, 2 \mathrm{H}, \\
6,6 \mathrm{~Hz})\end{array}$ & 48,844 & $\begin{array}{c}3,988(\mathrm{q}, 1 \mathrm{H}, \\
6,6 \mathrm{~Hz})\end{array}$ & 68,608 \\
\hline 3 & $\begin{array}{c}1,490(\mathrm{~d}, 3 \mathrm{H}, \\
7,2 \mathrm{~Hz})\end{array}$ & 20,418 & $1,336(\mathrm{~m}, 1 \mathrm{H})$ & 32,903 & $\begin{array}{c}1,302(\mathrm{~d}, 3 \mathrm{H}, \\
6,6 \mathrm{~Hz})\end{array}$ & 21,247 \\
\hline 4 & & & $\begin{array}{c}0,890(\mathrm{t}, 3 \mathrm{H}, 7,2 \\
\mathrm{Hz})\end{array}$ & 10,814 & $\begin{array}{c}1,223(\mathrm{~d}, 3 \mathrm{H}, \\
6,6 \mathrm{~Hz})\end{array}$ & 18,788 \\
\hline 5 & & & & & $\begin{array}{c}3,075(\mathrm{~m}, 1 \mathrm{H} \\
6,6 \mathrm{~Hz})\end{array}$ & 48,888 \\
\hline 6 & & & & & $\begin{array}{c}1,495 / 1,668(\mathrm{~m}, \\
1 \mathrm{H}, 7,2 \mathrm{~Hz})\end{array}$ & 28,704 \\
\hline 7 & & & & & $\begin{array}{c}0,942(\mathrm{t}, 3 \mathrm{H}, \\
7,2)\end{array}$ & 10,181 \\
\hline $\mathrm{NH}_{2} / \mathrm{NH}_{3}{ }^{+}$ & & & $1,336(\mathrm{~m}, 2 \mathrm{H})$ & - & $5,401(\mathrm{~s}, 3 \mathrm{H})$ & - \\
\hline
\end{tabular}


Tabela 39 - Deslocamentos químicos $\left({ }^{1} \mathrm{H},{ }^{13} \mathrm{C}\right)$, multiplicidade $\left({ }^{1} \mathrm{H}\right)$, número de hidrogênios, constantes de acoplamento $(J)$ referentes aos espectros ${ }^{1} \mathrm{H}$-RMN e ${ }^{13} \mathrm{C}-\mathrm{RMN}$ para o LT e precursores

\begin{tabular}{|c|c|c|c|c|c|c|}
\hline \multirow[t]{2}{*}{ Posição } & \multicolumn{2}{|c|}{ Ácido láctico } & \multicolumn{2}{|c|}{ terc-butilamina } & \multicolumn{2}{|c|}{ Lactato de terc-butilamônio } \\
\hline & $\delta \mathrm{H}\left(\mathrm{m}, \mathrm{n}^{\circ} \mathrm{H}, J\right)$ & $\delta \mathrm{C}$ & $\delta \mathrm{H}\left(\mathrm{m}, \mathrm{n}^{\circ} \mathrm{H}, J\right)$ & $\delta \mathrm{C}$ & $\delta \mathrm{H}\left(\mathrm{m}, \mathrm{n}^{\circ} \mathrm{H}, J\right)$ & $\delta \mathrm{C}$ \\
\hline 1 & - & 179,399 & $1,146(\mathrm{~s}, 3 \mathrm{H})$ & 32,620 & - & 181,603 \\
\hline 2 & $\begin{array}{c}\text { 4,376 (q, 1H, } \\
\text { 6,6 Hz) }\end{array}$ & 66,662 & - & 47,501 & $\begin{array}{c}3,982(\mathrm{q}, 1 \mathrm{H} \\
6,6 \mathrm{~Hz})\end{array}$ & 68,491 \\
\hline 3 & $\begin{array}{c}\text { 1,490 (d, 3H, } \\
7,2 \mathrm{~Hz})\end{array}$ & 20,418 & $1,146(\mathrm{~s}, 3 \mathrm{H})$ & 32,620 & $1,334(\mathrm{~s}, 3 \mathrm{H})$ & 21,014 \\
\hline 4 & & & $1,146(\mathrm{~s}, 3 \mathrm{H})$ & 32,620 & $1,318(\mathrm{~s}, 3 \mathrm{H})$ & 27,931 \\
\hline 5 & & & & & - & 51,049 \\
\hline 6 & & & & & $1,318(\mathrm{~s}, 3 \mathrm{H})$ & 28,931 \\
\hline 7 & & & & & $1,318(\mathrm{~s}, 3 \mathrm{H})$ & 28,931 \\
\hline $\mathrm{NH}_{2} / \mathrm{NH}_{3}{ }^{+}$ & & & $1,383(\mathrm{~s}, 2 \mathrm{H})$ & - & $6,531(\mathrm{~s}, 3 \mathrm{H})$ & - \\
\hline
\end{tabular}

Fonte: Autor

\subsubsection{Processo de adsorção com adsorventes ativados com os líquidos iônicos}

Após a confirmação da formação dos LIs, foi realizada a ativação dos adsorventes CMCQF e CMCQDIC, e, da quitosana (Q) com os mesmos sendo obtidos 10 novos adsorventes, que foram submetidos ao processo de adsorção utilizando-se as condições otimizadas e descritas anteriormente $\left(\mathrm{CMCQF}=20^{\circ} \mathrm{C}, \mathrm{pH} 3\right.$ e, tempo de $60 \mathrm{~min}$; CMCQDIC $=20^{\circ} \mathrm{C}, \mathrm{pH} 2,5 \mathrm{e}$, tempo de $\left.180 \mathrm{~min}\right)$.

Após a obtenção dos novos adsorventes e realização dos experimentos, foram comparadas as capacidades de adsorção dos mesmos sendo que, os resultados encontram-se descritos na tabela 40 . 
Tabela 40 - Resultados de adsorção para os adsorventes ativados

\begin{tabular}{|c|c|c|c|c|}
\hline Condições & Adsorvente & $\begin{array}{c}\text { Líquido } \\
\text { Iônico }\end{array}$ & $\begin{array}{c}\text { Concentração } \\
\text { Final (ppm) }\end{array}$ & $\begin{array}{c}\text { Capacidade de adsorção } \\
\left(\mathrm{mg} \cdot \mathrm{g}^{-1}\right)\end{array}$ \\
\hline \multirow{10}{*}{$\begin{array}{c}\text { Tempo: } 60 \text { min } \\
\text { pH: } 3,0 \\
\text { Temperatura: } 20 \\
{ }^{\circ} \mathrm{C} \\
\text { Rotação: } 250 \\
\text { rpm }\end{array}$} & \multirow{5}{*}{ CMCQF } & - & $71,53 \pm 0,47$ & $80,31 \pm 0,67$ \\
\hline & & AS & $61,66 \pm 0,00$ & $85,55 \pm 0,36$ \\
\hline & & AT & $60,72 \pm 0,00$ & $86,19 \pm 0,12$ \\
\hline & & LS & $72,00 \pm 0,00$ & $80,31 \pm 0,23$ \\
\hline & & LT & $72,94 \pm 0,00$ & $80,41 \pm 0,34$ \\
\hline & \multirow{5}{*}{ Quitosana } & - & $122,31 \pm 1,41$ & $55,04 \pm 0,84$ \\
\hline & & AS & $102,56 \pm 1,41$ & $65,55 \pm 0,91$ \\
\hline & & AT & $56,96 \pm 0,94$ & $88,51 \pm 0,67$ \\
\hline & & LS & $116,67 \pm 0,47$ & $58,30 \pm 0,50$ \\
\hline & & LT & $110,56 \pm 0,47$ & $61,17 \pm 0,58$ \\
\hline \multirow{10}{*}{$\begin{array}{c}\text { Tempo: } 180 \text { min } \\
\text { pH: } 2,5 \\
\text { Temperatura: } 20 \\
{ }^{\circ} \mathrm{C} \\
\text { Rotação: } 250 \\
\text { rpm }\end{array}$} & \multirow{5}{*}{ CMCQDIC } & - & $17,93 \pm 0,47$ & $115,78 \pm 0,17$ \\
\hline & & AS & $12,76 \pm 0,00$ & $117,54 \pm 0,33$ \\
\hline & & AT & $10,41 \pm 0,47$ & $119,43 \pm 0,67$ \\
\hline & & LS & $9,00 \pm 0,00$ & $119,42 \pm 0,67$ \\
\hline & & LT & $6,18 \pm 0,94$ & $121,79 \pm 0,37$ \\
\hline & \multirow{5}{*}{ Quitosana } & - & $119,96 \pm 0,94$ & $63,78 \pm 0,48$ \\
\hline & & AS & $72,94 \pm 0,00$ & $86,97 \pm 0,36$ \\
\hline & & AT & $64,01 \pm 0,47$ & $91,57 \pm 0,46$ \\
\hline & & LS & $70,12 \pm 0,94$ & $88,80 \pm 0,41$ \\
\hline & & LT & $66,36 \pm 0,00$ & $91,03 \pm 0,26$ \\
\hline
\end{tabular}

Fonte: Autor

Verifica-se que, para o adsorvente CMCQF ativado ocorreu um aumento na capacidade de adsorção em relação a quitosana com e sem ativação e, também, em relação ao próprio adsorvente sem ativação (Figura 82).

Figura 82 - Dados de capacidade de adsorção para o CMCQF ativado

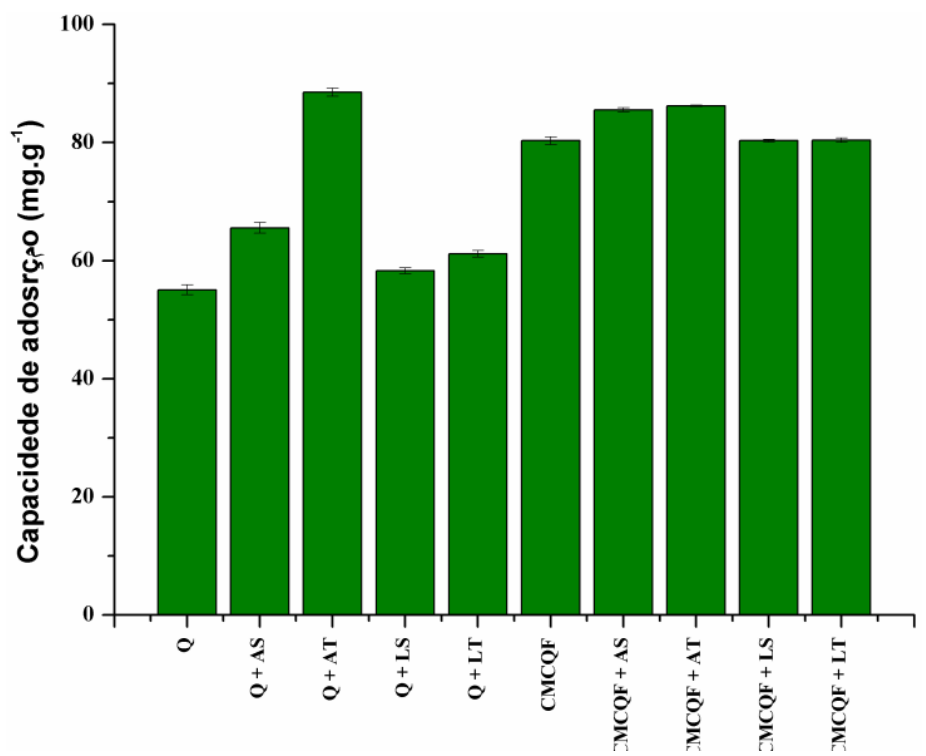

Fonte: Autor 
Verifica-se também que não ocorreram mudanças significativas na capacidade de adsorção entre adsorventes submetidos aos tratamentos com os LIs formados a partir do ácido acético e do ácido lático, respectivamente. Dessa forma, o ânion que compõe o líquido iônico não impacta no processo de ativação, uma vez que é o cátion do líquido iônico que passa a interagir com as hidroxilas livres. Porém, os lactatos apresentam uma melhora inferior aos acetatos e isso pode ser atribuído ao fato de na estrutura do mesmo existir uma hidroxila capaz de influênciar no processo de ativação.

Para o CMCQF, o líquido iônico acetato de terc-butilamônio apresentou os melhores resultados, porém, comparando-se com a quitosana apresenta resultado inferior. Isso se deve ao fato de a estrutura da CMCQF apresentar uma menor quantidade de hidroxilas livre passiveis de sofrerem ativação, o que justifica a competição com as hidroxilas presentes nos cátions dos lactatos que impactam de forma negativa nos resultados.

Já, para o adsorvente CMCQDIC (Figura 83) ocorreu um aumento na capacidade de adsorção conforme utilizou-se os líquidos iônicos sendo que, o lactato de terc-butilamônio apresentou melhores resultados em relação a capacidade de adsorção, embora para a quitosana, assim como anteriormente, tenha sido verificado os melhores resultados para o acetato de tercbutilamônio.

Figura 83 - Dados de capacidade de adsorção para o CMCQDIC ativado

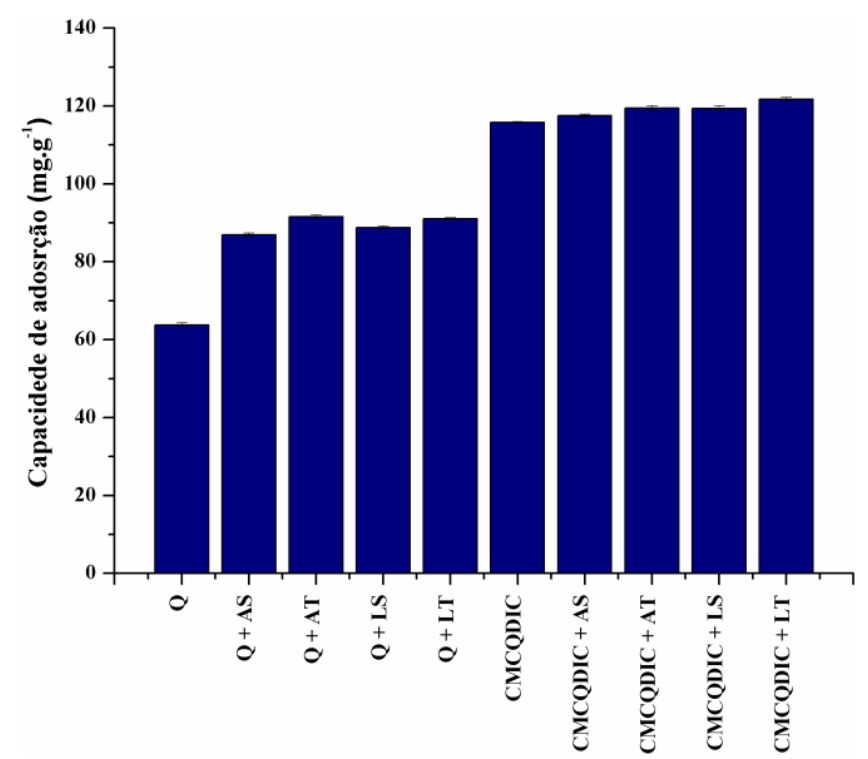

Fonte: Autor

Essa diferença nos resultados obtidos para os adsorventes CMCQF e CMCQDIC se deve, principalmente, a quantidade de hidroxilas presentes em ambas as estruturas, pois o CMCQDIC apresenta uma quantidade mais elevada que o CMCQF. Dessa forma, se ocorrer 
uma competição entre as hidroxilas presentes no composto e, a presente no cátion do líquido iônico para CMCQDIC não impacta na adsorção.

Em relação ao ânion para ambos, o terc-butilamônio apresentou melhores resultados comparado com o sec-butilamônio. Isso se deve ao fato de ser um íon de baixa mobilidade com maior volume que, quando interage o as hidroxilas livres, causa um impedimento de bloqueio maior reduzindo, assim, a interação dessas hidroxilas com os outros grupos presentes no polímero, enquanto o sec-butilamônio apresenta uma cadeia mais linear com maior mobilidade. 


\section{CONCLUSÃO}

Com a finalidade de realizar o tratamento de efluentes contendo cromo hexavalente de maneira eficaz e ambientalmente favorável foram estudados dois novos adsorventes, CMCQF e CMCQDIC, a base de carboximetilcelulose, obtida partir da palha de milho, e modificada com quitosana.

As condições ideias do processo de adsorção determinadas para CMCQF foram de 60 min de tempo de contato, $\mathrm{pH} 3,0$ e temperatura de $20^{\circ} \mathrm{C}$ e, para CMCQDIC, $120 \mathrm{~min}$ de tempo de contato, $\mathrm{pH} 2,5$ e temperatura de $20^{\circ} \mathrm{C}$, verificando-se uma melhora na capacidade de adsorção de 41,9 e 81,5 \% para CMCQF e CMCQDIC, respectivamente, quando comparado com a quitosana pura.

Ambos os adsorventes apresentaram resultados promissores em relação a remediação de íons cromo hexavalente de efluentes e, ainda, superaram algumas dificuldades de empregabilidade da quitosana e da carboximetilcelulose separadamente. Pois, em pH ácido a quitosana apresenta baixa estabilidade, sendo reportado que começa a degradar em $\mathrm{pHs}$ menores que 5,5 sendo totalmente solúvel em pH menor que 2,5. E a CMC, apresenta elevada solubilidade em água.

Assim, os novos adsorventes apresentaram maior resistência em meio ácido e se mostraram insolúveis em meio aquoso que são características primordiais para adsorventes quando empregados em tratamentos de efluentes.

Com relação ao tratamento com líquido iônicos, o processo apresentou uma melhora na capacidade de adsorção utilizando-se os líquidos iônicos acetato de sec-butilamônio, acetato de terc-butilamônio, lactato de sec-butilamônio e lactato de terc-butilamônio sendo que, para o adsorvente CMCQF e CMCQDIC, o tratamento com acetato de terc-butilamônio e lactato de terc-butilamônio levaram, respectivamente, a melhores resultados com aumento da capacidade de adsorção de 7,32 e 5,19 \%, respectivamante. Esses resultados sugerem que o emprego de líquidos iônios são uma alternativa na melhora do processo de adsorção utilizando adsorventes a base polímeros naturais, sendo um importante assunto a ser abordado.

Devido aos resultados promissores obtidos, os novos adsorventes apresentam vantagens que os tornam um alternativa para aplicações em escala industrial, uma vez que são obtidos a partir de compostos de grande disponibilidade, baixo custo de aquisição e não apresentam toxicidade elevada, bem como levam em sua produção a utilização resíduos lignocelulósicos, que são uma importante fonte de celulose e, em sua maioria, são descartados. 


\section{REFERÊNCIAS}

ABDELRAHMAN, E. A.; HEGAZEY, R. M. Utilization of waste aluminum cans in the fabrication of hydroxysodalite nanoparticles and their chitosan biopolymer composites for the removal of $\mathrm{Ni}(\mathrm{II})$ and $\mathrm{Pb}(\mathrm{II})$ ions from aqueous solutions: Kinetic, equilibrium, and reusability studies. Microchemical Journal, v. 145, p. 18-25, 2019. Disponível em: $<$ https://wwwsciencedirect.ez328.periodicos.capes.gov.br/science/article/pii/S0026265X18312268>. Acesso em: 31 out. 2018.

AHMED, M. J. K.; AHMARUZZAMAN, M. A review on potential usage of industrial waste materials for binding heavy metal ions from aqueous solutions. Journal of Water Process Engineering, v. 10, p. 39-47, 2016. Disponível em: $<$ https://wwwsciencedirect.ez328.periodicos.capes.gov.br/science/article/pii/S2214714416300241>. Acesso em: 31 out. 2018 .

AHMAD, M. et al. Chitosan centered bionanocomposites for medical specialty and curative applications: A review. International Journal of Pharmaceutics, v. 529, p. 200-217, 2017. Disponível em: $<$ https://wwwsciencedirect.ez328.periodicos.capes.gov.br/science/article/pii/S0378517317305872>. Acesso em: 31 out. 2018.

AJAO, V. et al. Natural flocculants from fresh and saline wastewater: Comparative properties and flocculation performances. Chemical Engineering Journal, v. 349, p. 622-632, 2018. Disponível em: $<$ https://wwwsciencedirect.ez328.periodicos.capes.gov.br/science/article/pii/S1385894718309379>. Acesso em: 31 out. 2018.

AMALRAJ, A. et al. Efficient removal of toxic hexavalent chromium from aqueous solution using threonine doped polypyrrole nanocomposite. Journal of Water Process Engineering, v. 13, p. 88-99, 2016. Disponível em: <https://www-

sciencedirect.ez328.periodicos.capes.gov.br/science/article/pii/S2214714416302161>. Acesso em: 31 out. 2018.

ANDRADE NETO, J. C. et al. Synthesis and characterization of new low-cost ILs based on butylammonium cation and application to lignocellulose hydrolysis. Carbohydrate Polymers, v. 143, p. 279-287, 2016. Disponível em: <https://wwwsciencedirect.ez328.periodicos.capes.gov.br/science/article/pii/S0144861716300339>. Acesso em: 31 out. 2018.

ANIRUDHAN, T. S.; LEKSHMI, G. S; SHAINY, F. Synthesis and characterization of amidoxime modified chitosan/bentonite composite for the adsorptive removal and recovery of uranium from seawater. Journal of Colloid and Interface Science, v. 534, p. 248-261, 2019. Disponível em: <https://www.ncbi.nlm.nih.gov/pubmed/30227381>. Acesso em: 07 nov. 2018. 
ARAÚJO, C. S. T. et al. Elucidation of mechanism involved in adsorption of $\mathrm{Pb}$ (II) onto lobeira fruit (Solanum lycocarpum) using Langmuir, Freundlich and Temkin isotherms. Microchemical Journal, v. 137, p. 348-354, 2018. Disponível em: $<$ https://wwwsciencedirect.ez328.periodicos.capes.gov.br/science/article/pii/S0026265X1630618X>. Acesso em: 31 out. 2018.

Standard Test Methods for Sodium Carboxymethylcellulose. ASTM D1439-03: ASTM International, West Conshohocken, PA, 2008.

BARAKAT, A.; DE VRIES, H.; ROUAU, X. Dry fractionation process as an important step in current and future lignocellulose biorefineries: A review. Bioresource Technology, v. 134, p. 362-373, 2013. Disponível em: $<$ https://www-ncbi-nlm-nihgov.ez328.periodicos.capes.gov.br/pubmed/23499177>. Acesso em: 31 out. 2018.

BALLADARES, E. et al. Neutralization and co-precipitation of heavy metals by lime addition to effluent from acid plant in a copper smelter. Minerals Engineering, v. 122, p. 122-129, 2018. Disponível em: $<$ https://wwwsciencedirect.ez328.periodicos.capes.gov.br/science/article/pii/S0892687518301353>. Acesso em: 31 out. 2018.

BISWAS, A. et al. Conversion of agricultural residues to carboxymethylcellulose and carboxymethylcellulose acetate. Indústrial Crops and Products, v. 60, p. 259-265, 2014. Disponível em: $<$ https://www-

sciencedirect.ez328.periodicos.capes.gov.br/science/article/pii/S0926669014003379>. Acesso em: 31 out. 2018.

BISWAS, P. et al. Biosensor for detection of dissolved chromium in potable water: A review. Biosensors and Bioelectronics, v. 94, p. 589-604, 2017. Disponível em: $<\mathrm{https}$ :/wwwsciencedirect.ez328.periodicos.capes.gov.br/science/article/pii/S0956566317302105>. Acesso em: 31 out. 2018.

BORSAGLI, F. G. L. M. et al. O-carboxymethyl functionalization of chitosan, Complexation and adsorption of $\mathrm{Cd}$ (II) and $\mathrm{Cr}$ (VI) as heavy metal pollutant ions. Reactive and Functional Polymers, v. 97, p. 37-47, 2015. Disponível em: $<$ https://www-

sciencedirect.ez328.periodicos.capes.gov.br/science/article/pii/S1381514815300535>. Acesso em: 31 out. 2018.

BRODIN, M. et al. Lignocellulosics as sustainable resources for production of bioplastics - A review. Journal of Cleaner Production, v. 162, p. 646-664, 2017. Disponível em:

$<$ https://www-

sciencedirect.ez328.periodicos.capes.gov.br/science/article/pii/S0959652617311617>. Acesso em: 31 out. 2018.

BURAKOV, A. E. et al. Adsorption of heavy metals on conventional and nanostructured materials for wastewater treatment purposes: A review. Ecotoxicology and Environmental Safety, v. 148, p. 702-712, 2018. Disponível em: <https://wwwsciencedirect.ez328.periodicos.capes.gov.br/science/article/pii/S0147651317307881>. Acesso em: 31 out. 2018. 
CAMPOS, A. F. C. et al. Core-Shell Bimagnetic Nanoadsorbents for Hexavalent Chromium Removal from Aqueous Solutions. Journal of Hazardous Materials, v. 362, p. 82-91, 2019. Disponível em: $<$ https://www-

sciencedirect.ez328.periodicos.capes.gov.br/science/article/pii/S0304389418307957>. Acesso em: 31 out. 2018.

CANDIDO, R. G.; GONÇALVES, A. R. Synthesis of cellulose acetate and carboxymethylcellulose from sugarcane straw. Carbohydrate Polymers, v. 152, p. 679-686, 2016. Disponível em: $<$ https://www-

sciencedirect.ez328.periodicos.capes.gov.br/science/article/pii/S0144861716308694>. Acesso em: 31 out. 2018.

CAROLIN, C. F. et al. Efficient Techniques for the Removal of Toxic Heavy Metals from Aquatic Environment: A Review. Journal of Environmental Chemical Engineering, v. 5, n. 3, p. 2782-2799, 2017. Disponível em: <https://www-

sciencedirect.ez328.periodicos.capes.gov.br/science/article/pii/S2213343717302208>. Acesso em: 31 out. 2018.

CEGłOWSKI, M. et al. A new low-cost polymeric adsorbents with polyamine chelating groups for efficient removal of heavy metal ions from water solutions. Reactive and

Functional Polymers, v. 131, p. 64-74, 2018. Disponível em: $<$ https://wwwsciencedirect.ez328.periodicos.capes.gov.br/science/article/pii/S1381514818306448>. Acesso em: 31 out. 2018.

CHEN, H. et al. Study of the adsorption process of heavy metals cations on Kraft lignin. Chemical Engineering Research and Design, v. 139, p. 248-258, 2018. Disponível em: $<$ https://wwwsciencedirect.ez328.periodicos.capes.gov.br/science/article/pii/S026387621830474X>. Acesso em: 31 out. 2018.

CHOPPALA, G.; BOLAN, N.; PARK, J. H. Chromium Contamination and Its Risk Management in Complex Environmental Settings. Advances in Agronomy, v. 120, p. 129172, 2013. Disponível em: $<$ https://wwwsciencedirect.ez328.periodicos.capes.gov.br/science/article/pii/B9780124076860000026>. Acesso em: 31 out. 2018.

CHOUDHARY, B.; PAUL, D. Isotherms, kinetics and thermodynamics of hexavalent chromium removal using biochar. Journal of Environmental Chemical Engineering, v. 6, n. 2, p. 2335-2343, 2018. Disponível em:

$<$ https://www.sciencedirect.com/science/article/pii/S2213343718301490>. Acesso em: 31 out. 2018.

CORTI, G. Modificação química da celulose usando poliaminas: uso dos novos materiais obtidos na adsorção de íons cobre. Dissertação (Mestrado em Meio Ambiente - Uso e Conservação de Recursos Hídricos) - Universidade Federal de Ouro Preto, Ouro Preto, 2004. Disponível em:

$<$ http://bdtd.ibict.br/vufind/Record/UFOP_9a7077f4341043fe2ed1flad8a9bd4ee>. Acesso em: 31 out. 2018. 
DAS, A. M.; ALI, A. A.; HAZARIKA, M. P. Synthesis and characterization of cellulose acetate from rice husk: Eco-friendly condition. Carbohydrate Polymers, v. 112, p. 342-349, 2014. Disponível em: $<$ https://www-

sciencedirect.ez328.periodicos.capes.gov.br/science/article/pii/S0144861714005827>. Acesso em: 31 out. 2018.

DAUD, W. R. W.; DJUNED, F. M. Cellulose acetate from oil palm empty fruit bunch via a one step heterogeneous acetylation. Carbohydrate Polymers, v. 132, p. 252-260, 2015. Disponível em: $<$ https://wwwsciencedirect.ez328.periodicos.capes.gov.br/science/article/pii/S0144861715005044>. Acesso em: 31 out. 2018.

DE GISI, S. et al. Characteristics and adsorption capacities of low-cost sorbents for wastewater treatment: A review. Sustainable Materials and Technologies, v. 9, p. 10-40, 2016. Disponível em:

$<$ https://www.sciencedirect.com/science/article/pii/S2214993715300221>. Acesso em: 31 out. 2018.

DOTTO, G. L.; CAMPANA-FILHO, S. P.; PINTO, L. A. A. Chitosan based materials and its applications. Sharjah: Bentham Science Publishers, 2017.

ELIODÓRIO, K. P. et al. Treatment of chromium effluent by adsorption on chitosan activated with ionic liquids. Cellulose, v. 24, p. 2559-2570, 2017. Disponível em:

$<$ https://link.springer.com/article/10.1007/s10570-017-1264-3>. Acesso em: 31 out. 2018.

FAUST, S. D.; ALY, O. M. Elements of Surface Chemistry. Adsorption Processes for Water Treatment, p.1-23, 1987.

GHNIMIA, S.; FRINI-SRASRA, N. A comparison of single and mixed pillared clays for zinc and chromium cations removal. Applied Clay Science, v. 158, p. 150-157, 2018. Disponível em: $<$ https://www-

sciencedirect.ez328.periodicos.capes.gov.br/science/article/pii/S016913171830125X>.

Acesso em: 31 out. 2018.

GIERSZEWSKA, M. A.; OSTROWSKA-CZUBENKO, J.; KWIATKOWSKA, A. Effect of ionic crosslinking on density of hydrogel chitosan membranes. Progress on Chemistry and Application of Chitin and its Derivatives, v. 18, p. 49-58, 2013. Disponível em:

$<$ https://www.researchgate.net/publication/282197138_Effect_of_ionic_crosslinking_on_dens ity_of_hydrogel_chitosan_membranes> Acesso em: $0 \overline{7}$ nov. 2018.

GOMES, C. S.; PICCIN, J. S.; GUTTERRES, M. Optimizing adsorption parameters in tannery-dye-containing effluent treatment with leather shaving waste. Process Safety and Environmental Protection, v. 99, p. 98-106, 2016. Disponível em: $<$ https://wwwsciencedirect.ez328.periodicos.capes.gov.br/science/article/pii/S0957582015001913>. Acesso em: 31 out. 2018. 
GORE, C. T. et al. Interweaved LDH/PAN nanocomposite films, Application in the design of effective hexavalent chromium adsorption technology. Chemical Engineering Journal, v. 284, p. 794-801, 2016. Disponível em: <https://www-

sciencedirect.ez328.periodicos.capes.gov.br/science/article/pii/S1385894715013133>. Acesso em: 31 out. 2018.

GUERTIN, J.; JACOBS, J. A.; AVAKIAN, C. P. Chromium (VI) Handbook. Boca Raton, FL: CRC, p. 215-234, 2005.

HARGREAVES, A. J. et al. Impacts of coagulation-flocculation treatment on the size distribution and bioavailability of trace metals $(\mathrm{Cu}, \mathrm{Pb}, \mathrm{Ni}, \mathrm{Zn})$ in municipal wastewater. Water Research, v. 128, p. 120-128, 2018. Disponível em: <https://wwwsciencedirect.ez328.periodicos.capes.gov.br/science/article/pii/S0043135417308771>. Acesso em: 31 out. 2018.

HU, D.; QIANGA, T.; WANG, L. Quaternized chitosan/polyvinyl alcohol/sodium carboxymethylcellulose blend film for potential wound dressing application. Wound Medicine. v. 16, p. 15-21, 2017. Disponível em: $<$ https://www.sciencedirect.com/science/article/abs/pii/S221390951630043X>. Acesso em: 31 out. 2018.

HUANG, Y. et al. Fast and efficient removal of chromium (VI) anionic species by a reusable chitosan-modified multi-walled carbon nanotube composite. Chemical Engineering Journal, v. 339, p. 259-267, 2018. Disponível em: $<$ https://www-

sciencedirect.ez328.periodicos.capes.gov.br/science/article/pii/S1385894718301554>. Acesso em: 31 out. 2018.

HUANG, R. et al. A novel ion-imprinted polymer based on graphene oxide-mesoporous silica nanosheet for fast and efficient removal of chromium (VI) from aqueous solution. Journal of Colloid and Interface Science, v. 514, p. 544-553, 2018. Disponível em: <https://wwwncbi-nlm-nih-gov.ez328.periodicos.capes.gov.br/pubmed/29291553>. Acesso em: 31 out. 2018.

IHSANULLAH, A. A. et al. Heavy metal removal from aqueous solution by advanced carbon nanotubes: Critical review of adsorption applications, Separation and purification technology, v. 157, p. 141-161, 2017. Disponível em: <https://wwwsciencedirect.ez328.periodicos.capes.gov.br/science/article/pii/S1383586615303622>. Acesso em: 31 out. 2018.

JIANG, M. et al. Removal of heavy metal chromium using cross-linked chitosan composite nanofiber mats. International Journal of Biological Macromolecules, v. 120, p. 213-221, 2018. Disponível em: $<$ https://www-

sciencedirect.ez328.periodicos.capes.gov.br/science/article/pii/S0141813018314703>. Acesso em: 31 out. 2018.

JACOB, J. M. et al. Biological approaches to tackle heavy metal pollution: A survey of literature. Journal Of Environmental Management, v. 217, p. 56-70, 2018. Disponível em: $<$ https://www.ncbi.nlm.nih.gov/pubmed/29597108>. Acesso em: 03 nov. 2018. 
JOBBY, R. et al. Biosorption and Biotransformation of Hexavalent Chromium [Cr(VI)]: a Comprehensive Review. Chemosphere, v. 207, p. 255-266, 2018. Disponível em:

$<$ https://www-

sciencedirect.ez328.periodicos.capes.gov.br/science/article/pii/S0045653518308981>. Acesso em: 31 out. 2018.

KAHU, S. S. et al. Two fold modified chitosan for enhanced adsorption of hexavalent chromium from simulated wastewater and indústrial effluents. Carbohydrate Polymer, v. 146, p. 264-273, 2016. Disponível em: <https://www-

sciencedirect.ez328.periodicos.capes.gov.br/science/article/pii/S0144861716302703>. Acesso em: 31 out. 2018.

KASPRZAK, D.; STENIAK, I.; GALINSKI, M. Acetate- and lactate-based ionic liquids: Synthesis, characterisation and electrochemical properties. Journal Of Molecular Liquids, v. 264, p. 233-241, 2018. Disponível em: <https://www-

sciencedirect.ez328.periodicos.capes.gov.br/science/article/pii/S0167732218312960>. Acesso em: 31 out. 2018.

KIM, B. et al. Application of ionic liquids for metal dissolution and extraction. Journal of Indústrial And Engineering Chemistry, v. 61, p. 388-397, 2018. Disponível em: $<$ https://wwwsciencedirect.ez328.periodicos.capes.gov.br/science/article/pii/S1226086X17307001>. Acesso em: 31 out. 2018.

KONG, Q. et al. abrication of terminal amino hyperbranched polymer modified graphene oxide and its prominent adsorption performance towards Cr(VI). Journal of Hazardous Materials, v. 363, p. 161-169, 2019. Disponível em: $<$ https://wwwsciencedirect.ez328.periodicos.capes.gov.br/science/article/pii/S0304389418308781>. Acesso em: 31 out. 2018.

KUMAR, A. S. K. et al. Effective adsorption of hexavalent chromium through a three center (3c) co-operative interaction with an ionic liquid and biopolymer. Journal of Hazardous Materials, v. 239-240, p. 213-224, 2012. Disponível em: <https://wwwsciencedirect.ez328.periodicos.capes.gov.br/science/article/pii/S0304389412008801>. Acesso em: 31 out. 2018.

LANGMUIR, I. The dissociation of hydrogen into atoms. III. The mechanism of the reaction. The Journal of the American Chemical Society, v. 38 , p. 1145-1156, 1916. Disponível em: $<$ https://pubs.acs.org/doi/abs/10.1021/ja02263a001>. Acesso em: 31 out. 2018.

LI, J. et al. Adsorption of reactive red 136 onto chitosan/montmorillonite intercalated composite from aqueous solution. Applied Clay Science, v. 167, p. 9-22, 2019. Disponível em: <https://wwwsciencedirect.ez328.periodicos.capes.gov.br/science/article/pii/S0169131718304344>. Acesso em: 31 out. 2018. 
LI, Y. et al. Molecular simulation of reverse osmosis for heavy metal ions using functionalized nanoporous graphenes. Computational Materials Science, v. 139, p. 65-74, 2017. Disponível em: <https://www-

sciencedirect.ez328.periodicos.capes.gov.br/science/article/pii/S0927025617303932>. Acesso em: 31 out. 2018.

LI, Z. et al. Highly efficient chromium (VI) adsorption with nanofibrous filter paper prepare through electrospinning chitosan/polymethylmethacrylate composite. Carbohydrate

Polymers, v. 137, p. 119-126, 2016. Disponível em: <https://www-

sciencedirect.ez328.periodicos.capes.gov.br/science/article/pii/S0144861715010395>. Acesso em: 31 out. 2018.

LUO, X. et al. Synergic adsorption of acid blue 80 and heavy metal ions $\left(\mathrm{Cu}^{2+} / \mathrm{Ni}^{2+}\right)$ onto activated carbon and its mechanisms. Journal of Indústrial and Engineering Chemistry, v. 27, p. 164-174, 2015. Disponível em: <https://www-

sciencedirect.ez328.periodicos.capes.gov.br/science/article/pii/S1226086X1400700X>. Acesso em: 31 out. 2018.

LYTRAS, G. et al. A novel two-phase bioreactor for microbial hexavalent chromium removal from wastewater. Journal of Hazardous Materials, v. 336, p. 41-51, 2017. Disponível em: $<$ https://www-ncbi-nlm-nih-gov.ez328.periodicos.capes.gov.br/pubmed/28472707>. Acesso em: 31 out. 2018.

MA, A. et al. Ion exchange homogeneous surface diffusion modelling by binary site resin for the removal of nickel ions from wastewater in fixed beds. Chemical Engineering Journal, v. 358, p.1-10, 2019. Disponível em: <https://www-

sciencedirect.ez328.periodicos.capes.gov.br/science/article/pii/S1385894718318473>. Acesso em: 31 out. 2018.

MA, X. et al. Modification of porous starch for the adsorption of heavy metal ions from aqueous solution. Food Chemistry, v. 181, p. 133-139, 2015. Disponível em: <https://wwwsciencedirect.ez328.periodicos.capes.gov.br/science/article/pii/S0308814615002794>. Acesso em: 31 out. 2018 .

MALEKIA, A. et al. Adsorption of hexavalent chromium by metal organic frameworks from aqueous solution. Journal of Indústrial and Engineering Chemistry, v. 28, p. 211-216, 2015. Disponível em: $<$ https://wwwsciencedirect.ez328.periodicos.capes.gov.br/science/article/pii/S1226086X15000660>. Acesso em: 31 out. 2018.

MARCONCINI, L. V. Plataforma Instrumental de RMN > Laboratório II. Disponível em: < https://www.iq.unesp.br/\#!/laboratorios-multiusuarios/rmn4419/laboratorio-ii/>. Acesso em: 03 fev. 2019.

MATOUQ, M. et al. The adsorption kinetics and modeling for heavy metals removal from wastewater by Moringa pods. Journal of Environmental Chemical Engineering, v. 3, p. 775-784, 2015. Disponível em: <https://wwwsciencedirect.ez328.periodicos.capes.gov.br/science/article/pii/S2213343715000755>. Acesso em: 31 out. 2018. 
MCINTOSH, A. J. S.; GRIFFITH, J.; GRÄSVIK, J. Methods of Synthesis and Purification of Ionic Liquids. Application, Purification, and Recovery of Ionic Liquids, p. 59-99, 2016. Disponível em: $<$ https://wwwsciencedirect.ez328.periodicos.capes.gov.br/science/article/pii/B978044463713000002X>. Acesso em: 31 out. 2018.

MINEA, A. A.; MURSHED, S. M. S. A review on development of ionic liquid based nanofluids and their heat transfer behavior. Renewable and Sustainable Energy Reviews, v. 91, p. 584-599, 2018. Disponível em: < https://www-

sciencedirect.ez328.periodicos.capes.gov.br/science/article/pii/S1364032118302314>. Acesso em: 31 out. 2018.

MORAIS, J. P. S.; ROSA, M. F.; MARCONCINI, J. M.; Documento 236: Procedimento para Análise Lignocelulósicas. Campina Grande, PB: Embrapa, 2010. Disponível em:

$<$ https://www.infoteca.cnptia.embrapa.br/bitstream/doc/883400/1/DOC236.pdf $>$. Acesso em: 03 nov. 2018.

MOSIER, N. et al. Features of promising technologies for pretreatment of lignocellulosic biomass. Bioresource Technology, v. 96, p. 673 - 686, 2005. Disponível em: <https://wwwsciencedirect.ez328.periodicos.capes.gov.br/science/article/pii/S0960852404002536>. Acesso em: 31 out. 2018.

MOUSSOUTA, H. et al. Performances of local chitosan and its nanocomposite $5 \%$ Bentonite/Chitosan in the removal of chromium ions (Cr(VI)) fromwastewater.

International Journal of Biological Macromolecules, v. 108, p. 1063-1073, 2018.

Disponível em: $<$ https://www-

sciencedirect.ez328.periodicos.capes.gov.br/science/article/pii/S0141813017323565>. Acesso em: 31 out. 2018.

NAWAłA, J. et al. Applications of ionic liquids in analytical chemistry with a particular emphasis on their use in solid-phase microextraction. Trac Trends in Analytical Chemistry, v. 105, p. 18-36, 2018. Disponível em: <https://www-

sciencedirect.ez328.periodicos.capes.gov.br/science/article/pii/S0165993618300128>. Acesso em: 31 out. 2018.

NELLAIAPPAN, S.; KUMAR, A. S. A bipotentiostat based separation-free method for simultaneous flow injection analysis of chromium (III) and (VI) species. Electrochimica Acta, v. 273, p. 248-256, 2018. Disponível em: <https://wwwsciencedirect.ez328.periodicos.capes.gov.br/science/article/pii/S0013468618307540>. Acesso em: 31 out. 2018.

NEMATI, M.; HOSSEINI, S. M.; SHABANIAN, M. Novel electrodialysis cation exchange membrane prepared by 2-acrylamido-2-methylpropane sulfonic acid; heavy metal ions removal. Journal of Hazardous Materials, v. 337, p. 90-104, 2017. Disponível em: $<$ https://www-

sciencedirect.ez328.periodicos.capes.gov.br/science/article/pii/S0304389417303357>. Acesso em: 31 out. 2018. 
NERIS, J. B. et al. Evaluation of adsorption processes of metal ions in multi-element aqueous systems by lignocellulosic adsorbents applying different isotherms: A critical review.

Chemical Engineering Journal, v. 357, p. 404-420, 2019. Disponível em: $<$ https://wwwsciencedirect.ez328.periodicos.capes.gov.br/science/article/pii/S1385894718318424>. Acesso em: 31 out. 2018.

NEVÁREZ, L. M. et al. Biopolymers-based nanocomposites: Membranes from propionated lignin and cellulose for water purification. Carbohydrate Polymers, v. 86, p. 732- 741, 2011. Disponível em: $<$ https://wwwsciencedirect.ez328.periodicos.capes.gov.br/science/article/pii/S0144861711003948>. Acesso em: 31 out. 2018.

NGAH, W. S. W.; TEONG, L. C.; HANAFIAH, M. A. K. M. Adsorption of dyes and heavy metal ions by chitosan composites: A review. Carbohydrate Polymers, v. 83, p. 1446-1456, 2011. Disponível em: $<$ https://www-

sciencedirect.ez328.periodicos.capes.gov.br/science/article/pii/S0144861710008908>. Acesso em: 31 out. 2018.

NITHYA, K. et al. Fast kinetics and high adsorption capacity of green extract capped superparamagnetic iron oxide nanoparticles for the adsorption of Ni(II) ions. Journal of Indústrial and Engineering Chemistry, v. 59, p. 230-241, 2018. Disponível em: $<$ https://www-

sciencedirect.ez328.periodicos.capes.gov.br/science/article/pii/S1226086X17305683>. Acesso em: 31 out. 2018.

PACHECO, J. W. F. et al. Guia Técnico Ambiental de Curtumes: grupo de trabalho "Produção Mais Limpa (P + L) no Setor Coureiro - Calçadista de São Paulo". São Paulo: CETESB, 2. ed., 2014. Disponível em: <https://cetesb.sp.gov.br/consumosustentavel/wpcontent/uploads/sites/20/2018/04/Guia-T\%C3\%A9cnico-Ambiental-de-Curtumesv2015.pdf $>$. Acesso em: 31 out. 2018.

PAVIA, D. L., et al. Introduction to Spectroscopy, 5. ed. Washington: Cengage Learning, 2015.

PEREDO, K. et al. Thermochemical properties of cellulose acetate blends with acetosolv and sawdust lignin: A comparative study. International Journal of Biological Macromolecules, v. 83, p. $403-409,2016$. Disponível em: <https://www-ncbi-nlm-nihgov.ez328.periodicos.capes.gov.br/pubmed/26582340>. Acesso em: 31 out. 2018.

POLOWCZYK, I. et al. Equilibrium and kinetic study of chromium sorption on resins with quaternary ammonium and N-methyl-D-glucamine groups. Chemical Engineering Journal, v. 284, p. 395-404, 2016. Disponível em: $<$ https://wwwsciencedirect.ez328.periodicos.capes.gov.br/science/article/pii/S1385894715012759>. Acesso em: 31 out. 2018 . 
RANGABHASHIYAM, S.; BALASUBRAMANIAN, P. Adsorption behaviors of hazardous methylene blue and hexavalent chromium on novel materials derived from Pterospermum acerifolium shells. Journal of Molecular Liquids, v. 254, p. 433-445, 2018. Disponível em: $<$ https://www-

sciencedirect.ez328.periodicos.capes.gov.br/science/article/pii/S016773221735376X>. Acesso em: 31 out. 2018.

ROUQUEROL, F.; ROUQUEROL, J.; SING, K. Adsorption by powders and porous solids: principles, methodology and applications. San Diego: Academic Press, 1999.

RUIZ-ACEITUNO, L. et al. Selective fractionation of sugar alcohols using ionic liquids. Separation and Purification Technology, v. 209, p. 800-805, 2019. Disponível em: $<$ https://wwwsciencedirect.ez328.periodicos.capes.gov.br/science/article/pii/S1383586618321816>. Acesso em: 31 out. 2018.

SAMUEL, M. S. et al. Efficient removal of Chromium(VI) from aqueous solution using chitosan grafted graphene oxide (CS-GO) nanocomposite. International Journal of Biological Macromolecules, v. 121, p. 285-292, 2019. Disponível em: <https://wwwsciencedirect.ez328.periodicos.capes.gov.br/science/article/pii/S0141813018341503>. Acesso em: 31 out. 2018.

SALIM, A. J. Adsorption of Hexavalent Chromium Ion from Aqueous Solution by Sodium Alginate and Carboxymethyl Cellulose Beads: Kinetics and Isotherm Studies. Journal of AlNahrain University, v. 18, p. 40-48, 2015. Disponível em:

$<$ http://jnus.org/pdf/1/2015/1/1139.pdf>. Acesso em: 31 out. 2018.

SARODE, S. et al. Overview of wastewater treatment methods with special focus on biopolymer chitin-chitosan. International Journal of Biological Macromolecules, v. 121, p. 1086-1100, 2019. Disponível em: <https://www-

sciencedirect.ez328.periodicos.capes.gov.br/science/article/pii/S0141813018339588>. Acesso em: 31 out. 2018.

SEADER, J. D; HENLEY, E. J. Separation Process Principles. US: Wiley and Sons, 1998.

SHAHID, M. et al. Chromium speciation, bioavailability, uptake, toxicity and detoxification in soil-plant system: A review. Chemosphere, v. 178, p. 513-533, 2017. Disponível em: $<$ https://wwwsciencedirect.ez328.periodicos.capes.gov.br/science/article/pii/S004565351730437X>. Acesso em: 31 out. 2018.

SHAHATA, M. M. Adsorption of some heavy metal ions by used different immobilized substances on silica gel. Arabian Journal of Chemistry, v. 9, n. 6, p. 755-763, 2016. Disponível em: $<$ https://wwwsciencedirect.ez328.periodicos.capes.gov.br/science/article/pii/S187853521100311X>. Acesso em: 31 out. 2018. 
SHARMA, M. et al. ZnO tetrapods and activated carbon based hybrid composite: Adsorbents for enhanced decontamination of hexavalent chromium from aqueous solution. Chemical Engineering Journal, v. 358, p. 540-551, 2019. Disponível em: $<$ https://wwwsciencedirect.ez328.periodicos.capes.gov.br/science/article/pii/S1385894718319727>. Acesso em: 31 out. 2018.

SHERLALA, A. I. A. et al. A review of the applications of organo-functionalized magnetic graphene oxide nanocomposites for heavy metal adsorption. Chemosphere, v. 193, p. 10041017, 2018. Disponível em: <https://www-

sciencedirect.ez328.periodicos.capes.gov.br/science/article/pii/S0045653517318702>. Acesso em: 31 out. 2018.

SIYAL, A. A. et al. A review on geopolymers as emerging materials for the adsorption of heavy metals and dyes. Journal of Environmental Management, v. 224, p. 327-339, 2018. Disponível em: $<$ https://www-

sciencedirect.ez328.periodicos.capes.gov.br/science/article/pii/S0301479718307989>. Acesso em: 31 out. 2018.

SMITH, J. M.; VAN NESS, H. C.; ABBOTT, M. M. Introdução à termodinâmica da engenharia química. Rio de Janeiro: LTC, 2013.

SU, M. et al. Enhanced hexavalent chromium removal by activated carbon modified with micro-sized goethite using a facile impregnation method. Science of the Total Environment, v. 647, p. 47-56, 2019. Disponível em: <https://www-

sciencedirect.ez328.periodicos.capes.gov.br/science/article/pii/S0048969718328687>. Acesso em: 31 out. 2018.

TAHAR, L. B.; OUESLATI, M. H.; ABUALREISH, M. J. A. Synthesis of magnetite derivatives nanoparticles and their application for the removal of chromium (VI) from aqueous solutions. Journal of Colloid and Interface Science, v. 512, p. 115-126, 2018. Disponível em: $<$ https://wwwsciencedirect.ez328.periodicos.capes.gov.br/science/article/pii/S0021979717311992>. Acesso em: 31 out. 2018.

TAHERZADEH, M. K.; KARIMI, K. Pretreatment of lignocellulosic wastes to improve ethanol and biogas production: A review. International Journal of Molecular Sciences. v. 9, p. 1621-1651, 2008. Disponível em: <https://www-ncbi-nlm-nihgov.ez328.periodicos.capes.gov.br/pmc/articles/PMC2635757/>. Acesso em: 31 out. 2018.

TAPPI - Technical Association of the Pulp and Paper Industry. Official TestMethods, Provisional Test Methods, and Useful Test Methods - Fibrous Materials and Pulp Testing, Atlanta, USA, Np, 1979.

TAN, C. et al. Adsorption behavior comparison of trivalent and hexavalent chromium on biochar derived from municipal sludge. Bioresource Technology, v. 190, p. 388-394, 2015. Disponível em: $<$ https://wwwsciencedirect.ez328.periodicos.capes.gov.br/science/article/pii/S0960852415006495>. Acesso em: 31 out. 2018. 
TRAN, H. N. et al. Mistakes and inconsistencies regarding adsorption of contaminants from aqueous solutions: A critical review. Water Research, v. 120, p. 88-116, 2017. Disponível em: $<$ https://www-

sciencedirect.ez328.periodicos.capes.gov.br/science/article/pii/S0043135417302695>. Acesso em: 31 out. 2018.

UDDIN, M. K. A review on the adsorption of heavy metals by Clay minerals, with special focus on the past decade, Chemical Engineering Journal, v. 308, p. 438-462, 2017.

Disponível em: $<$ https://www-

sciencedirect.ez328.periodicos.capes.gov.br/science/article/pii/S1385894716312670>. Acesso em: 31 out. 2018.

ÜNLÜ, C. H. Carboxymethylcellulose from recycled newspaper in aqueous médium. Carbohydrate Polymers, v. 97, p. 159-163, 2013. Disponível em:

$<$ https://www.sciencedirect.com/science/article/pii/S0144861713003925>. Acesso em: 03 nov. 2018.

VAKILI, M. et al. Novel crosslinked chitosan for enhanced adsorption of hexavalent chromium in acidic solution. Chemical Engineering Journal, v. 347, p. 782-790, 2018. Disponível em: $<$ https://www-

sciencedirect.ez328.periodicos.capes.gov.br/science/article/pii/S138589471830754X>. Acesso em: 31 out. 2018.

VELEMPINI, T. et al. Epichlorohydrin crosslinked carboxymethyl cellulose-ethylenediamine imprinted polymer for the selective uptake of $\mathrm{Cr}(\mathrm{VI})$. International Journal of Biological Macromolecules, v. 101, p. 837-844, 2017. Disponível em: <https://www-ncbi-nlm-nihgov.ez328.periodicos.capes.gov.br/pubmed/28300589>. Acesso em: 31 out. 2018.

VENKATESWAR, R. L. et al. Bioconversion of lignocellulosic biomass to xylitol: An overview. Bioresource Technology, v. 213, p. 299-310, 2016. Disponível em: <https://wwwncbi-nlm-nih-gov.ez328.periodicos.capes.gov.br/pubmed/27142629>. Acesso em: 31 out. 2018.

WANG, B. et al. Selective heavy metal removal and water purification by microfluidically generated chitosan microspheres: Characteristics, modeling and application. Journal of Hazardous Materials, v. 364, p. 192-205, 2019. Disponível em: <https://www-ncbi-nlm-nihgov.ez328.periodicos.capes.gov.br/pubmed/30366241>. Acesso em: 31 out. 2018.

WANG, F. et al. Single and binary adsorption of heavy metal ions from aqueous solutions using sugarcane cellulose-based adsorbent. Bioresource Technology, v. 241, p. 482-490, 2017. Disponível em: $<$ https://www-

sciencedirect.ez328.periodicos.capes.gov.br/science/article/pii/S0960852417308301>. Acesso em: 31 out. 2018.

WEBER, W. J.; MORRIS, J. C. Kinetics of adsorption on carbon from solution. Journal of Sanitary Engineering Division ASCE. v. 89, p. 31-60, 1963. Disponível em:

$<$ http://cedb.asce.org/CEDBsearch/record.jsp?dockey=0013042>. Acesso em: 31 out. 2018. 
WISE, L. E. M.; MURPHY, A. A. D. Chlorite holocellulose, its fractionationand bearing on summative wood analysis and on studies on the hemicellulose. Paper Trade Journal, v. 122, n. 2, p. 35-43, 1946. Disponível em: <http://www.worldcat.org/title/chlorite-holocellulose-itsfractionation-and-bearing-on-summative-wood-analysis-and-studies-on-thehemicelluloses/oclc/708721051>. Acesso em: 03 nov. 2018.

WEN, J.; DONG, H.; ZENG, G. Application of zeolite in removing salinity/sodicity from wastewater: A review of mechanisms, challenges and opportunities. Journal of Cleaner Production, v. 197, p. 1435-1446, 2018. Disponível em: <https://wwwsciencedirect.ez328.periodicos.capes.gov.br/science/article/pii/S0959652618319292>. Acesso em: 31 out. 2018.

WONGKOM L., JIMTAISONG A. Novel biocomposite of carboxymethyl chitosan and pineapple peel carboxymethylcellulose as sunscreen carrier. International Journal of Biological Macromolecules. v. 95, p. 873-880, 2017. Disponível em: $<$ https://www.ncbi.nlm.nih.gov/pubmed/27777081>. Acesso em: 03 nov. 2018.

WORCH, E. Adsorption Technology in Water Treatment: Fundamentals, Processes, and Modeling. Boston: Walter de Gruyter GmbH, 2012. Disponível em: $<$ https://www.researchgate.net/profile/...adsorption...water_treatments/.../eeeee.pdf $>$. Acesso em: 31 out. 2018.

XIANG, B. et al. Dithiocarbamate-modified starch derivatives with high heavy metaladsorption performance. Carbohydrate Polymers, v. 136, p. 30-37, 2016. Disponível em: <https://www-ncbi-nlm-nih-gov.ez328.periodicos.capes.gov.br/pubmed/26572325>. Acesso em: 31 out. 2018.

XIAO, K. et al. Resin oxidization phenomenon and its influence factor during chromium (VI) removal from wastewater using gel-type anion exchangers. Chemical Engineering Journal, v. 283, p. 1349-1356, 2016. Disponível em:

$<$ https://www.sciencedirect.com/science/article/pii/S1385894715011663>. Acesso em: 31 out. 2018.

XIE, M. et al. Synthesis and adsorption behavior of magnetic microspheres based on chitosan/organic rectorite for low-concentration heavy metal removal. Journal of Alloys and Compounds, v. 647, p. 892-905, 2015. Disponível em:

$<$ https://www.sciencedirect.com/science/article/abs/pii/S0925838815301833>. Acesso em: 03 nov. 2018.

$\mathrm{XU}$, J. et al. A review of functionalized carbon nanotubes and graphene for heavy metal adsorption from water: Preparation, application, and mechanism. Chemosphere, v. 195, p. 351-364, 2018. Disponível em:

$<$ https://www.sciencedirect.com/science/article/pii/S0045653517320313>. Acesso em: 31 out. 2018 .

YANG, X. et al. Effects of preparation methods on the morphology and properties of nanocellulose (NC) extracted from corn husk. Industrial Crops and Products, v. 109, p. 241-247, 2017. Disponível em:

$<$ https://www.sciencedirect.com/science/article/pii/S0926669017305435>. Acesso em: 03 nov. 2018. 
YUE, Z. B. et al. Component analysis and heavy metal adsorption ability of extracellular polymeric substances (EPS) from sulfate reducing bacteria. Bioresource Technology, v. 194, p. 399-402, 2015. Disponível em: <https://www-

sciencedirect.ez328.periodicos.capes.gov.br/science/article/pii/S0960852415010044>. Acesso em: 31 out. 2018.

ZHANG, L.; ZENG, Y.; CHENG, Z. Removal of heavy metal ions using chitosan and modified chitosan: A review. Journal of Molecular Liquids, v. 214, p. 175-191, 2016. Disponível em: $<$ https://www-

sciencedirect.ez328.periodicos.capes.gov.br/science/article/pii/S0167732215308801>. Acesso em: 31 out. 2018.

ZHANG, L. et al. Recycling of Cr (VI) from weak alkaline aqueous media using a chitosan/ triethanolamine/Cu (II) composite adsorbent. Carbohydrate Polymers, v. 205, p. 151-158, 2019. Disponível em: <https://www-

sciencedirect.ez328.periodicos.capes.gov.br/science/article/pii/S0144861718311809>. Acesso em: 31 out. 2018.

ZHANG, W. et al. Hybrid functionalized chitosan- $\mathrm{Al}_{2} \mathrm{O}_{3} @ \mathrm{SiO}_{2}$ composite for enhanced Cr(VI) adsorption. Chemosphere, v. 203, p. 188-198, 2018. Disponível em: <https://wwwncbi-nlm-nih-gov.ez328.periodicos.capes.gov.br/pubmed/29614412>. Acesso em: 31 out. 2018.

ZHOU, J. et al. Effective removal of hexavalent chromium from aqueous solutions by adsorption on mesoporous carbon microspheres. Journal of Colloid and Interface Science, v. 462, p. 200-207, 2016. Disponível em: $<$ https://wwwsciencedirect.ez328.periodicos.capes.gov.br/science/article/pii/S0021979715302472>. Acesso em: 31 out. 2018. 
Apêndice A - Dados experimentais de adsorção 
Figura 84 - Curva de Calibração para CMCQF

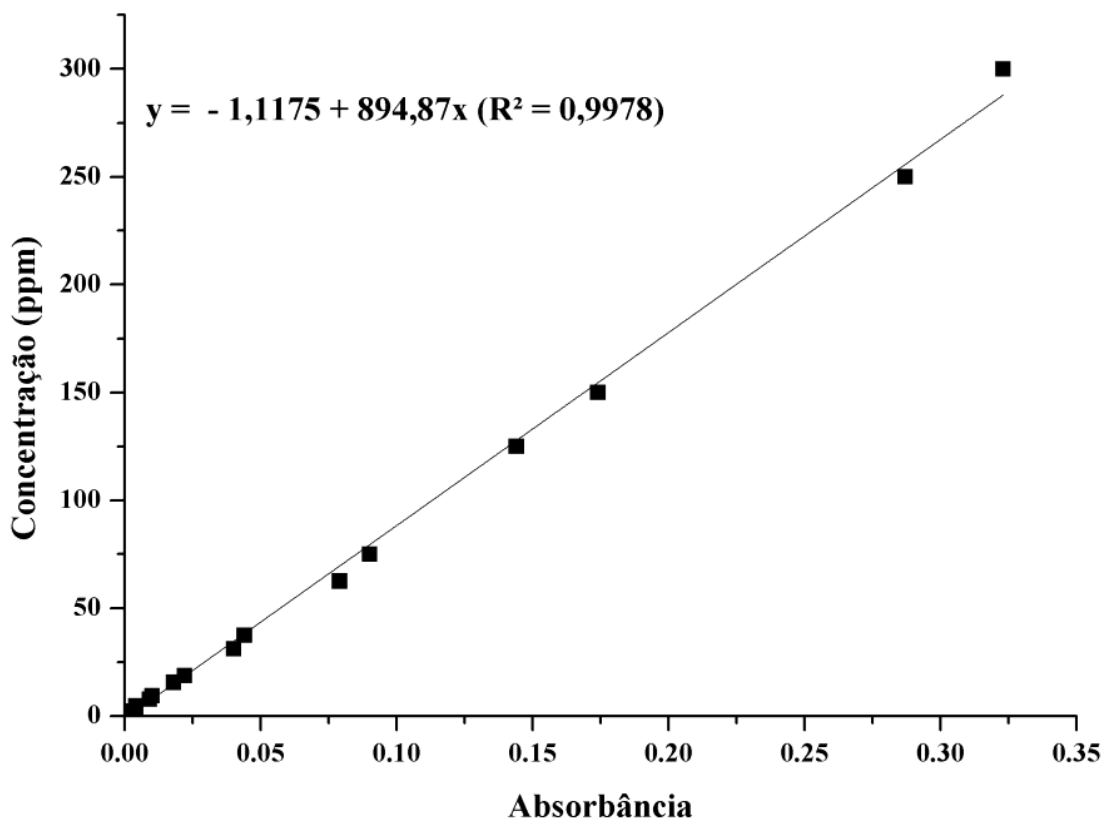

Fonte: Autor

Legenda: Utilizada para cálculos nas tabelas 39 e 40 
Tabela 41 - Dados referentes à influência do pH

\begin{tabular}{|c|c|c|c|c|c|c|c|}
\hline $\mathrm{pH}$ & & Absorbância & $\begin{array}{c}\text { Concentração } \\
(\mathrm{ppm})\end{array}$ & $\begin{array}{l}\text { Desvio } \\
\text { Padrão } \\
\text { (ppm) }\end{array}$ & $\begin{array}{c}\text { Massa de } \\
\text { Adsorvente (g) }\end{array}$ & $\begin{array}{c}\text { Capacidade de } \\
\text { Adsorção } \\
\text { (mg.g-1) }\end{array}$ & $\begin{array}{c}\text { Desvio } \\
\text { Padrão } \\
(\mathrm{mg} . \mathrm{g}-1)\end{array}$ \\
\hline \multirow{4}{*}{2,5} & \multirow{2}{*}{ Efluente } & 0,260 & 231,55 & \multirow{2}{*}{1,47} & \multirow{2}{*}{-} & \multirow{2}{*}{ - } & \multirow{2}{*}{ - } \\
\hline & & 0,276 & 245,87 & & & & \\
\hline & \multirow{2}{*}{ Amostra } & 0,118 & 104,48 & \multirow{2}{*}{1,58} & 0,0504 & 66,58 & \multirow{2}{*}{1,60} \\
\hline & & 0,126 & 111,64 & & 0,0501 & 63,41 & \\
\hline \multirow{4}{*}{3} & \multirow{2}{*}{ Efluente } & 0,277 & 246,76 & \multirow{2}{*}{0,30} & \multirow{2}{*}{ - } & \multirow{2}{*}{ - } & \multirow{2}{*}{ - } \\
\hline & & 0,278 & 247,66 & & & & \\
\hline & \multirow{2}{*}{ Amostra } & 0,140 & 124,16 & \multirow{2}{*}{1,71} & 0,05 & 61,52 & \multirow{2}{*}{3,30} \\
\hline & & 0,125 & 110,74 & & 0,0501 & 68,10 & \\
\hline \multirow{4}{*}{4} & \multirow{2}{*}{ Efluente } & 0,269 & 239,60 & \multirow{2}{*}{1,49} & \multirow{2}{*}{-} & \multirow{2}{*}{ - } & \multirow{2}{*}{ - } \\
\hline & & 0,274 & 244,08 & & & & \\
\hline & \multirow{2}{*}{ Amostra } & 0,134 & 118,80 & \multirow{2}{*}{1,37} & 0,0504 & 61,03 & \multirow{2}{*}{2,50} \\
\hline & & 0,146 & 129,53 & & 0,0501 & 56,04 & \\
\hline \multirow{4}{*}{5} & \multirow{2}{*}{ Efluente } & 0,260 & 231,55 & \multirow{2}{*}{1,19} & \multirow[t]{2}{*}{ - } & 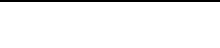 & 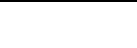 \\
\hline & & 0,256 & 227,97 & & & - & - \\
\hline & Amostra & 0,155 & 137,59 & 158 & 0,0503 & 45,81 & 180 \\
\hline & Amostra & 0,147 & 130,43 & 1,58 & 0,0502 & 49,47 & 1,80 \\
\hline & Fflunte & 0,258 & 229,76 & 140 & 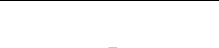 & 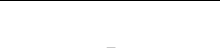 & 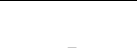 \\
\hline 6 & Efluente & 0,253 & 225,28 & 1,49 & - & - & - \\
\hline 0 & Amostra & 0,183 & 162,64 & 158 & 0,05 & 32,44 & 160 \\
\hline & Amostra & 0,175 & 155,48 & 1,58 & 0,0505 & 35,66 & 1,00 \\
\hline & Fflunte & 0,246 & 219,02 & 080 & 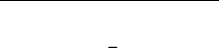 & 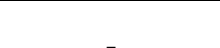 & 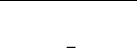 \\
\hline 7 & Eriuente & 0,249 & 221,71 & 0,89 & - & - & - \\
\hline 1 & Amostra & 0,212 & 188,59 & 000 & 0,0501 & 15,85 & ר0 0 \\
\hline & Amostra & 0,212 & 188,59 & 0,00 & 0,05 & 15,88 & 0,02 \\
\hline & Efluente & 0,231 & 205,60 & 089 & - & & - \\
\hline 8 & Enuente & 0,228 & 202,91 & & - & - & - \\
\hline 0 & Amostra & 0,213 & 189,49 & 134 & 0,0502 & 7,35 & 069 \\
\hline & Amostra & 0,210 & 186,81 & 1,34 & 0,05 & 8,72 & 0,09 \\
\hline
\end{tabular}

Fonte: Autor 
Tabela 42 - Dados de cinética de adsorção para CMCQF

\begin{tabular}{|c|c|c|c|c|c|c|}
\hline $\begin{array}{l}\text { Tempo } \\
\text { (min) }\end{array}$ & Absorbância & $\begin{array}{c}\text { Concentração } \\
(\mathrm{ppm})\end{array}$ & $\begin{array}{c}\text { Desvio } \\
\text { Padrão } \\
(\mathrm{ppm})\end{array}$ & $\begin{array}{c}\text { Massa de } \\
\text { Adsorvente (g) }\end{array}$ & $\begin{array}{c}\text { Capacidade } \\
\text { de Adsorção } \\
\left(\mathrm{mg} \cdot \mathrm{g}^{-1}\right)\end{array}$ & $\begin{array}{c}\text { Desvio } \\
\text { Padrão } \\
\left(\mathrm{mg} \cdot \mathrm{g}^{-1}\right)\end{array}$ \\
\hline \multirow{2}{*}{1} & 0,198 & 176,05 & \multirow{2}{*}{0,00} & 0,0505 & 38,24 & \multirow{2}{*}{0,15} \\
\hline & 0,198 & 176,05 & & 0,0501 & 38,55 & \\
\hline \multirow{2}{*}{2} & 0,186 & 165,32 & \multirow{2}{*}{1,49} & 0,0502 & 43,82 & \multirow{2}{*}{2,34} \\
\hline & 0,196 & 174,26 & & 0,0505 & 39,13 & \\
\hline \multirow{2}{*}{4} & 0,182 & 161,74 & \multirow{2}{*}{1,05} & 0,0503 & 45,51 & \multirow{2}{*}{3,92} \\
\hline & 0,200 & 177,84 & & 0,0501 & 37,66 & \\
\hline \multirow{2}{*}{5} & 0,185 & 164,42 & \multirow{2}{*}{1,68} & 0,0499 & 44,53 & \multirow{2}{*}{1,34} \\
\hline & 0,191 & 169,79 & & 0,0499 & 41,84 & \\
\hline \multirow{2}{*}{10} & 0,170 & 151,00 & \multirow{2}{*}{1,92} & 0,0501 & 51,05 & \multirow{2}{*}{2,50} \\
\hline & 0,181 & 160,84 & & 0,0502 & 46,05 & \\
\hline \multirow{2}{*}{15} & 0,152 & 134,89 & \multirow{2}{*}{1,92} & 0,0499 & 59,32 & \multirow{2}{*}{2,57} \\
\hline & 0,163 & 144,73 & & 0,0501 & 54,18 & \\
\hline \multirow{2}{*}{20} & 0,166 & 147,42 & \multirow{2}{*}{1,79} & 0,0506 & 52,31 & \multirow{2}{*}{1,09} \\
\hline & 0,162 & 143,84 & & 0,0502 & 54,51 & \\
\hline \multirow{2}{*}{25} & 0,156 & 138,47 & \multirow{2}{*}{0,45} & 0,0503 & 57,07 & \multirow{2}{*}{0,39} \\
\hline & 0,155 & 137,58 & & 0,0500 & 57,86 & \\
\hline 30 & 0,141 & 125,05 & 105 & 0,0504 & 63,62 & 372 \\
\hline 30 & 0,159 & 141,16 & 1,05 & 0,0499 & 56,19 & $3, / 2$ \\
\hline & 0,162 & 143,84 & & 0,0505 & 54,19 & \\
\hline 60 & 0,144 & 127,73 & 1,05 & 0,0505 & 62,16 & 3,99 \\
\hline & 0,157 & 139,37 & & 0,0503 & 56,63 & \\
\hline 15 & 0,157 & 139,37 & 0,00 & 0,0506 & 56,29 & 0,17 \\
\hline 105 & 0,162 & 143,84 & & 0,0501 & 54,62 & \\
\hline 105 & 0,159 & 141,16 & 1,34 & 0,0505 & 55,52 & 0,45 \\
\hline 120 & 0,162 & 143,84 & 110 & 0,0501 & 54,62 & \\
\hline 120 & 0,137 & 121,47 & 1,19 & 0,0504 & 65,39 & 5,39 \\
\hline 150 & 0,153 & 135,79 & 212 & 0,0501 & 58,64 & 178 \\
\hline 150 & 0,160 & 142,05 & 3,13 & 0,0505 & 55,08 & 1,18 \\
\hline 180 & 0,159 & 141,16 & 313 & 0,0501 & 55,96 & 144 \\
\hline 180 & 0,152 & 134,89 & 3,13 & 0,0503 & 58,85 & 1,44 \\
\hline 210 & 0,159 & 141,16 & 22 & 0,0504 & 55,63 & 105 \\
\hline 210 & 0,154 & 136,68 & 2,24 & 0,0505 & 57,73 & 1,05 \\
\hline & 0,157 & 139,37 & 250 & 0,0503 & 56,63 & 160 \\
\hline 240 & 0,165 & 146,52 & 3,58 & 0,0500 & 53,39 & 1,02 \\
\hline חר & 0,159 & 141,16 & 217 & 0,0502 & 55,85 & 25 \\
\hline $2 / 0$ & 0,149 & 132,21 & $2,4 /$ & 0,0500 & 60,55 & 2,35 \\
\hline & 0,154 & 136,68 & & 0,0500 & 58,31 & \\
\hline 300 & 0,157 & 139,37 & 1,34 & 0,0503 & 56,63 & 0,84 \\
\hline 720 & 0,161 & 142,95 & م & 0,0504 & 54,74 & 005 \\
\hline 120 & 0,161 & 142,95 & 0,00 & 0,0503 & 54,85 & 0,03 \\
\hline & 0,164 & 145,63 & & 0,0503 & 53,52 & \\
\hline 1440 & 0,171 & 151,89 & 3,13 & 0,0506 & 50,10 & 1,71 \\
\hline
\end{tabular}


Figura 85 - Curva de calibração para CMCQDIC

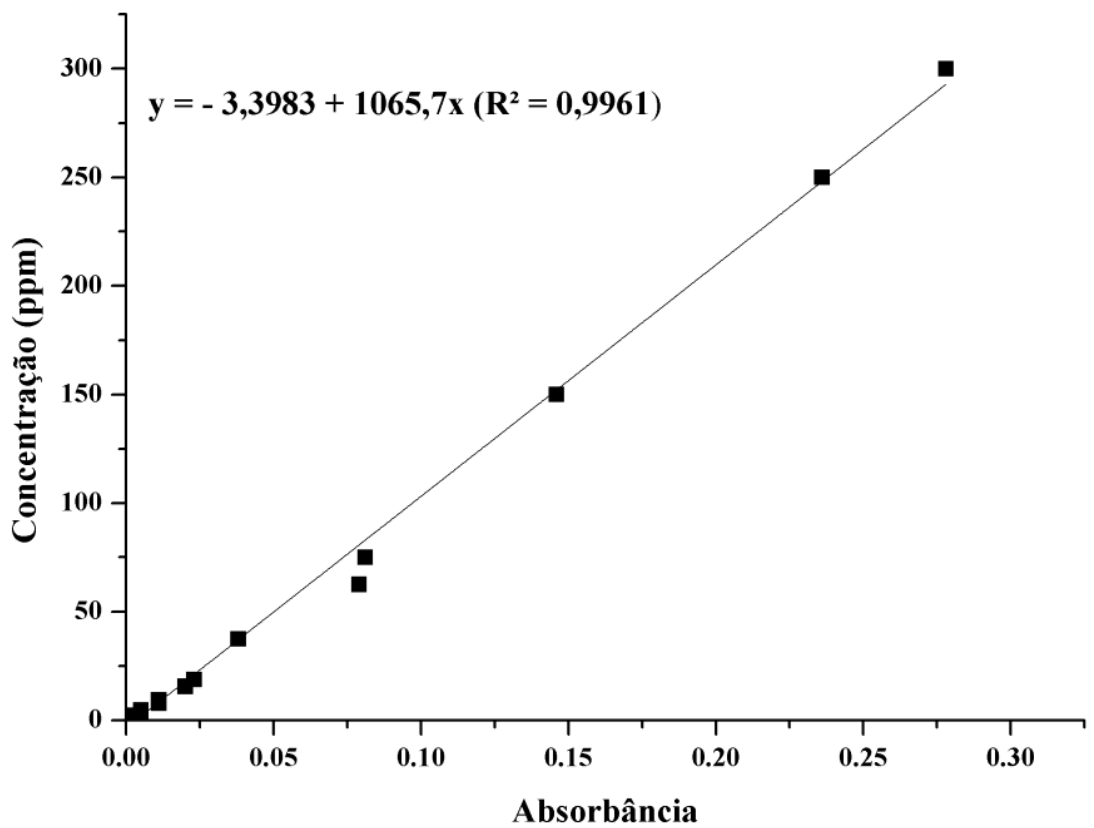

Fonte: Autor

Legenda: Utilizada para cálculos na tabela 41 
Tabela 43 - Dados de cinética de adsorção para CMCQDIC

\begin{tabular}{|c|c|c|c|c|c|c|}
\hline Tempo (min) & Absorbância & $\begin{array}{l}\text { Concentração } \\
(\mathrm{ppm})\end{array}$ & $\begin{array}{c}\text { Desvio } \\
\text { Padrão } \\
(\mathrm{ppm})\end{array}$ & $\begin{array}{l}\text { Massa de } \\
\text { adsorvente } \\
(\mathrm{g})\end{array}$ & $\begin{array}{c}\text { Capacidade de } \\
\text { Adsorção } \\
\left(\mathrm{mg}^{-1} \mathrm{~g}^{-1}\right)\end{array}$ & $\begin{array}{c}\text { Desvio } \\
\text { Padrão } \\
\left(\mathrm{mg}^{\left.-g^{-1}\right)}\right.\end{array}$ \\
\hline \multirow{2}{*}{1} & 0,230 & 241,71 & \multirow{2}{*}{3,20} & 0,0501 & 12,23 & \multirow{2}{*}{1,55} \\
\hline & 0,224 & 235,32 & & 0,0504 & 15,33 & \\
\hline \multirow{2}{*}{2} & 0,217 & 227,86 & \multirow{2}{*}{3.20} & 0,0499 & 19,22 & \multirow{2}{*}{1,59} \\
\hline & 0,223 & 234,25 & & 0,0498 & 16,05 & \\
\hline \multirow{2}{*}{4} & 0,194 & 203,35 & \multirow{2}{*}{1,60} & 0,0502 & 31,31 & \multirow{2}{*}{0,83} \\
\hline & 0,191 & 200,15 & & 0,0501 & 32,97 & \\
\hline \multirow{2}{*}{5} & 0,180 & 188,43 & \multirow{2}{*}{1,60} & 0,0504 & 38,59 & \multirow{2}{*}{0,76} \\
\hline & 0,183 & 191,62 & & 0,0503 & 37,08 & \\
\hline \multirow{2}{*}{10} & 0,179 & 187,36 & \multirow{2}{*}{0,53} & 0,0506 & 38,96 & \multirow{2}{*}{0,30} \\
\hline & 0,180 & 188,43 & & 0,0507 & 38,36 & \\
\hline \multirow{2}{*}{15} & 0,176 & 184,16 & \multirow{2}{*}{0,00} & 0,0502 & 40,87 & \multirow{2}{*}{0,04} \\
\hline & 0,176 & 184,16 & & 0,0501 & 40,95 & \\
\hline \multirow{2}{*}{20} & 0,174 & 182,03 & \multirow{2}{*}{0,00} & 0,0505 & 41,68 & \multirow{2}{*}{0,30} \\
\hline & 0,175 & 183,10 & & 0,0506 & 41,07 & \\
\hline \multirow{2}{*}{25} & 0,173 & 180,97 & & 0,0503 & 42,37 & \\
\hline & 0,173 & 180,97 & $1,0 /$ & 0,0506 & 42,12 & 0,13 \\
\hline 30 & 0,172 & 179,90 & 052 & 0,0501 & 43,07 & \\
\hline 30 & 0,172 & 179,90 & 0,53 & 0,0500 & 43,16 & 0,04 \\
\hline 45 & 0,170 & 177,77 & 053 & 0,0498 & 44,40 & \\
\hline 45 & 0,170 & 177,77 & 0,53 & 0,0499 & 44,32 & 0,04 \\
\hline 60 & 0,168 & 175,64 & & 0,0501 & 45,20 & \\
\hline 60 & 0,166 & 173,51 & 0,00 & 0,0497 & 46,64 & 0,72 \\
\hline 75 & 0,167 & 174,57 & 160 & 0,0501 & 45,55 & 022 \\
\hline 75 & 0,166 & 173,51 & 1,60 & 0,0497 & 45,99 & 0,22 \\
\hline (O) & 0,166 & 173,51 & $0-52$ & 0,0498 & 46,54 & ר 0 \\
\hline 90 & 0,165 & 172,44 & 0,33 & 0,0499 & 46,98 & $0, \angle 2$ \\
\hline & 0,164 & 171,38 & 053 & 0,0504 & 47,05 & 005 \\
\hline 105 & 0,164 & 171,38 & 0,53 & 0,0505 & 46,95 & \\
\hline 120 & 0,163 & 170,31 & 107 & 0,0502 & 47,77 & 70 \\
\hline 120 & 0,166 & 173,51 & 1,01 & 0,0500 & 46,36 & $0, / 0$ \\
\hline & 0,164 & 171,38 & & 0,0497 & 47,71 & \\
\hline 150 & 0,165 & 172,44 & 0,53 & 0,0496 & 47,27 & 0,22 \\
\hline 180 & 0,163 & 170,31 & & 0,0499 & 48,05 & \\
\hline 180 & 0,162 & 169,25 & 0,53 & 0,0500 & 48,49 & 0,22 \\
\hline & 0,160 & 167,11 & & 0,0506 & 48,97 & 043 \\
\hline 210 & 0,162 & 169,25 & 1,07 & 0,0504 & 48,10 & 0,43 \\
\hline 240 & 0,161 & 168,18 & 053 & 0,0500 & 49,02 & 027 \\
\hline 240 & 0,162 & 169,25 & 0,53 & 0,0500 & 48,49 & 0,27 \\
\hline 270 & 0,163 & 170,31 & 053 & 0,0499 & 48,05 & 032 \\
\hline 270 & 0,162 & 169,25 & 0,53 & 0,0498 & 48,68 & 0,32 \\
\hline 300 & 0,163 & 170,31 & & 0,0498 & 48,15 & 032 \\
\hline 300 & 0,162 & 169,25 & 0,53 & 0,0497 & 48,78 & 0,32 \\
\hline 720 & 0,176 & 184,16 & 053 & 0,0501 & 40,95 & 023 \\
\hline 120 & 0,177 & 185,23 & 0,53 & 0,0500 & 40,50 & 0,23 \\
\hline 1440 & 0,200 & 209,74 & 053 & 0,0502 & 28,13 & 006 \\
\hline 1440 & 0,200 & 209,74 & 0,53 & 0,0500 & 28,24 & 0,06 \\
\hline
\end{tabular}

Fonte: Autor 
Figura 86 - Curva de calibração para CMCQDIC

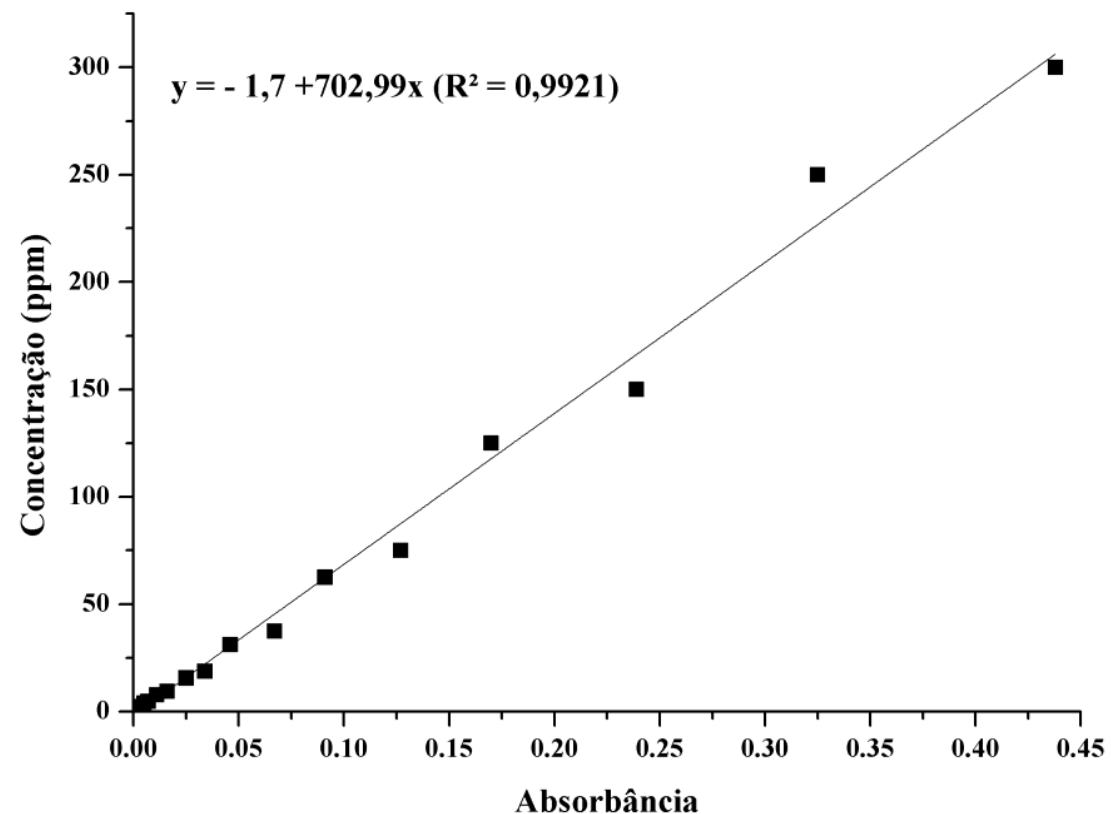

Fonte: Autor

Legenda: Utilizada para cálculos na tabela 42 
Tabela 44 - Dados referentes à influência do $\mathrm{pH}$ para CMCQDIC

\begin{tabular}{|c|c|c|c|c|c|c|c|}
\hline $\mathrm{pH}$ & & Absorbância & $\begin{array}{l}\text { Concentração } \\
(\mathrm{ppm})\end{array}$ & $\begin{array}{c}\text { Desvio } \\
\text { Padrão } \\
(\mathrm{ppm}) \\
\end{array}$ & $\begin{array}{c}\text { Massa de } \\
\text { Adsorvente } \\
\text { (g) }\end{array}$ & $\begin{array}{c}\text { Capacidade } \\
\text { de adsorção } \\
\left(\mathrm{mg} \cdot \mathrm{g}^{-1}\right)\end{array}$ & $\begin{array}{c}\text { Desvio } \\
\text { Padrão } \\
\left(\mathrm{mg}^{\left.-g^{-1}\right)}\right.\end{array}$ \\
\hline \multirow{4}{*}{2} & \multirow{2}{*}{ Efluente } & 0,330 & 230,29 & \multirow{2}{*}{0,47} & \multirow{2}{*}{ - } & \multirow[b]{2}{*}{ - } & \multirow[b]{2}{*}{-} \\
\hline & & 0,332 & 231,69 & & & & \\
\hline & \multirow{2}{*}{ Amostra } & 0,136 & 93,91 & \multirow{2}{*}{0,35} & 0,0505 & 67,86 & \multirow{2}{*}{0,24} \\
\hline & & 0,137 & 94,61 & & 0,0506 & 67,38 & \\
\hline \multirow{4}{*}{2,5} & \multirow{2}{*}{ Efluente } & 0,329 & 229,58 & \multirow{2}{*}{0,70} & \multirow{2}{*}{-} & \multirow{2}{*}{ - } & \multirow{2}{*}{-} \\
\hline & & 0,326 & 227,47 & & & & \\
\hline & \multirow{2}{*}{ Amostra } & 0,136 & 93,91 & \multirow{2}{*}{0,35} & 0,0499 & 67,45 & \multirow{2}{*}{0,24} \\
\hline & & 0,137 & 94,61 & & 0,0500 & 66,96 & \\
\hline \multirow{4}{*}{3} & \multirow{2}{*}{ Efluente } & 0,328 & 228,88 & \multirow{2}{*}{0,70} & \multirow{2}{*}{ - } & \multirow{2}{*}{ - } & \multirow[b]{2}{*}{ - } \\
\hline & & 0,331 & 230,99 & & & & \\
\hline & \multirow{2}{*}{ Amostra } & 0,193 & 133,98 & \multirow{2}{*}{1,05} & 0,0496 & 48,37 & \multirow{2}{*}{0,63} \\
\hline & & 0,196 & 136,09 & & 0,0498 & 47,11 & \\
\hline \multirow{4}{*}{4} & \multirow{2}{*}{ Efluente } & 0,335 & 233,80 & & & & \\
\hline & & 0,332 & 231,69 & 0,70 & - & - & - \\
\hline & & 0,220 & 152,96 & 140 & 0,0498 & 40,05 & \\
\hline & Amostra & 0,227 & 157,88 & 1,49 & 0,0500 & 37,43 & 1,30 \\
\hline & & 0,330 & 230,29 & & & & \\
\hline 5 & Efluente & 0,331 & 230,99 & 0,23 & - & - & - \\
\hline 5 & $\Delta$ mostro & 0,224 & 155,77 & 181 & 0,0499 & 37,51 & 140 \\
\hline & Amostra & 0,232 & 161,39 & 1,81 & 0,0498 & 34,76 & 1,40 \\
\hline & Eflunte & 0,339 & 236,61 & & & & \\
\hline 6 & Efluente & 0,338 & 235,91 & 0,23 & - & - & - \\
\hline & Amostra & 0,253 & 176,16 & 181 & 0,0504 & 29,81 & 140 \\
\hline & Amostra & 0,245 & 170,53 & 1,81 & 0,0503 & 32,67 & 1,40 \\
\hline & Eflunte & 0,325 & 226,77 & 023 & & & \\
\hline 7 & Efluente & 0,324 & 226,07 & 0,23 & - & - & - \\
\hline 1 & & 0,320 & 223,26 & 151 & 0,0498 & 1,59 & 180 \\
\hline & Amostra & 0,310 & 216,23 & 1,51 & 0,0498 & 5,12 & 1,80 \\
\hline & Efluente & 0,321 & 223,96 & 023 & & 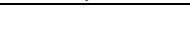 & \\
\hline 0 & Efluente & 0,320 & 223,26 & 0,23 & - & - & - \\
\hline 8 & & 0,309 & 215,52 & 181 & 0,0503 & 4,02 & \\
\hline & Amostra & 0,317 & 221,15 & 1,81 & 0,0501 & 1,23 & 1,40 \\
\hline
\end{tabular}

Fonte: Autor 
Figura 87 - Curva calibração para CMCQF

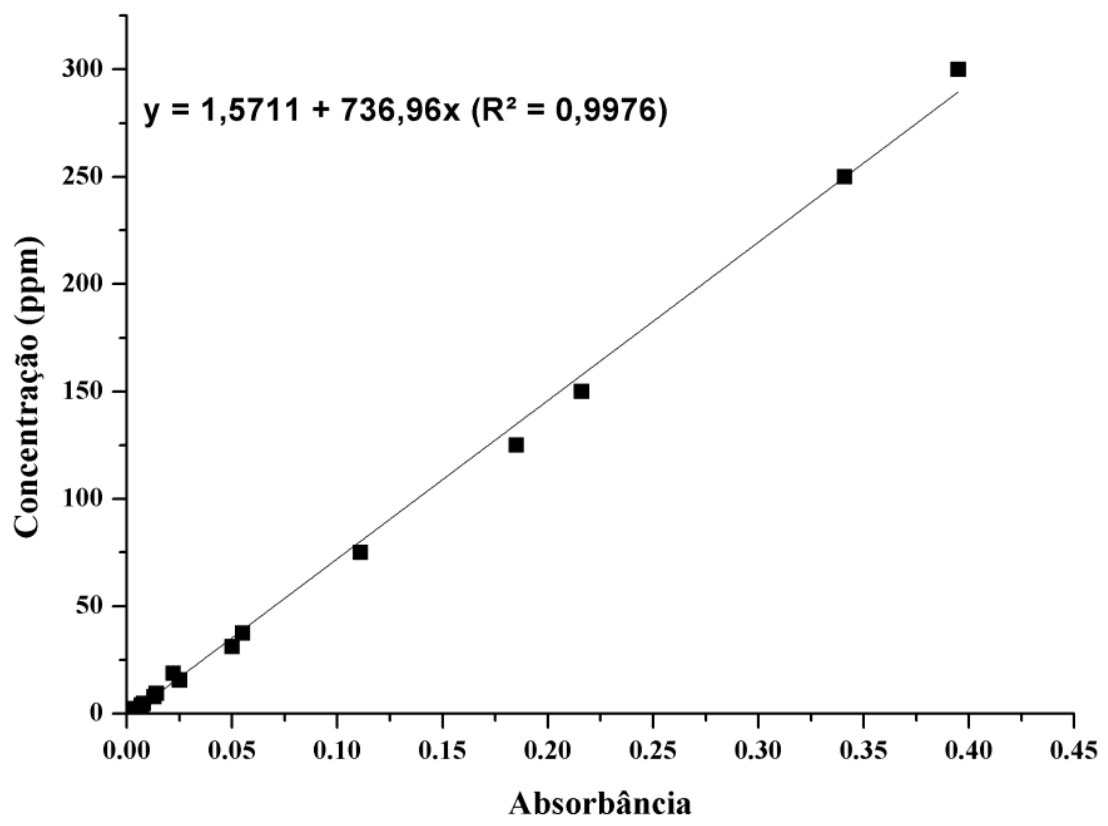

Fonte: Autor

Legenda: Utilizada para cálculos nas tabelas 45 a 48

Tabela 45 - Dados dos efluentes utilizados nos ensaios de isotermas para CMCQF

\begin{tabular}{|c|c|c|c|}
\hline $\begin{array}{c}\text { Concentração teórica } \\
(\mathrm{ppm})\end{array}$ & Absorbância & $\begin{array}{c}\text { Concentração Real } \\
(\mathrm{ppm})\end{array}$ & $\begin{array}{c}\text { Desvio Padrão } \\
(\mathrm{ppm})\end{array}$ \\
\hline \multirow{2}{*}{25} & 0,035 & 24,22 & \multirow{2}{*}{0,01} \\
\hline & 0,036 & 24,96 & \\
\hline \multirow{2}{*}{50} & 0,069 & 49,28 & \multirow{2}{*}{0,03} \\
\hline & 0,068 & 48,54 & \\
\hline \multirow{2}{*}{100} & 0,137 & 99,39 & \multirow{2}{*}{0,02} \\
\hline & 0,136 & 98,66 & \\
\hline \multirow{2}{*}{150} & 0,205 & 149,51 & \multirow{2}{*}{0,05} \\
\hline & 0,204 & 148,77 & \\
\hline \multirow{2}{*}{200} & 0,273 & 199,62 & \multirow{2}{*}{0,07} \\
\hline & 0,274 & 200,36 & \\
\hline \multirow{2}{*}{250} & 0,342 & 250,47 & \multirow{2}{*}{0,10} \\
\hline & 0,340 & 249,00 & \\
\hline \multirow{2}{*}{300} & 0,409 & 299,85 & \multirow{2}{*}{0,00} \\
\hline & 0,407 & 298,37 & \\
\hline \multirow{2}{*}{350} & 0,239 & 349,12 & \multirow{2}{*}{0,04} \\
\hline & 0,240 & 350,60 & \\
\hline \multirow{2}{*}{400} & 0,273 & 399,24 & \multirow{2}{*}{0,04} \\
\hline & 0,274 & 400,71 & \\
\hline \multirow{2}{*}{450} & 0,307 & 449,35 & \multirow{2}{*}{0,03} \\
\hline & 0,307 & 449,35 & \\
\hline
\end{tabular}

Fonte: Autor 
Tabela 46 - Dados experimenteis referentes à temperatura de $20^{\circ} \mathrm{C}$ para $\mathrm{o}$ CMCQF

\begin{tabular}{|c|c|c|c|c|c|}
\hline Absorbância & $\begin{array}{l}\text { Concentração final } \\
(\mathrm{ppm})\end{array}$ & $\begin{array}{c}\text { Desvio } \\
\text { Padrão } \\
(\mathrm{ppm})\end{array}$ & $\begin{array}{l}\text { Massa de } \\
\text { adsorvente } \\
(\mathrm{g})\end{array}$ & $\begin{array}{c}\text { Capacidade de } \\
\left.\text { adsorção (mg.g } \mathrm{g}^{-1}\right)\end{array}$ & $\begin{array}{c}\text { Desvio } \\
\text { Padrão } \\
\left(\mathrm{mg} \cdot \mathrm{g}^{-1}\right)\end{array}$ \\
\hline 0,007 & 3,59 & \multirow{2}{*}{0,00} & 0,0498 & 10,54 & \multirow{2}{*}{0,05} \\
\hline 0,007 & 3,59 & & 0,0503 & 10,44 & \\
\hline 0,014 & 8,75 & \multirow{2}{*}{0,37} & 0,0497 & 20,20 & \multirow{2}{*}{0,26} \\
\hline 0,015 & 9,48 & & 0,0501 & 19,67 & \\
\hline 0,028 & 19,06 & \multirow{2}{*}{0,37} & 0,0502 & 39,82 & \multirow{2}{*}{0,10} \\
\hline 0,029 & 19,80 & & 0,0500 & 39,61 & \\
\hline 0,061 & 43,38 & \multirow{2}{*}{0,37} & 0,0497 & 53,20 & \multirow{2}{*}{0,03} \\
\hline 0,060 & 42,65 & & 0,0501 & 53,14 & \\
\hline 0,085 & 61,07 & \multirow{2}{*}{0,37} & 0,0505 & 68,77 & \multirow{2}{*}{0,18} \\
\hline 0,086 & 61,81 & & 0,0505 & 68,41 & \\
\hline 0,129 & 93,50 & \multirow{2}{*}{0,37} & 0,0500 & 78,12 & \multirow{2}{*}{0,18} \\
\hline 0,128 & 92,76 & & 0,0500 & 78,49 & \\
\hline 0,176 & 128,13 & \multirow{2}{*}{1,47} & 0,0500 & 85,49 & \multirow{2}{*}{0,39} \\
\hline 0,172 & 125,19 & & 0,0504 & 86,27 & \\
\hline 0,211 & 153,93 & \multirow{2}{*}{1,79} & 0,0504 & 97,19 & \multirow{2}{*}{2,10} \\
\hline 0,224 & 163,51 & & 0,0501 & 92,99 & \\
\hline 0,134 & 194,36 & \multirow{2}{*}{0,74} & 0,0501 & 102,60 & \multirow{2}{*}{0,57} \\
\hline 0,133 & 192,89 & & 0,0499 & 103,75 & \\
\hline 0,166 & 241,53 & \multirow{2}{*}{1,47} & 0,0503 & 103,29 & \multirow{2}{*}{0,94} \\
\hline 0,164 & 238,58 & & 0,0501 & 105,17 & \\
\hline
\end{tabular}

Fonte Autor

Tabela 47 - Dados experimenteis referentes à temperatura de $25{ }^{\circ} \mathrm{C}$ para $\mathrm{o}$ CMCQF

\begin{tabular}{|c|c|c|c|c|c|}
\hline Absorbância & $\begin{array}{l}\text { Concentração final } \\
(\text { ppm) }\end{array}$ & $\begin{array}{c}\text { Desvio } \\
\text { Padrão } \\
(\mathrm{ppm})\end{array}$ & $\begin{array}{l}\text { Massa de } \\
\text { adsorvente } \\
(\mathrm{g})\end{array}$ & $\begin{array}{c}\text { Capacidade } \\
\text { de adsorção } \\
\left(\mathrm{mg} . \mathrm{g}^{-1}\right)\end{array}$ & $\begin{array}{c}\text { Desvio } \\
\text { Padrão } \\
\left(\mathrm{mg}^{\left.-g^{-1}\right)}\right.\end{array}$ \\
\hline 0,009 & 5,06 & \multirow{2}{*}{0,37} & 0,0496 & 9,84 & \multirow{2}{*}{0,17} \\
\hline 0,008 & 4,32 & & 0,0498 & 10,17 & \\
\hline 0,016 & 10,22 & \multirow{2}{*}{0,37} & 0,0501 & 19,31 & \multirow{2}{*}{0,16} \\
\hline 0,015 & 9,48 & & 0,0502 & 19,64 & \\
\hline 0,042 & 29,38 & \multirow{2}{*}{1,11} & 0,0502 & 34,68 & \multirow{2}{*}{0,48} \\
\hline 0,039 & 27,17 & & 0,0504 & 35,64 & \\
\hline 0,069 & 49,28 & \multirow{2}{*}{1,47} & 0,0501 & 49,83 & \multirow{2}{*}{0,89} \\
\hline 0,065 & 46,33 & & 0,0498 & 51,61 & \\
\hline 0,098 & 70,65 & \multirow{2}{*}{0,74} & 0,0500 & 64,67 & \multirow{2}{*}{0,11} \\
\hline 0,096 & 69,18 & & 0,0504 & 64,89 & \\
\hline 0,143 & 103,81 & \multirow{2}{*}{0,00} & 0,0503 & 72,52 & \multirow{2}{*}{0,07} \\
\hline 0,143 & 103,81 & & 0,0504 & 72,38 & \\
\hline 0,191 & 139,19 & \multirow{2}{*}{0,00} & 0,0495 & 80,77 & \multirow{2}{*}{0,56} \\
\hline 0,191 & 139,19 & & 0,0502 & 79,64 & \\
\hline 0,225 & 164,24 & \multirow{2}{*}{1,11} & 0,0496 & 93,56 & \multirow{2}{*}{1,10} \\
\hline 0,228 & 166,46 & & 0,0502 & 91,34 & \\
\hline 0,145 & 210,58 & \multirow{2}{*}{0,00} & 0,0497 & 95,27 & \multirow{2}{*}{0,94} \\
\hline 0,145 & 210,58 & & 0,0507 & 93,39 & \\
\hline 0,168 & 244,48 & \multirow{2}{*}{0,74} & 0,0501 & 102,23 & \multirow{2}{*}{0,04} \\
\hline 0,167 & 243,00 & & 0,0505 & 102,15 & \\
\hline
\end{tabular}

Fonte Autor 
Tabela 48 - Dados experimenteis referentes à temperatura de $30{ }^{\circ} \mathrm{C}$ para $\mathrm{o}$ CMCQF

\begin{tabular}{|c|c|c|c|c|c|}
\hline Absorbância & $\begin{array}{l}\text { Concentração } \\
\text { final (ppm) }\end{array}$ & $\begin{array}{l}\text { Desvio Padrão } \\
\quad(\mathrm{ppm})\end{array}$ & $\begin{array}{l}\text { Massa de } \\
\text { adsorvente } \\
(\mathrm{g})\end{array}$ & $\begin{array}{c}\text { Capacidade de } \\
\left.\text { adsorção (mg.g } \mathrm{g}^{-1}\right)\end{array}$ & $\begin{array}{c}\text { Desvio } \\
\text { Padrão } \\
\left(\mathrm{mg}^{\circ} \mathrm{g}^{-1}\right)\end{array}$ \\
\hline 0,011 & 6,54 & \multirow{2}{*}{0,00} & 0,0501 & 9,01 & \multirow{2}{*}{0,05} \\
\hline 0,011 & 6,54 & & 0,0496 & 9,10 & \\
\hline 0,015 & 9,48 & \multirow{2}{*}{0,37} & 0,0499 & 19,75 & \multirow{2}{*}{0,23} \\
\hline 0,014 & 8,75 & & 0,0497 & 20,20 & \\
\hline 0,047 & 33,07 & \multirow{2}{*}{2,58} & 0,0499 & 33,05 & \multirow{2}{*}{1,30} \\
\hline 0,040 & 27,91 & & 0,0499 & 35,63 & \\
\hline 0,075 & 53,70 & \multirow{2}{*}{0,00} & 0,0496 & 48,10 & \multirow{2}{*}{0,00} \\
\hline 0,075 & 53,70 & & 0,0496 & 48,10 & \\
\hline 0,094 & 67,70 & \multirow{2}{*}{0,00} & 0,0500 & 66,14 & \multirow{2}{*}{0,00} \\
\hline 0,094 & 67,70 & & 0,0500 & 66,14 & \\
\hline 0,150 & 108,97 & \multirow{2}{*}{1,47} & 0,0501 & 70,24 & \multirow{2}{*}{0,52} \\
\hline 0,146 & 106,03 & & 0,0504 & 71,28 & \\
\hline 0,190 & 138,45 & \multirow{2}{*}{0,74} & 0,0504 & 79,69 & \multirow{2}{*}{0,19} \\
\hline 0,192 & 139,93 & & 0,0497 & 80,07 & \\
\hline 0,231 & 168,67 & \multirow{2}{*}{0,37} & 0,0503 & 90,06 & \multirow{2}{*}{0,45} \\
\hline 0,230 & 167,93 & & 0,0500 & 90,97 & \\
\hline 0,148 & 215,00 & \multirow{2}{*}{0,74} & 0,0499 & 92,67 & \multirow{2}{*}{0,09} \\
\hline 0,147 & 213,52 & & 0,0502 & 92,85 & \\
\hline 0,173 & 251,85 & \multirow{2}{*}{2,21} & 0,0504 & 97,97 & \multirow{2}{*}{0,71} \\
\hline 0,176 & 256,27 & & 0,0500 & 96,54 & \\
\hline
\end{tabular}

Fonte Autor

Tabela 49 - Dados experimenteis referentes à temperatura de $40{ }^{\circ} \mathrm{C}$ para o CMCQF

\begin{tabular}{|c|c|c|c|c|c|}
\hline Absorbância & $\begin{array}{l}\text { Concentração } \\
\text { final (ppm) }\end{array}$ & $\begin{array}{l}\text { Desvio } \\
\text { Padrão } \\
(\mathrm{ppm}) \\
\end{array}$ & $\begin{array}{l}\text { Massa de } \\
\text { adsorvente } \\
(\mathrm{g})\end{array}$ & $\begin{array}{c}\text { Capacidade de } \\
\text { adsorção (mg.g-1) }\end{array}$ & $\begin{array}{c}\text { Desvio } \\
\text { Padrão } \\
\left(\mathrm{mg} \cdot \mathrm{g}^{-1}\right)\end{array}$ \\
\hline 0,010 & 5,80 & \multirow{2}{*}{0,00} & 0,0497 & 9,45 & \multirow{2}{*}{0,08} \\
\hline 0,010 & 5,80 & & 0,0505 & 9,30 & \\
\hline 0,016 & 10,22 & \multirow{2}{*}{0,37} & 0,0497 & 19,46 & \multirow{2}{*}{0,17} \\
\hline 0,017 & 10,96 & & 0,0496 & 19,13 & \\
\hline 0,044 & 30,86 & \multirow{2}{*}{1,84} & 0,0499 & 34,15 & \multirow{2}{*}{0,92} \\
\hline 0,049 & 34,54 & & 0,0499 & 32,31 & \\
\hline 0,077 & 55,17 & \multirow{2}{*}{1,47} & 0,0503 & 46,70 & \multirow{2}{*}{0,59} \\
\hline 0,073 & 52,23 & & 0,0506 & 47,88 & \\
\hline 0,095 & 68,44 & \multirow{2}{*}{1,47} & 0,0506 & 64,99 & \multirow{2}{*}{0,73} \\
\hline 0,099 & 71,39 & & 0,0506 & 63,54 & \\
\hline 0,138 & 100,13 & \multirow{2}{*}{0,74} & 0,0505 & 74,06 & \multirow{2}{*}{0,81} \\
\hline 0,136 & 98,66 & & 0,0499 & 75,69 & \\
\hline 0,185 & 134,77 & \multirow{2}{*}{0,00} & 0,0504 & 81,52 & \multirow{2}{*}{0,32} \\
\hline 0,185 & 134,77 & & 0,0508 & 80,88 & \\
\hline 0,230 & 167,93 & \multirow{2}{*}{0,74} & 0,0505 & 90,07 & \multirow{2}{*}{0,01} \\
\hline 0,232 & 169,40 & & 0,0501 & 90,05 & \\
\hline 0,145 & 210,58 & \multirow{2}{*}{1,47} & 0,0501 & 94,51 & \multirow{2}{*}{0,83} \\
\hline 0,147 & 213,52 & & 0,0502 & 92,85 & \\
\hline 0,175 & 254,79 & \multirow{2}{*}{1,47} & 0,0501 & 97,08 & \multirow{2}{*}{0,93} \\
\hline 0,177 & 257,74 & & 0,0503 & 95,23 & \\
\hline
\end{tabular}

Fonte Autor 
Tabela 50 - Dados experimenteis referentes à temperatura de $50{ }^{\circ} \mathrm{C}$ para $\mathrm{o}$ CMCQF

\begin{tabular}{|c|c|c|c|c|c|}
\hline Absorbância & $\begin{array}{l}\text { Concentração } \\
\text { final (ppm) }\end{array}$ & $\begin{array}{c}\text { Desvio } \\
\text { Padrão } \\
(\mathrm{ppm})\end{array}$ & $\begin{array}{c}\text { Massa de } \\
\text { adsorvente } \\
(\mathrm{g})\end{array}$ & $\begin{array}{c}\text { Capacidade } \\
\text { de adsorção } \\
\left(\mathrm{mg} \cdot \mathrm{g}^{-1}\right)\end{array}$ & $\begin{array}{l}\text { Desvio } \\
\text { Padrão } \\
\left(\mathrm{mg}^{\left.-g^{-1}\right)}\right.\end{array}$ \\
\hline 0,010 & 5,80 & \multirow{2}{*}{0,37} & 0,0504 & 9,32 & \multirow{2}{*}{0,23} \\
\hline 0,011 & 6,54 & & 0,0509 & 8,87 & \\
\hline 0,016 & 10,22 & \multirow{2}{*}{0,37} & 0,0506 & 19,12 & \multirow{2}{*}{0,07} \\
\hline 0,017 & 10,96 & & 0,0500 & 18,98 & \\
\hline 0,040 & 27,91 & \multirow{2}{*}{3,68} & 0,0497 & 35,77 & \multirow{2}{*}{1,90} \\
\hline 0,050 & 35,28 & & 0,0499 & 31,94 & \\
\hline 0,079 & 56,65 & \multirow{2}{*}{0,37} & 0,0498 & 46,43 & \multirow{2}{*}{0,09} \\
\hline 0,078 & 55,91 & & 0,0500 & 46,61 & \\
\hline 0,101 & 72,86 & \multirow{2}{*}{0,37} & 0,0499 & 63,69 & \multirow{2}{*}{0,18} \\
\hline 0,102 & 73,60 & & 0,0499 & 63,32 & \\
\hline 0,142 & 103,08 & \multirow{2}{*}{0,00} & 0,0501 & 73,18 & \multirow{2}{*}{0,07} \\
\hline 0,142 & 103,08 & & 0,0502 & 73,04 & \\
\hline 0,190 & 138,45 & \multirow{2}{*}{0,74} & 0,0497 & 80,81 & \multirow{2}{*}{0,29} \\
\hline 0,192 & 139,93 & & 0,0496 & 80,23 & \\
\hline 0,235 & 171,61 & \multirow{2}{*}{0,37} & 0,0496 & 89,84 & \multirow{2}{*}{0,01} \\
\hline 0,236 & 172,35 & & 0,0494 & 89,83 & \\
\hline 0,149 & 216,47 & \multirow{2}{*}{0,74} & 0,0495 & 92,68 & \multirow{2}{*}{0,37} \\
\hline 0,150 & 217,95 & & 0,0495 & 91,93 & \\
\hline 0,178 & 259,22 & \multirow{2}{*}{0,74} & 0,0500 & 95,07 & \multirow{2}{*}{0,11} \\
\hline 0,179 & 260,69 & & 0,0495 & 95,28 & \\
\hline
\end{tabular}

Fonte Autor 
Figura 88 - Curva de calibração para CMCQDIC

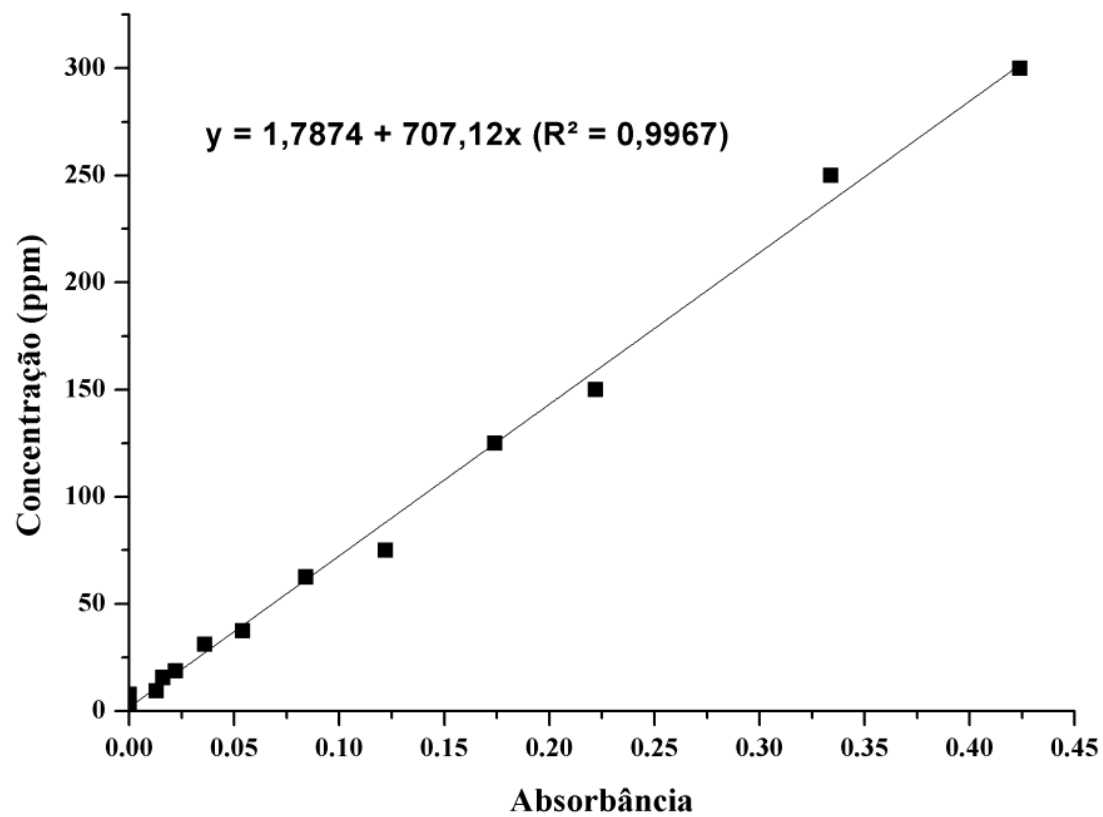

Fonte: Autor

Legenda: Utilizada para cálculos nas tabelas 49 a 54

Tabela 51 - Dados dos efluentes utilizados nos ensaios de isotermas para CMCQDIC

\begin{tabular}{|c|c|c|c|}
\hline $\begin{array}{c}\text { Concentração teórica } \\
(\mathrm{ppm})\end{array}$ & Absorbância & $\begin{array}{c}\text { Concentração real } \\
(\mathrm{ppm})\end{array}$ & $\begin{array}{c}\text { Desvio Padrão } \\
(\mathrm{ppm})\end{array}$ \\
\hline \multirow{2}{*}{25} & 0,032 & 24,41 & \multirow{2}{*}{0,35} \\
\hline & 0,031 & 23,70 & \\
\hline \multirow{2}{*}{50} & 0,067 & 49,15 & \multirow{2}{*}{0,71} \\
\hline & 0,065 & 47,74 & \\
\hline \multirow{2}{*}{100} & 0,138 & 99,35 & \multirow{2}{*}{0,71} \\
\hline & 0,136 & 97,94 & \\
\hline \multirow{2}{*}{150} & 0,209 & 149,55 & \multirow{2}{*}{0,35} \\
\hline & 0,208 & 148,84 & \\
\hline \multirow{2}{*}{200} & 0,278 & 198,33 & \multirow{2}{*}{0,35} \\
\hline & 0,277 & 197,62 & \\
\hline \multirow{2}{*}{250} & 0,350 & 249,23 & \multirow{2}{*}{0,00} \\
\hline & 0,350 & 249,23 & \\
\hline \multirow{2}{*}{300} & 0,415 & 295,19 & \multirow{2}{*}{0,71} \\
\hline & 0,417 & 296,60 & \\
\hline \multirow{2}{*}{350} & 0,245 & 350,00 & \multirow{2}{*}{0,00} \\
\hline & 0,245 & 350,00 & \\
\hline \multirow{2}{*}{400} & 0,278 & 396,66 & \multirow{2}{*}{0,71} \\
\hline & 0,279 & 398,08 & \\
\hline \multirow{2}{*}{450} & 0,310 & 441,91 & \multirow{2}{*}{1,41} \\
\hline & 0,312 & 444,74 & \\
\hline
\end{tabular}

Fonte: Autor 
Tabela 52 - Dados experimenteis referentes à temperatura de $20{ }^{\circ} \mathrm{C}$ para $\mathrm{o}$ CMCQDIC

\begin{tabular}{|c|c|c|c|c|c|}
\hline Absorbância & $\begin{array}{l}\text { Concentração final } \\
(\mathrm{ppm})\end{array}$ & $\begin{array}{l}\text { Desvio } \\
\text { Padrão } \\
\text { (ppm) } \\
\end{array}$ & $\begin{array}{c}\text { Massa de } \\
\text { adsorvente } \\
(\mathrm{g})\end{array}$ & $\begin{array}{c}\text { Capacidade } \\
\text { de adsorção } \\
\left(\mathrm{mg} \cdot \mathrm{g}^{-1}\right)\end{array}$ & $\begin{array}{c}\text { Desvio } \\
\text { Padrão } \\
\left(\mathrm{mg}^{\left.-g^{-1}\right)}\right.\end{array}$ \\
\hline 0,002 & 0,95 & \multirow{2}{*}{0,00} & 0,0496 & 11,65 & \multirow{2}{*}{0,21} \\
\hline 0,001 & 0,11 & & 0,0496 & 12,07 & \\
\hline 0,000 & 1,78 & \multirow{2}{*}{0,00} & 0,0500 & 23,33 & \multirow{2}{*}{0,09} \\
\hline 0,000 & 1,78 & & 0,0504 & 23,15 & \\
\hline 0,007 & 6,73 & \multirow{2}{*}{1,41} & 0,0500 & 45,95 & \multirow{2}{*}{0,52} \\
\hline 0,003 & 3,91 & & 0,0504 & 46,99 & \\
\hline 0,016 & 13,10 & \multirow{2}{*}{1,06} & 0,0502 & 67,78 & \multirow{2}{*}{0,53} \\
\hline 0,013 & 10,98 & & 0,0502 & 68,83 & \\
\hline 0,035 & 28,51 & \multirow{2}{*}{0,00} & 0,0507 & 83,57 & \multirow{2}{*}{0,12} \\
\hline 0,034 & 27,67 & & 0,0508 & 83,81 & \\
\hline 0,061 & 50,22 & \multirow{2}{*}{0,35} & 0,0497 & 100,11 & \multirow{2}{*}{0,03} \\
\hline 0,058 & 47,72 & & 0,0503 & 100,16 & \\
\hline 0,091 & 75,28 & \multirow{2}{*}{1,41} & 0,0503 & 109,65 & \multirow{2}{*}{0,21} \\
\hline 0,092 & 76,11 & & 0,0503 & 109,24 & \\
\hline 0,165 & 118,46 & \multirow{2}{*}{1,41} & 0,0499 & 116,00 & \multirow{2}{*}{0,47} \\
\hline 0,161 & 115,63 & & 0,0501 & 116,95 & \\
\hline 0,180 & 129,07 & \multirow{2}{*}{0,00} & 0,0502 & 133,62 & \multirow{2}{*}{0,27} \\
\hline 0,180 & 129,07 & & 0,0500 & 134,15 & \\
\hline 0,225 & 160,89 & \multirow{2}{*}{1,06} & 0,0507 & 139,27 & \multirow{2}{*}{0,52} \\
\hline 0,222 & 158,77 & & 0,0507 & 140,31 & \\
\hline
\end{tabular}

Fonte Autor

Tabela 53 - Dados experimenteis referentes à temperatura de $25{ }^{\circ} \mathrm{C}$ para $\mathrm{o}$ CMCQDIC

\begin{tabular}{|c|c|c|c|c|c|}
\hline Absorbância & $\begin{array}{c}\text { Concentração } \\
\text { final (ppm) }\end{array}$ & $\begin{array}{l}\text { Desvio } \\
\text { Padrão } \\
(\mathrm{ppm})\end{array}$ & $\begin{array}{c}\text { Massa de } \\
\text { adsorvente } \\
(\mathrm{g})\end{array}$ & $\begin{array}{c}\text { Capacidade } \\
\text { de adsorção } \\
\left(\mathrm{mg}^{-1} \mathrm{~g}^{-1}\right)\end{array}$ & $\begin{array}{l}\text { Desvio } \\
\text { Padrão } \\
\left(\mathrm{mg}^{\left.-g^{-1}\right)}\right.\end{array}$ \\
\hline 0,003 & 1,78 & \multirow{2}{*}{0,00} & 0,0501 & 11,11 & \multirow{2}{*}{0,01} \\
\hline 0,003 & 1,78 & & 0,0500 & 11,14 & \\
\hline 0,001 & 2,49 & \multirow{2}{*}{0,35} & 0,0502 & 22,89 & \multirow{2}{*}{0,13} \\
\hline 0,000 & 1,78 & & 0,0504 & 23,15 & \\
\hline 0,009 & 8,15 & \multirow{2}{*}{0,35} & 0,0502 & 45,07 & \multirow{2}{*}{0,22} \\
\hline 0,008 & 7,44 & & 0,0501 & 45,51 & \\
\hline 0,022 & 17,34 & \multirow{2}{*}{1,77} & 0,0503 & 65,53 & \multirow{2}{*}{0,94} \\
\hline 0,027 & 20,88 & & 0,0504 & 63,65 & \\
\hline 0,047 & 35,02 & \multirow{2}{*}{0,35} & 0,0507 & 80,35 & \multirow{2}{*}{0,30} \\
\hline 0,048 & 35,73 & & 0,0501 & 80,96 & \\
\hline 0,075 & 54,82 & \multirow{2}{*}{1,13} & 0,0502 & 96,82 & \multirow{2}{*}{0,80} \\
\hline 0,079 & 57,65 & & 0,0503 & 95,22 & \\
\hline 0,100 & 82,79 & \multirow{2}{*}{1,95} & 0,0501 & 106,34 & \multirow{2}{*}{0,01} \\
\hline 0,097 & 80,29 & & 0,0507 & 106,32 & \\
\hline 0,163 & 117,05 & \multirow{2}{*}{0,00} & 0,0500 & 116,48 & \multirow{2}{*}{0,12} \\
\hline 0,163 & 117,05 & & 0,0501 & 116,24 & \\
\hline 0,197 & 141,09 & \multirow{2}{*}{0,35} & 0,0506 & 126,62 & \multirow{2}{*}{0,30} \\
\hline 0,198 & 141,79 & & 0,0507 & 126,02 & \\
\hline 0,245 & 175,03 & \multirow{2}{*}{1,30} & 0,0505 & 132,82 & \multirow{2}{*}{0,66} \\
\hline 0,242 & 172,91 & & 0,0504 & 134,13 & \\
\hline
\end{tabular}

Fonte: Autor 
Tabela 54 - Dados experimenteis referentes à temperatura de $30{ }^{\circ} \mathrm{C}$ para o CMCQDIC

\begin{tabular}{|c|c|c|c|c|c|}
\hline Absorbância & $\begin{array}{l}\text { Concentração } \\
\text { final (ppm) }\end{array}$ & $\begin{array}{l}\text { Desvio } \\
\text { Padrão } \\
\text { (ppm) }\end{array}$ & $\begin{array}{l}\text { Massa de } \\
\text { adsorvente } \\
(\mathrm{g})\end{array}$ & $\begin{array}{c}\text { Capacidade } \\
\text { de adsorção } \\
\left(\mathrm{mg}^{-1} \mathrm{~g}^{-1}\right)\end{array}$ & $\begin{array}{c}\text { Desvio } \\
\text { Padrão } \\
\left(\mathrm{mg} \cdot \mathrm{g}^{-1}\right)\end{array}$ \\
\hline 0,005 & 3,45 & \multirow{2}{*}{0,35} & 0,0497 & 10,36 & \multirow{2}{*}{0,19} \\
\hline 0,004 & 2,62 & & 0,0499 & 10,74 & \\
\hline 0,007 & 6,73 & \multirow{2}{*}{0,71} & 0,0502 & 20,77 & \multirow{2}{*}{0,13} \\
\hline 0,006 & 6,03 & & 0,0504 & 21,04 & \\
\hline 0,011 & 9,56 & \multirow{2}{*}{0,71} & 0,0501 & 44,45 & \multirow{2}{*}{0,00} \\
\hline 0,011 & 9,56 & & 0,0501 & 44,45 & \\
\hline 0,023 & 18,05 & \multirow{2}{*}{0,35} & 0,0499 & 65,70 & \multirow{2}{*}{0,95} \\
\hline 0,028 & 21,58 & & 0,0500 & 63,81 & \\
\hline 0,063 & 46,33 & \multirow{2}{*}{0,35} & 0,0499 & 75,97 & \multirow{2}{*}{0,20} \\
\hline 0,062 & 45,63 & & 0,0504 & 75,57 & \\
\hline 0,093 & 67,55 & \multirow{2}{*}{0,00} & 0,0497 & 91,39 & \multirow{2}{*}{0,44} \\
\hline 0,090 & 65,43 & & 0,0498 & 92,27 & \\
\hline 0,113 & 81,69 & \multirow{2}{*}{0,71} & 0,0500 & 107,10 & \multirow{2}{*}{1,20} \\
\hline 0,119 & 85,93 & & 0,0501 & 104,77 & \\
\hline 0,154 & 127,89 & \multirow{2}{*}{0,00} & 0,0501 & 110,83 & \multirow{2}{*}{0,39} \\
\hline 0,150 & 124,55 & & 0,0505 & 111,61 & \\
\hline 0,226 & 161,59 & \multirow{2}{*}{0,71} & 0,0495 & 119,08 & \multirow{2}{*}{0,83} \\
\hline 0,222 & 158,77 & & 0,0508 & 117,42 & \\
\hline 0,270 & 192,71 & \multirow{2}{*}{1,41} & 0,0503 & 124,56 & \multirow{2}{*}{0,10} \\
\hline 0,272 & 194,12 & & 0,0501 & 124,35 & \\
\hline
\end{tabular}

Fonte: Autor

Tabela 55 - Dados experimenteis referentes à temperatura de $40{ }^{\circ} \mathrm{C}$ para $\mathrm{o}$ CMCQDIC

\begin{tabular}{|c|c|c|c|c|c|}
\hline Absorbância & $\begin{array}{c}\text { Concentração } \\
\text { final (ppm) }\end{array}$ & $\begin{array}{c}\text { Desvio } \\
\text { Padrão } \\
(\mathrm{ppm})\end{array}$ & $\begin{array}{l}\text { Massa de } \\
\text { adsorvente } \\
(\mathrm{g})\end{array}$ & $\begin{array}{c}\text { Capacidade } \\
\text { de adsorção } \\
\left(\mathrm{mg} \cdot \mathrm{g}^{-1}\right)\end{array}$ & $\begin{array}{c}\text { Desvio } \\
\text { Padrão } \\
\left(\mathrm{mg}^{\circ} \mathrm{g}^{-1}\right)\end{array}$ \\
\hline 0,005 & 3,45 & \multirow{2}{*}{0,00} & 0,0497 & 10,36 & \multirow{2}{*}{0,00} \\
\hline 0,005 & 3,45 & & 0,0497 & 10,36 & \\
\hline 0,007 & 6,73 & \multirow{2}{*}{0,35} & 0,0503 & 20,73 & \multirow{2}{*}{0,11} \\
\hline 0,008 & 7,44 & & 0,0500 & 20,50 & \\
\hline 0,015 & 12,39 & \multirow{2}{*}{0,35} & 0,0504 & 42,78 & \multirow{2}{*}{0,05} \\
\hline 0,016 & 13,10 & & 0,0501 & 42,69 & \\
\hline 0,024 & 18,76 & \multirow{2}{*}{0,35} & 0,0500 & 65,22 & \multirow{2}{*}{0,08} \\
\hline 0,023 & 18,05 & & 0,0504 & 65,05 & \\
\hline 0,066 & 48,45 & \multirow{2}{*}{2,12} & 0,0503 & 74,32 & \multirow{2}{*}{0,32} \\
\hline 0,067 & 49,16 & & 0,0505 & 73,67 & \\
\hline 0,099 & 81,96 & \multirow{2}{*}{0,35} & 0,0499 & 83,81 & \multirow{2}{*}{0,04} \\
\hline 0,096 & 79,45 & & 0,0507 & 83,72 & \\
\hline 0,120 & 99,50 & \multirow{2}{*}{2,12} & 0,0502 & 97,81 & \multirow{2}{*}{0,08} \\
\hline 0,119 & 98,66 & & 0,0505 & 97,64 & \\
\hline 0,193 & 138,26 & \multirow{2}{*}{0,00} & 0,0507 & 104,41 & \multirow{2}{*}{0,10} \\
\hline 0,193 & 138,26 & & 0,0506 & 104,61 & \\
\hline 0,230 & 164,42 & \multirow{2}{*}{0,35} & 0,0495 & 117,65 & \multirow{2}{*}{0,35} \\
\hline 0,220 & 157,35 & & 0,0507 & 118,35 & \\
\hline 0,275 & 196,24 & \multirow{2}{*}{2,83} & 0,0501 & 123,29 & \multirow{2}{*}{0,02} \\
\hline 0,273 & 194,83 & & 0,0504 & 123,26 & \\
\hline
\end{tabular}

Fonte: Autor 
Tabela 56 - Dados experimenteis referentes à temperatura de $50{ }^{\circ} \mathrm{C}$ para o CMCQDIC

\begin{tabular}{|c|c|c|c|c|c|}
\hline Absorbância & $\begin{array}{c}\text { Concentração } \\
\text { final (ppm) }\end{array}$ & $\begin{array}{l}\text { Desvio } \\
\text { Padrão } \\
\text { (ppm) }\end{array}$ & $\begin{array}{l}\text { Massa de } \\
\text { adsorvente } \\
(\mathrm{g})\end{array}$ & $\begin{array}{c}\text { Capacidade } \\
\text { de adsorção } \\
\left(\mathrm{mg}^{-1} \mathrm{~g}^{-1}\right)\end{array}$ & $\begin{array}{c}\text { Desvio } \\
\text { Padrão } \\
\left(\mathrm{mg} \cdot \mathrm{g}^{-1}\right)\end{array}$ \\
\hline 0,006 & 4,29 & \multirow{2}{*}{0,00} & 0,0498 & 9,92 & \multirow{2}{*}{0,02} \\
\hline 0,006 & 4,29 & & 0,0496 & 9,96 & \\
\hline 0,006 & 6,03 & \multirow{2}{*}{0,35} & 0,0501 & 21,17 & \multirow{2}{*}{0,20} \\
\hline 0,007 & 6,73 & & 0,0502 & 20,77 & \\
\hline 0,024 & 18,76 & \multirow{2}{*}{0,35} & 0,0500 & 39,94 & \multirow{2}{*}{0,10} \\
\hline 0,023 & 18,05 & & 0,0507 & 39,74 & \\
\hline 0,042 & 31,48 & \multirow{2}{*}{1,06} & 0,0496 & 59,33 & \multirow{2}{*}{0,48} \\
\hline 0,045 & 33,61 & & 0,0495 & 58,38 & \\
\hline 0,083 & 60,48 & \multirow{2}{*}{0,71} & 0,0495 & 69,45 & \multirow{2}{*}{0,29} \\
\hline 0,081 & 59,06 & & 0,0496 & 70,02 & \\
\hline 0,111 & 80,28 & \multirow{2}{*}{0,35} & 0,0498 & 84,82 & \multirow{2}{*}{0,26} \\
\hline 0,112 & 80,98 & & 0,0499 & 84,29 & \\
\hline 0,158 & 113,51 & \multirow{2}{*}{1,06} & 0,0495 & 92,11 & \multirow{2}{*}{0,07} \\
\hline 0,155 & 111,39 & & 0,0500 & 92,25 & \\
\hline 0,170 & 141,26 & \multirow{2}{*}{0,53} & 0,0509 & 102,53 & \multirow{2}{*}{0,73} \\
\hline 0,176 & 146,27 & & 0,0504 & 101,06 & \\
\hline 0,220 & 183,02 & \multirow{2}{*}{0,53} & 0,0507 & 105,70 & \multirow{2}{*}{0,62} \\
\hline 0,225 & 187,19 & & 0,0503 & 104,46 & \\
\hline 0,245 & 203,90 & \multirow{2}{*}{2,83} & 0,0503 & 119,00 & \multirow{2}{*}{0,30} \\
\hline 0,243 & 202,23 & & 0,0504 & 119,59 & \\
\hline
\end{tabular}

Fonte: Autor 
Apêndice B - Distribuição de tamanho de partícula 
Figura 89 - Distribuição de tamanho de partícula para a CMC, quitosana e adsorventes
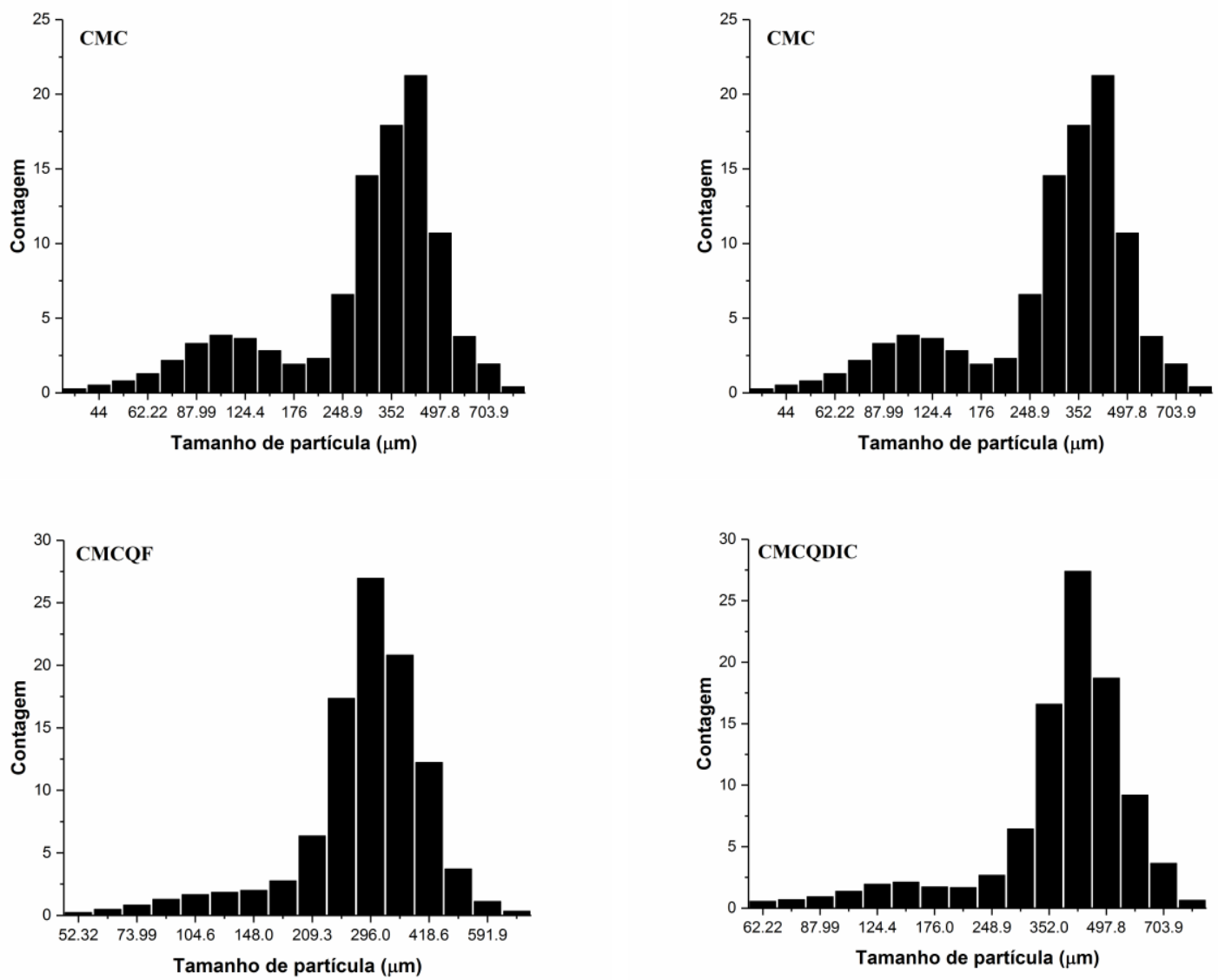

Fonte: Autor 
Apêndice C - Espectros de ${ }^{1} \mathrm{H}-\mathrm{RMN}$ e ${ }^{13} \mathrm{C}$-RMN dos precursores de síntese e dos líquidos iônicos sintetizados 
Figura 90 - Espectro de ${ }^{1} \mathrm{H}$-RMN obtido para a sec-butilamina $\left(\mathrm{CDCl}_{3}, 14,1 \mathrm{~T}\right)$

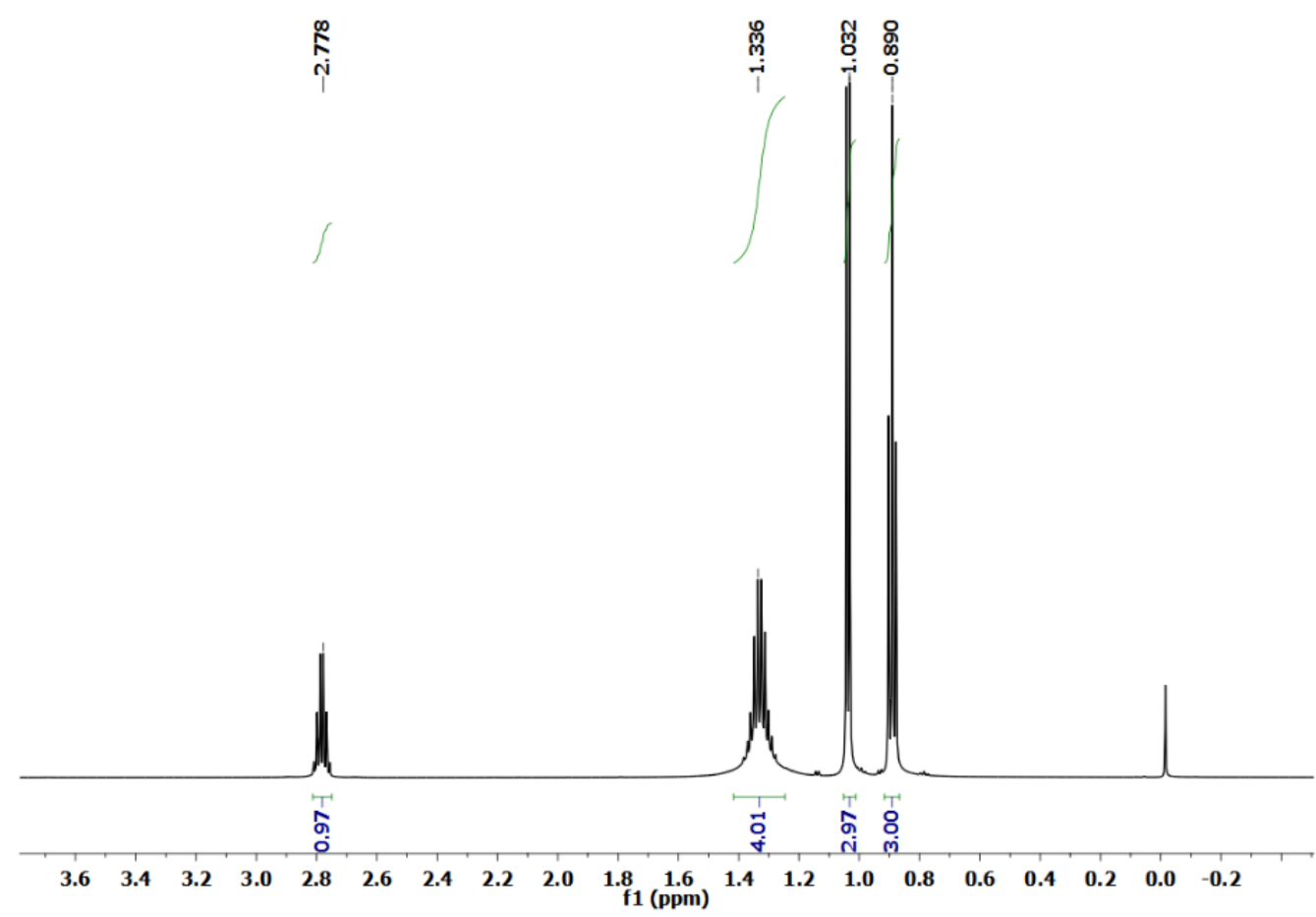

Fonte: Autor

Figura 91 - Espectro de ${ }^{13} \mathrm{C}-\mathrm{RMN}$ obtido para a sec-butilamina $\left(\mathrm{CDCl}_{3}, 14,1 \mathrm{~T}\right)$

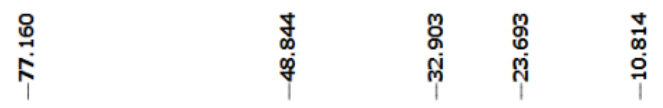

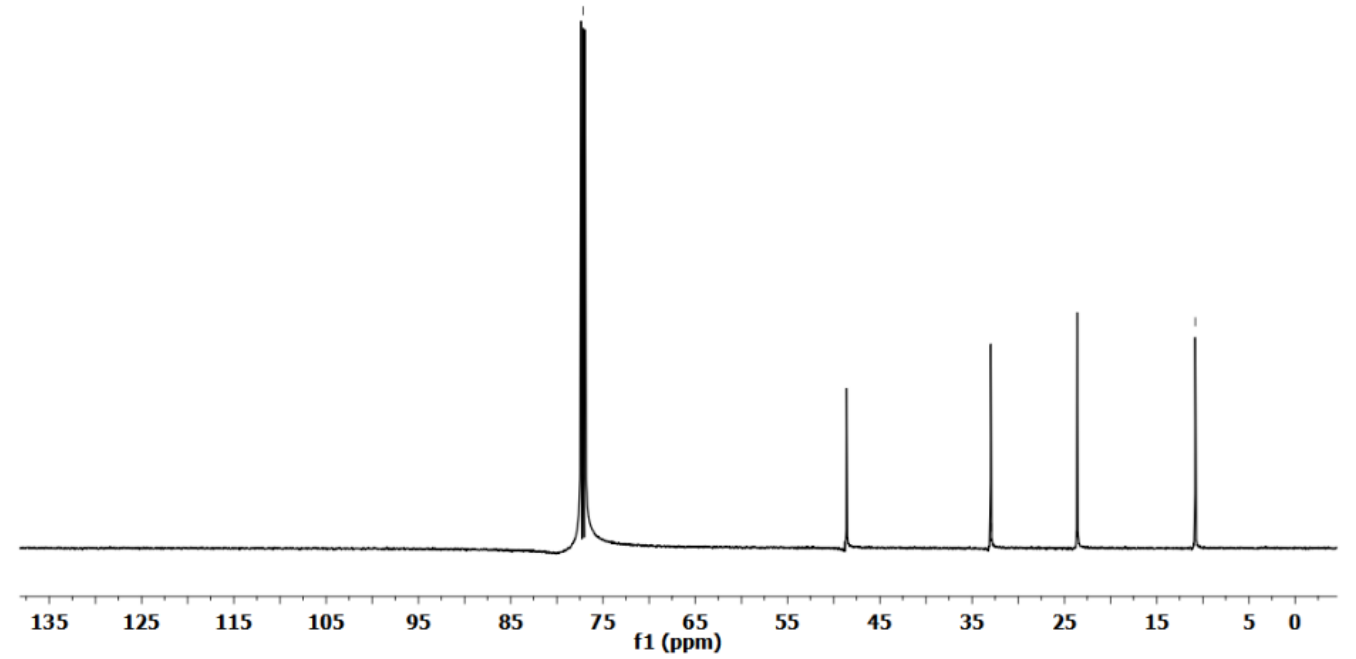

Fonte: Autor 
Figura 92 - Espectro de ${ }^{1} \mathrm{H}-\mathrm{RMN}$ obtido para a terc-butilamina $\left(\mathrm{CDCl}_{3}, 14,1 \mathrm{~T}\right)$

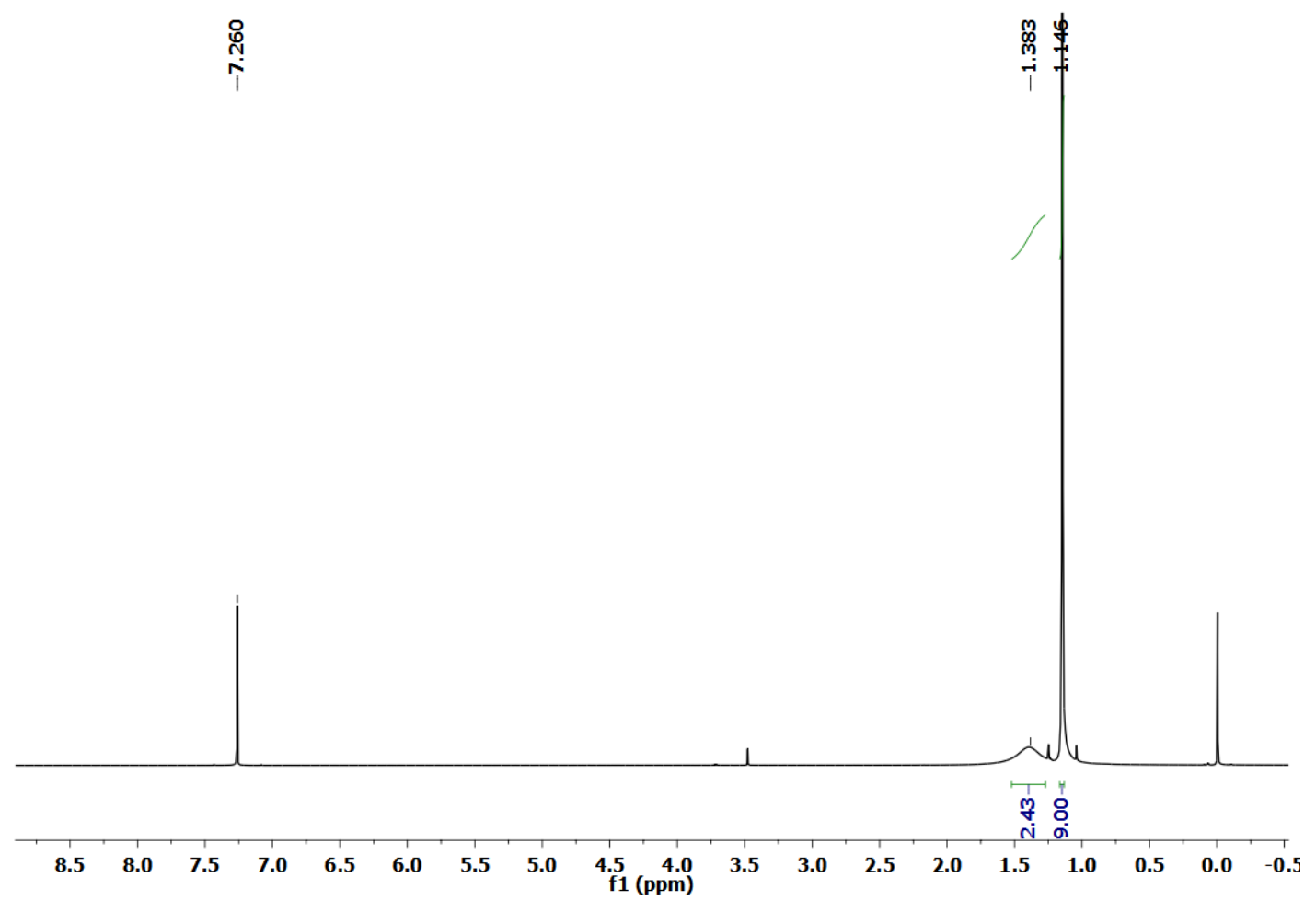

Fonte: Autor

Figura 93 - Espectro de ${ }^{13} \mathrm{C}-\mathrm{RMN}$ obtido para a terc-butilamina $\left(\mathrm{CDCl}_{3}, 14,1 \mathrm{~T}\right)$
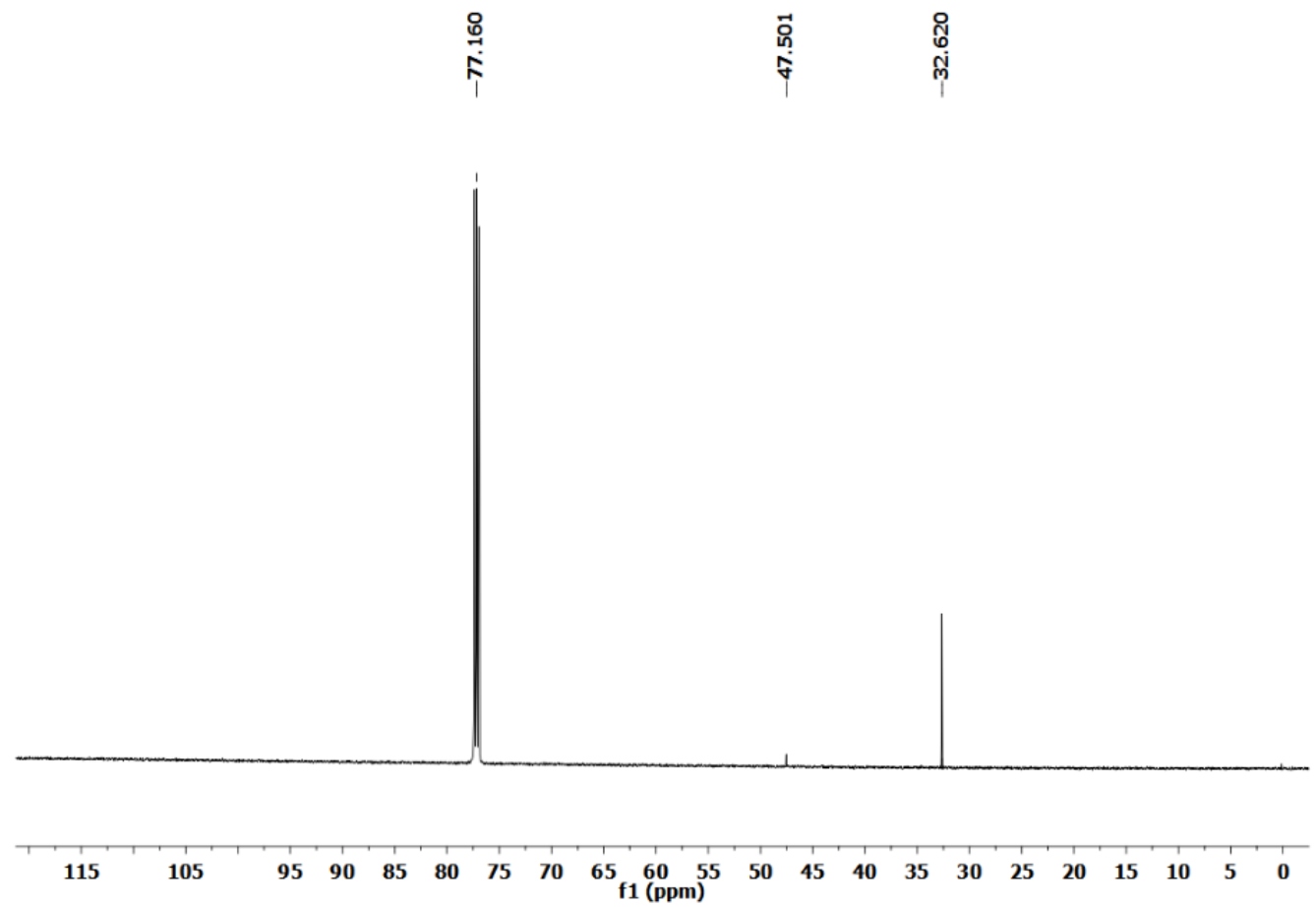

Fonte: Autor 
Figura 94 - Espectro de ${ }^{1} \mathrm{H}-\mathrm{RMN}$ obtido para o ácido acético $\left(\mathrm{CDCl}_{3}, 14,1 \mathrm{~T}\right)$

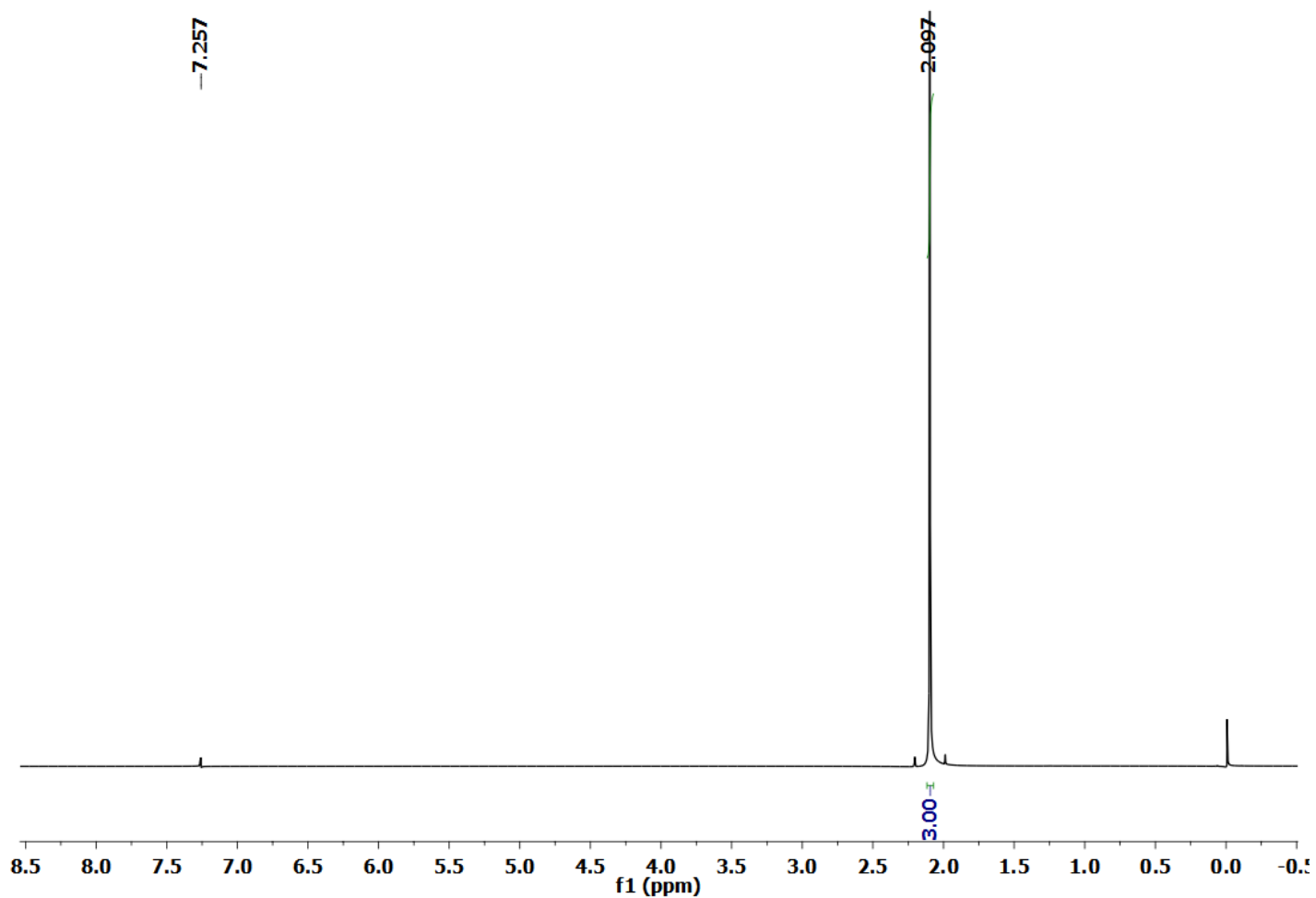

Fonte: Autor

Figura 95 - Espectro de ${ }^{13} \mathrm{C}-\mathrm{RMN}$ obtido para o ácido acético $\left(\mathrm{CDCl}_{3}, 14,1 \mathrm{~T}\right)$
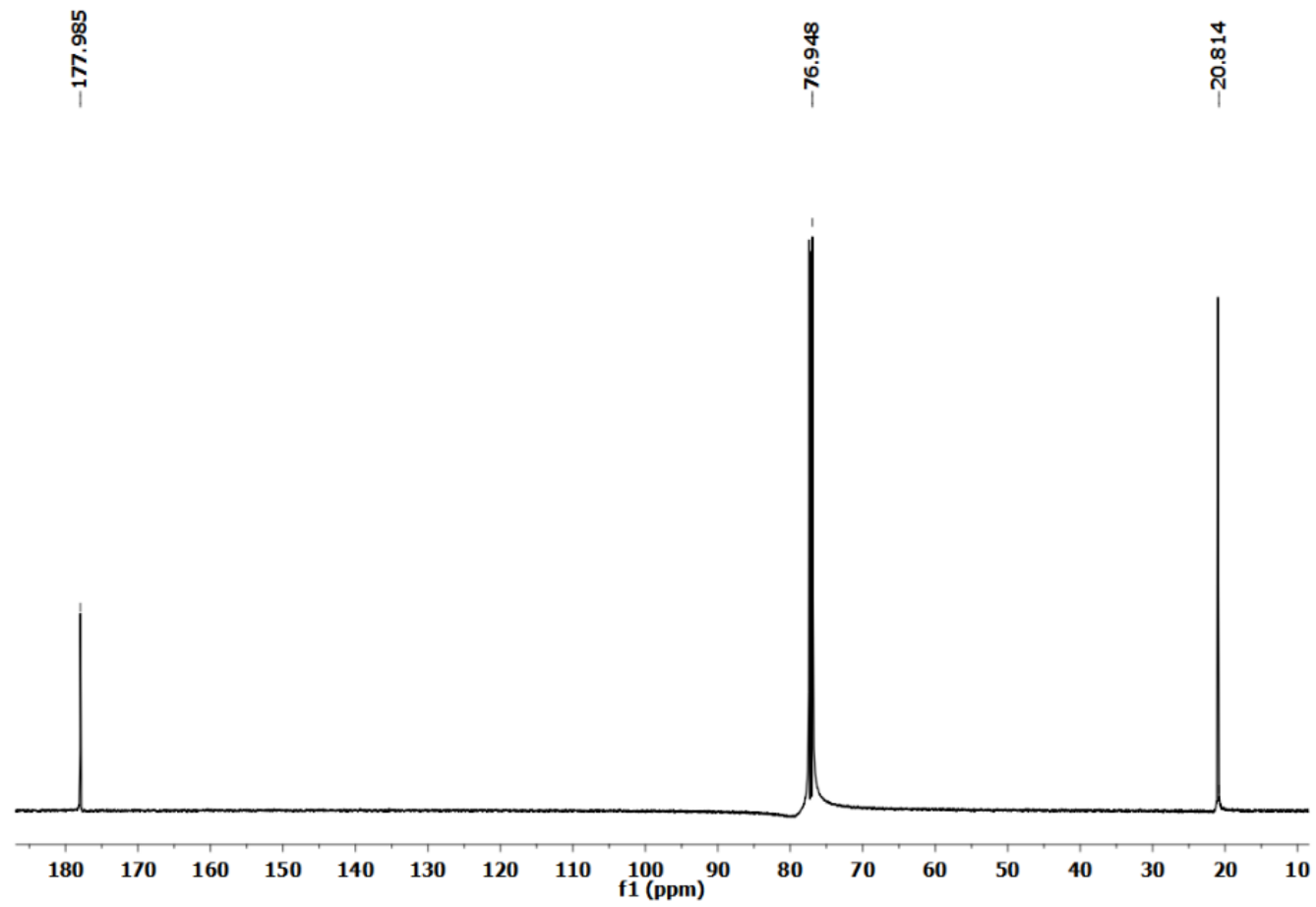

Fonte: Autor 
Figura 96 - Espectro de ${ }^{1} \mathrm{H}-\mathrm{RMN}$ obtido para o ácido láctico $\left(\mathrm{CDCl}_{3}, 14,1 \mathrm{~T}\right)$

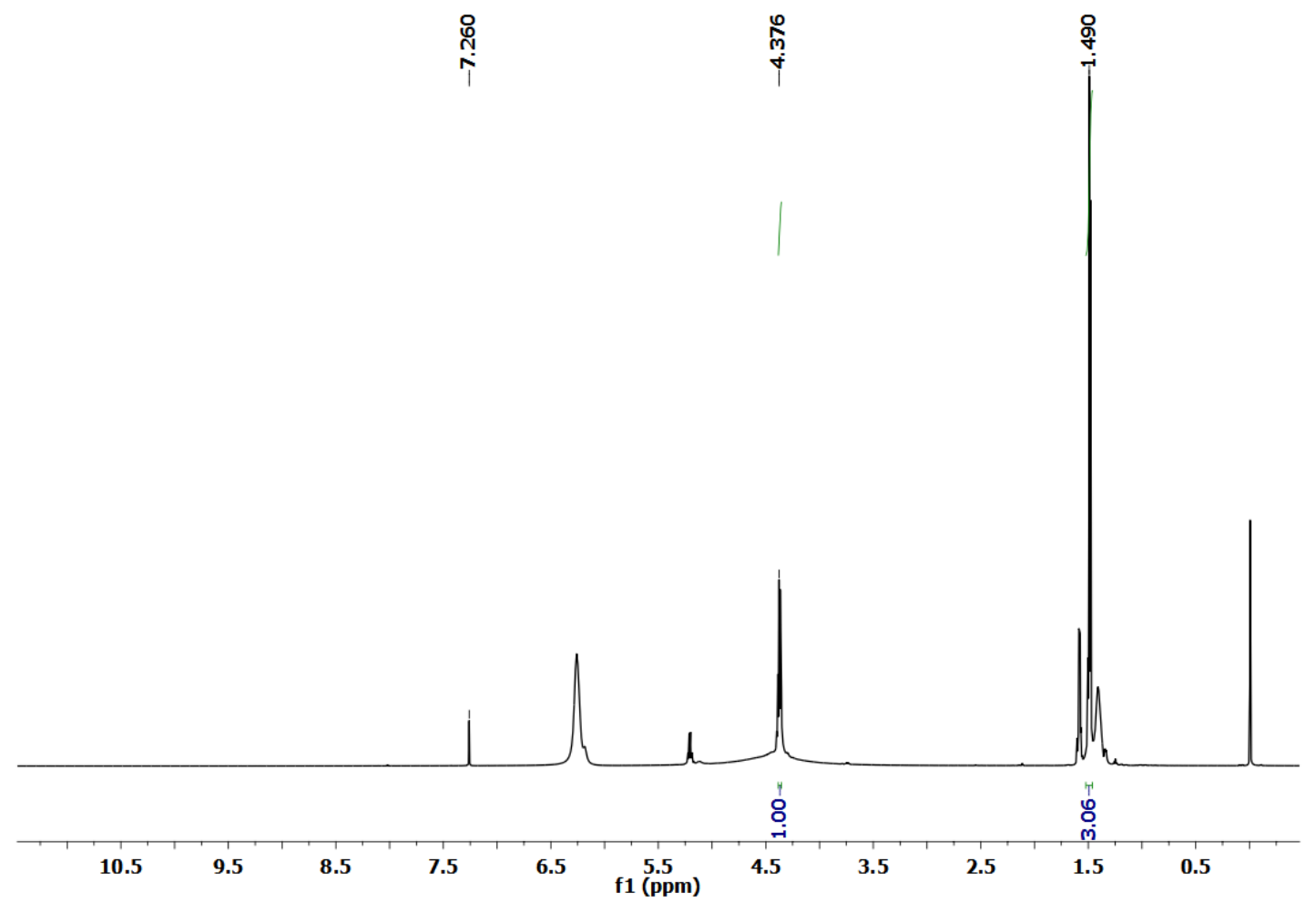

Fonte: Autor

Figura 97 - Espectro de ${ }^{13} \mathrm{C}-\mathrm{RMN}$ obtido para o ácido láctico $\left(\mathrm{CDCl}_{3}, 14,1 \mathrm{~T}\right)$
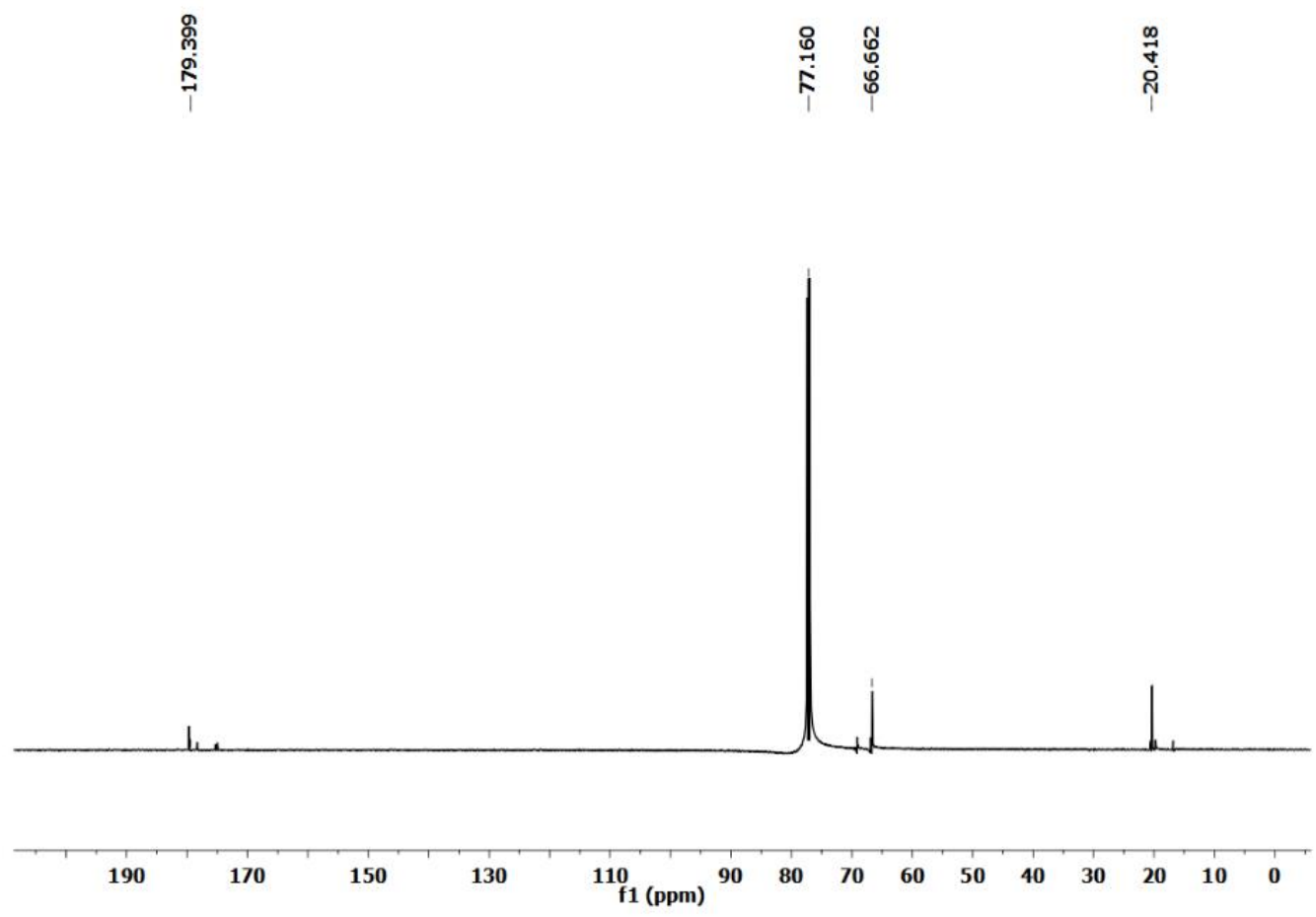

Fonte: Autor 
Figura 98 - Espectro de ${ }^{1} \mathrm{H}-\mathrm{RMN}$ obtido para o $\mathrm{AS}\left(\mathrm{CDCl}_{3}, 14,1 \mathrm{~T}\right)$

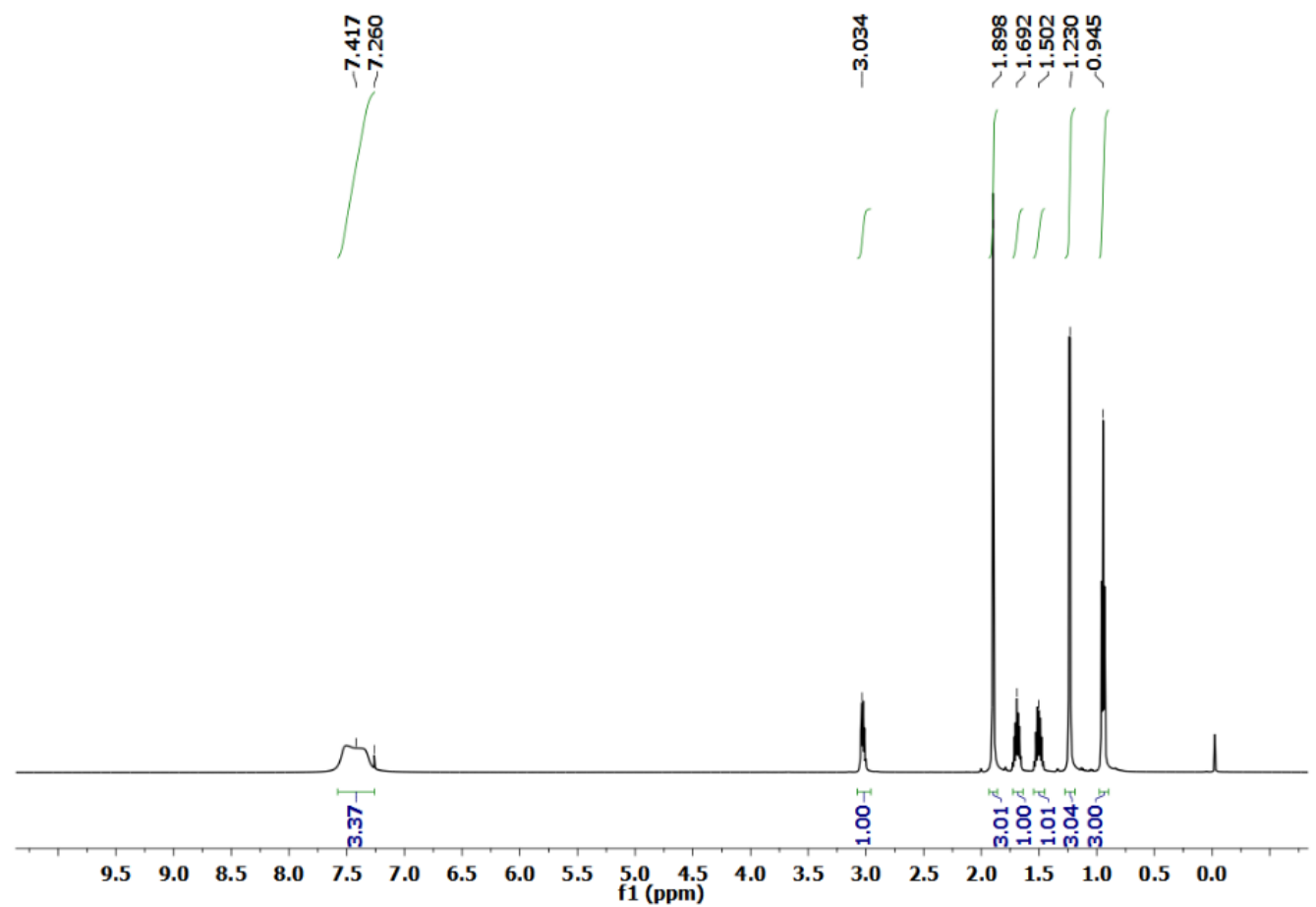

Fonte: Autor

Figura 99 - Espectro de ${ }^{13} \mathrm{C}-\mathrm{RMN}$ obtido para o $\mathrm{AS}\left(\mathrm{CDCl}_{3}, 14,1 \mathrm{~T}\right)$
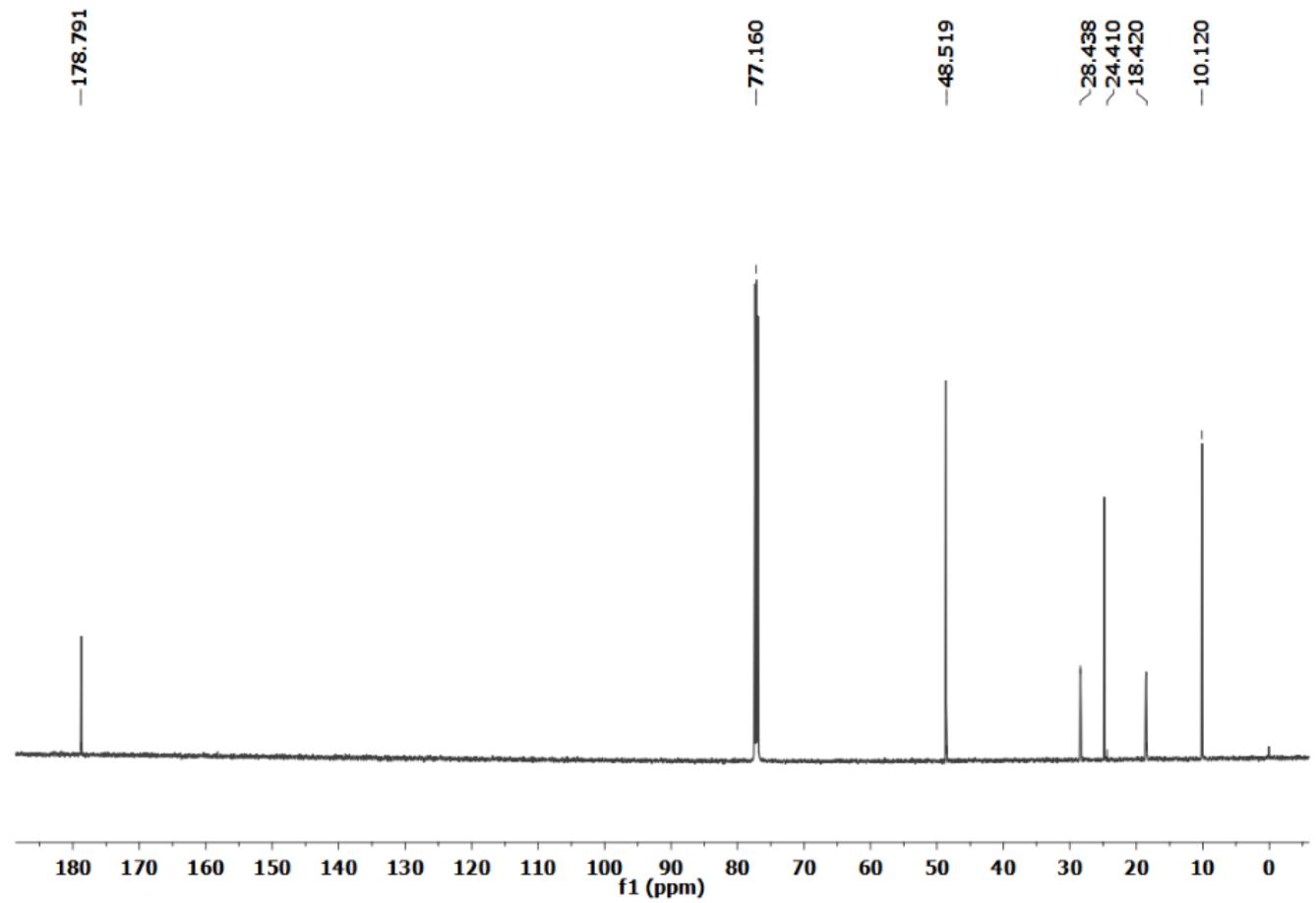

Fonte: Autor 
Figura 100 - Espectro de ${ }^{1} \mathrm{H}-\mathrm{RMN}$ obtido para o AT $\left(\mathrm{CDCl}_{3}, 14,1 \mathrm{~T}\right)$

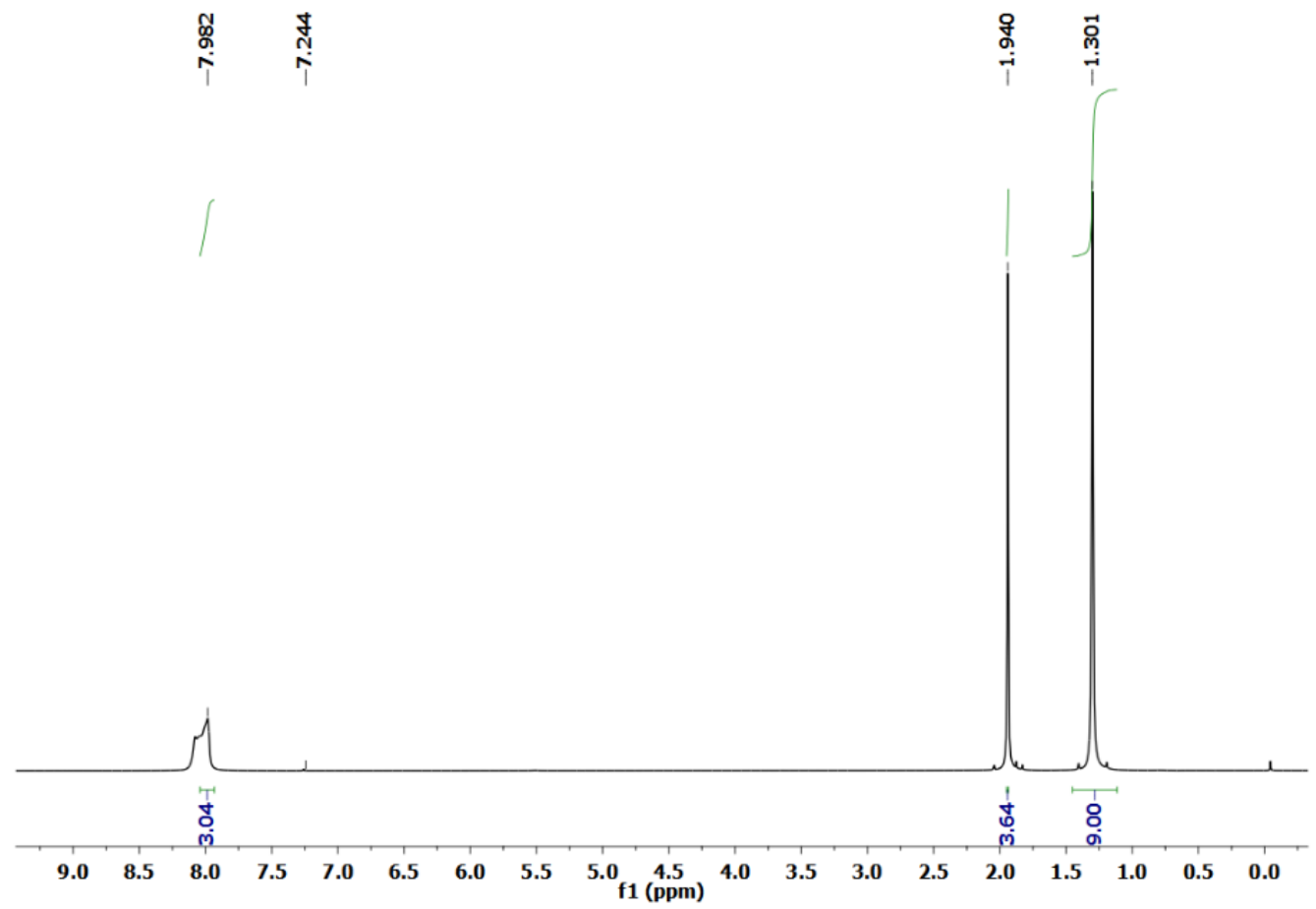

Fonte: Autor

Figura 101 - Espectro de ${ }^{13} \mathrm{C}-\mathrm{RMN}$ obtido para o $\mathrm{AT} \mathrm{CDCl}_{3}, 14,1 \mathrm{~T}$ )
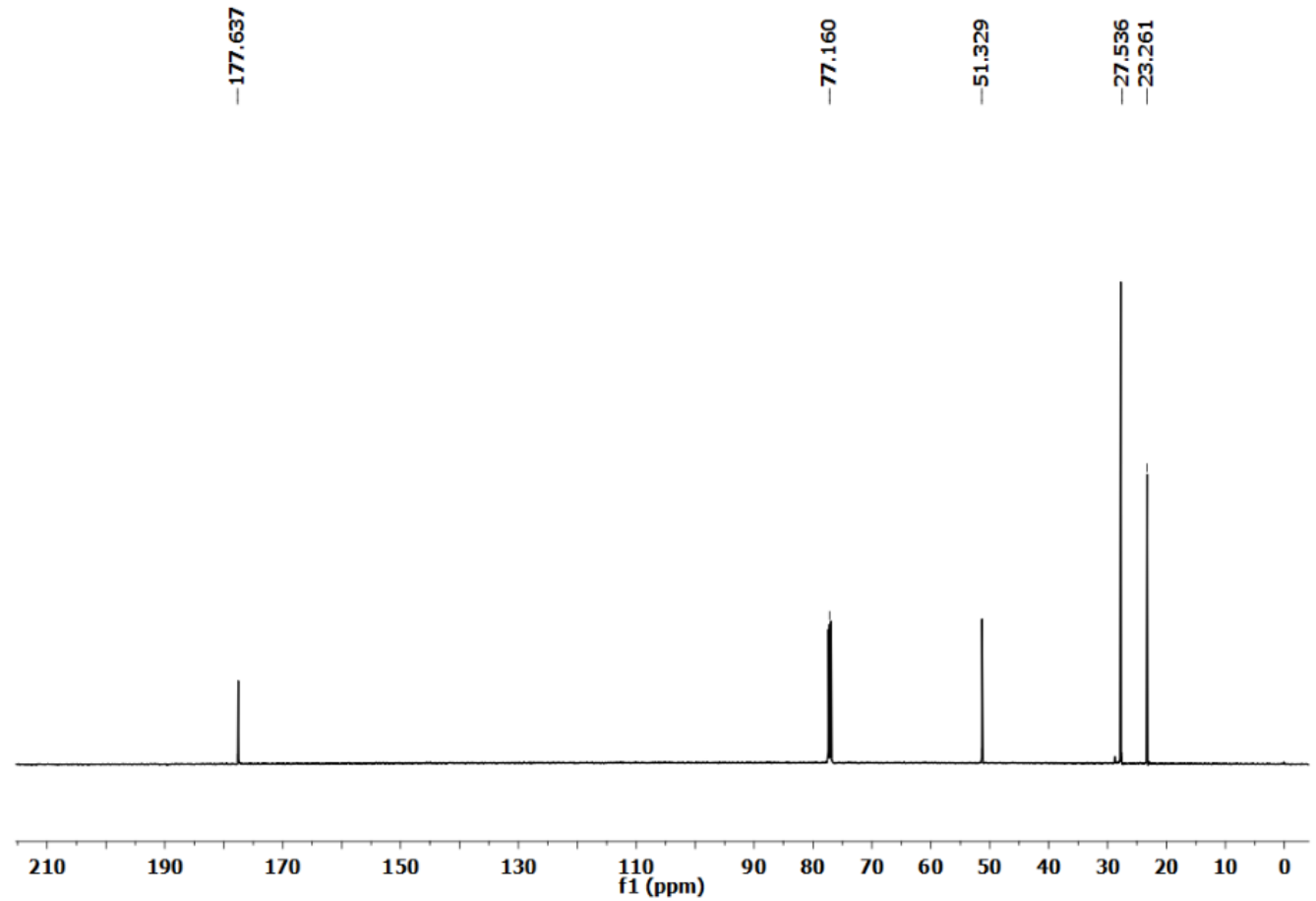

Fonte: Autor 
Figura 102 - Espectro de ${ }^{1} \mathrm{H}-\mathrm{RMN}$ obtido para o $\mathrm{LS}\left(\mathrm{CDCl}_{3}, 14,1 \mathrm{~T}\right)$

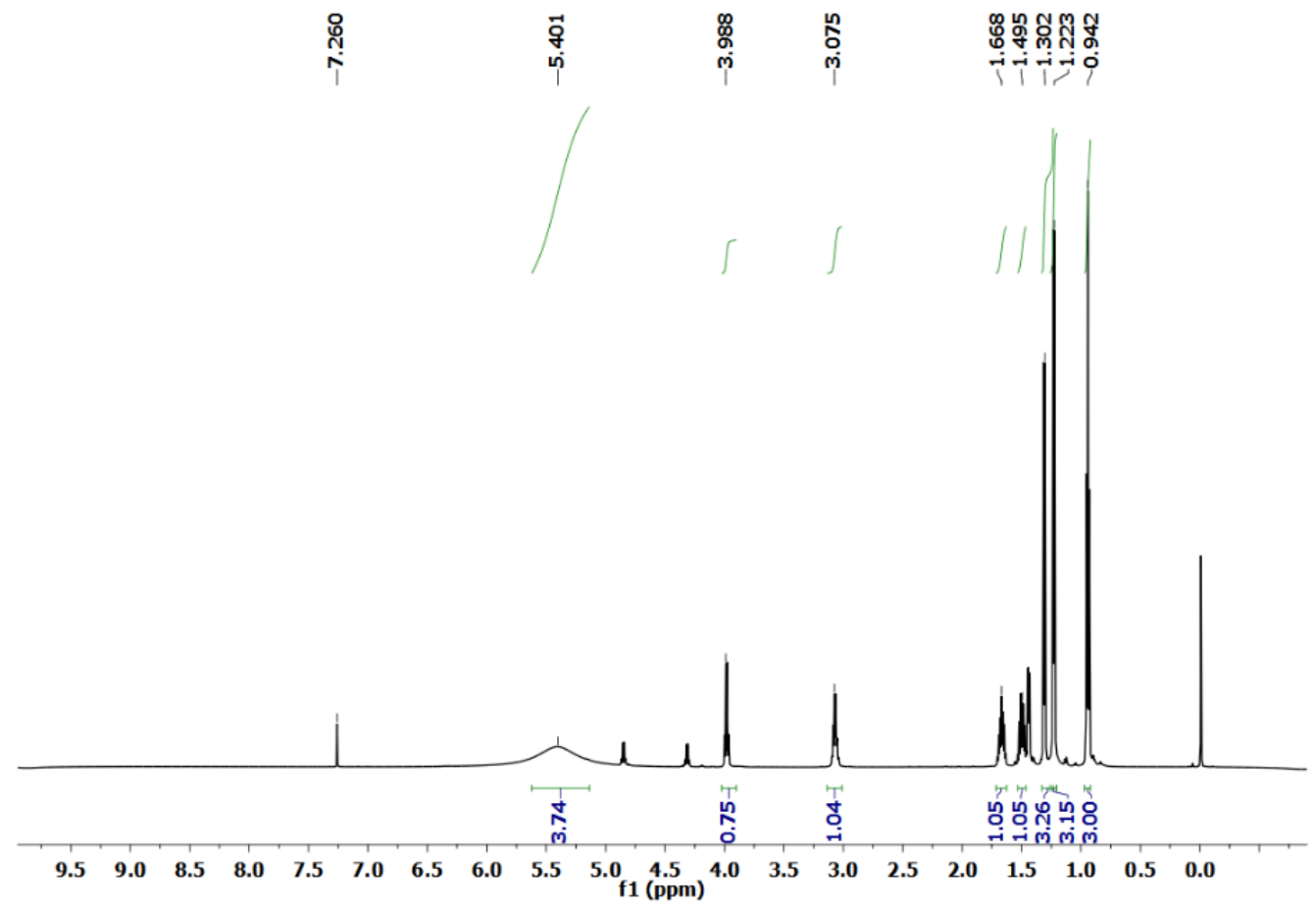

Fonte: Autor

Figura 103 - Espectro de ${ }^{13} \mathrm{C}-\mathrm{RMN}$ obtido para o $\mathrm{LS}\left(\mathrm{CDCl}_{3}, 14,1 \mathrm{~T}\right)$

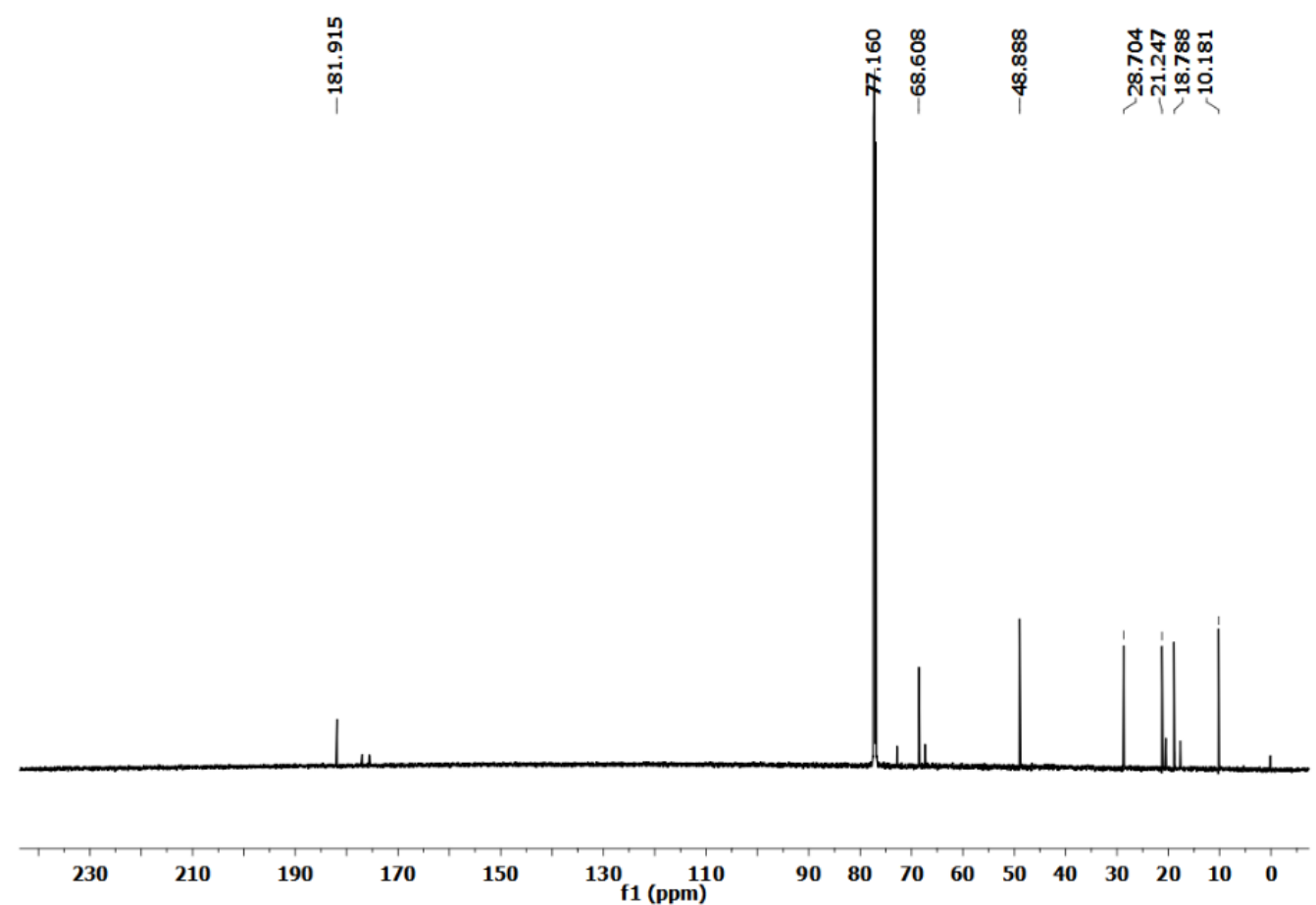

Fonte: Autor 
Figura 104 - Espectro de ${ }^{1} \mathrm{H}-\mathrm{RMN}$ obtido para o $\mathrm{LT}\left(\mathrm{CDCl}_{3}, 14,1 \mathrm{~T}\right)$

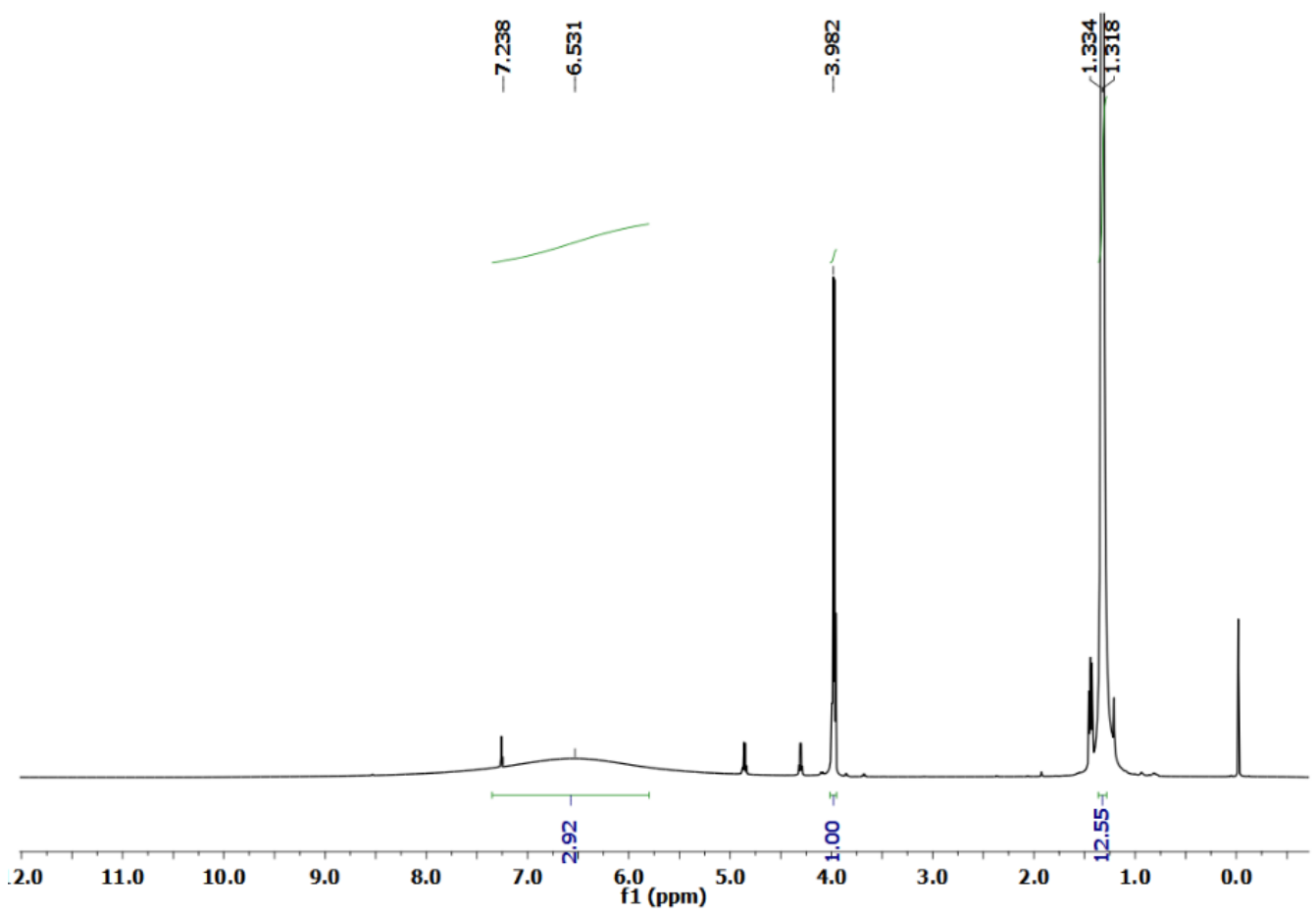

Fonte: Autor

Figura 105 - Espectro de ${ }^{13} \mathrm{C}-\mathrm{RMN}$ obtido para o LT $\left(\mathrm{CDCl}_{3}, 14,1 \mathrm{~T}\right)$
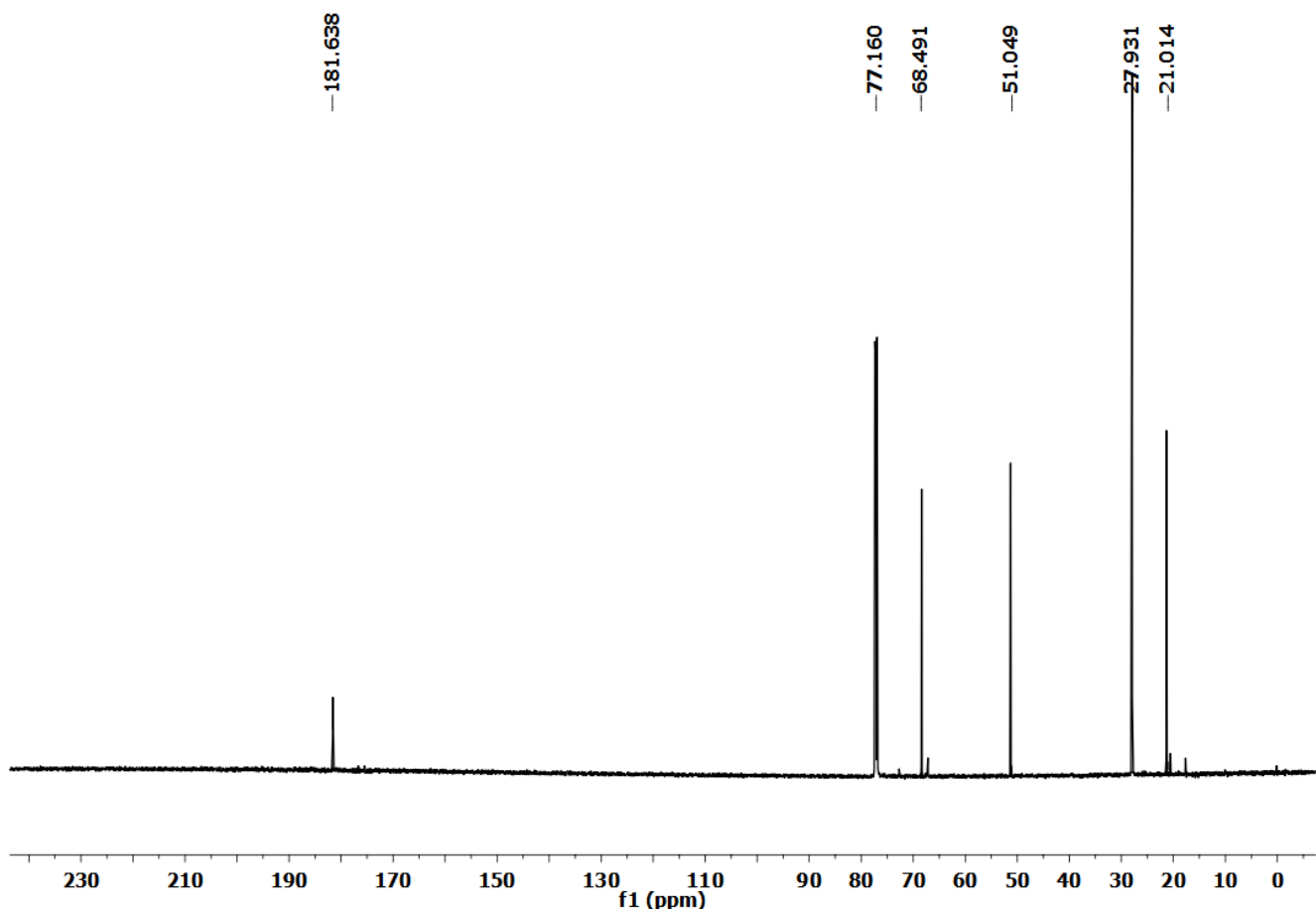

Fonte: Autor 
Apêndice D - Isotermas de Adsorção para CMCQF 
Figura 106 - Isoterma de Langmuir à temperatura de $20^{\circ} \mathrm{C}$

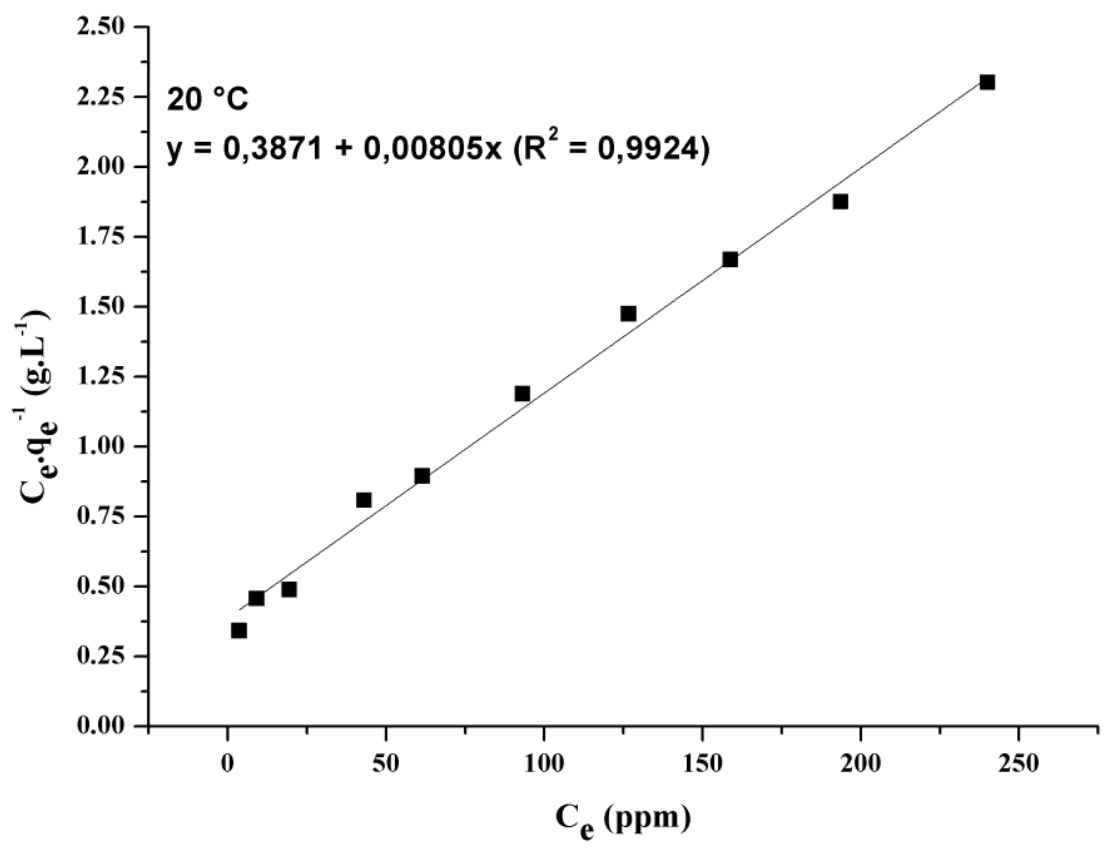

Fonte: Autor

Figura 107 - Isoterma de Langmuir à temperatura de $25^{\circ} \mathrm{C}$

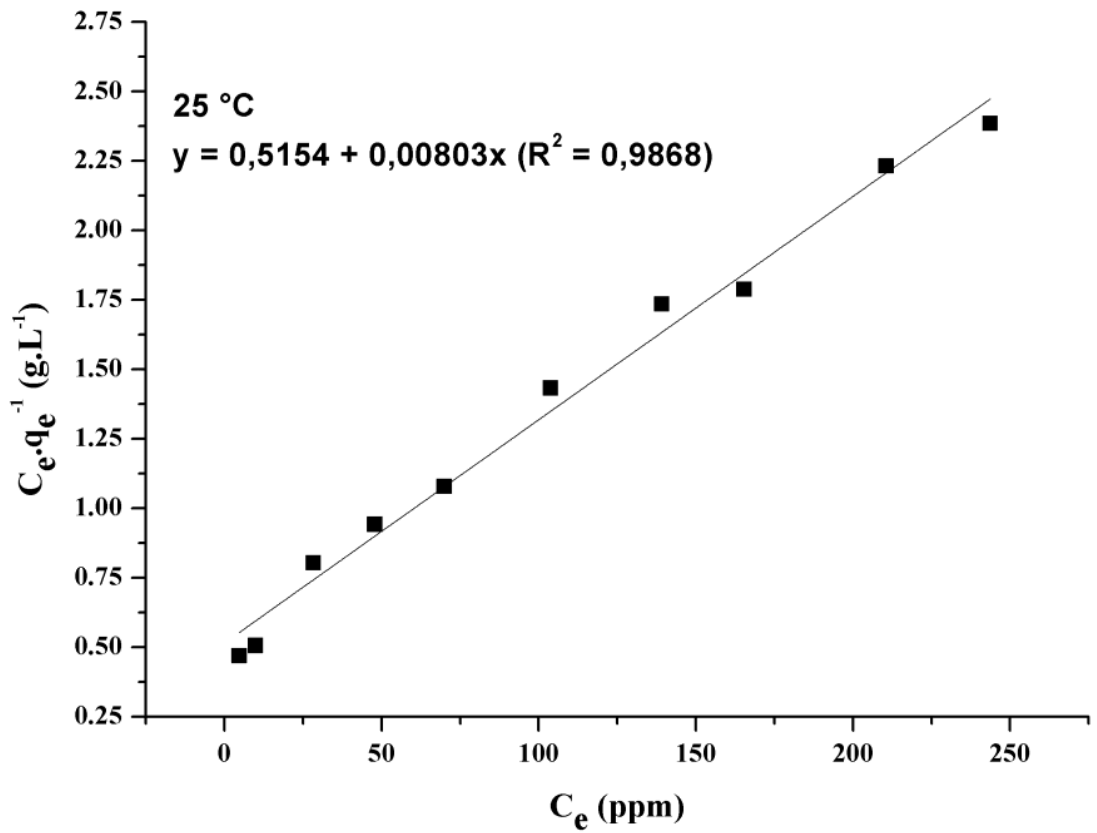

Fonte: Autor 
Figura 108 - Isoterma de Langmuir à temperatura de $30^{\circ} \mathrm{C}$

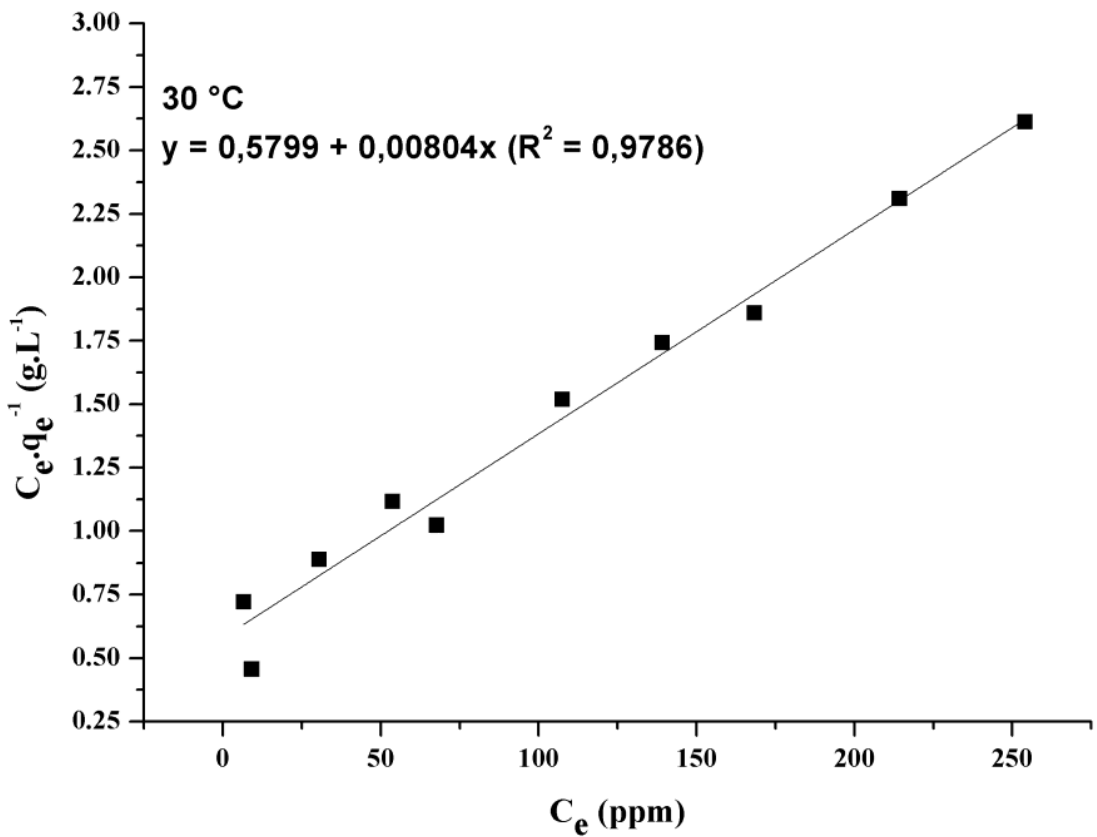

Fonte: Autor

Figura 109 - Isoterma de Langmuir à temperatura de $40^{\circ} \mathrm{C}$

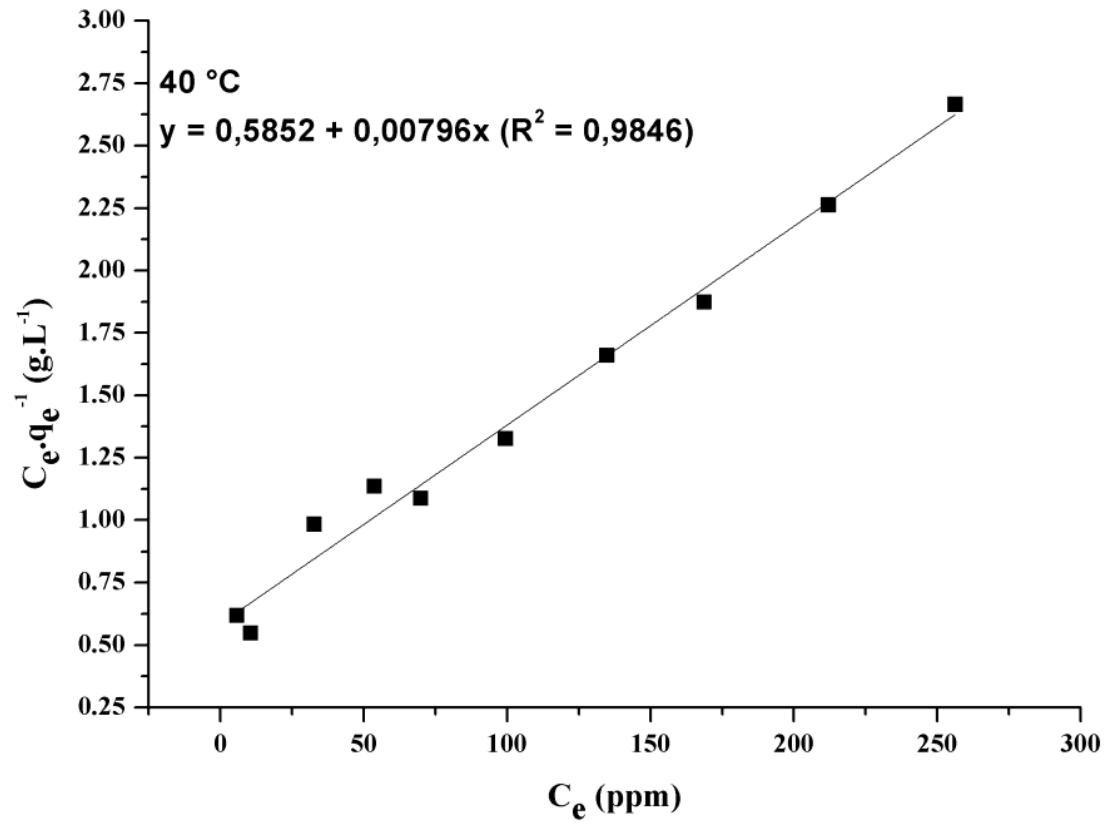

Fonte: Autor 
Figura 110 - Isoterma de Langmuir à temperatura de $50^{\circ} \mathrm{C}$

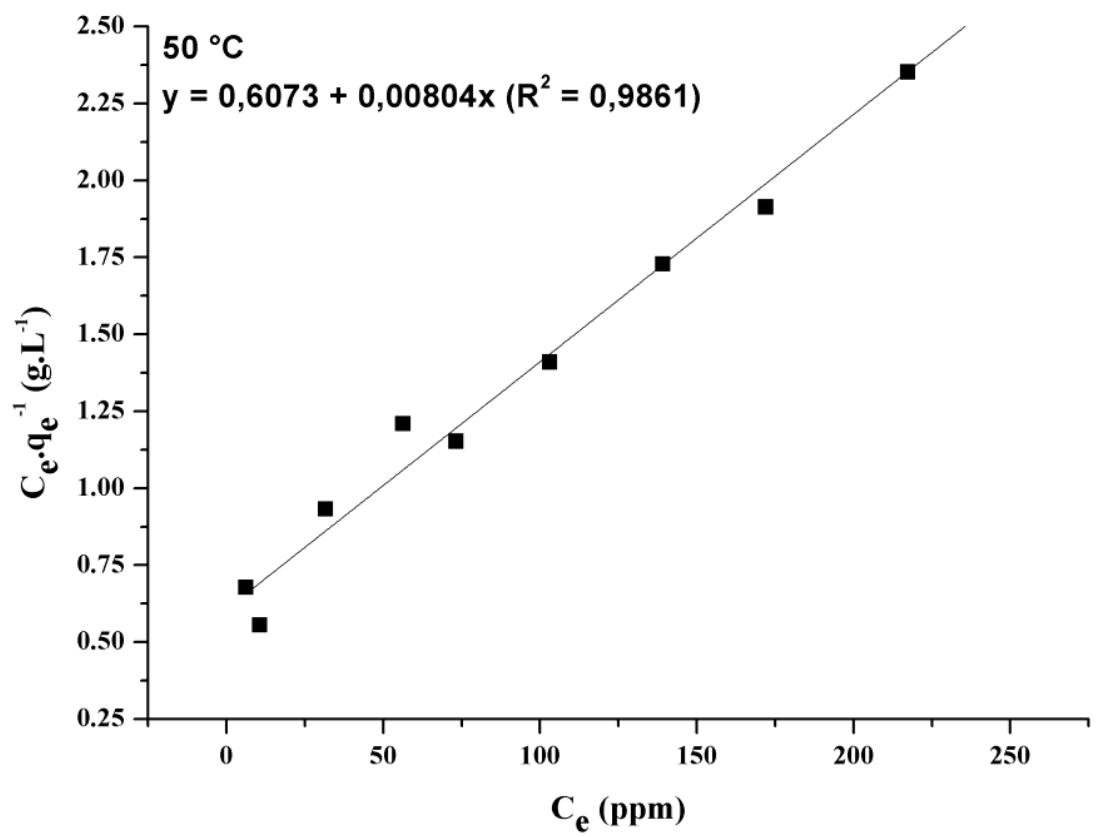

Fonte: Autor

Figura 111 - Isoterma de Freundlich à temperatura de $20^{\circ} \mathrm{C}$

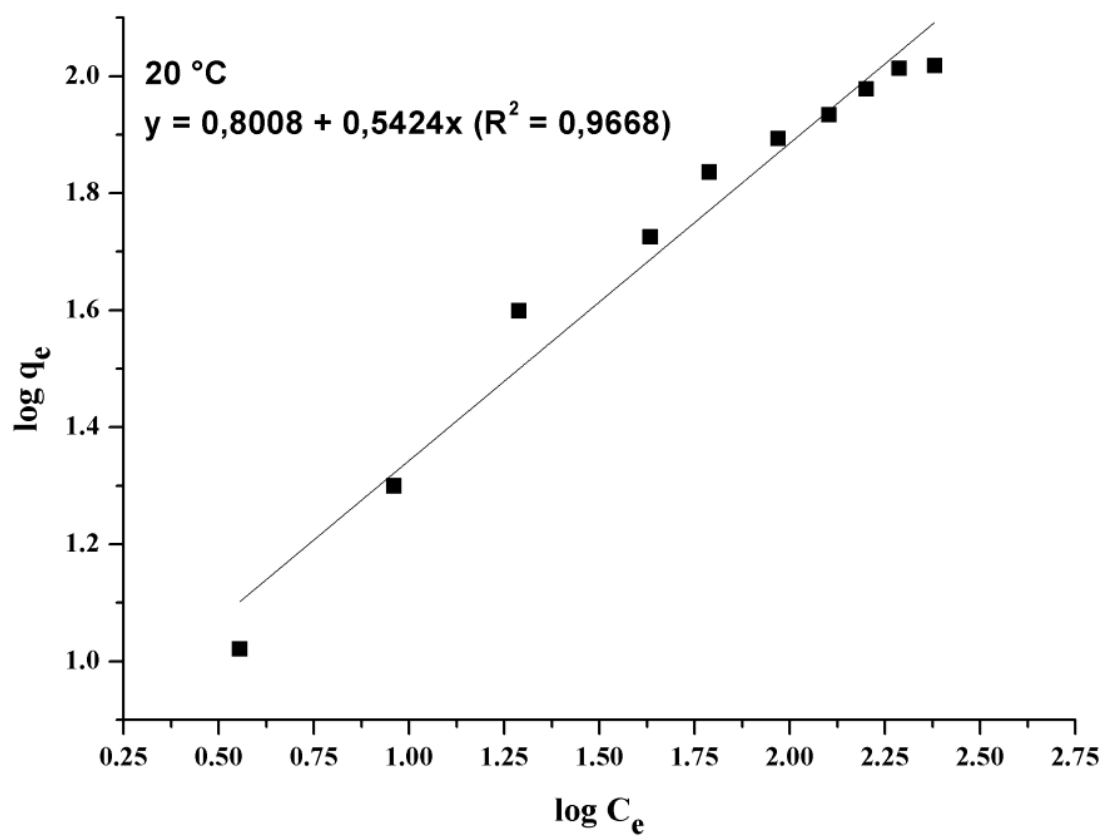

Fonte: Autor 
Figura 112 - Isoterma de Freundlich à temperatura de $25^{\circ} \mathrm{C}$

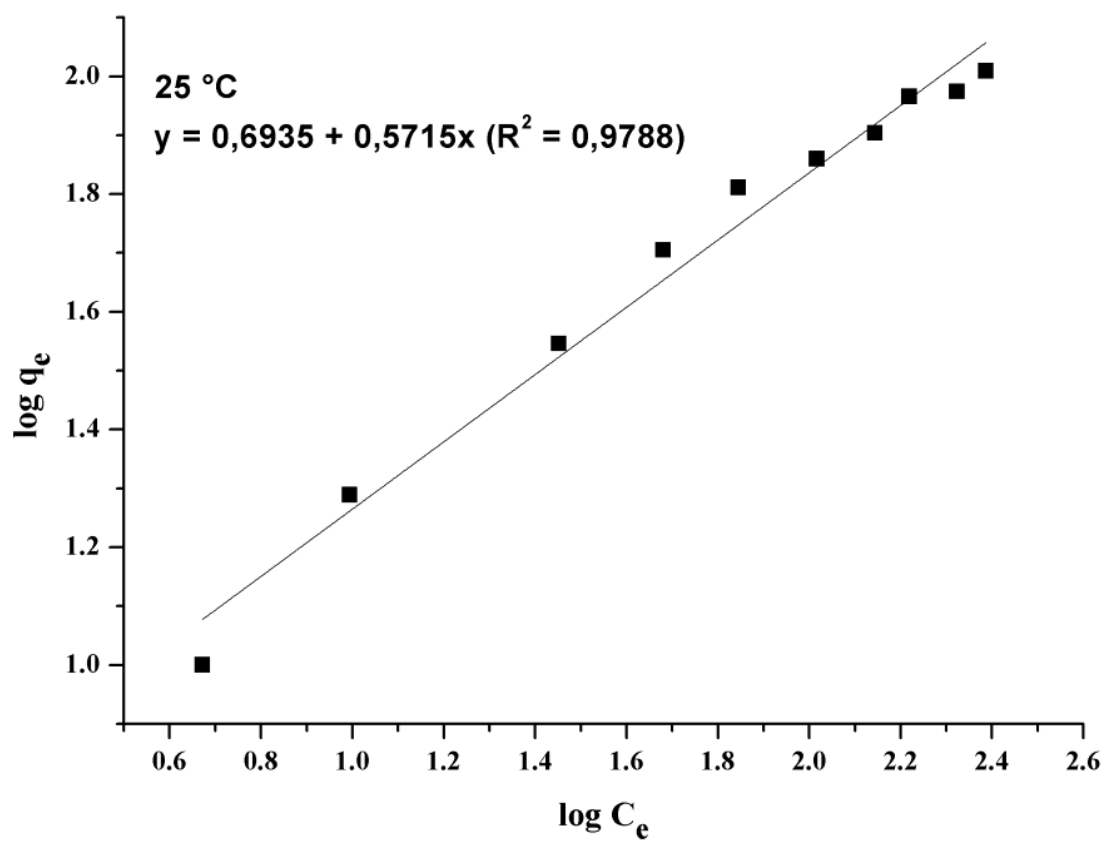

Fonte: Autor

Figura 113 - Isoterma de Freundlich à temperatura de $30^{\circ} \mathrm{C}$

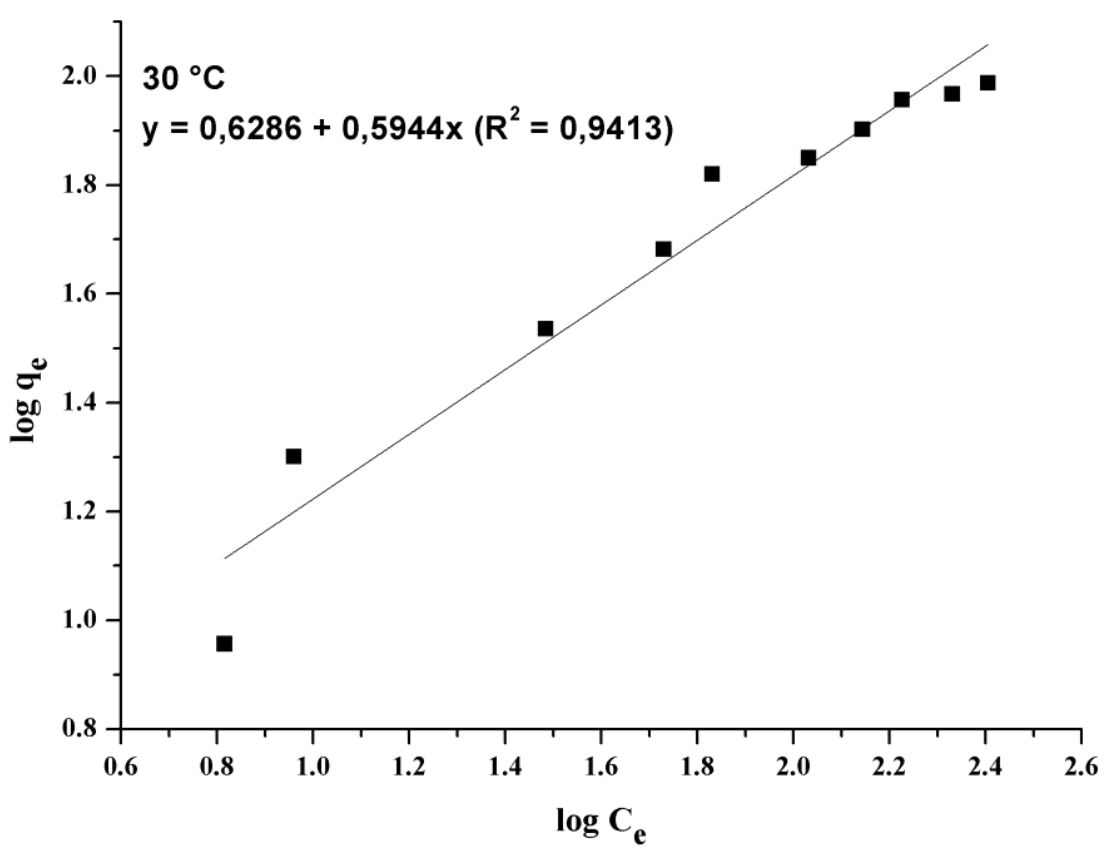

Fonte: Autor 
Figura 114 - Isoterma de Freundlich à temperatura de $40^{\circ} \mathrm{C}$

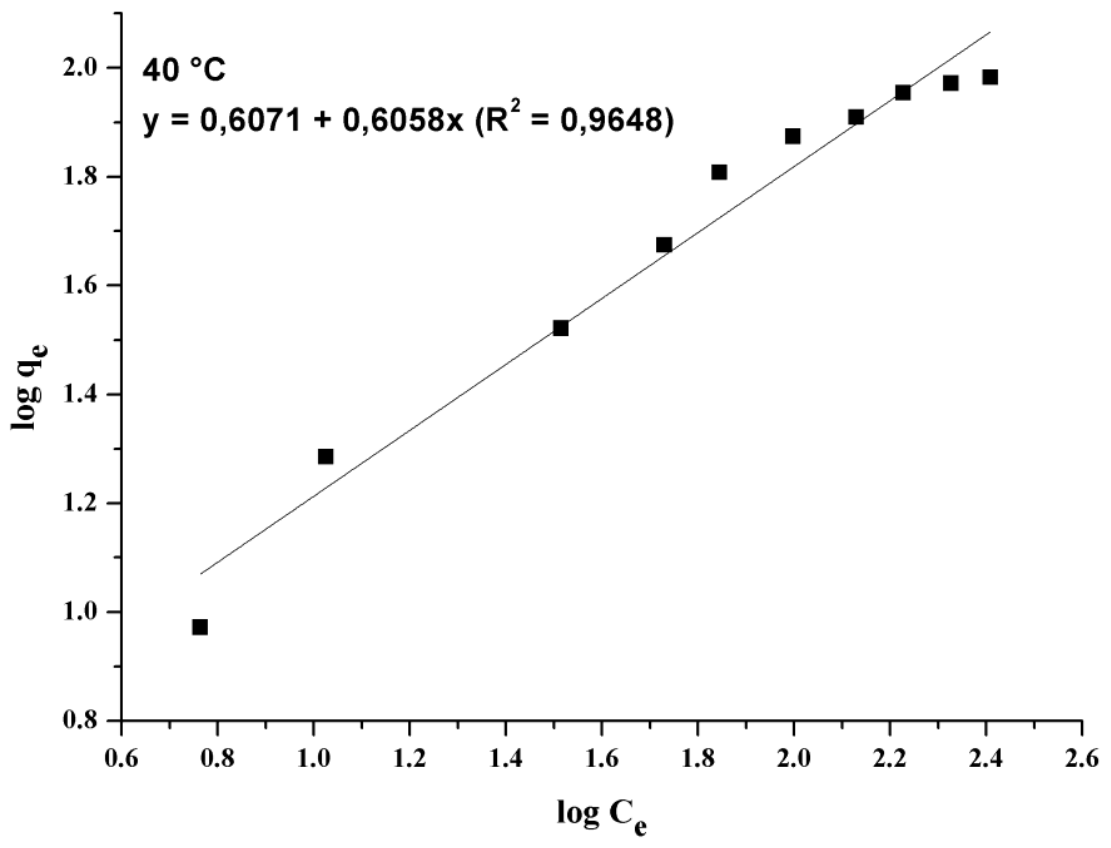

Fonte: Autor

Figura 115 - Isoterma de Freundlich à temperatura de $50^{\circ} \mathrm{C}$

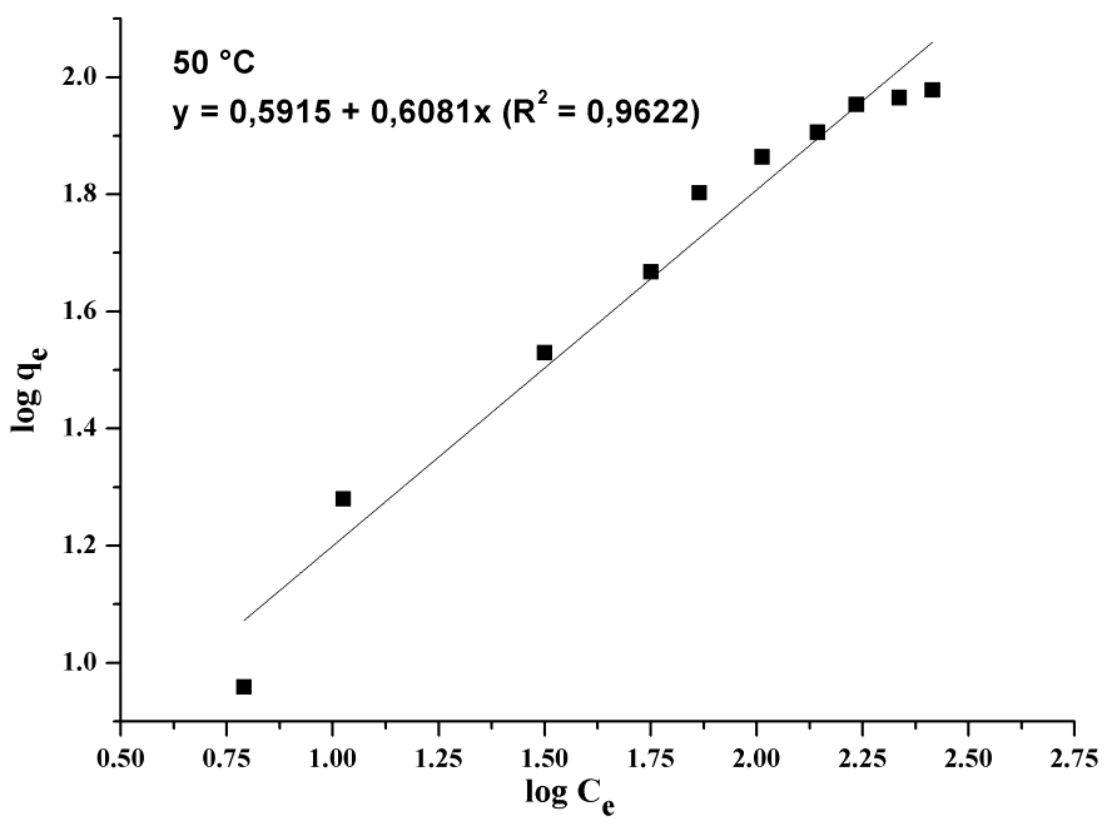

Fonte: Autor 
Figura 116 - Isoterma de Temkin à temperatura de $20^{\circ} \mathrm{C}$

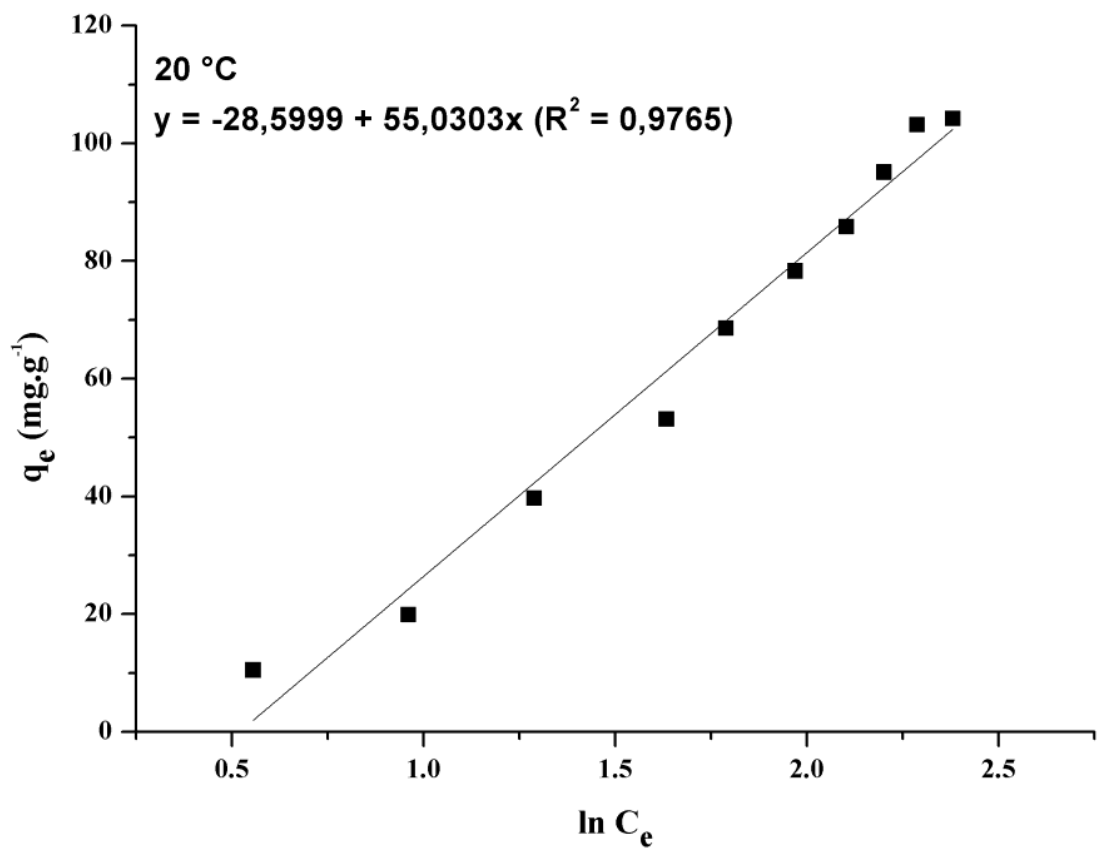

Fonte: Autor

Figura 117 - Isoterma de Temkin à temperatura de $25^{\circ} \mathrm{C}$

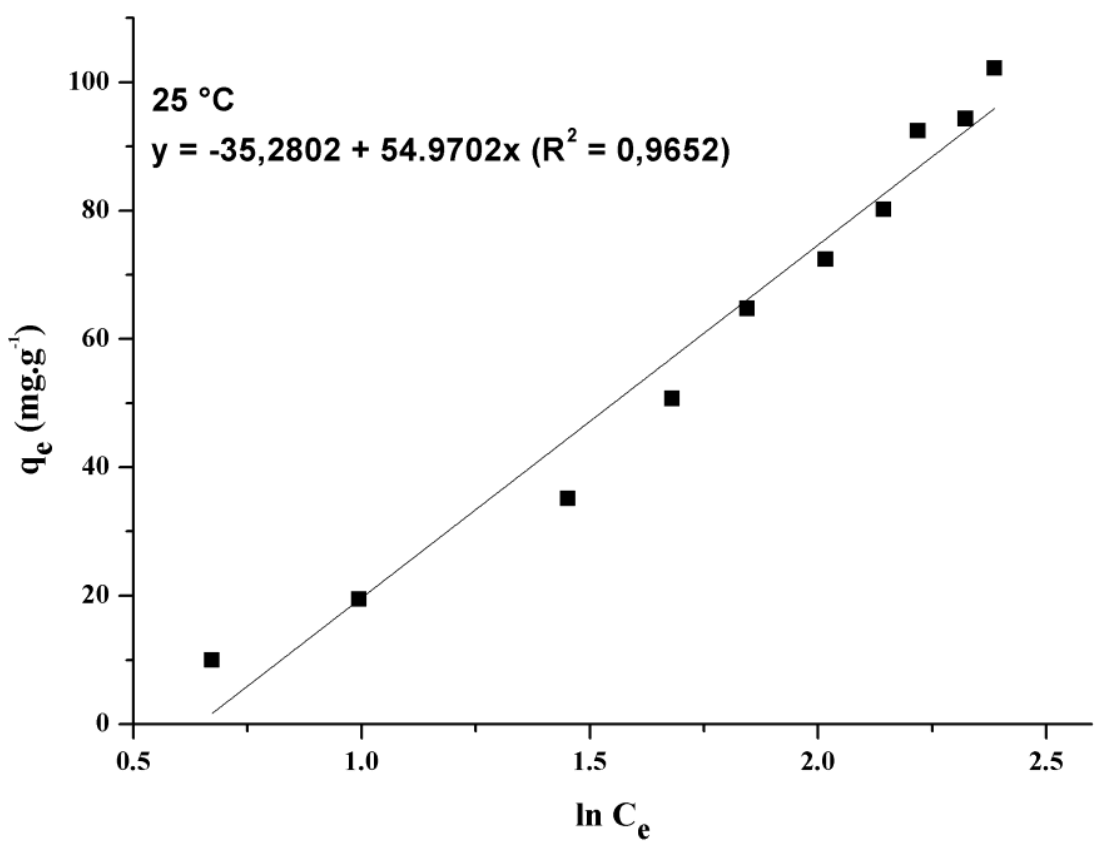

Fonte: Autor 
Figura 118 - Isoterma de Temkin à temperatura de $30^{\circ} \mathrm{C}$

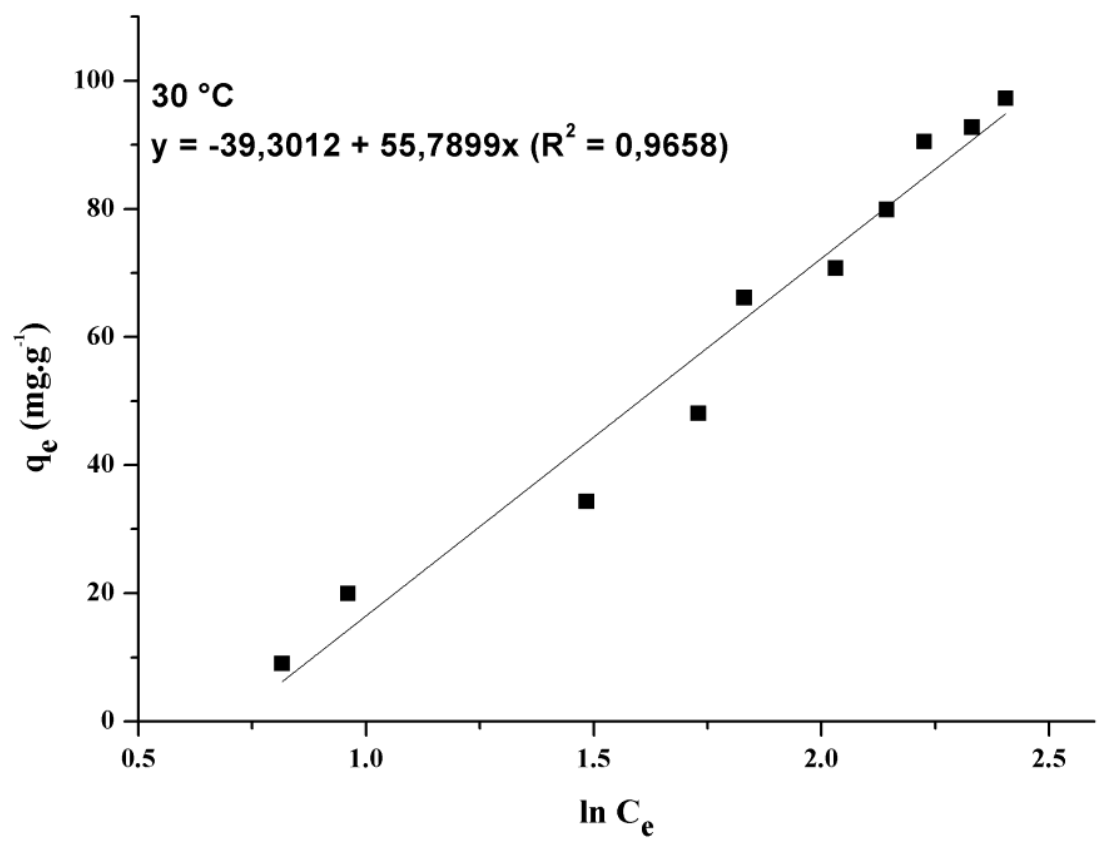

Fonte: Autor

Figura 119 - Isoterma de Temkin à temperatura de $40^{\circ} \mathrm{C}$

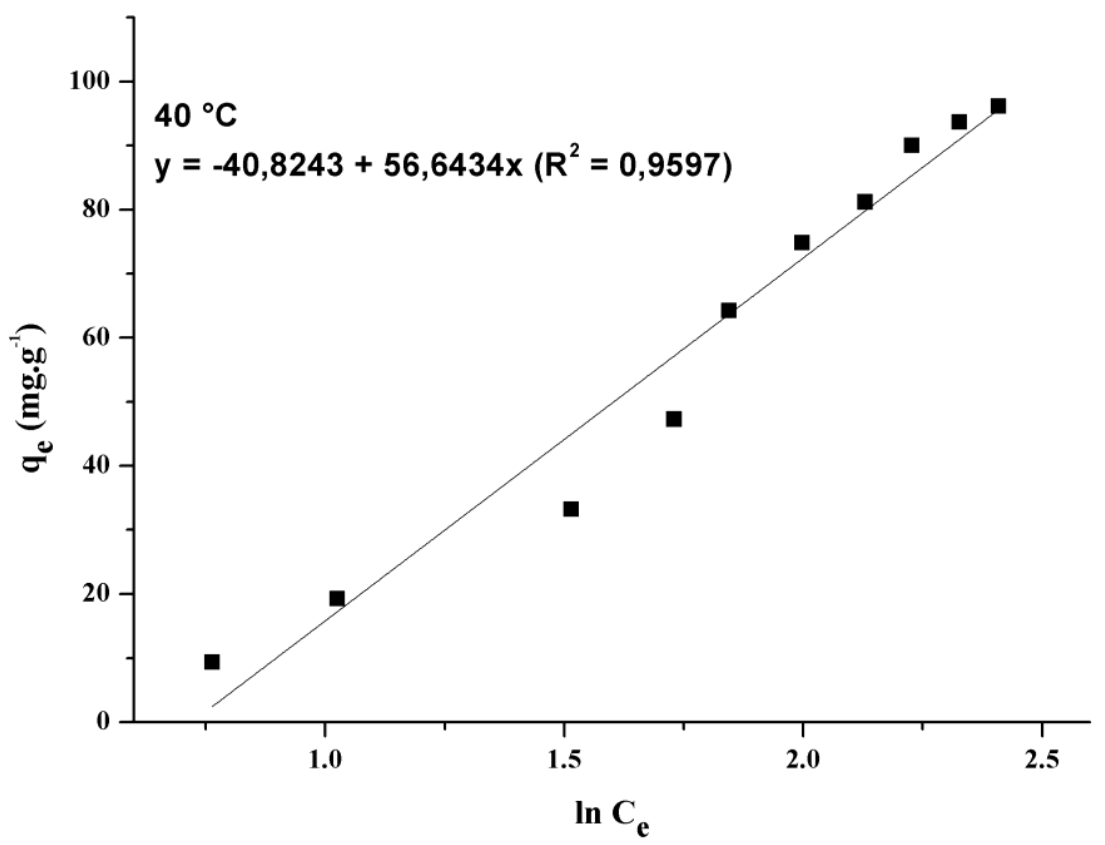

Fonte: Autor 
Figura 120 - Isoterma de Temkin à temperatura de $50^{\circ} \mathrm{C}$

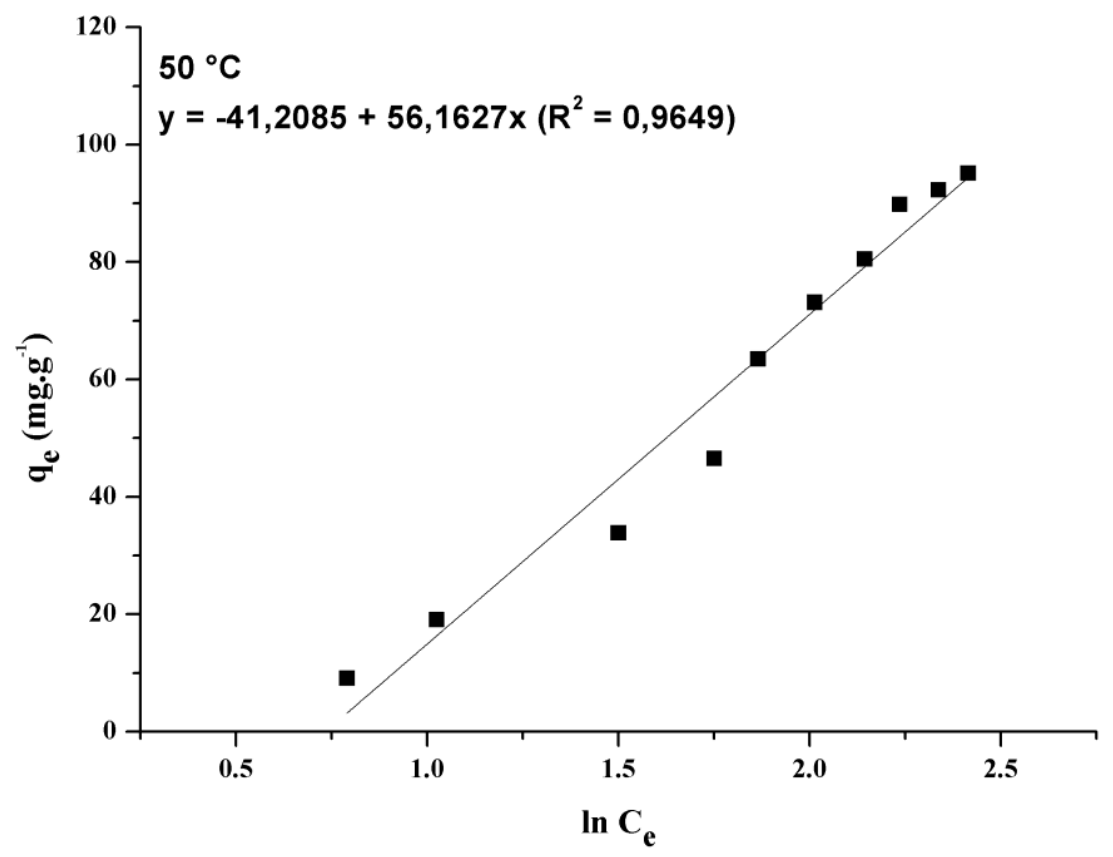

Fonte: Autor 
Apêndice E - Isotermas de Adsorção para CMCQDIC 
Figura 121 - Isoterma de Langmuir à temperatura de $20^{\circ} \mathrm{C}$

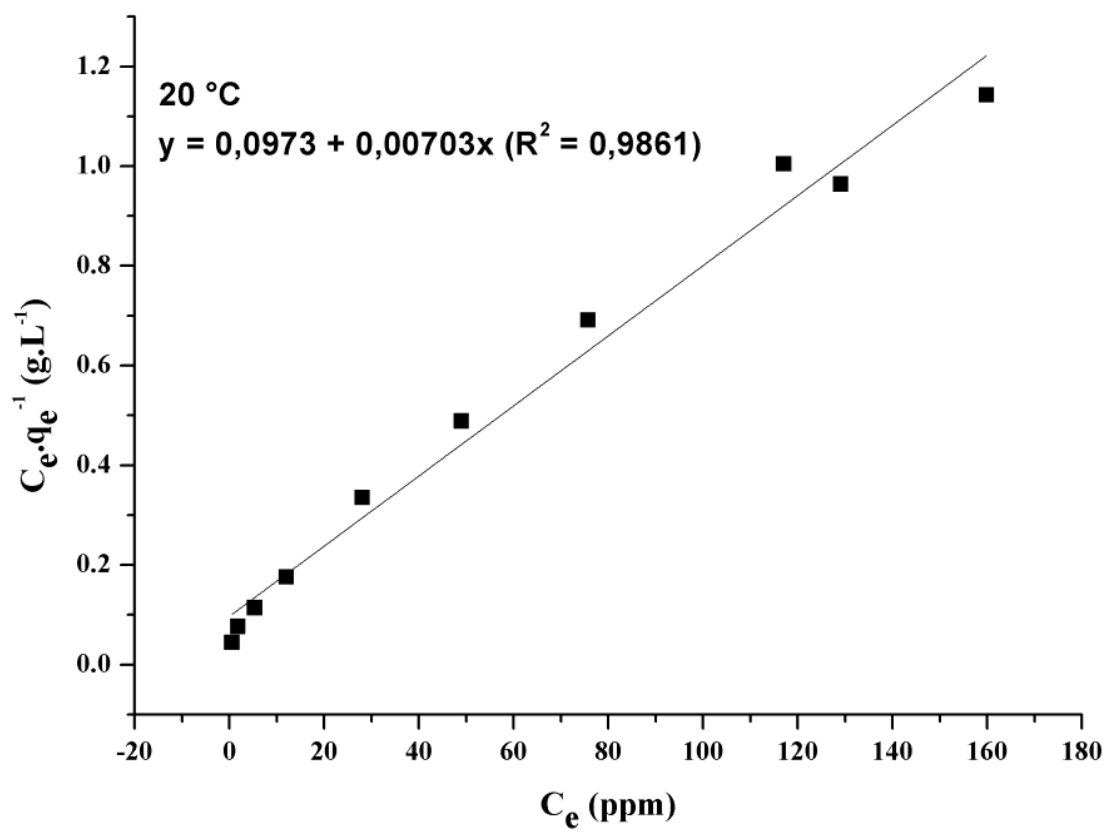

Fonte: Autor

Figura 122 - Isoterma de Langmuir à temperatura de $25^{\circ} \mathrm{C}$

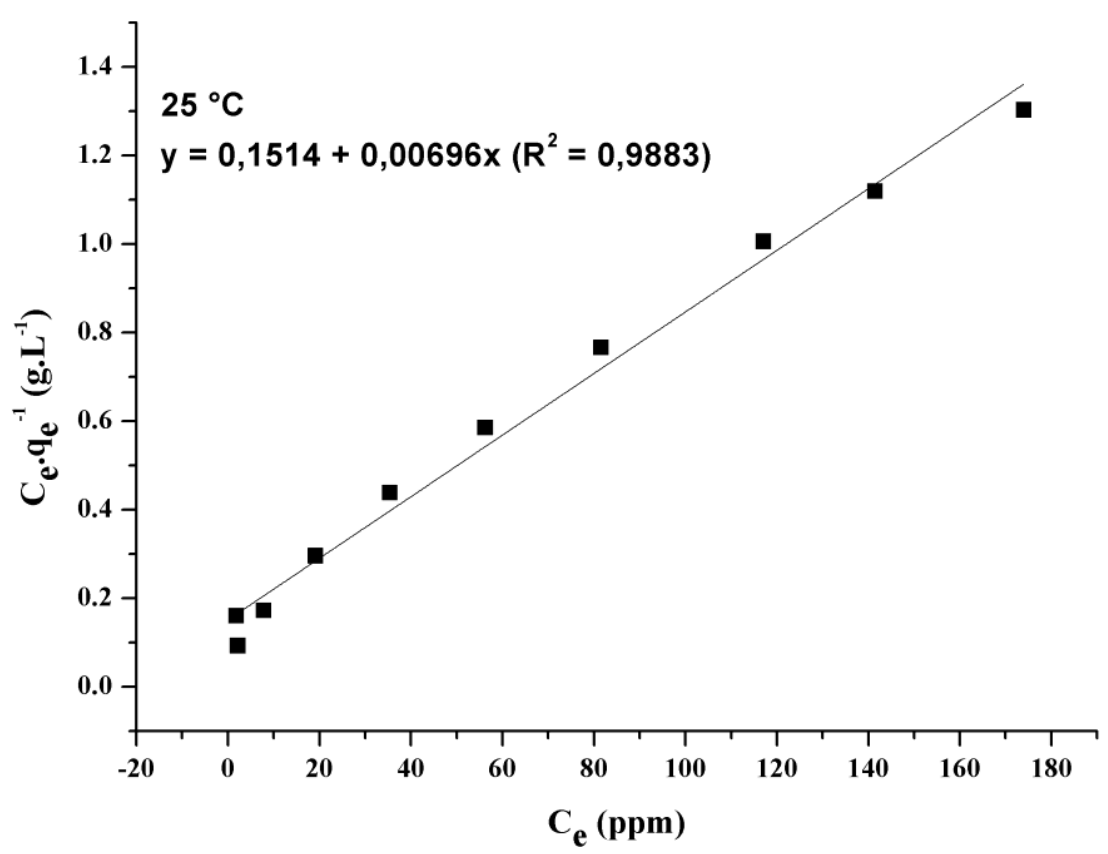

Fonte: Autor 
Figura 123 - Isoterma de Langmuir à temperatura de $30^{\circ} \mathrm{C}$

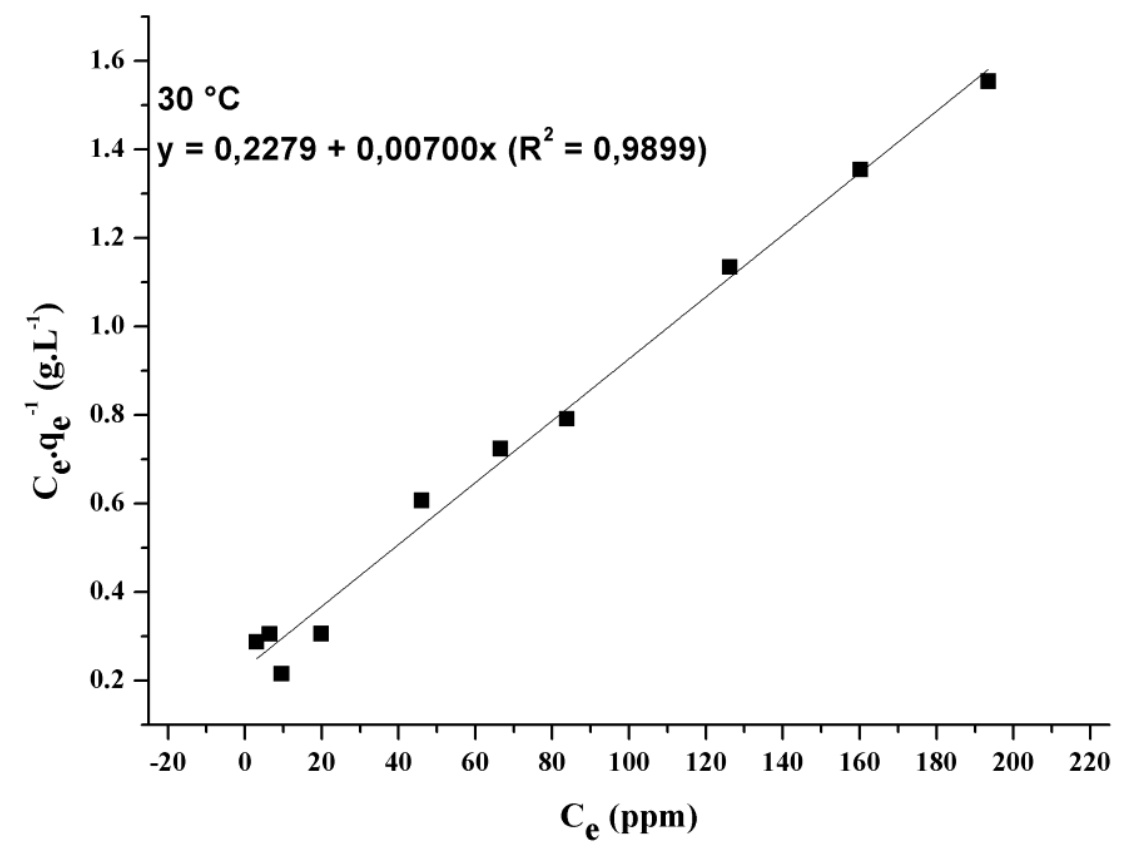

Fonte: Autor

Figura 124 - Isoterma de Langmuir à temperatura de $40^{\circ} \mathrm{C}$

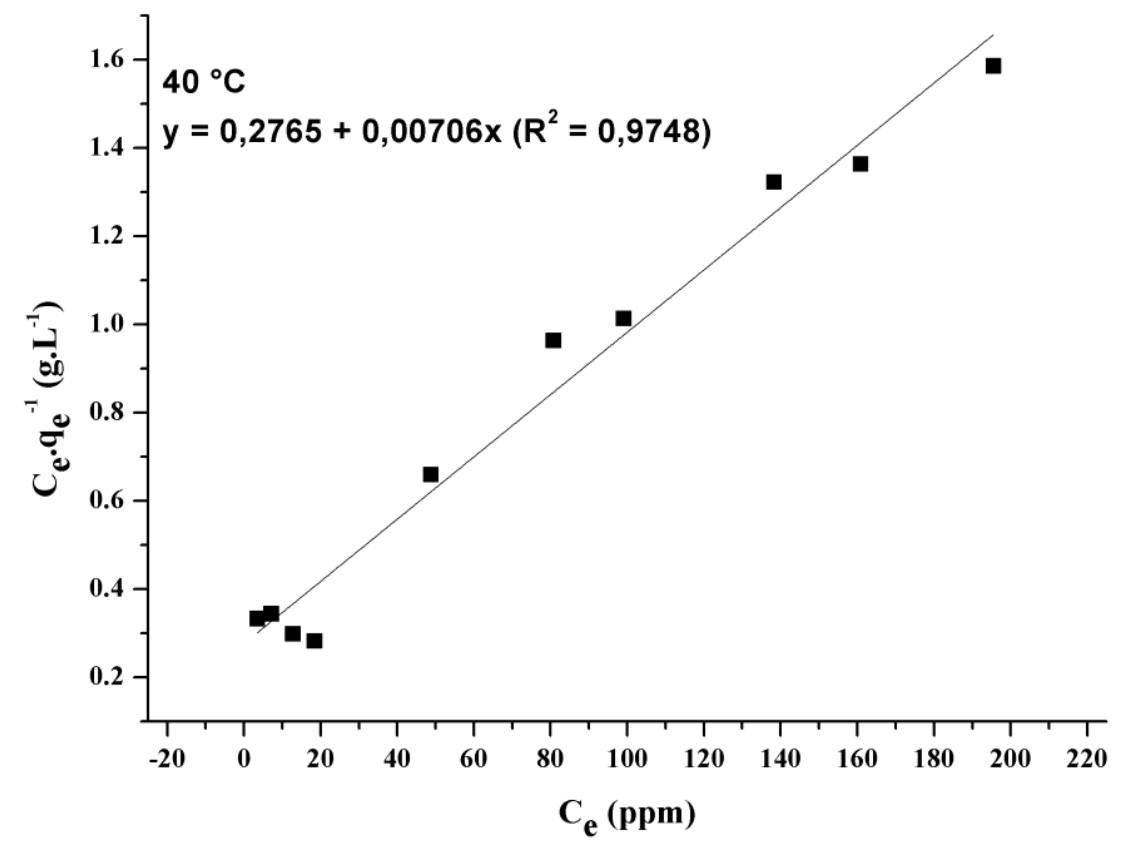

Fonte: Autor 
Figura 125 - Isoterma de Langmuir à temperatura de $50^{\circ} \mathrm{C}$

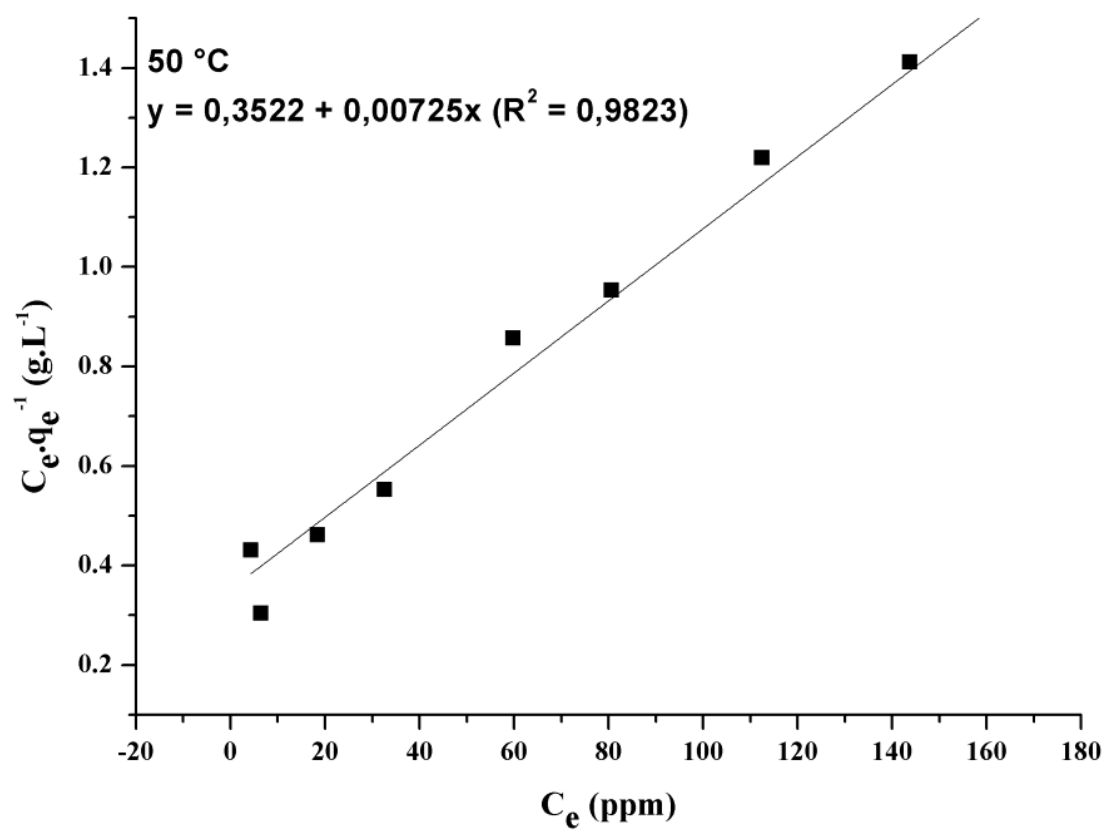

Fonte: Autor

Figura 126 - Isoterma de Freundlich à temperatura de $20^{\circ} \mathrm{C}$

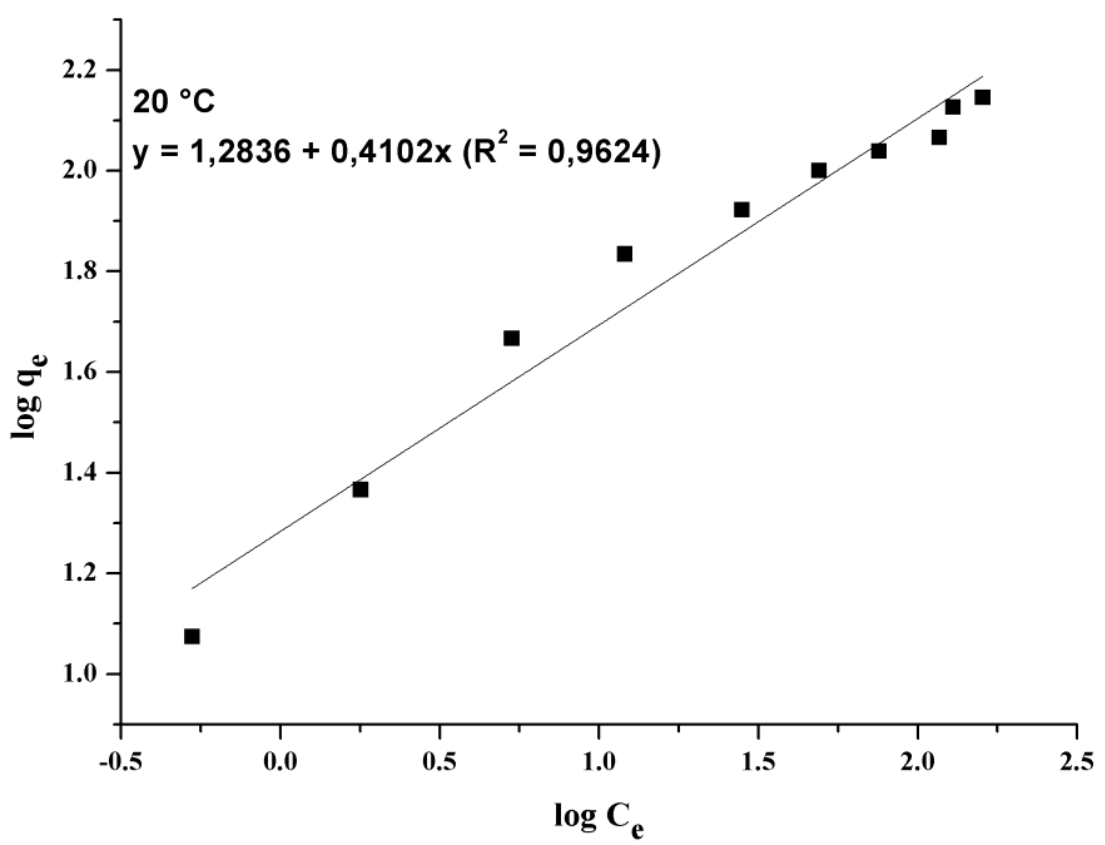

Fonte: Autor 
Figura 127 - Isoterma de Freundlich à temperatura de $25^{\circ} \mathrm{C}$

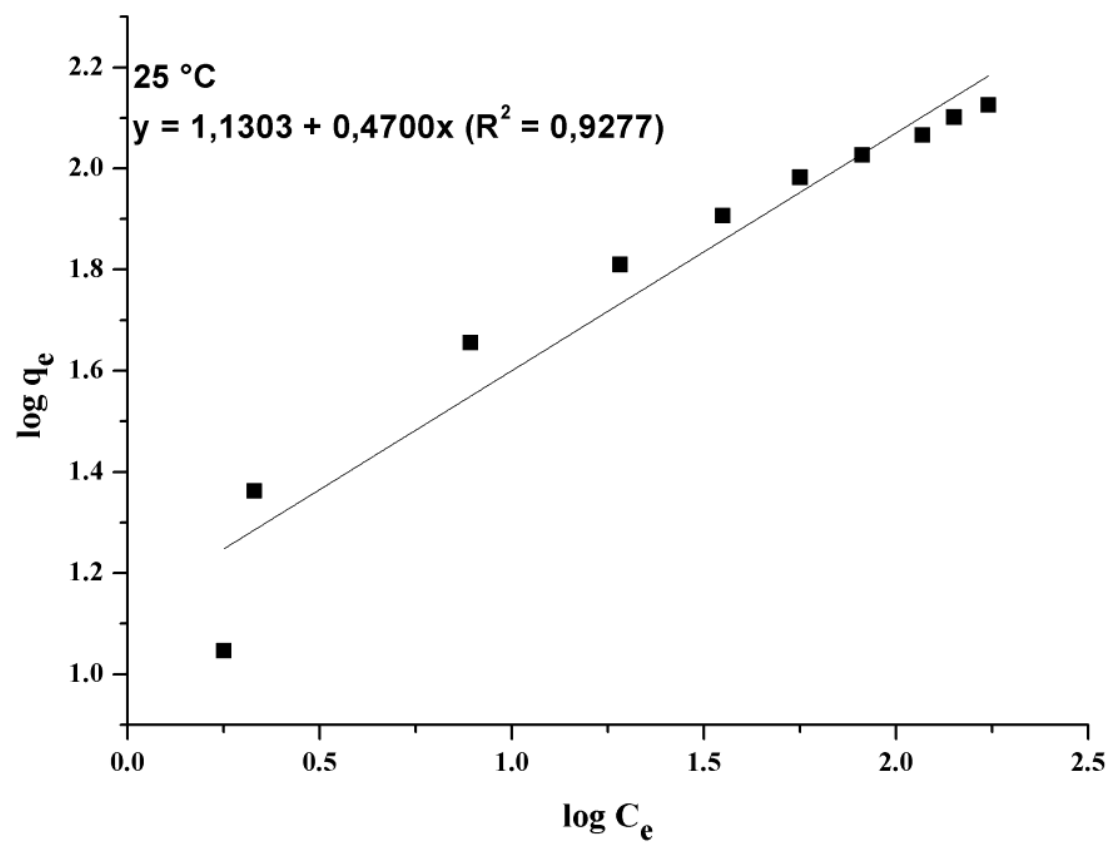

Fonte: Autor

Figura 128 - Isoterma de Freundlich à temperatura de $30^{\circ} \mathrm{C}$

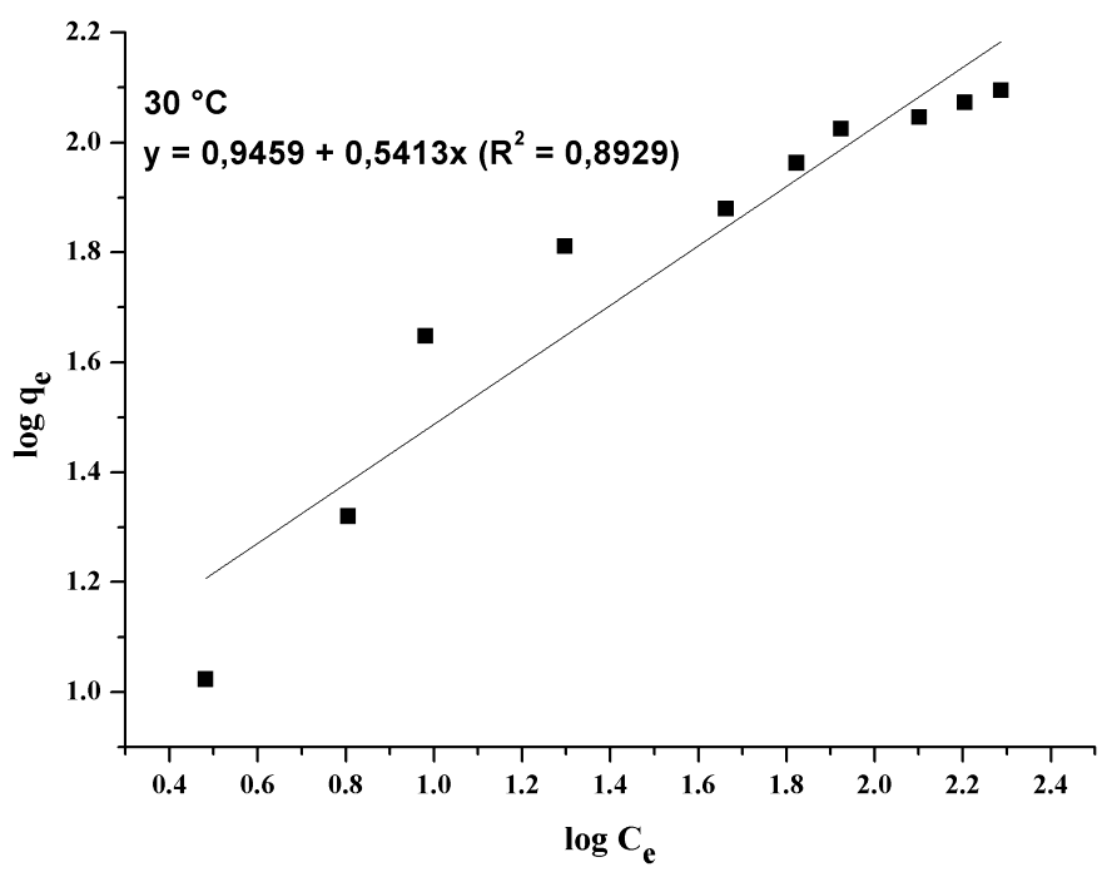

Fonte: Autor 
Figura 129 - Isoterma de Freundlich à temperatura de $40^{\circ} \mathrm{C}$

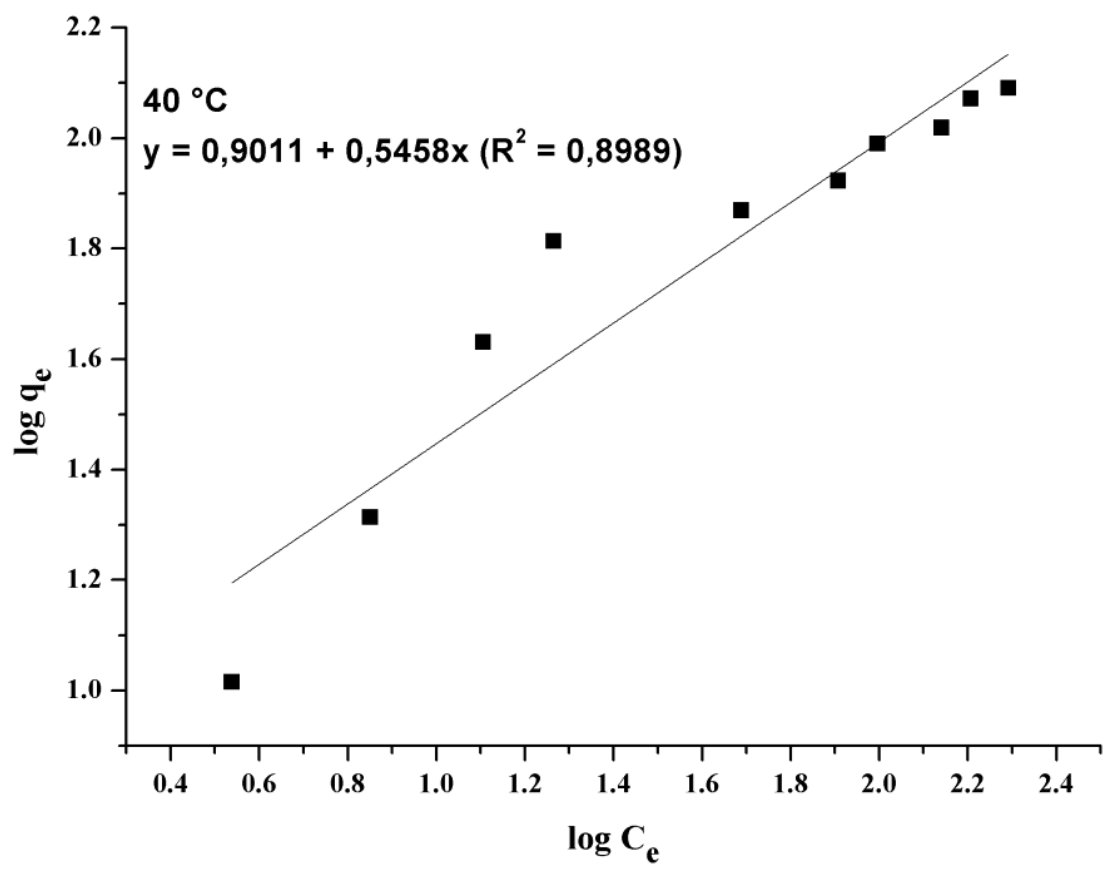

Fonte: Autor

Figura 130 - Isoterma de Freundlich à temperatura de $50^{\circ} \mathrm{C}$

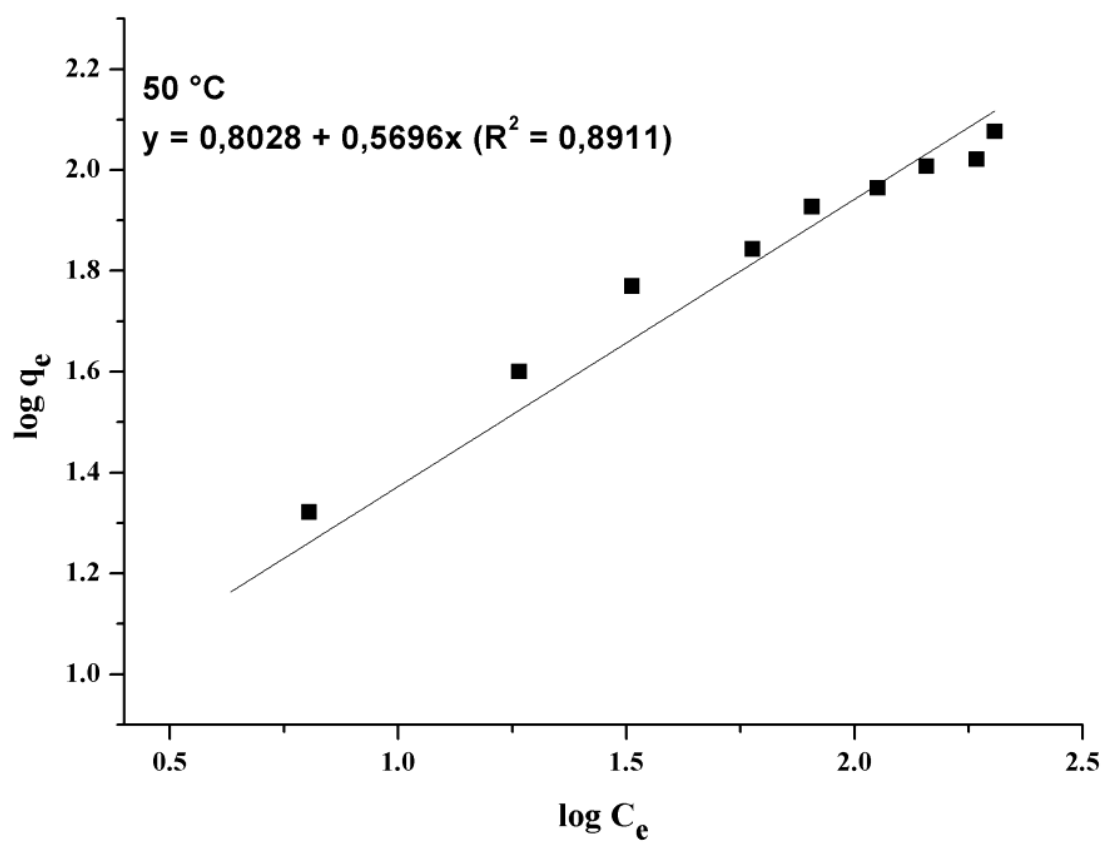

Fonte: Autor 
Figura 131 - Isoterma de Temkin à temperatura de $20^{\circ} \mathrm{C}$

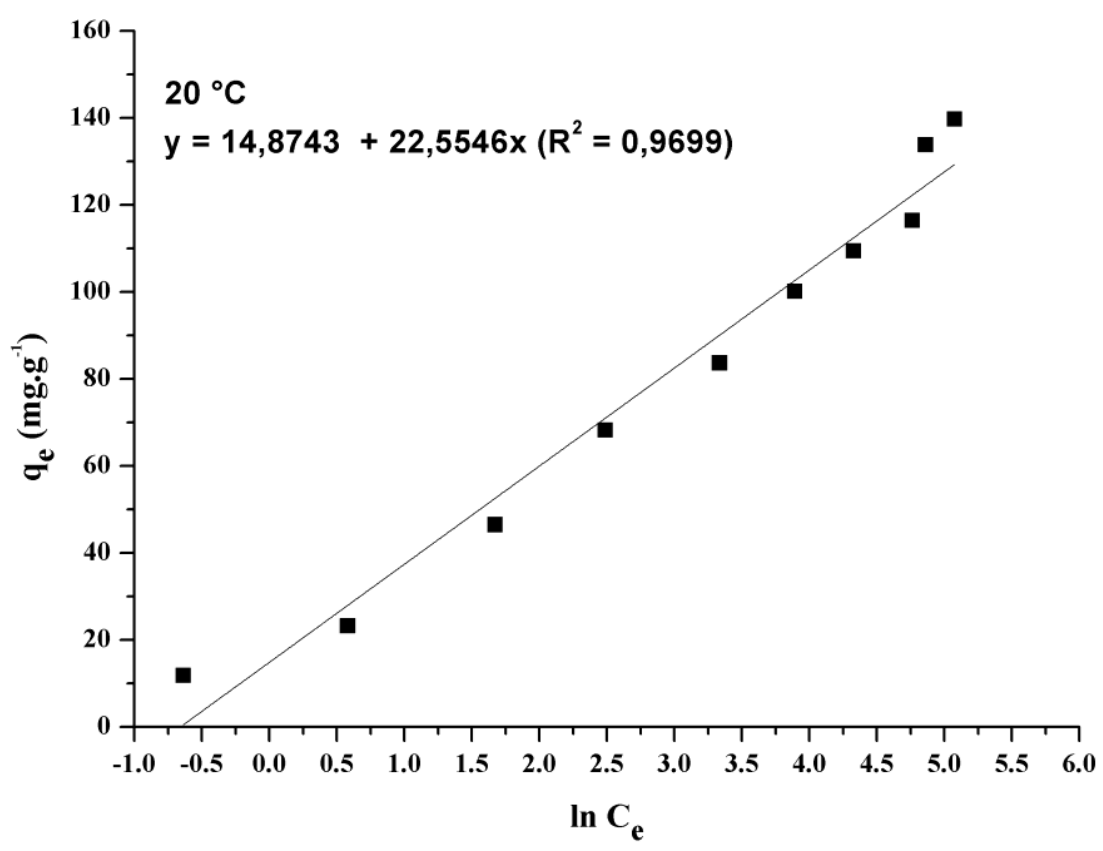

Fonte: Autor

Figura 132 - Isoterma de Temkin à temperatura de $25^{\circ} \mathrm{C}$

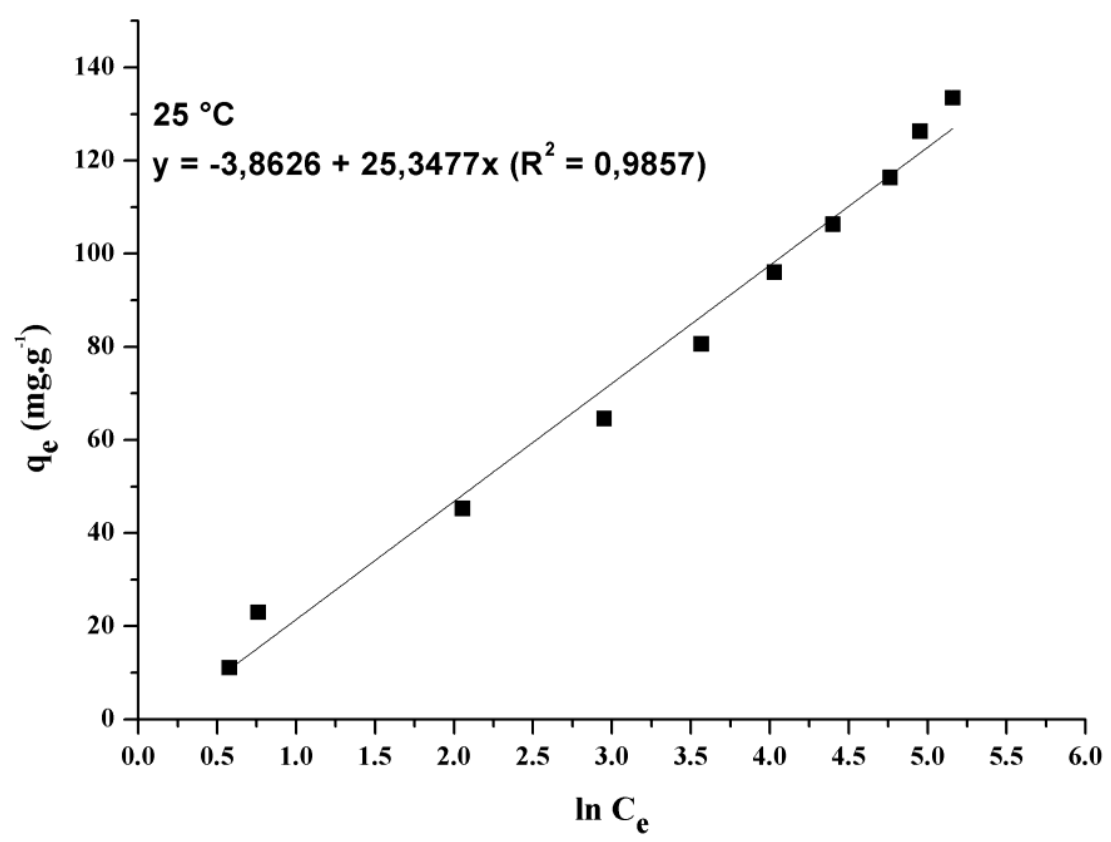

Fonte: Autor 
Figura 133 - Isoterma de Temkin à temperatura de $30^{\circ} \mathrm{C}$

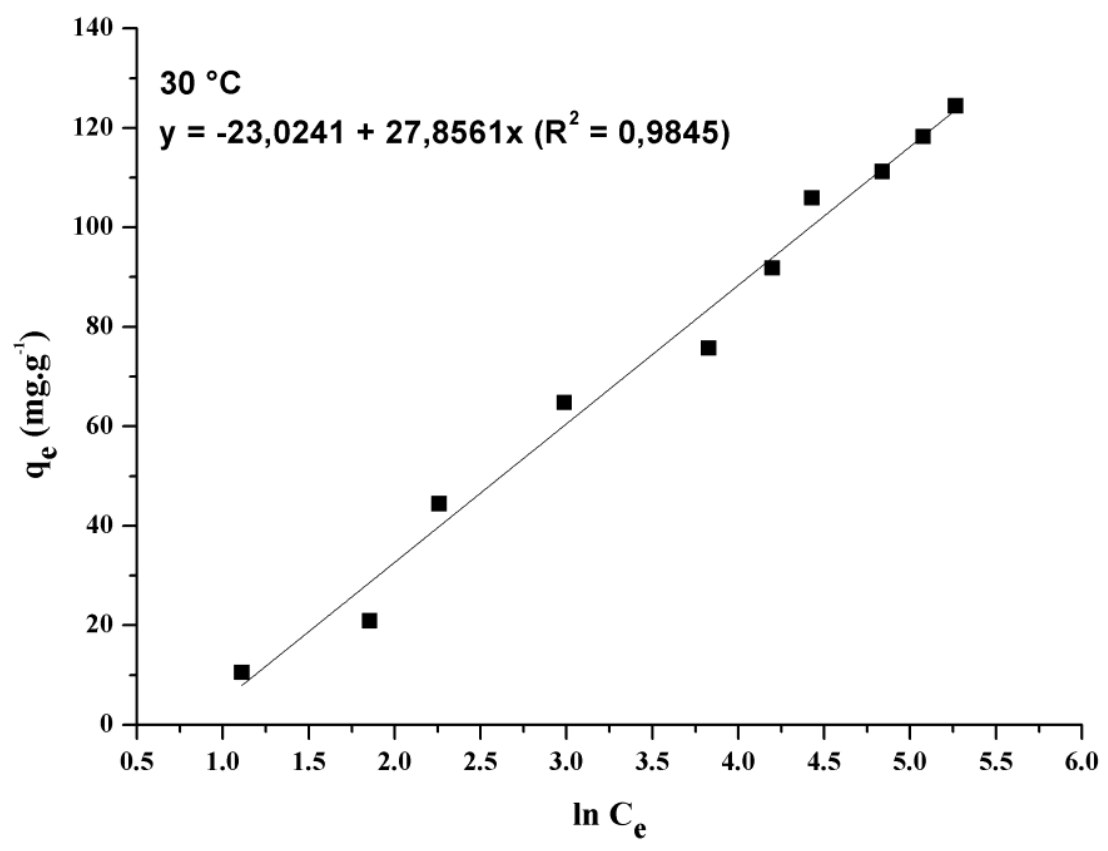

Fonte: Autor

Figura 134 - Isoterma de Temkin à temperatura de $40^{\circ} \mathrm{C}$

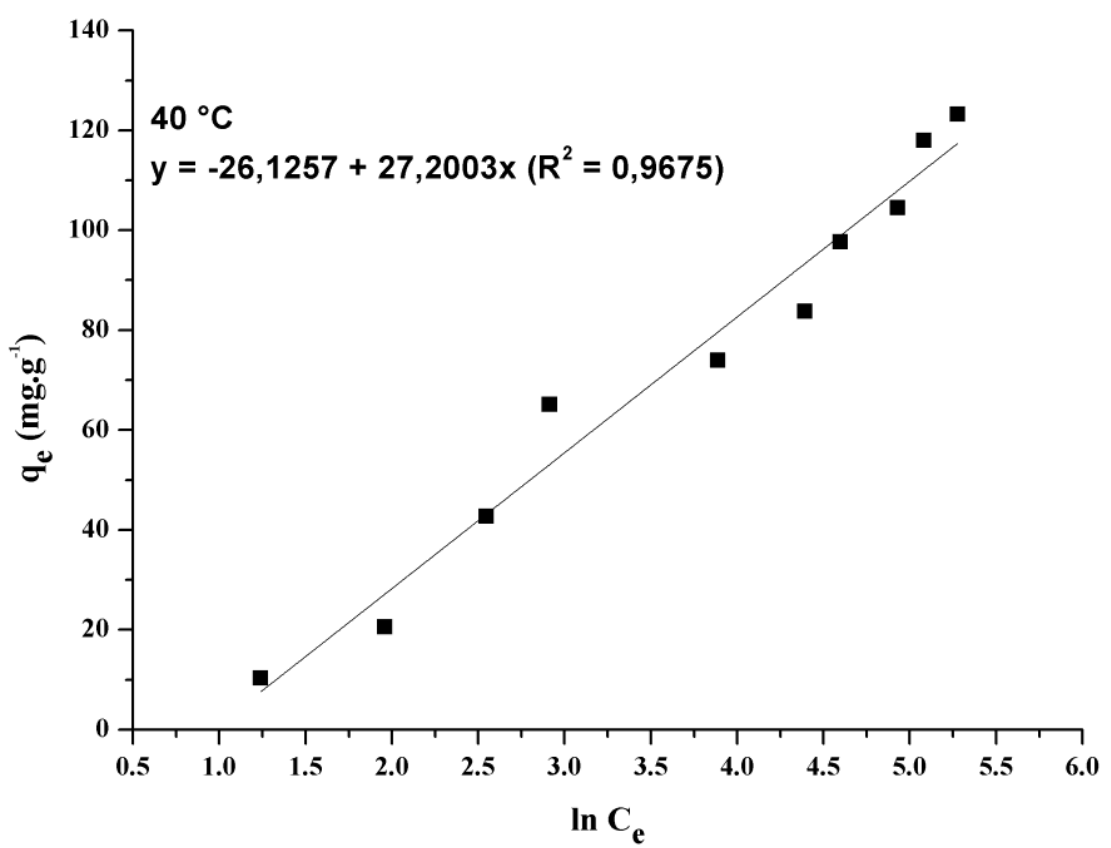

Fonte: Autor 
Figura 135 - Isoterma de Temkin à temperatura de $50^{\circ} \mathrm{C}$

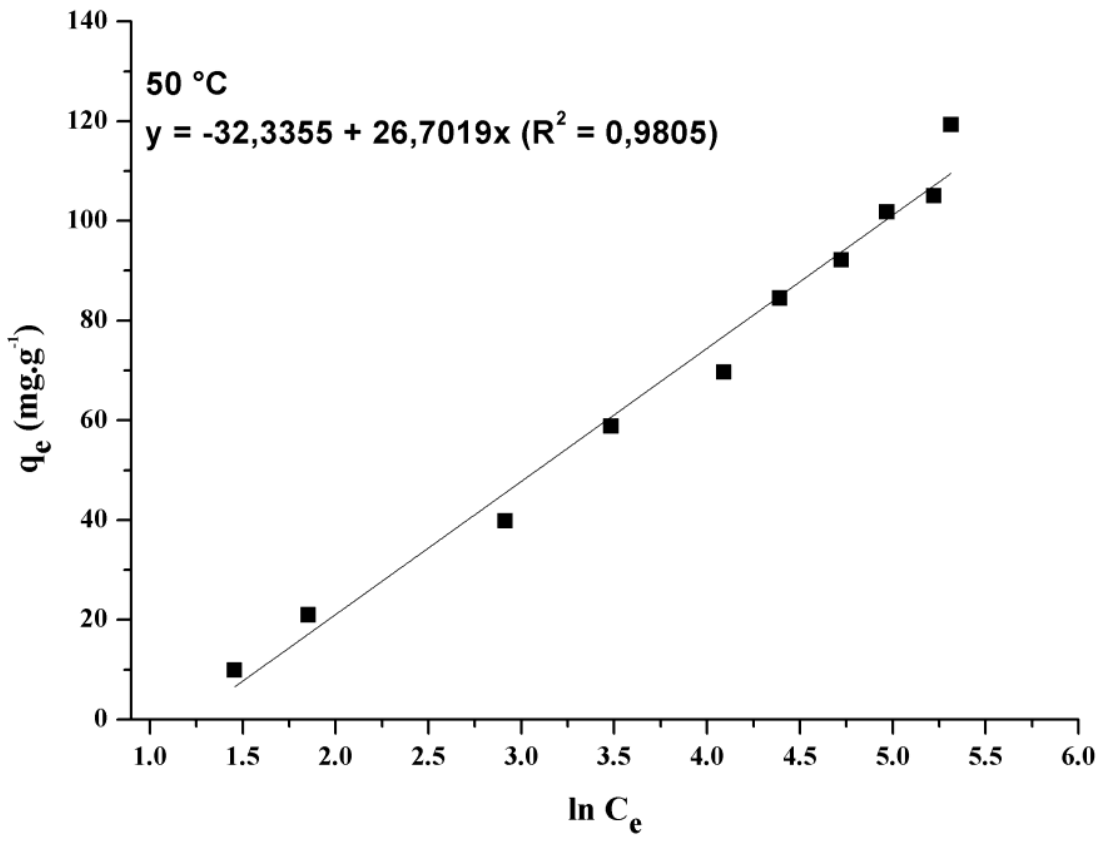

Fonte: Autor 
Apêndice F - Micrografias 
Figura 136 - Micrografias dos resíduos lignocelulósicos com ampliação de 50x

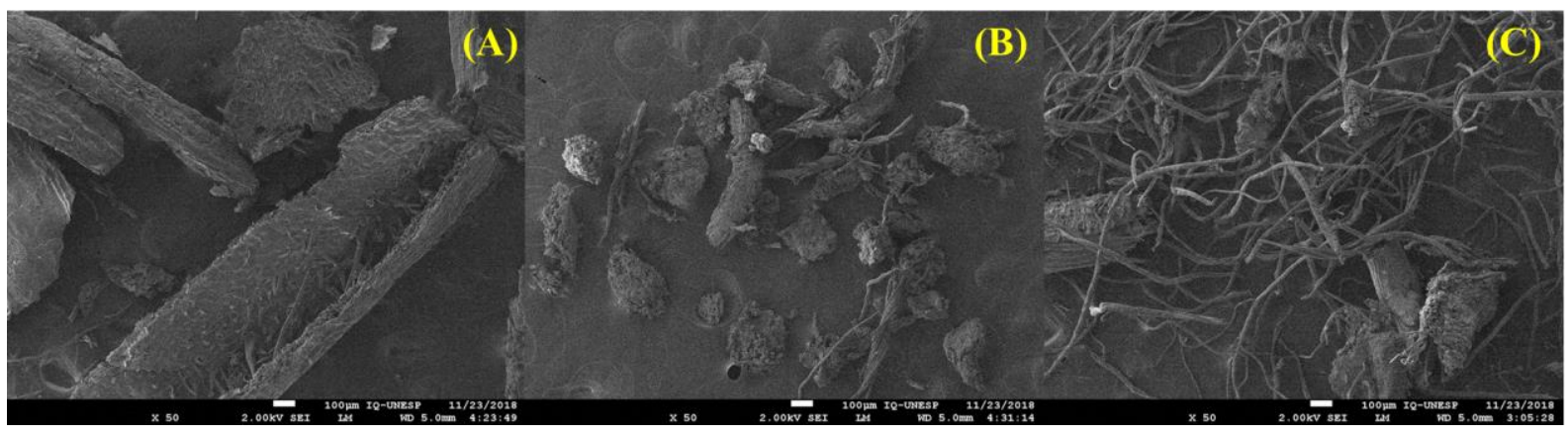

Fonte: Autor

Legenda: (A), (B) e (C) referem-se as palhas bruta, polpada e branqueada, respectivamente

Figura 137 - Micrografias dos resíduos lignocelulósicos com ampliação de 200x

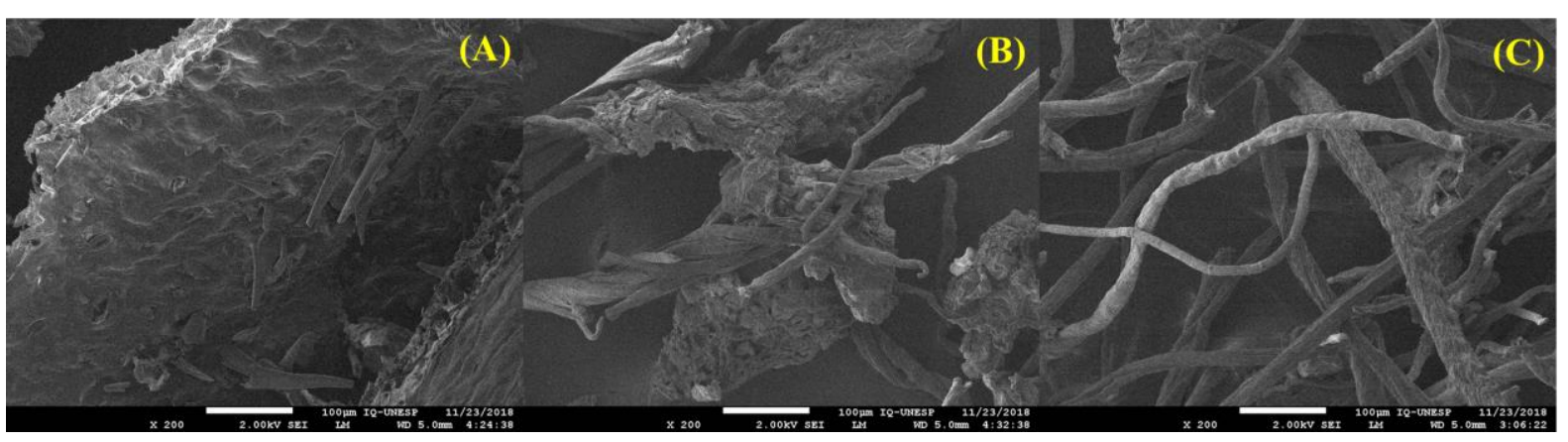

Fonte: Autor

Legenda: (A), (B) e (C) referem-se as palhas bruta, polpada e branqueada, respectivamente

Figura 138 - Micrografias dos resíduos lignocelulósicos com ampliação de 1.000x

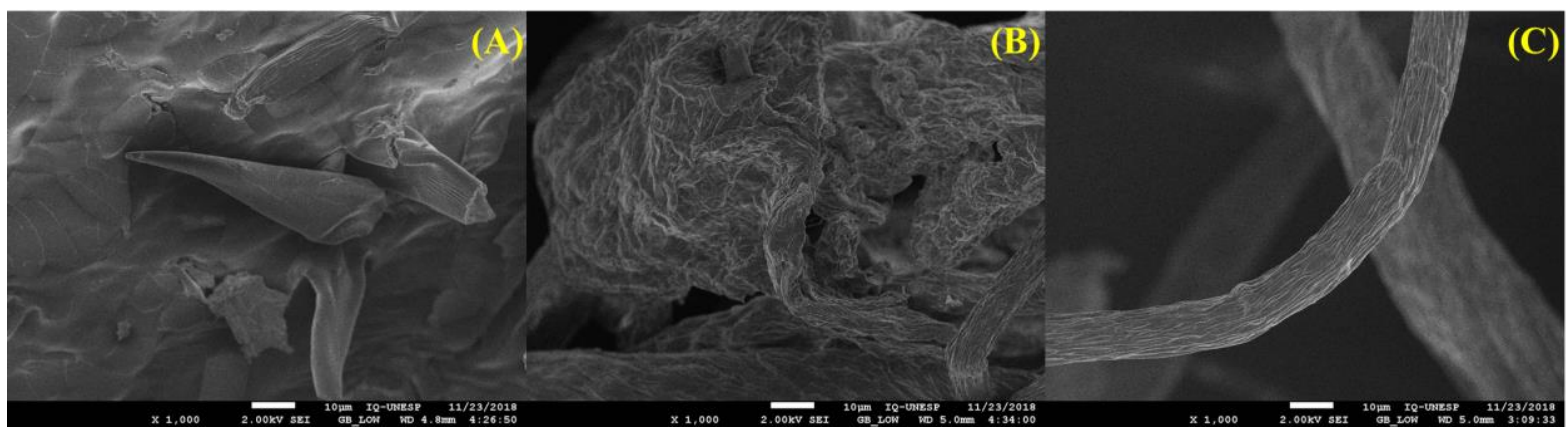

Fonte: Autor

Legenda: (A), (B) e (C) referem-se as palhas bruta, polpada e branqueada, respectivamente 
Figura 139 - Micrografias dos resíduos lignocelulósicos com ampliação de 3.000x

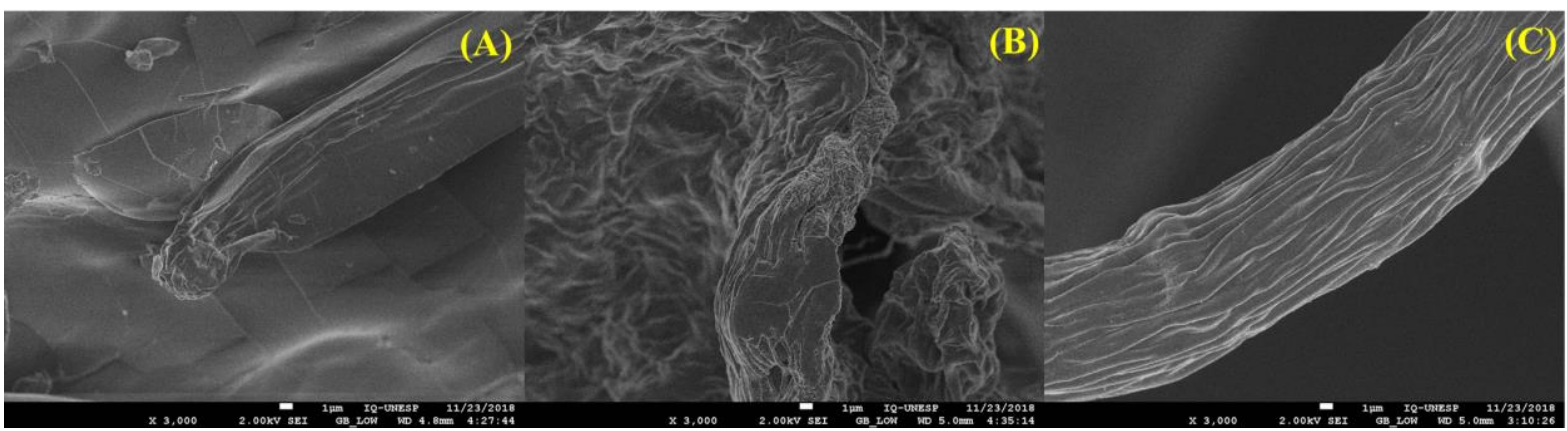

Fonte: Autor

Legenda: (A), (B) e (C) referem-se as palhas bruta, polpada e branqueada, respectivamente

Figura 140 - Micrografias dos resíduos lignocelulósicos com ampliação de 10.000x

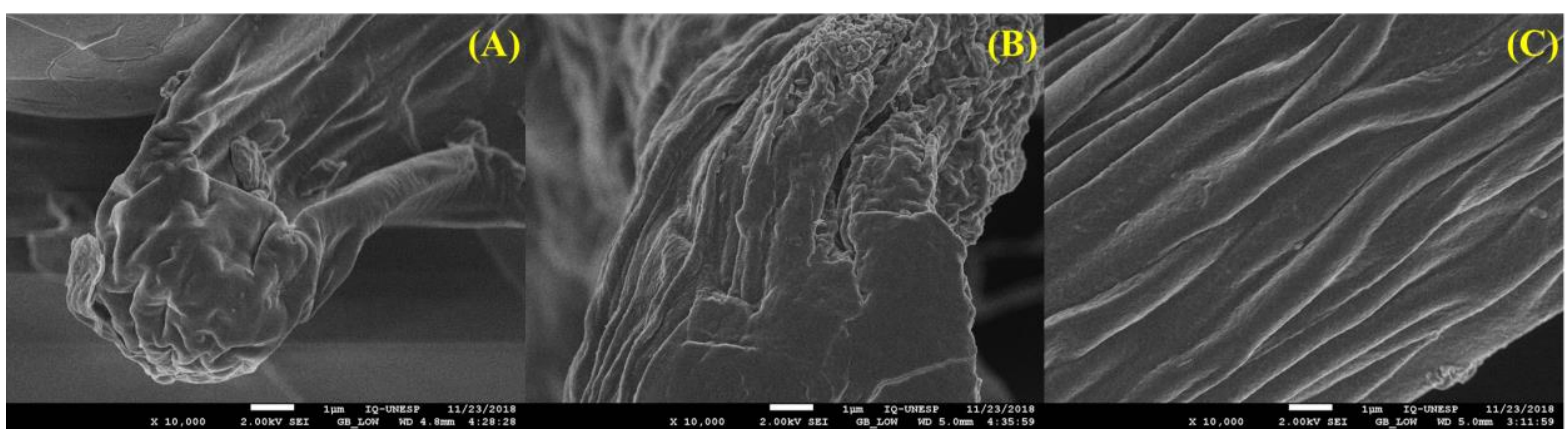

Fonte: Autor

Legenda: (A), (B) e (C) referem-se as palhas bruta, polpada e branqueada, respectivamente

Figura 141 - Micrografias dos resíduos lignocelulósicos com ampliação de 25.000x

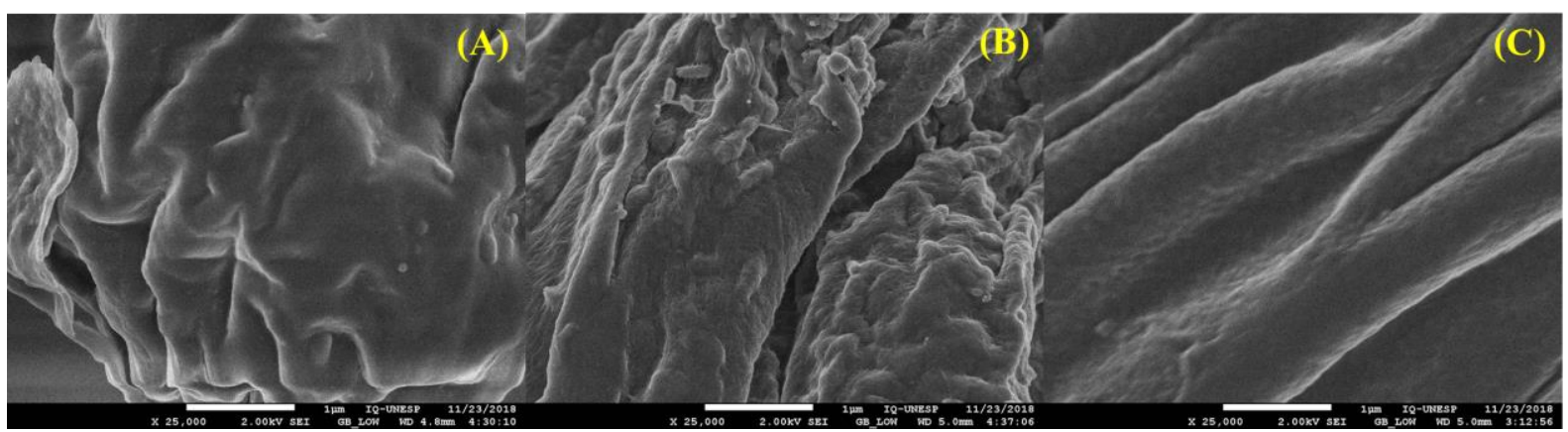

Fonte: Autor

Legenda: (A), (B) e (C) referem-se as palhas bruta, polpada e branqueada, respectivamente 
Figura 142 - Micrografias da CMC

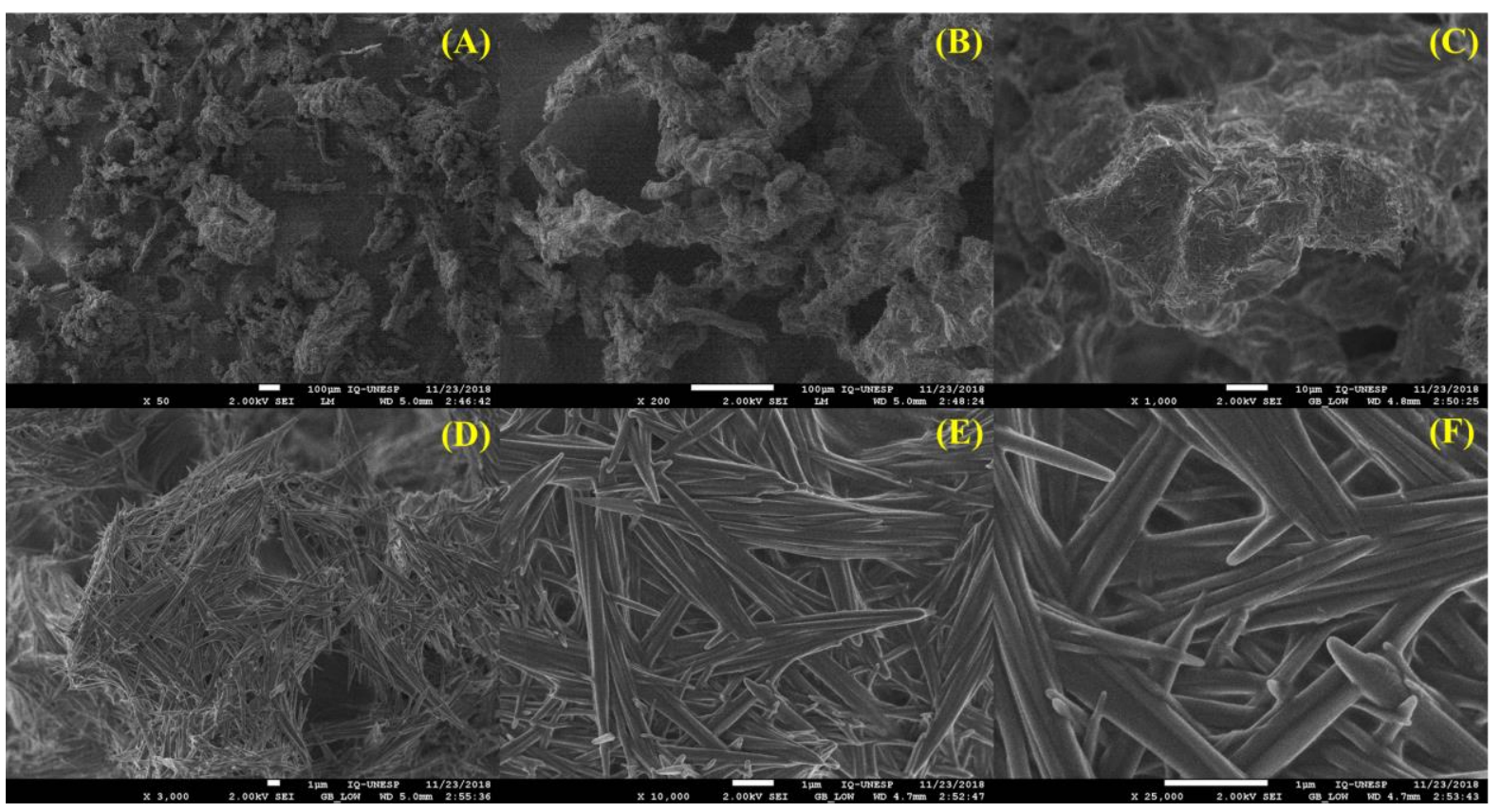

Fonte: Autor

Legenda: (A), (B), (C), (D), (E) e (F) referem-se ampliações de 50, 200, 1.000, 3.000, 10.000 e 25.000x, respectivamente

Figura 143 - Micrografias da quitosana

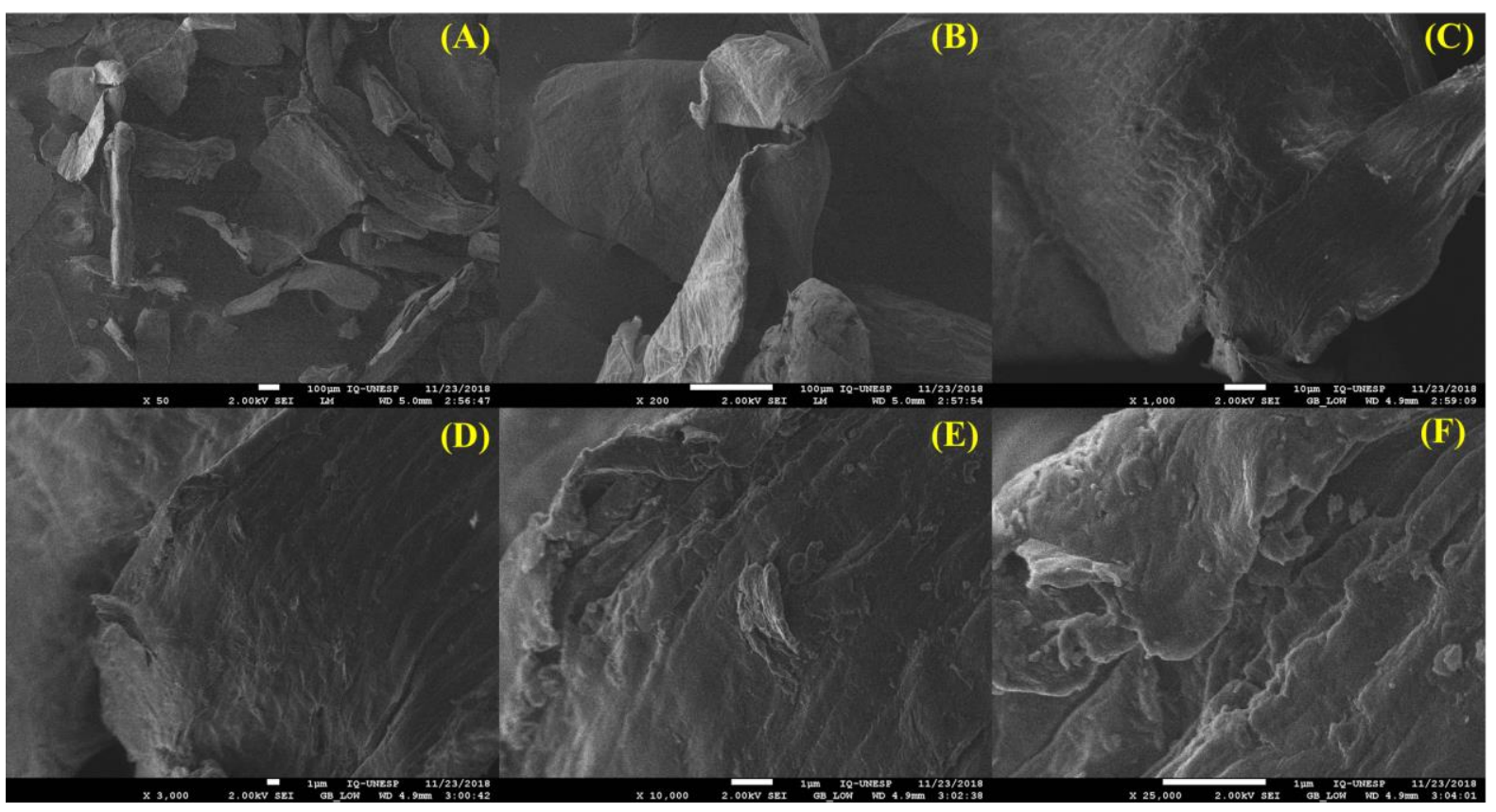

Fonte: Autor

Legenda: (A), (B), (C), (D), (E) e (F) referem-se ampliações de 50, 200, 1.000, 3.000, 10.000 e 25.000x, respectivamente 
Figura 144 - Micrografias do adsorvente CMCQF

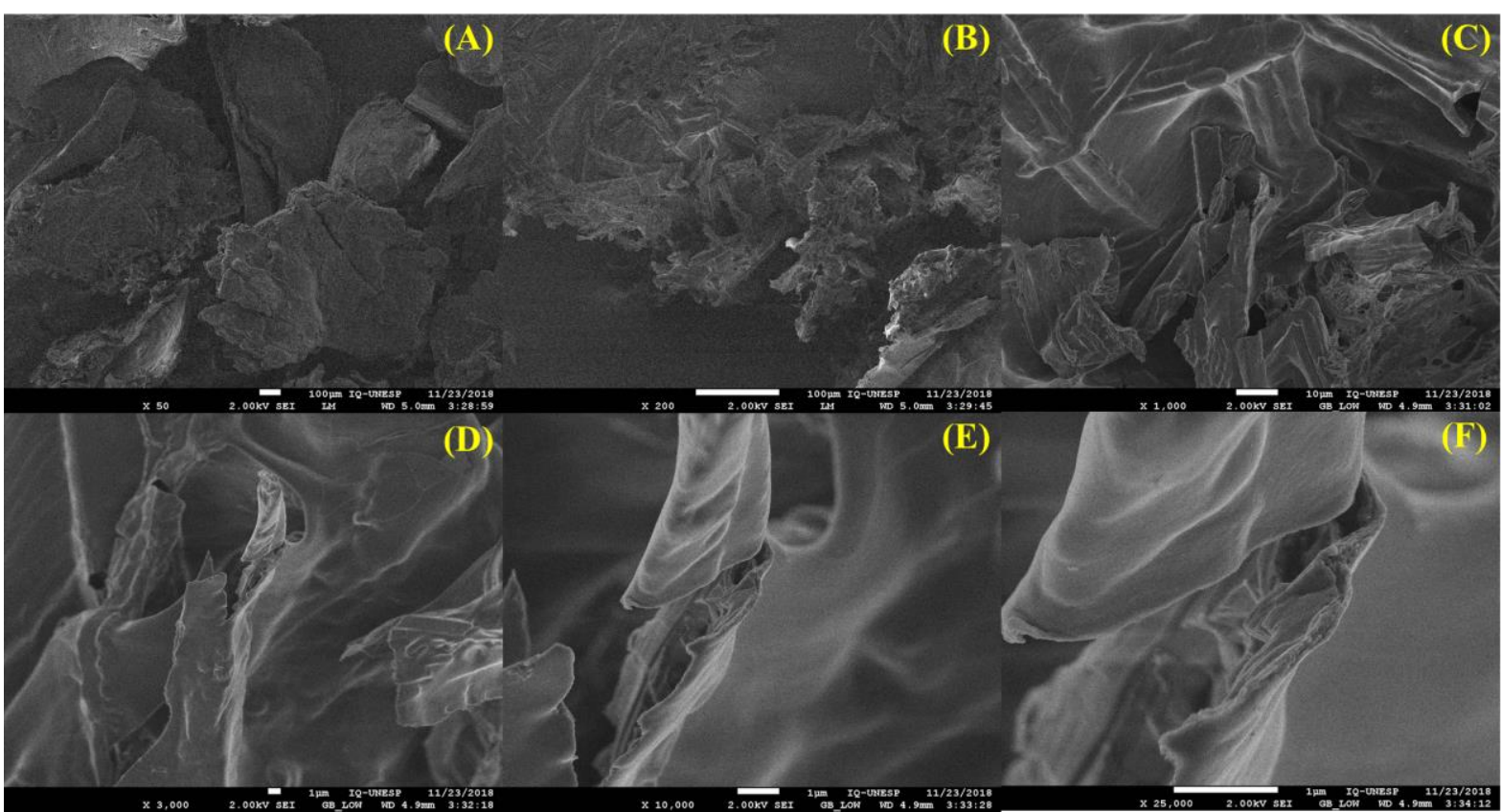

Fonte: Autor

Legenda: (A), (B), (C), (D), (E) e (F) referem-se ampliações de 50, 200, 1.000, 3.000, 10.000 e 25.000x, respectivamente

Figura 145 - Micrografias do adsorvente CMCQDIC

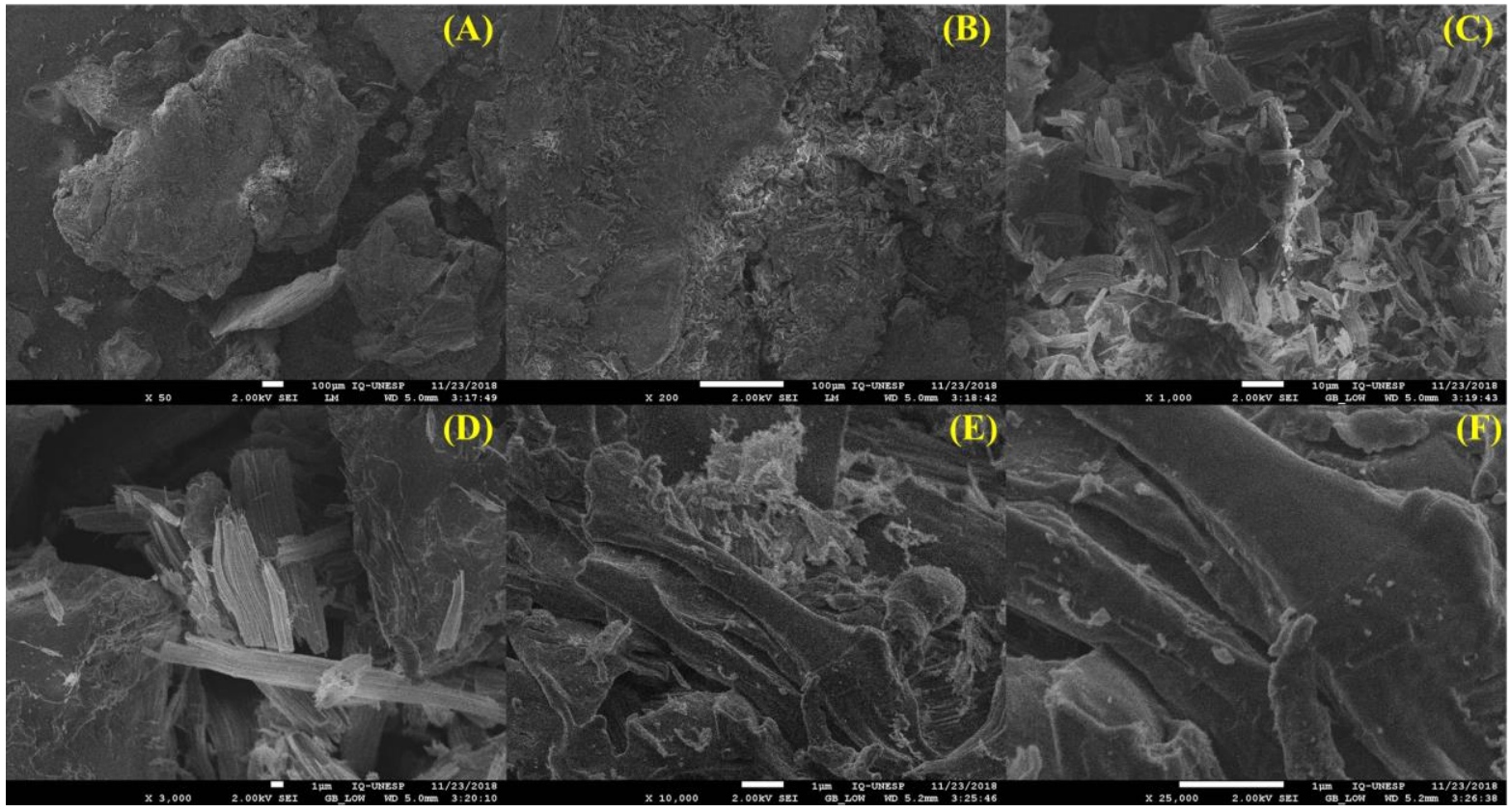

Fonte: Autor

Legenda: (A), (B), (C), (D), (E) e (F) referem-se ampliações de 50, 200, 1.000, 3.000, 10.000 e 25.000x, respectivamente 